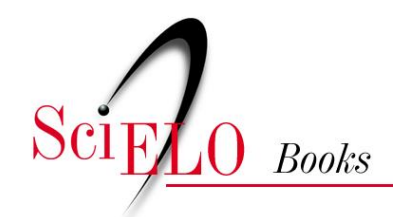

\title{
Psicologia da Saúde
}

teoria, intervenção e pesquisa

Railda Fernandes Alves (org.)

ALVES, RF., org. Psicologia da saúde: teoria, intervenção e pesquisa [online]. Campina Grande: EDUEPB, 2011. 345 p. ISBN 978-85-7879-192-6. Available from SciELO Books $<$ http://books.scielo.org>.

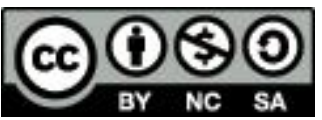

All the contents of this work, except where otherwise noted, is licensed under a Creative Commons Attribution-Non Commercial-ShareAlike 3.0 Unported.

Todo o conteúdo deste trabalho, exceto quando houver ressalva, é publicado sob a licença Creative Commons Atribuição Uso Não Comercial - Partilha nos Mesmos Termos 3.0 Não adaptada.

Todo el contenido de esta obra, excepto donde se indique lo contrario, está bajo licencia de la licencia Creative Commons Reconocimento-NoComercial-CompartirIgual 3.0 Unported. 


\section{Universidade Estadual da Paraíba}

Profa. Marlene Alves Sousa Luna

Reitora

Prof. Aldo Bezerra Maciel

Vice-Reitor

\section{eduepb}

\section{Editora da Universidade Estadual da Paraíba}

\section{Diretor}

Cidoval Morais de Sousa

Coordenação de Editoração

Arão de Azevedo Souza

\section{Conselho Editorial}

Célia Marques Teles - UFBA

Dilma Maria Brito Melo Trovão - UEPB

Djane de Fátima Oliveira - UEPB

Gesinaldo Ataíde Cândido - UFCG

Joseilda de Sousa Diniz - UEPB

Joviana Quintes Avanci - FIOCRUZ

Marcionila Fernandes - UEPB

Rosilda Alves Bezerra - UEPB

Waleska Silveira Lira - UEPB

\section{Editoração Eletrônica}

Jefferson Ricardo Lima Araujo Nunes

Leonardo Ramos Araujo

\section{Capa}

Arão de Azevedo Souza

Comercialização e Divulgação

Júlio Cézar Gonçalves Porto

Zoraide Barbosa de Oliveira Pereira

\section{Revisão Linguística}

Elizete Amaral de Medeiros

\section{Normalização Técnica}

Heliane Maria Idalino da Silva 
Railda Fernandes Alves

(Organizadora)

\section{Psicologia da Saúde \\ teoria, intervenção e pesquisa}

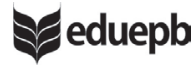

Campina Grande-PB

2011 


\section{Copyright $\odot 2011$ EDUEPB}

A reprodução não-autorizada desta publicação, por qualquer meio, seja total ou parcial, constitui violação da Lei n 9.610/98.

A EDUEPB segue o acordo ortográfico da Língua Portuguesa de 1990, em vigor no Brasil, desde 2009.

\section{Depósito legal na Biblioteca Nacional, conforme decreto n¹.825, de 20 de dezembro de 1907.} FICHA CATALOGRÁFICA ELABORADA PELA BIBLIOTECA CENTRAL - UEPB

150

P974 Psicologia da Saúde: teoria, intervenção e pesquisa./Railda Fernandes Alves (Organizadora)... [et al.]. - Campina Grande: EDUEPB, 2011. $346 \mathrm{p}$.

\section{ISBN 978-85-7879-080-6}

1. Psicologia. 2.Psicologia da Saúde $\quad$ 3. Saúde Mental 4. Qualidade de vida.

21. ed. CDD

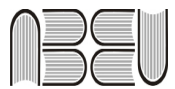

Editora filiada a ABEU

\section{EDITORA DA UNIVERSIDADE ESTADUAL DA PARAÍBA}

Rua Baraúnas, 351 - Bodocongó - Bairro Universitário - Campina Grande-PB - CEP 58429-500 Fone/Fax: (83) 3315-3381 - http://eduepb.uepb.edu.br - email: eduepb@uepb.edu.br 


\section{Errata}

\section{Sumário}

Prefácio

\section{Primeira Parte}

Capítulo 1

A Psicologia da Saúde

José Luís Pais Ribeiro

\section{Capítulo 2}

Abrangência e níveis de aplicação da Psicologia da Saúde

Railda Fernandes Alves / Maria do Carmo Eulálio

\section{Capítulo 3}

La Psicología Clínica y de la Salud en España: evolución, perspectivas y modelos teóricos ......89 Gualberto Buela-Casal / Raúl Quevedo-Blasco

\section{Capítulo 4}

Saúde: apontamentos topográficos

para a cartografia de um conceito

Edmundo de Oliveira Gaudêncio 


\section{Capítulo 5}

A saúde do homem na interface

com a Psicologia da Saúde.

Railda Fernandes Alves / Ana Gabriella Barros de Lima Fabiana Maria de Souza / Monalisa Vasconcelos Ernesto Renata Pimentel da Silva

\section{Segunda Parte}

\section{Capítulo 6}

Os sentidos do termo Saúde em discursos de praticantes e não-praticantes de atividades físicas da cidade de Campina Grande/PB

Thelma Maria Grisi Velôso / Pedro de Oliveira Filho

Halline Iale Barros Henriques / Hamana Dáphne Barros

Henriques / Karoliny Rafaela Sousa de Andrade

Marcela Costa Meira / Roseane Barros Pinto

\section{Capítulo 7}

Velhice e atividade profissional:

um estudo sobre qualidade de vida ............ 199

Isis Simões Leão / Maria do Carmo Eulálio

\section{Capítulo 8}

Saúde Mental em enfermeiros plantonistas do Serviço de Atendimento Móvel de Urgência -

SAMU

Silvânia da Cruz Barbosa / Renata Pimentel da Silva José Ulisses do Nascimento / Sandra Souza 


\section{Capítulo 9}

Grupo com pacientes institucionalizados portadores de esquizofrenia: contribuições da Psicologia da Saúde e da Psicologia Humanista 243 Carla de Sant'Ana Brandão / Danielly Farias da Silva Araújo Lorena Leal Máximo

Capítulo 10

La menopausia un ciclo de vida .............. 287 Maria Jose Robles Delgado / Luciana Ramirez Imedio

Sobre os autores

(de acordo com a ordem dos capítulos) ............. 335 



\section{Prefácio}

Esta obra, publicada pela EDUEPB sobre a Psicologia da Saúde, é um marco importante para a consolidação do grupo de pesquisa em Psicologia da Saúde, da Universidade Estadual da Paraíba - UEPB. Nela, estão reunidos capítulos inéditos que fazem parte da produção dos pesquisadores que compõem o referido grupo, durante o biênio de 2008/2009.

Tal grupo, abrigado pelo Departamento de Psicologia da UEPB, encontra-se devidamente registrado e certificado pelo CNPq, acolhe seis pesquisadores, mais de vinte alunos da graduação em Psicologia e se constitui a partir de quatro linhas de pesquisa, a saber: Processos Psicossociais e Saúde; Saúde e representações sociais; Saúde, posições identitárias e práticas discursivas; e Saúde mental, adolescência e juventude: comportamentos específicos e procedimentos preventivos no campo da saúde.

Além dos pesquisadores da "casa" esta coletânea conta também com a colaboração de pesquisadores europeus de renomado prestígio. Motivo pelo qual o livro é bilíngue. Aliás, optamos pela não tradução dos textos que vêm em espanhol para preservar a originalidade dos mesmos. E, ainda, porque temos a tranquilidade de saber que tanto os profissionais como os estudantes da área da saúde, interessados na leitura deste livro, compreendem bem a língua espanhola.

Esta publicação é eminentemente didática e poderá ser útil aos vários profissionais da área de saúde. Está organizada em duas partes. A primeira, dedicada à teoria da Psicologia da Saúde, visa dar ao leitor um panorama geral dos aspectos que embasam a compreensão da segunda 
parte do livro voltada aos trabalhos de pesquisa desenvolvidos pelos pesquisadores da Psicologia da Saúde, aqui reunidos.

No capítulo primeiro, o autor nos brinda com a apresentação do contexto de desenvolvimento da Psicologia da Saúde em Portugal. E mostra que a Psicologia da Saúde constitui um campo de aplicação da Psicologia com interesse crescente. Crescente porque as condições médicas tendem a aumentar e é necessário desenvolver competências para enfrentar estes acontecimentos que se tornam normativos; porque as doenças crônicas aumentam cada vez mais e se torna necessário implementar medidas de prevenção secundária para esta população; porque a população envelhece e é necessário implementar medidas de prevenção primária para um envelhecimento saudável. Tudo isto se faz através do desenvolvimento de competências úteis para lidar com as novas demandas de saúde.

Dando prosseguimento ao texto, o autor adentra aos aspectos históricos da Psicologia da Saúde e mostra que ela surge num período de grandes mudanças sociais, políticas e econômicas - a década de 70 do século XX - e expressa uma melhoria e um ajustamento às novas condições de saúde. Ela continuou a evoluir e a desenvolver-se, constituindo hoje um componente fundamental nas equipes multidisciplinares que intervêm no sistema de saúde.

O futuro da Psicologia da Saúde tenderá a especializar-se por áreas ou contextos de aplicação - promoção, proteção da saúde e prevenção e tratamento das doenças; contextos formais de saúde como hospitais ou equivalentes versus comunidade; crianças, adolescentes ou mais velhos; homens versus mulheres; etc. -, mesmo por áreas mais especializadas como, por exemplo, o tratamento das doenças. É desejável que isso aconteça sem que represente psicologias diversas, separadas, mas que continue a ser um domínio de aplicação 
da Psicologia que recorre aos conhecimentos provenientes de todas as áreas da Psicologia, tal como proposto na definição fundadora.

O segundo capítulo trata da abrangência e dos níveis de aplicação da Psicologia da Saúde. O texto se desenvolve buscando alcançar dois objetivos. O primeiro: demonstrar a importância das ações dos psicólogos no nível da promoção de saúde. O segundo: apresentar, explicar e justificar a pertinência da intervenção do psicólogo na prevenção de doenças no âmbito da saúde pública/coletiva. A partir do desenvolvimento desses dois argumentos, propõe, sem ânimo de exaustividade, uma lista de atividades voltadas à prevenção de doenças para orientar minimamente as atuações do psicólogo nos três níveis de assistência de saúde.

O texto procura vincular cada intervenção ao nível mais apropriado de atenção de saúde, de modo a destacar as diversas possibilidades desde, onde e quando fazer a prevenção.

Cabe sublinhar que a prevenção de doenças é, entre todas as novidades das intervenções psicológicas na saúde pública/coletiva, a menos desenvolvida e conhecida. Motivo pelo qual lhe é atribuída maior ênfase.

A prevenção entendida como uma prática psicológica requer do profissional o conhecimento de múltiplas ações de saúde geral. A falta de tradição da intervenção preventiva põe, em evidência, a dificuldade em adequar cada ação a seu nível de pertinência. Essa conjuntura deverá ter na Psicologia da Saúde seu suporte tanto epistemológico como prático.

O terceiro capítulo apresenta um panorama geral tanto da evolução da Psicologia Clínica e da Saúde na Espanha, como dos modelos teóricos mais destacados na área. Para isso, em primeiro lugar, os autores realizam uma análise da evolução histórica até a atualidade da Psicologia no país e, posteriormente, contextualizam e diferenciam 
conceitualmente a Psicologia Clínica da Psicologia da Saúde. Em seguida, analisam, de forma mais concreta, os antecedentes em Psicologia e Saúde, mostrando a trajetória desde os finais do século XIX até a década de 90, do século XX. No segundo ponto do capítulo, fazem uma reflexão sobre a Psicologia e sua aplicação no âmbito clínico e sanitário. Para isso, fazem uma revisão das divisões dos Conselhos de Psicólogos, na Espanha, e do número de psicólogos registrados nos referidos Conselhos, que têm a especialidade clínica. Também justificam esta relação em diferentes níveis (formação, revistas científicas, âmbito hospitalar e afinidade com a medicina), com o objetivo de dar uma visão coerente à mesma. Essa conjuntura conduziu à formalização do terceiro ponto, no qual os autores descrevem a Psicologia como profissão sanitária mediante a análise de diferentes estudos realizados sobre este tema. Por último, descrevem os principais modelos atuais em Psicologia e as denominadas “Terapias de Terceira Geração”.

O quarto capítulo apresenta uma série de apontamentos sobre o conceito de saúde. Nele, o autor afirma que vivemos em um mundo de conceitos esquecidos que, graças à representação do mundo que fazemos por meio da linguagem, perdemos a possibilidade do contato com as coisas reais, e esquecidos, ainda, que todo conceito é fato histórico-social. O autor, sob a influência de Foucault, faz um levantamento topográfico que pode auxiliar na arqueologia do conceito de saúde, pondo a descoberto as torções e contorções por ele sofridas ao longo do tempo. Sob a influência de Deleuze, o autor demonstra que um conceito, qualquer conceito, é sempre atravessado por conceitos sinônimos ou antônimos, os quais findam dando o sentido final a uma conceituação que, desarticulada de uma rede conceitual (metaforicamente expressa a partir da noção de rizoma, como deseja Deleuze), nenhum sentido teria. 
O quinto capítulo, fechando a primeira parte do livro, traz um artigo sobre a saúde do homem, o qual apresenta um levantamento bibliográfico, não exaustivo, da literatura sobre a relação entre a saúde dos homens e as políticas públicas de saúde dedicadas a eles, numa interface com a Psicologia da Saúde. Concomitantemente, levanta e discute a relação gênero e saúde, entendida como diretamente imbricada nos processos psicossociais que explicam alguns dos desdobramentos da relação de gênero masculino com a saúde.

No tocante às políticas públicas de saúde, as autoras evidenciam que, historicamente, tais políticas priorizaram o atendimento às mulheres e que, somente nas últimas décadas, a literatura sobre gênero e saúde voltou-se para o estudo do universo masculino.

O texto mostra que os altos índices de morbi/mortalidade dos homens, quando comparados aos das mulheres, tornou a saúde do homem um assunto de interesse para os que fazem as políticas públicas de saúde no Brasil. Assunto que vem ganhando visibilidade midiática e passou a receber do sistema nacional de saúde um tratamento diferenciado, atestado pela criação do Programa Nacional de Saúde do Homem (PNAISH).

As autoras expõem as dificuldades dos homens brasileiros em utilizarem os serviços de saúde e afirmam que a compreensão dos processos que explicam o comportamento demonstrado pelos homens brasileiros à hora de zelar pela sua saúde é objeto de estudo de várias disciplinas. As autoras apontam a Psicologia da Saúde como disciplina de suporte para o estudo e a compreensão do tema e a definem como um campo de aplicação da Psicologia dedicado aos cuidados de saúde geral. Com prioridade para as assistências de promoção de saúde e de prevenção de doenças. Nesse modelo, as práticas do psicólogo se alargam para além das práticas 
clínicas e da saúde mental já que, autônoma em relação à Psicologia Clínica, seu objetivo maior é a saúde global das pessoas inseridas em seus coletivos sociais.

As autoras reafirmam a necessidade de aumentar o número de investigações sobre a relação gênero e saúde, e denunciam também que as políticas públicas de saúde ainda não são suficientes e não contemplam de modo satisfatório as relações entre as construções culturais de masculinidade e as práticas de prevenção em saúde.

$\mathrm{Na}$ sequência dos debates teóricos que fundamentam o tema central desta obra, encontram-se agrupados, na segunda parte do livro, os capítulos dedicados às investigações de temas da Psicologia da Saúde.

Assim, no sexto capítulo, os autores fazem uma reflexão sobre a questão da saúde a partir dos resultados obtidos em duas pesquisas realizadas em Campina Grande/PB. Nessas pesquisas, foram analisados os sentidos do termo saúde em discursos de praticantes e não praticantes de atividades físicas. O método qualitativo na modalidade de história oral conduziu a obtenção dos 24 (vinte e quatro) depoimentos orais de adultos jovens e de meia-idade - 12 (doze) mulheres e 12 (doze) homens - e 14 (quatorze) depoimentos orais de idosos - (05) cinco homens e 09 (nove mulheres). Os autores, fundamentando-se na Psicologia Social, estudaram a produção de sentidos a partir da análise das práticas discursivas. As entrevistas, submetidas à análise de discurso, evidenciaram que os relatos de praticantes e de não praticantes de atividades físicas são muito semelhantes. Os dois grupos tendem a conceber a saúde como sinônimo de ausência de doença, ainda que alguns a definam como bem-estar físico e mental. O termo saúde é recorrentemente seguido de expressões como "fundamental”, "é tudo", "primordial", o que denota uma sobrevalorização da saúde. Para ser saudável é preciso se submeter a uma disciplina rígida, 
priorizando uma boa alimentação e a prática de exercícios físicos, pois é através desses cuidados que se consegue a longevidade.

O sétimo capítulo traz um estudo sobre a velhice e a atividade profissional. Trata-se de um estudo sobre a qualidade de vida entre idosos que desempenham ou não algum tipo de atividade profissional. Para tanto, as autoras fizeram uma comparação da qualidade de vida entre idosos profissionalmente ativos (PA) e inativos (PI) realizando uma análise intergrupos; e a correlação da qualidade de vida de cada grupo com a idade, com a renda e com a escolaridade dos idosos, utilizando também a análise intragrupos. 60 idosos (30 PA e $30 \mathrm{PI}$ ) responderam o questionário WHOQOL-abreviado, que subdivide a qualidade de vida em quatro fatores: físico, psicológico, relações sociais e meio ambiente. Utilizaram também um questionário sociodemográfico a fim de traçar o perfil dos participantes e o Mini-Exame do Estado Mental (MEEM), adotado como teste de rastreamento para assegurar a capacidade dos participantes em responder aos demais instrumentos. Os dados do questionário foram tratados segundo a estatística-descritiva, e as correlações inter e intragrupos foram realizadas com auxílio do programa SPSS 15. As análises intergrupos sugerem que os idosos PA possuem melhores condições físicas, psicológicas e de meio ambiente. $\mathrm{O}$ fator relações sociais é semelhante entre os dois grupos, não indicando influência da atividade profissional nesse aspecto da vida dos idosos. As análises intragrupos indicam, tanto entre os PA quanto entre os PI, significativa correlação entre a qualidade de vida e a escolaridade. Entre os idosos ativos, há correlação entre a escolaridade com o meio ambiente. Entre os inativos, há correlação entre escolaridade e a qualidade de vida geral e o fator físico. Os dados mostram a influência comum da escolaridade na forma como as pessoas envelhecem independente do desempenho ou não de uma atividade profissional. Os resultados evidenciam que a qualidade de 
vida dos idosos é resultado não apenas da atenção que lhes é oferecida na velhice, mas das condições que tiveram durante toda a vida. Para que as futuras gerações envelheçam, de forma saudável, é necessário que sejam oferecidas, hoje, condições satisfatórias para o desenvolvimento de crianças, jovens e adultos.

O oitavo capítulo mostra os resultados de uma pesquisa descritiva e de corte transversal que teve como objetivo analisar os efeitos do regime de plantão sobre a saúde mental em profissionais de enfermagem que trabalham no SAMU de Campina Grande (PB). Participaram 34 profissionais, correspondendo a uma amostra de $54 \%$ do total. Os autores utilizaram como instrumentos: o QSG-12 (versão reduzida de 12 itens) para avaliar o nível de bem-estar psicológico, um questionário semiestruturado para avaliar a percepção do regime de plantão e das condições de trabalho, e uma ficha sociodemográfica para caracterizar a amostra. Os resultados indicam $77,3 \%$ dos participantes com carga horária de trabalho elevada (mínimo de três plantões semanais de $12 \mathrm{~h}$ ), sendo essa carga ainda mais extensa entre os que possuem mais de um emprego. Mostram também que $37,4 \%$ da amostra não têm folgas e, mesmo entre os que as dispõem $(25,5 \%)$, os intervalos são muito curtos, sendo desfavoráveis à recuperação da saúde, sobretudo quando se leva em conta que $51,6 \%$ dormem menos de seis horas por dia e $16,2 \%$ têm sono irregular. Os resultados também indicam que $94,1 \%$ da amostra apresentam esgotamento emocional e $91,2 \%$ percebem a própria competência profissional afetada ou em declínio. Conjuntamente, os dados sugerem que a dificuldade em conciliar o regime de plantão com outros horários de trabalho, vida familiar e lazer, vêm gerando tensão emocional e conduzindo a equipe de enfermagem a perceber uma baixa eficiência no serviço que presta à sociedade. 
O nono capítulo traz, à baila, uma reflexão acerca do trabalho em saúde mental e tem como base norteadora a Psicologia da Saúde e os fundamentos da Psicologia Humanista. O ponto de partida para o debate em torno da saúde mental são as condições nas quais se encontram aqueles que, mesmo após a promulgação da Lei 10.216, que institui os investimentos na assistência em saúde mental, nos serviços de base comunitária para o tratamento de pessoas portadoras de transtornos mentais, continuam internos em hospitais psiquiátricos sob condições pouco ou nada favoráveis à recuperação da saúde, da autonomia, da qualidade de vida e da reinserção social. A partir da análise de tais condições, as autoras propõem-se a discutir as possibilidades de melhoria das condições de vida e, consequentemente, da qualidade de vida por meio de relações humanizadoras e favoráveis à promoção da saúde de pacientes internos em um hospital psiquiátrico da cidade de João Pessoa (PB), com diagnóstico de esquizofrenia crônica. Estes, devido ao tempo de internação (mais de 12 anos) e a perda de contato com a família, constituem um grupo socialmente isolado e em condições pouco favoráveis para alcançar a recuperação e a desinstitucionalização. Assim, o estudo é uma modalidade de pesquisa interventiva que teve como meio de ação a realização de sessões de psicoterapia grupal de base humanista com cinco pacientes com o diagnóstico acima mencionado, sob a facilitação de duas psicólogas e uma estagiária. As sessões semanais, com duração de uma hora e meia cada uma, fomentam as análises dos resultados observados nos primeiros três meses de intervenção (22 encontros), os quais revelam a diminuição dos sintomas negativos do quadro clínico da esquizofrenia, a ampliação da interação entre os participantes e entre estes e as facilitadoras, uma maior expressão de sentimentos e opiniões, um aumento da autonomia e uma ampliação nas modalidades de comunicação. A constatação da relação entre as mudanças observadas nos comportamentos dos 
participantes e as intervenções grupais têm como base a inexistência de outras mudanças nos tratamentos oferecidos a estes, como alterações no tratamento farmacológico ou mudanças/inclusão de atividades terapêuticas. A manutenção da rotina e dos tratamentos aos quais os internos eram submetidos antes da intervenção grupal apontam os benefícios do grupo para a melhoria das condições de saúde destes.

O décimo e último capítulo do livro trata de um estudo comparativo da percepção de mulheres urbanas e rurais, de nacionalidade espanhola, sobre a percepção que têm de sua própria menopausa. O viés teórico adotado pelas autoras compreende a menopausa como um acontecimento natural na vida das mulheres, sendo assim não há obrigatoriedade de serem medicalizadas; não implica necessariamente uma diminuição de suas necessidades sexuais, e a atribuição de seu significado depende dos antecedentes culturais. Os principais objetivos estabelecidos para o estudo foram: analisar comparativamente as atitudes, as crenças e as expectativas das mulheres e como estas se relacionam com algumas variáveis pessoais; conhecer os acontecimentos familiares e sociais que coincidem com esta etapa da vida; verificar qual a porcentagem da amostra que toma medicação específica para a menopausa; e estabelecer as diferenças entre um grupo e outro. Em termos metodológicos, trata-se de estudo quanti/qualitativo e os instrumentos utilizados foram um questionário e uma entrevista em profundidade. Os resultados mostraram que a percepção da menopausa é bastante diversa nos grupos estudados e que é fundamental, para compreender tais percepções, levar em consideração as peculiaridades de cada mulher, pois é impossível falar sobre menopausa sem falar antes da vida das mulheres.

A leitura deste livro, iniciada por sólido embasamento teórico e sequenciada por pesquisas que demonstram o leque de possibilidades de aplicação da Psicologia da Saúde, deverá 
possibilitar ao leitor o conhecimento acerca das teorias e de alguns teóricos que fomentam o trabalho do psicólogo que se propõe atuar neste campo, bem como das possibilidades (e necessidade) de intercâmbio entre os profissionais das diferentes áreas da saúde para fins de implantação de serviços e de intervenções que tenham como fim a prevenção e a promoção da saúde da coletividade e de grupos específicos, tendo em vista as condições de vida destes.

Esperamos ter ilustrado para o leitor, ainda que não exaustivamente, o vasto campo - ainda pouco explorado para o desenvolvimento de pesquisas e de intervenções sob a perspectiva da Psicologia da Saúde.

Campina Grande, outono de 2011.

Railda Fernandes Alves, Maria do Carmo Eulálio, Carla de Sant'Ana Brandão, Thelma Maria Grisi Velôso, Edmundo de Oliveira Gaudêncio.

Pesquisadores do Grupo de Pesquisa em Psicologia da Saúde - UEPB/CNPQ. 

PRIMEIRA PARTE

Aportes teóricos da Psicologia da Saúde 



\section{1 \\ A Psicologia da Saúde}

José Luís Pais Ribeiro

A

Psicologia da Saúde (PS) emergiu, na década de 70, do século passado, uma época de grandes alterações políticas, sociais, econômicas, e culturais. Ela abre a Psicologia para dois campos até então pouco considerados: a Saúde como dimensão diferente das doenças; as Doenças Físicas como campo diferente das Doenças Mentais onde até então a Psicologia tinha estado acantonada.

Das mudanças no campo da saúde, associadas à emergência da Psicologia da Saúde, são paradigmáticos, na década de 70, o Relatório Lalonde que consiste no livro branco sobre a saúde dos Canadianos publicado por este ministro em 1974 (LALONDE, 1974); o Relatório Richmond (RICHMOND, 1979); a reunião de Alma-Ata de Setembro de 1978 que produziu uma declaração que constituiu um novo paradigma social nos cuidados de saúde, principalmente porque mudou o enfoque das intervenções na saúde e nas doenças para os cuidados primários de saúde.

Formalmente, a Psicologia da Saúde começa em 1973, nos Estados Unidos da América. Neste país, no seio da American Psychological Association (APA) foi criada uma Task Force on 
Health Research, com o intuito de estudar "a natureza e a extensão da contribuição dos psicólogos para a investigação básica e aplicada dos aspectos comportamentais nas doenças físicas e na manutenção da saúde" (APA TASK FORCE ON HEALTH RESEARCH, 1976, p.263). Em 1976 esta Task Force publica um relatório sobre as relações entre a Psicologia e os contextos tradicionais de saúde e doenças, propondo orientações doutrinárias. Nesse relatório, afirmava-se:

The focus of the task force has been on research contributions by psychologists who are working on health and illness problems lying outside the traditional concerns with mental health and mental illness (p.269).

A palavra "outside" é sublinhada no original. Ou seja, entendia-se que a Psicologia da Saúde centrar-se-ia nas doenças físicas e na saúde, por contradição com a Psicologia Clínica que tendia a centrar-se na saúde mental e nas doenças mentais.

A primeira definição de Psicologia da Saúde deve-se a Stone, em 1979, que, num dos primeiros livros que tinha no título a expressão "Psicologia da Saúde", dizia que esta é, qualquer aplicação científica ou profissional de conceitos e métodos psicológicos, a todas as situações próprias do campo da saúde, não apenas nos cuidados de saúde mas também na saúde pública, educação para a saúde, planificação da saúde, financiamento, legislação, etc. Deu origem à definição clássica de Matarazzo, $(1980 ; 1982)$ que afirmava que a Psicologia da Saúde consiste no domínio da Psicologia que recorre aos conhecimentos provenientes das diversas áreas da Psicologia com vista à promoção e proteção da saúde, à prevenção e tratamento das doenças, à identificação da etiologia e diagnósticos relacionados com a saúde, com as doenças e disfunções associadas, à análise e melhoria do sistema de cuidados de saúde, e ao aperfeiçoamento da política de saúde. 
Trata-se de uma definição muito ampla que abrange tudo o que é possível fazer no sistema de saúde em geral. Mais tarde a Conferência de Arden House que discutiu a formação e a prática da Psicologia da Saúde, adotou uma declaração de consenso que pretende esclarecer a definição anterior onde afirma que a Psicologia da Saúde é um campo genérico da Psicologia, com o seu corpo próprio de teoria e conhecimento, que se diferencia de outros campos da psicologia (OLBRISCH; WEISS; STONE; SCHWARTZ, 1985, p. 1038). Esta definição está de algum modo em contradição com a definição clássica de Matarazzo no sentido em que diz que tem um corpo próprio de teoria e conhecimento que se diferencia dos outros campos da Psicologia, onde anteriormente dizia que recorria aos conhecimentos provenientes das outras áreas da Psicologia.

O relatório de 1976 constituiu, assim, o embrião da nova área da Psicologia que ficou conhecida por Psicologia da Saúde. Em 1978, criou-se a Divisão de Psicologia da Saúde da American Psychological Association (Divisão 38) que, a partir de 1982, fez sair o primeiro número do seu periódico Journal of Health Psychology. Depois deste, inúmeros outros jornais especializados aparecem, quer publicados pelas divisões nacionais de Psicologia da Saúde (em Portugal, Psicologia, Saúde \& Doenças), quer por editoras. Na Europa surge a European Health Psychology Society e o seu periódico o Psychology \& Health; Mais recentemente, surge o Psychology Health \& Medicine, entre outros, ou ligados a domínios ou doenças específicos como o Psycho-Oncology.

Na mesma época, na Europa, um relatório publicado pela Organização Mundial da Saúde (WHO, 1985) da autoria do European Federation of Professional Psychologists Associations foca a contribuição dos psicólogos para a consecução do programa "Saúde para Todos no Ano 2000" (OMS, 1986), discutindo a mudança do papel tradicional do psicólogo que intervém na saúde em função de novos objetivos de saúde planetários, decorrentes da reunião de Alma-Ata já referida. 
O interesse da Psicologia pelos ambientes tradicionais de saúde e doença (não mentais) é paralelo ao desenvolvimento da consciência acerca do papel do comportamento na saúde e nas doenças mais comuns, área de interesse conhecida como Medicina Comportamental (Behavioral Medicine), que se define como "campo interdisciplinar preocupado com o desenvolvimento e integração dos conhecimentos e técnicas das ciências comportamentais e biomédicas, relevantes para a compreensão da saúde e doença e a aplicação desse conhecimento e dessas técnicas para a prevenção, diagnóstico, tratamento e reabilitação. (SCHWARTZ; WEISS, 1978, p. 250). Nesta área, surgiram títulos especializados de que é exemplo, o Journal of Behavioral Medicine, cuja publicação se iniciou, em 1978, editado pela Academy of Behavioral Medicine dos Estados Unidos da América, enquanto outros periódicos mudam de nome para se adaptarem às novas perspectivas, caso do Journal of Human Stress que passa, em 1988, a chamar-se Behavioral Medicine.

Uma das características da Psicologia da Saúde, para além de focar o seu interesse nos aspectos de saúde e de doenças não mentais é, também, a deslocação da atenção do polo "doença" para o polo "saúde", passando a considerar este polo como objeto epistemológico diferente das doenças, com definição própria e métodos de intervenção e de avaliação específicos.

\section{O interesse da Psicologia pela Saúde e doenças não mentais}

Uma questão interessante a colocar é: por que o aparente interesse súbito da Psicologia pelas áreas tradicionais da saúde? Segundo Millon (1982), desde os primórdios da Psicologia, havia exemplos de colaboração entre os domínios médicos e psicológicos: no final do século XIX, são conhecidas as colaborações de Wundt com Kraepelin, nos EUA, e 
de Heymans com Weirsma, na Europa, embora estas colaborações focassem primordialmente as psicopatologias. Já dentro do século XX, esboçaram-se relações institucionais entre a Psicologia e a Medicina: em 1911, na reunião anual da American Psychological Association, houve encontros formais entre psicólogos e médicos com o intuito de discutir a participação dos profissionais de Psicologia nos contextos tradicionais de saúde e doenças. Apesar destas tentativas, as relações entre os dois domínios mantiveram-se incipientes até ao final da década de 70 , concluindo o relatório da APA task force on health research (1976), que os psicólogos americanos não se sentiam atraídos pelas áreas das doenças físicas e da saúde.

Subitamente, na década de 80, verifica-se uma explosão do interesse dos psicólogos pela área. O que é que aconteceu que provocou tal mudança? Belar, Deardorff e Kelly (1987) enumeram algumas das razões possíveis para este interesse:

a) Fracasso do modelo biomédico na explicação das doenças e da saúde;

b) Crescimento da preocupação com a qualidade de vida e com a prevenção das doenças;

c) Mudança da atenção dos profissionais de saúde das doenças infecciosas para as doenças crônicas, com o reconhecimento do papel fundamental que o estilo de vida tinha naquelas;

d) Maturidade da investigação nas ciências comportamentais;

e) Aumento dos custos dos cuidados de saúde e procura de alternativas aos cuidados de saúde tradicionais. 


\section{Psicologia Clínica, Psicologia da Saúde e Psicologia Clínica da Saúde}

Etimologicamente, o termo "clínico" tem origem no latim clinicus, emprestado do grego Klinicos e significa "o que visita o doente na cama, por sua vez com origem na palavra klinein que significa “estar deitado”. Segundo Mucchielli e Mucchielli (1969), o termo, com aplicação mais antiga na medicina, significa estar à cabeceira do doente salientando, simultaneamente, um atendimento personalizado e prático. $\mathrm{Na}$ Psicologia, as origens do significado do termo são diferentes, embora hoje, mais de cem anos depois de ter sido introduzido na Psicologia, ele passe a ter o significado literal original.

No final do século XIX, Witmer apresentou um novo método de investigação e instrução que designou por Psicologia Clínica (GARFIELD, 1965). O termo clínico sublinhava a função prática do psicólogo em oposição ao que era a atividade tradicional de então que era laboratorial. Por essa altura, a expressão Psicologia Clínica é também utilizada por Freud numa carta escrita a Fliess.

Como explicam Pais Ribeiro e Leal (1996), a preocupação dos pioneiros da Psicologia Clínica visava predominantemente às crianças com atrasos de desenvolvimento. Já dentro do século XX, a Psicologia foi-se generalizando a outras disfunções, nomeadamente às dos indivíduos com ferimentos cerebrais. Entre a primeira e segunda guerras mundiais, o desenvolvimento de técnicas de avaliação psicológica, e a afirmação dos psicólogos como os grandes, aliás, os únicos, especialistas nessa função, arrastou os psicólogos para a área de sua maior competência, a avaliação psicológica que, para os menos informados, por vezes se tende a identificar com a função principal do psicólogo.

No final da Segunda Guerra Mundial, a Psicologia Clínica desenvolve-se no auxílio às vítimas da guerra. Data, aliás, de 1947, o primeiro programa significativo de formação 
nesta área desenhado por Shakow, na época presidente do Committee on Training in Clinical Psychology da American Psychological Association (GARFIELD, 1965). Mais tarde, clarificou-se o âmbito da Psicologia Clínica, mais concretamente em 1949, em Boulder, Colorado, nos EUA, na reunião promovida por David Shakow onde se definiu o modelo de formação conhecido por Boulder Model (renovado, atualizado ou modificado, consoante a perspectiva, em 1973, pelo Vail Model). A Psicologia Clínica começava a afastar-se do que era a sua zona de segurança - a avaliação psicológica - e começava a desenvolver e a implementar modelos de intervenção baseados na ciência psicológica.

A Psicologia começava realmente a aplicar o que verdadeiramente se pode chamar o método clínico e o raciocínio clínico. Segundo Isselbacher, Adams, Brawnwald, Petersdorf e Wilson (1980), o método clínico é idêntico ao método científico, começando com dados de observação que sugerem uma série de hipóteses que depois são examinadas à luz de novas observações, algumas das quais são feitas na clínica e outras no laboratório. Finalmente, chega-se a uma conclusão de que em ciência se denomina teoria e em medicina diagnóstico operacional. Goldman (1991) explica que o raciocínio clínico se inicia numa investigação das queixas através da análise da história e da observação. Num segundo momento, recolhe dados a partir de técnicas de diagnóstico apropriadas em termos de utilidade, validade e fidelidade. Depois integra os dados recolhidos nas duas fases anteriores de modo a conhecer adequadamente o estado do sujeito. Em seguida, estima os custos e benefícios da necessidade de realizar mais testes ou de iniciar o processo de ajuda. Finalmente, as várias opções são discutidas com o sujeito e dá-se início ao plano terapêutico.

A Psicologia Clínica instalava-se e ganhava estatuto nos hospitais psiquiátricos onde os psicólogos se estabeleciam com vigor. Shakow (1975) definia Psicologia Clínica como 
"área de conhecimento e de habilidades que visa ajudar as pessoas com alterações comportamentais ou perturbações mentais a alcançar modos mais satisfatórios de ajustamento pessoal ou de autoexpressão" (p.2376).

Entretanto, a evolução dos sistemas de saúde, o desenvolvimento de medicamentos que controlavam o comportamento dos indivíduos, e as críticas ferozes ao modelo de internamento tornaram obsoletos os hospitais psiquiátricos. Estes foram substituídos por serviços de psiquiatria a par de outros serviços em hospitais gerais, e os hospitais psiquiátricos começaram a desaparecer. Os profissionais que trabalhavam com a doença mental começaram a ser solicitados nestes hospitais gerais para ajudar pessoas com doenças não mentais, mas com problemas de adaptação à sua doença, às sequelas da doença, ou outras equivalentes. É nesta época que emerge a Psicologia da Saúde.

De então para cá, nos Estados Unidos da América, na Europa e um pouco por todo o mundo, a Psicologia da Saúde tem-se desenvolvido rapidamente e emprestado uma nova e interessante dinâmica não só à própria Psicologia, mas também ao Campo da Saúde em que está implementada ou se tenta implementar. De fato, para lá da perspectiva da Psicologia como ciência da saúde, que contribui para uma melhor compreensão dos fatores envolvidos na saúde e nas doenças, é de destacar a Psicologia como profissão de saúde. Se esta perspectiva é clássica no que concerne especificamente ao psicólogo como técnico de saúde mental não é, de modo nenhum, para uma saúde que se pretende geral e preze o papel dos próprios indivíduos e das comunidades na sua saúde e qualidade de vida, bem como em muitas das formas de ser e estar doente.

Então, se desde a Segunda Guerra Mundial, a Psicologia Clínica se dirigia essencialmente às doenças mentais, a emergência da Psicologia da Saúde, visando, no início, essencialmente às doenças físicas, empurrou estes dois grupos 
para uma aproximação, visto que o que as separava deixava de ter sentido - para um lado a dimensão física, para outro a mental.

Nesse sentido, vemos as posições de Milon e de Fox. Logo em 1982, o primeiro defendia que a Psicologia Clínica e a Psicologia da Saúde fossem consideradas como apenas uma, dado que

clinical psychology was misguided in its evolution when it followed a dualistic mind-body model and there by itself to ministering to the «mentally» disordered. Health psychology came into being in great measure as an antidote to the deficits and imbalance this created (MILLON, 1982, p.9).

Na mesma época, Fox num texto com um título sugestivo - The need for a reorientation of clinical psychology - defendia que

we devoted $90 \%$ of our efforts serving the needs of the $10 \%-15 \%$ of the population that suffers from diagnosable mental illness. (...) If psychology is to become a true health profession it must greatly expand its concerns with general health issues. Psychologists should be concerned not only with helping people to cope with anxiety or emotional disturbances, but also with helping people to cope with such physical health problems as chronic illness, impending surgery, heart attacks, unhealthy life-styles, and so forth. If clinical psychology were defined as the profession devoted to enhancing the effectiveness of human coping skills, the profession then should be concerned with 
all human functioning and the ability to cope with all types of health conditions (FOX, 1982, p.1052).

Estava-se no início da Psicologia da Saúde. A ex-presidente da divisão 38 da American Psychological Association - Health psychology - afirmava, em 1987, "obviously, clinical health psychologists engage in the same broad range of functions as more traditional clinical psychologist" (Belar, et al. 1987, p.8). Ou seja, a partir da década de 70, a intervenção no Sistema de Saúde, em geral, e no de Cuidados de Saúde, em particular, e a evolução seguinte, que consistiu em fechar os tradicionais hospitais psiquiátricos e criar serviços de saúde mental a par de todos os outros serviços de cuidados de saúde, empurra e obriga a Psicologia a repensar a sua postura neste campo e, principalmente, a rever, o seu arsenal de teorias, técnicas usadas, e fins.

Não se pense, no entanto, que o que foi dito acima é universalmente aceito. Os valores não mudam assim e, tal, nota-se na terminologia utilizada. Para alguns, a Psicologia Clínica continua a ser a que se faz no âmbito da saúde mental enquanto a Psicologia da Saúde seria a que se pratica com as doenças físicas, ou seja, a continuação da adoção do dualismo estrito mente/corpo. A par desta divisão, muitas outras existem e variam de significado em países diferentes.

\section{Psicologias Clínicas e da Saúde}

Depois da década de 70, o papel da Psicologia na área da saúde ultrapassa muito para além do que, tradicionalmente, tendia a ser atribuído à Psicologia, nomeadamente ao que tendia a ser denominado Psicologia Clínica (ALBEE, 1982; APA TASK FORCE ON HEALTH RESEARCH,1976; BRANT, 1982; DELON; PALLAK, 1982; ENRIGHT; RESNICK; DELEON; SCIARA; TANNEY, 1990; ENRIGHT, WELCH; NEWMAN; 
PERRY, 1990; HATCH, 1982; ISCOE, 1982; MATARAZZO, 1980, 1982, 1984; MILLER; FOWLER; BRIDGERS, 1982; TANABE, 1982; WHO, 1985). As exigências que passaram a ser feitas ao profissional denominado "Psicólogo Clínico" provocaram alterações em todos os domínios epistemológicos que davam acesso a esta especialidade profissional, aproximando os seus objetos.

Para ultrapassar a dualidade instituída entre o mental e o físico, nasce assim o que alguns denominaram "Psicologia Clínica da Saúde", inicialmente definida como a aplicação dos conhecimentos e métodos de todos os campos práticos da Psicologia, na promoção e proteção da saúde física e mental do indivíduo e na prevenção, avaliação e tratamento de todas as formas de perturbação mental e física, nas quais as influências psicológicas podem ser usadas ou podem contribuir para aliviar o mau funcionamento ou distress (BELLAR et al., 1987, MILLON, 1982)

Com as mudanças que ocorreram na concepção de saúde a partir de década de 70, alterou-se concomitantemente o papel da Psicologia no sistema de saúde. Estas alterações conduziram a uma proliferação de expressões que pretendiam intitular a Psicologia que se praticava no sistema de saúde como, por exemplo: Psicologia Clínica do Desenvolvimento que expressa o interesse por uma abordagem desenvolvimental no ciclo de vida (BIBACE; WALSH, 1979); Psicologia Clínica da Criança, que qualifica a Psicologia Clínica que se dedica às crianças (BIBACE; WALSH, 1979); Psicologia da Reabilitação que qualifica atividades orientadas para a restauração funcional subsequente a traumatismos ou a deficiência física (MILLON, 1982), Neuropsicologia Clínica (BELAR et al.,1987) que Kaplan e Saccuzzo (1993) definem como a disciplina científica que foca as incapacidades do sistema nervoso central e o seu tratamento, ou Psicologia da Saúde da Criança (MADDUX; ROBERTS; SLEDDEN; WRIGHT, 1986). 
Outras expressões tendem a confundir-se com a Psicologia Clínica como é o caso, por exemplo, de Psicologia Médica, que é um termo geral abrangendo o uso de procedimentos e princípios psicológicos no diagnóstico e avaliação da doença física e na avaliação do tratamento (ALCORN, 1991) e que, em Portugal, tende a ser exercida, quase exclusivamente por médicos; Psicossomática, que se interessa pela relação entre variáveis fisiológicas e psicossociais na doença, conceito que se baseia na ligação entre explicações psicanalíticas da personalidade e o desenvolvimento subsequente de certas doenças (ALCORN, 1991; MILLON, 1982), etc. Por vezes, recorre-se a outras expressões como "Psicologia clínica em contextos médicos", título do livro de Sweet, Rozensky e Tovian (1991).

Para esclarecer as relações entre a Psicologia e o sistema de saúde, Sherr (1996) propõe figurativamente as várias áreas de intervenção da Psicologia no Campo da Saúde que resultariam do cruzamento de dois eixos em que um representa o tipo de problemas e o outro o tipo de intervenção. Desse cruzamento, resultariam quatro celas que expressavam modos de intervenção diferentes:

\begin{tabular}{|l|c|c|}
\cline { 2 - 3 } \multicolumn{1}{c|}{} & \multicolumn{2}{c|}{ Problemas } \\
\cline { 2 - 3 } \multicolumn{1}{c|}{} & psicológicos & médicos \\
\hline intervenção psicológica & A & B \\
\hline intervenção médica & C & D \\
\hline
\end{tabular}

Assim, a cela A abrangeria problemas psicológicos com intervenção psicológica, (seria a área tradicional da Psicologia Clínica); a B, problemas médicos com intervenção psicológica (área da Psicologia da Saúde); a C, problemas psicológicos com intervenção médica (área da psiquiatria) e a D, problemas médicos com intervenção médica. 


\section{Como designar a Psicologia que se pratica no sistema de saúde ou no campo da saúde?}

O exercício profissional da Psicologia da Saúde não tem sido claro, principalmente pelo choque com o exercício da Psicologia Clínica, já instalada na sociedade e nas instituições. Países diferentes adotaram estratégias diferentes. Por exemplo, em Portugal, a definição de lei de psicólogo clínico assume que as suas funções abrangem as funções que eram clássicas da Psicologia Clínica mais as novas da Psicologia da Saúde. No entanto, noutros países não sucederam assim como seja o exemplo dos Estados Unidos da América e do Reino Unido.

\section{Críticas à Psicologia da Saúde}

Marks (2002) referindo-se ao Reino Unido, explica que se desenvolveram quatro abordagens à Psicologia da Saúde. Uma denominada "Psicologia Clínica da Saúde" foca a intervenção no sistema de cuidados de saúde e inspira-se no modelo biopsicossocial. Considera este autor que é um tipo de intervenção semelhante ao da Psicologia Clínica. A segunda abordagem denomina-a de "psicologia da saúde pública”. Interessa-se pala saúde pública, e é uma atividade multidisciplinar que envolve estudos epidemiológicos, avaliação e intervenção psicológica na promoção da saúde e na educação para a saúde. Uma terceira abordagem é a "psicologia da saúde comunitária" foca a investigação comunitária e a intervenção social. A quarta abordagem é a "psicologia da saúde crítica analítica”, que foca como os processos macrossociais e econômicos e o poder influenciam a saúde, os cuidados de saúde, e a sua influência na teoria e na prática da Psicologia da Saúde.

Estas quatro áreas estão explicitas na definição matriz de Psicologia da Saúde de Matarazzo (1982). Na prática, as áreas propostas por Marks constituem grandes áreas no 
sentido em que se constituem inúmeras especialidades de intervenção em cada uma delas, com base na área de intervenção mais próxima da divisão tradicional do sistema de saúde (p.ex. oncologia, cardiologia, endocrinologia, etc.), com base noutras áreas de intervenção que podem constituir subáreas das anteriores (p. ex. doenças sexualmente transmissíveis, toxicodependência, reprodução medicamente assistida, diabetes, obesidade, etc.), com base na idade (pediatria, gerontologia, etc.).

Em muitos países, a Psicologia da Saúde confundese com a Psicologia Clínica. A divisão mais simples entre estas duas Psicologias faz-se na fronteira entre o mental e o físico. A Psicologia Clínica trataria das doenças mentais e Psicologia da Saúde trataria da saúde e das doenças físicas. No entanto, esta fronteira não existe. Desde o século XIX, que cientistas, como Claude Bernard, advogam uma perspectiva de indissociabilidade do mental e do físico. Em geral, poucos psicólogos defenderão esta clivagem. Se de fato ela existe é mais por razões de ordem profissional ou de cartel. Em muitos países, a Psicologia da Saúde constitui uma área de intervenção dentro da Psicologia Profissional denominada de "clínica", noutros, elas são áreas diferentes.

Por exemplo, no Reino Unido, definem explicitamente o campo de ação da Psicologia Clínica como o trabalho com pessoas com problemas mentais e físicos que podem incluir ansiedade e depressão, doenças mentais graves e duradouras, ajustamento à doença física, perturbações neurológicas, comportamentos aditivos, perturbações comportamentais da criança, relações pessoais e familiares. Trabalham com as pessoas ao longo do ciclo de vida e com as que têm dificuldades de aprendizagem. Por outro lado, definem a Psicologia da Saúde como a prática e aplicação dos métodos psicológicos ao estudo do comportamento relevante para a saúde, doença, e cuidados de saúde. A diferença chave para o Reino Unido é que os psicólogos clínicos são os que praticam a psicologia 
com as pessoas enquanto os psicólogos da saúde são os que estudam: É uma divisão curiosa, já não entre mental e físico, entre doenças e saúde, mas entre prática e estudo.

O Inglês McDermott (2001), nesta linha, e discutindo a Psicologia da Saúde no Reino Unido, crítica a definição clássica de Matarazzo considerando-a excessivamente ampla e, por isso, pouco útil e imperialista (nas suas palavras) no sentido em que por ser tão abrangente inclui toda a Psicologia. Afirma que a Psicologia da Saúde ameaça o território da Psicologia Clínica bem estabelecido neste país, e considera a Psicologia da Saúde como invasora. Assim compreende-se a organização da Psicologia Clínica no Reino Unido que, por um lado, expressa na sua definição a evolução da Psicologia Clínica tal como a entendemos, ou seja, abrindo-se ao campo da saúde e saindo do seu gueto de saúde mental, e por outro envia a Psicologia da Saúde para um campo de investigação, ou de estudo, sem prática.

Como refere McDermott o que acaba por se verificar, no Reino Unido, é a invenção de inúmeros termos que designam esta prática tais como "Psicologia Clínica da Saúde". Este autor propõe uma definição de Psicologia da Saúde que corresponde à definição de saúde comportamental de Matarazzo (1980) e que já discutimos anteriormente (PAIS RIBEIRO, 1989), e que se esgotaria na promoção da saúde e na prevenção primária.

Algo semelhante acontece nos Estados Unidos da América onde, em 1997, a American Psychological Association (1997) definia a especialidade de Psicologia Clínica da Saúde que, explicava; aplica o conhecimento científico da inter-relação entre componentes comportamental, emocional, cognitivo, social e biológico, nas doenças e na saúde para a promoção e manutenção da saúde; prevenção, tratamento e reabilitação das doenças e incapacidades; e a melhoria do sistema de cuidados de saúde. O foco distinto da Psicologia Clínica da Saúde é nos problemas de saúde físicos. A especialidade 
dedica-se ao desenvolvimento de conhecimento relativo à interface entre comportamento e saúde e ao fornecimento de serviços de elevada qualidade baseado naqueles conhecimentos aos indivíduos, famílias e sistema de cuidados de saúde.

Exemplo diferente é o de Portugal. O fato de a Psicologia Clínica só passar a estar regulamentada por lei, em 1994, foi benéfico na medida em que não foi necessário anular ou acrescentar funções à Psicologia Clínica que se deveria praticar na interface com o sistema de saúde.

Com o Dec. Lei 241/94 de 22 de Setembro de 1994 (com aditamentos da Portaria $\mathrm{n}^{\mathrm{O}}$ 1109/95 de 9 de Setembro) surge, em Portugal, a consagração da prática da Psicologia Clínica no sistema de saúde como profissão que desenvolve "funções científicas e técnicas de avaliação, psicodiagnóstico e tratamento no campo da saúde"(p.5671). Mais especificamente, consagrou-se, como funções da Psicologia Clínica no âmbito do sistema de saúde, o estudo psicológico de indivíduos e grupos populacionais, a participação e elaboração de programas de educação para a saúde, o aconselhamento psicológico individual, conjugal, familiar ou de grupo, bem como a intervenção psicológica e psicoterapêutica. Estabeleceu-se ainda que, além destes níveis de intervenção, é função do Psicólogo Clínico no sistema de saúde a elaboração, promoção e coordenação de ações de formação complementar, a participação em ações de formação na área da especialidade e afins, assim como a participação em programas de investigação em aspectos relacionados com a sua área profissional. A chave está no termo Campo da Saúde. Este é um conceito cunhado por Lalonde (1974) que, introduziu uma distinção que, sendo óbvia, não era utilizada na linguagem da saúde e da doença. Distinguiu as expressões "Cuidados de Saúde" (health care) de "Campo da Saúde" (health field) para salientar que a primeira se referia, essencialmente, ao que se fazia nos hospitais e noutros contextos de saúde tradicionais mais 
relacionados com o tratamento, enquanto a segunda expressava tudo o que dizia respeito à saúde: O Campo da Saúde integra os Cuidados de Saúde. Explicava que o conceito de Campo da Saúde (health field concept) se suportava em quatro pilares: biologia humana, meio ambiente, estilo de vida, organização dos cuidados de saúde. Estes quatro pilares deviam (afirmava) ser considerados em simultâneo quando se pensava a saúde.

Em Portugal, aquele Decreto-lei, ao explicitar que a intervenção do Psicólogo Clínico se realiza no Campo da Saúde, em geral, e já não somente no da saúde mental, faz uma integração da nova área de Psicologia da Saúde na tradicional Psicologia Clínica, refletindo, por um lado, desenvolvimentos importantes que ocorreram no sistema de saúde e, por outro, impõem adaptações importantes nas práticas tradicionais do Psicólogo Clínico e na sua formação.

No Brasil, a organização é diferente. Possuem uma especialidade profissional reconhecida, designada Psicologia Hospitalar. Iniciou-se com o intuito de agrupar os psicólogos que trabalhavam em hospitais, mas acabou por constituir o título de especialista em Psicologia Hospitalar. Sendo uma profissão que se define pelo contexto onde se pratica tem, no entanto na sua definição a integração da saúde e da doença e do físico e mental, ficando mais próximo do que se faz em Portugal do que se faz nos países anglo-saxônicos. Mais recentemente, criou-se a Sociedade Brasileira de Psicologia da Saúde que já realizou o seu primeiro congresso e que realizou a par com a Sociedade Portuguesa de Psicologia da Saúde, um congresso Luso-Brasileiro de Psicologia da Saúde. De fato em termos técnicos, tal como a Psicologia Clínica e a Psicologia da Saúde se confundem, também a Psicologia da Saúde e a Psicologia Hospitalar, ou outras Psicologias se misturam (ver, MIYAZAKI; DOMINGOS; VALERIO; SANTOS; ROSA, 2002). 


\section{Aspectos novos da Psicologia que se pratica no sistema de saúde}

As mudanças ocorridas, no Campo da Saúde, introduziram aspectos novos na prática do psicólogo que intervém no sistema de cuidados de saúde. De entre estes salientamos:

1. Definição de quem é o cliente;

2. Alteração na relação psicólogo doente;

3. Tempo de intervenção.

Definição de quem é o cliente

Não se trata realmente de um aspecto novo. Nos hospitais psiquiátricos tradicionais, esta questão já existia. No entanto, ela existia ao nível dos "psi's" e era, provavelmente, mais fácil de resolver. Lembramos que etimologicamente a palavra "cliente" qualifica aquele que pede ajuda. Quando alguém se dirige ao gabinete do psicólogo a pedir ajuda na resolução de um problema, não há dúvidas acerca de quem é o cliente.

Hoje, as equipes onde o psicólogo está incluído, são maiores e mais complexas, informadas por conhecimentos mais diversificados. Quando o doente se dirige ao sistema de Cuidados de Saúde a pedir ajuda, não o faz para aspectos psicológicos. Fá-lo, geralmente, para pedir ajuda para o malestar, o sofrimento, provocado por uma qualquer presumível doença. É no âmbito da relação com o médico, ou outro dos que participam no diagnóstico, que surge a eventual necessidade de apoio psicológico ou psicoterapeuta. Então o médico ou outro, pedem apoio ao psicólogo. Ora, assim, o cliente passa a ser o médico que pediu ajuda para o doente (ou de modo mais alargado o próprio sistema de saúde) e não o doente. 
No seio da equipe multidisciplinar, surgirá a discussão do caso e o psicólogo deverá questionar-se sobre qual a informação que pode partilhar com a equipe sem violar o código de ética. Qual é a informação que poderá ser útil à equipe e, por conseguinte, ajudar o doente? Qual é a informação que nunca deve ser divulgada?

\section{Alteração na relação psicólogo doente}

Ainda na continuação do referido anteriormente, quando o psicólogo, no seu gabinete, perante um cliente que o procura, pode recorrer à expressão metafórica "então o que é que o traz por cá?”, quando lhe é pedido que se dirija à cama "x" porque um doente está particularmente "nervoso" ou ansioso, o normal será que o doente lhe faça aquela pergunta. À primeira vista pareceria que o cliente é o psicólogo. Muitos doentes nem sequer sabem o que é o psicólogo, outros, não sabem que existem naquele serviço, outros pensam que os estão a considerar loucos, e muitas outras possibilidades. Portanto, esta Psicologia que se faz à cabeceira do doente, ou seja, esta "verdadeira" Psicologia Clínica (no sentido que se faz à cabeceira do doente), este apoio psicológico, implicará, forçosamente, uma abordagem diferente. Por outro lado, como os doentes estão em enfermarias com outros, os que estão nas camas ao lado, estão em posição de escutar o apoio do psicólogo ao doente, o que significa que este apoio tem limitações.

\section{Tempo de intervenção}

Finalmente, e na sequência dos aspectos anteriores, o apoio que é dado nestes casos é normalmente breve. O doente, na maioria dos casos, abandona o hospital e o tempo que o psicólogo passa com o doente é muito curto, não só o que está à cabeceira do doente como o número de vezes que está com ele. Este modo de relacionamento está longe 
dos parâmetros que tradicionalmente são considerados na relação de apoio.

\section{A formação em psicologia da saúde}

Em 1983, realizou-se a conferência de Arden House, New York com vista a propor recomendações visando à formação na área da Psicologia da Saúde (OLBRISCH et al., 1985). Os participantes nesta reunião apresentaram uma conclusão consensual sobre o estado atual da Psicologia da Saúde e esclareciam que a

health psychology is a generic field of psychology, with its own body of theory and knowledge, which is differentiated from other fields in psychology. Within healthpsychologyaprofessionalspeciality is evolving. Health psychology has strong interdisciplinary ties of research and practice and it has clear professional implications that are developing that relate to professional developments in other applied specialities in psychology." (OLBRISCH et al., 1985, p.1038).

A conferência de Arden House salientou os seguintes aspectos que deviam ser considerados na formação da especialidade em Psicologia da Saúde, nomeadamente: o psicólogo da saúde deve funcionar como um cientista prático; a formação em Psicologia é um requisito essencial para o exercício da Psicologia da Saúde; o domínio de conhecimento é interdisciplinar e o vocabulário médico e o conhecimento do sistema de saúde são essenciais para trabalhar em vários contextos de investigação e de prática; deve dominar perícias interpessoais básicas fundamentais para a intervenção nestes contextos, quer com utentes quer com outros profissionais; deve dominar os aspectos éticos e legais inerentes 
a estes contextos frequentados por populações mais vulneráveis; a formação em Psicologia da Saúde requer tempo e recursos e deve ser feita com programas flexíveis que facilitem a promoção da criatividade e o desenvolvimento do conhecimento; salientam, finalmente, a estreita relação com a Psicologia Clínica.

Dois inquéritos realizados por Morrow e Clayman (1982) e por Stabler e Mesibov (1984) sobre as atividades de psicólogos da saúde concluem que a atividade a que dedicam mais tempo é a investigação ( 15 a $25 \%$ do tempo), dedicando-se menos ao diagnóstico (10\%), ensino (15\%), terapia (15\%), administração (5 a 10\%). O dispêndio de tempo com a investigação justifica-se pelo fato da área ser nova, ser vasta, e a atenção para os aspectos psicossociais na saúde e nas doenças estar em expansão. A Psicologia Clínica da Saúde é um campo muito vasto, provavelmente a requerer sub-especializações. É impossível para o psicólogo clínico da saúde dominar todas as áreas onde é passível de intervir, áreas tão diversas como: biofeedback para as arritmias cardíacas, tratamento da dor crônica, aconselhamento genético, etc (BELAR et al., 1987).

Parece, no entanto, relativamente consensual que a formação base deve ser genérica e que a sub-especialização deve ocorrer após o término da formação. A ideia de especialização não deve perder de vista os aspectos que têm sido salientados (FOX, 1994; FOX et al, 1982; MATARAZZO, 1987) de que a Psicologia é só uma que se aplica a diferentes contextos. Matarazzo afirmava que "para mim como para muitos psicólogos que trabalham no contexto da saúde, acredita-se que a Psicologia da Saúde é, em 1987, apenas uma família vibrante de aplicações específicas às situações da saúde de conhecimentos comuns a toda a psicologia" (p.899). Considera que o termo saúde é um adjetivo que define o espaço em que se aplica o conjunto de conhecimentos fornecidos pela Psicologia. Fox (1994) defende que só 
deveria existir uma Psicologia Profissional que define como aquela profissão que se interessa pela exaltação e eficiência do comportamento humano. O psicólogo profissional seria aquele que possui as competências necessárias para desenvolver e aplicar serviços de qualidade dirigidos ao público, de um modo controlado, organizado, e segundo princípios éticos, baseados no conhecimento, atitudes e perícias psicológicas, com vista a aumentar a eficiência do funcionamento humano. Matarazzo (1987) defende que o que há são aplicações diferentes, não especialidades diferentes.

\section{A pré-história da Psicologia da Saúde, da saúde e das doenças}

Os conceitos de saúde e de doença evoluíram com a história do homem. Numa descrição genérica desta evolução, podem considerar-se cinco grandes períodos:

1. Um primeiro período pré-científico ou pré-cartesiano, até ao século XVII;

2. Um período científico ou de início de desenvolvimento do modelo biomédico, que se começou a instalar com a implementação do pensamento científico e o Iluminismo;

3. A primeira revolução da saúde, com o desenvolvimento da saúde pública no século XIX;

4. A segunda revolução da saúde, iniciada na década de 1970, com a evidência da multicausalidade associada às principais causas de morbilidade e de mortalidade, e à importância que o comportamento desempenha nessas causas; 
5. A terceira revolução da saúde, associada à necessidade da redução dos custos e ao aumento de um novo padrão de doenças, as doenças crônicas no idoso.

\section{Período precientífico}

Incluímos neste modelo todas as concepções de saúde, desde a origem do homem, até à Renascença. Convém, no entanto, não esquecer que esta visão é centrada na perspectiva da cultura ocidental, no sentido em que quase ignora os movimentos que, paralelamente, decorriam na China, Índia, Américas e Arábias, com quem estivemos em contato próximo. Por exemplo, Avicena, filósofo e médico árabe (século $\mathrm{X}$ ), teve um forte impacto na medicina ocidental muito antes da abertura permitida pelo Renascimento. Também a anatomia de Galeno orientou a medicina ocidental até ao Renascimento.

A tradição hipocrática, nascida na bacia do Mediterrâneo, tem constituído a fonte inspiradora da ciência médica ocidental. Esta tradição consiste num sistema de pensamento e prática médicos que floresceu na Grécia antiga, cerca de 400 a.C. Os seguidores dos deuses da medicina associavam a arte da cura não apenas com o deus Asclepius, mas também com as suas duas filhas, Panaceia e Hygieia. Enquanto Panaceia estava envolvida com a medicação da doença, a sua irmã Hygieia preocupava-se com o bem-estar e a preservação da saúde. De salientar que, na sua origem etimológica - grega, germânica, latina, judaica -, saúde e doença constituem dimensões independentes e não apresentam qualquer relação de sentido, embora a história e a linguagem do senso comum tendam a confundi-las, tratando-as como se fossem uma única.

Etimologicamente, o grego antigo tem duas palavras significando Saúde: Hygieia e Euexia. Hygieia, a fonte da palavra higiene, aparentemente, baseia-se na palavra indo-europeia suswives, que significa "viver bem", ou mais precisamente 
"boa maneira de viver". Euexia significa, literalmente, "bons hábitos do corpo". Estes termos apontam para a funcionalidade e a atividade. De acordo com o pensamento antigo, cuja expressão antecede a medicina chinesa, o bem-estar e a saúde resultavam do equilíbrio entre aspectos ambientais, tais como o vento, a água, a temperatura, a terra e os alimentos, e o comportamento ou a maneira de viver do indivíduo, nomeadamente, os hábitos alimentares, a bebida, o sexo, o trabalho e a recreação.

A prática médica de então implicava a compreensão da natureza do ecossistema humano (NOACK, 1987). O próprio médico era mais do que um técnico, era também filósofo, professor e sacerdote, o que facilitava a compreensão holística da relação Homem, Ambiente, Saúde e Doenças (GATCHEL; BAUM; KRANTZ, 1989). Na Idade Média, a saúde ainda era concebida numa perspectiva ecológica, com uma concepção holística: é disso exemplo a definição de saúde apresentada por São Tomás de Aquino, na Summa Theologica, como um hábito ou uma disposição habitual relativamente à natureza.

Myers e Benson (1992) explicam que, em meados do século XIX, o modelo prevalecente era um modelo interativo, que defendia que o estado de saúde individual era consequência da interacção de factores biológicos, ambientais e de personalidade, na óptica de uma perspectiva ecológica típica dos modelos que antecederam o modelo biomédico. Estas perspectivas ecológicas que dominaram o pensamento do homem ao longo da história foram, progressivamente, abandonadas com a emergência e o desenvolvimento do pensamento científico moderno, só regressando na segunda metade do século XX.

A perspectiva global, ecológica, constituiu, na época, uma das limitações do desenvolvimento da ciência médica. Uma das consequências negativas desta perspectiva ecológica foi a Teoria Miasmática da Doença. Esta postulava que doenças 
como a cólera ou a peste negra eram causadas por miasmas (com origem no Grego que significa poluição), ou maus ares, o que era confirmado pelos maus cheiros provenientes dos aglomerados urbanos, onde a higiene rareava e onde os lixos, os dejetos de todos os tipos eram deixados na rua. A Teoria Miasmática da Doença foi ultrapassada com a aceitação da "Teoria do Germe”.

\section{O Modelo Biomédico}

O Modelo Biomédico acompanha o desenvolvimento do pensamento científico iniciado no Renascimento. Galileu, Newton e Descartes enunciaram os princípios básicos da ciência (ENGEL, 1977), no que ficou conhecido por modelo cartesiano ou mecanicista. Este sistema de pensamento defendia que o universo inteiro (incluindo o homem) era uma máquina prodigiosa, funcionando como um relógio, de acordo com leis matemáticas. Para descobrir tais leis aplicavase o método analítico e estudavam-se as partes componentes deste conjunto mecânico. O Modelo Biomédico tradicional baseia-se em grande parte numa visão cartesiana do mundo, considerando que a doença consiste numa avaria temporal ou permanente do funcionamento de um componente ou da relação entre componentes. Curar a doença equivalia, nesta perspectiva, à reparação da máquina (ENGEL, 1977; NOACK, 1987). Engel (1977) explica que o "modelo biomédico inclui, simultaneamente, o reducionismo, uma perspectiva filosófica que defende que os fenômenos complexos derivam, em última análise, de uma origem primária singular, e o dualismo corpo-mente, a doutrina que separa o mental do somático” (p. 130). Este modelo, parecendo hoje constituir um retrocesso trouxe, de fato, inovações notáveis que se faltassem, não teriam permitido o desenvolvimento civilizacional atual.

O Modelo Biomédico respondeu às grandes questões de saúde que se manifestavam na época. Uma das produções 
fundamentais e que sintetiza este modelo, ficou conhecida por Teoria do Germe. A Teoria do Germe, Teoria Patogênica, ou Doutrina da Etiologia Específica substituiu a Teoria Miasmática da Doença. Postula que um organismo patogênico específico estava associado a uma doença específica.

Louis Pasteur, formado em Física e Química Orgânica, publica o seu primeiro texto na área da biologia, em 1857, onde expunha com vivacidade o que designou por Teoria do Germe da Fermentação, mais especificamente, que cada tipo particular de fermentação é causado por um tipo específico de micróbio. Neste texto, propunha que esta teoria poderia ser generalizada, formulando, assim, a etiologia microbiana específica da doença, que o conduziu mais tarde à vacinação específica (DUBOS, 1974). Em 1876, Robert Koch publica um artigo acerca do seu trabalho com o antraz, apontando explicitamente para uma bactéria como causadora, validando a Teoria do Germe. Em 1880, Pasteur desenvolve um método de atenuar a virulência do agente patogênico que causava uma doença aguda dos intestinos, a bactéria Vibrio cholerae, de tal modo que imunizava o indivíduo contra esta doença, atenuação esta que não era mais do que a vacinação. Robert Koch (1843-1910) isolou, em 1877, o Bacillus Anthracis e, em 1882, o Tuberculosis Bacillus, a bactéria que causa a tuberculose que, na altura, constituía uma das principais causas de morte, conhecida por peste branca, e cuja vacinação só ficou disponível cerca de 70 anos depois, em meados do século XX.

Esta formulação de causalidade linear da Teoria do Germe, que hoje nos parece simples, forneceu as bases conceptuais necessárias para combater as grandes epidemias. Este novo modelo permitiu enormes progressos na teoria e na investigação, reorientando a prática e a investigação médicas à volta dos seguintes princípios (MYERS; BENSON, 1992): 
1. A ênfase anterior no princípio de que todos os sistemas corporais funcionavam como um todo, foi substituída pela tendência de reduzir os sistemas a pequenas partes, podendo cada uma delas ser considerada separadamente;

2. Simultaneamente, o indivíduo, com as suas características particulares e idiossincráticas, deixou de ser o centro da atenção médica, sendo substituído pelas características universais de cada doença;

3. Um forte materialismo substituiu a tendência anterior de considerar significativos os fatores não materiais (morais, sociais, comportamentais);

4. O enfoque no corpo (no organismo e suas partes) menosprezava o meio ambiente e as emoções.

Esta nova maneira de pensar, consequência das mudanças políticas, econômicas e sociais, exprime um avanço da ciência tal como ela ainda hoje é, frequentemente, entendida no mundo ocidental. Esta grande revolução no modo de pensar as doenças ficou conhecida por Primeira Revolução da Saúde.

\section{Primeira Revolução da Saúde}

A Primeira Revolução da Saúde caracteriza-se pela aplicação do modelo biomédico à prevenção das doenças, na área que hoje designamos por saúde pública. O início da revolução industrial, no século XVIII, teve consequências nefastas para a saúde com a manifestação de grandes epidemias decorrentes das mudanças sociais e das alterações do sistema de produção. De fato, grande quantidade de pessoas migrou e aglomerou-se nas grandes cidades, com parcas condições de salubridade e habitabilidade, facilitadoras da difusão de microrganismos causadores de grande morbilidade e mortalidade. 
A tuberculose foi uma das doenças mais conhecidas da época, e a que mais vítima provocou, tendo-se verificado o mesmo padrão de mortalidade elevada para outras doenças infecciosas, tais como a pneumonia, o sarampo, a gripe, a escarlatina, a difteria e a varíola, entre outras.

A Primeira Revolução da Saúde foi um dos primeiros campos de aplicação prática do modelo biomédico, tendo conduzido ao desenvolvimento das modernas medidas de saúde pública. Tais medidas foram realizadas segundo a Teoria do Germe e consistiram na implementação de medidas sanitárias de canalização de água e esgotos, recolha de lixos, sistemas de ventilação e hospitais.

O modelo biomédico teve tanto sucesso que, no final da década de 70 do século XX, nos países desenvolvidos, rareavam os indivíduos com menos de 75 anos, cuja morte fosse devida a doenças infecciosas. Se em 1900 faleciam 5.800 pessoas por milhão devido a doenças como gripe, pneumonia, tuberculose, infecções gastrointestinais, difteria, no final da década de 1970, esse rácio era de 300 por milhão, ou seja, a implementação das medidas de prevenção das doenças segundo os princípios do modelo biomédico teve resultados espantosos e, por vezes, pouco evidenciados.

A tuberculose, ou praga branca como também era chamada, é um bom exemplo do sucesso da Teoria do Germe aplicada à saúde pública. Em 1838, na Inglaterra e País de Gales, a mortalidade devido à tuberculose era cerca de 4000 por milhão, passando, 50 anos depois, ainda antes do bacilo da tuberculose ter sido identificado, para cerca de metade. Por volta de 1945, antes de se começarem a utilizar os antibióticos, a relação era de 400 por milhão. Ou seja, entre o início do século XIX e meados do século XX, as medidas de saúde pública implementadas segundo o modelo biomédico conseguiram reduzir em cerca de $90 \%$ a mortalidade por tuberculose. 
Em meados do século XIX, as doenças deixaram de ser definidas holisticamente como estado de desequilíbrio não natural, para passarem a ser definidas como um desvio da norma, caracterizado por um número crescente de parâmetros fisiológicos específicos e mensuráveis. É por esta altura que se começam a estabelecer critérios universais para a identificação das doenças e, por isso, as doenças ganham uma identidade. Em 1900, institui-se a Bertillon Classification of Causes of Death, que tinha como objetivo classificar as causas de morte. Constitui a versão 1 da Classificação Internacional de Doenças (ICD-International Classification of Diseases) que vai na versão 10. Constituiu um avanço importante cuja consequência principal é que, agora, a pneumonia tem as mesmas características na América do Sul, na Ásia ou na Europa, perdendo as características idiossincráticas do lugar e da cultura onde se manifestava, e passando a ter características universais. Estes avanços da ciência médica são consequência da lógica subjacente à Teoria do Germe.

Segunda revolução da saúde

Na década de 70, ocorreu uma mudança radical no modo dos políticos e dos cientistas pensarem a saúde, dando origem ao que ficou conhecido por Segunda Revolução da Saúde (MICHAEL, 1982; RICHMOND, 1979). Esta revolução teve três características essenciais: a) passou a centrar-se sobre a saúde ao invés de sobre a doença e, b) reconheceu que, nos países desenvolvidos, o comportamento humano era a principal causa de morbilidade e mortalidade, c) preconizar o retorno a uma perspectiva ecológica.

Foi no contexto desta mudança radical que emergiu a Psicologia da Saúde.

Globalmente, pode afirmar-se que o desenvolvimento do modelo biomédico se centrou na doença, a primeira revolução da saúde se centrou na prevenção das doenças, e que a segunda revolução da saúde se centrou na saúde. 
Acreditara-se que, com a primeira revolução da saúde, os problemas das doenças estariam resolvidos. No entanto, a partir de meados do século XX, surge nova epidemia: uma epidemia comportamental. Com efeito, constatou-se que, nos países desenvolvidos, as doenças que mais contribuíam para a mortalidade eram doenças com etiologia comportamental.

Richmond (1979) citava como principais fatores de risco, responsáveis pela maioria das doenças e mortes prematuras nos Estados Unidos da América na época, os seguintes comportamentos: fumar, consumir álcool e drogas, correr riscos que dão origem a acidentes, principalmente os acidentes motorizados entre os jovens.

Segundo Richmond (1979), em 1976, nos Estados Unidos da América, cerca de 50\% das mortes prematuras eram devidas a comportamentos inadequados ou ao estilo de vida; $20 \%$ a fatores ambientais; $20 \%$ à biologia humana; e $10 \%$ a cuidados de saúde inadequados. Valores próximos foram atribuídos, posteriormente, por outros autores, como por exemplo, Hettler (1982) e Mullen, Gold, Belcastro e McDermott (1986), que consideravam o comportamento humano responsável por cerca de $45 \%$ das mortes prematuras, o meio ambiente por cerca de $17 \%$, a biologia humana por cerca de $26 \%$ e a organização dos cuidados de saúde por cerca de $12 \%$.

As doenças que se evidenciaram por meados do século $\mathrm{XX}$ foram as cardiovasculares e o cancro, doenças estas com forte etiologia comportamental. Entre 1900 e 1970, a mortalidade causada por doenças do sistema circulatório e pelo cancro aumentou 250\% nos países ocidentais. Atualmente, cerca de $50 \%$ das mortes anuais são devidas a doenças do sistema circulatório e $20 \%$ a cancro. Com base nestas evidências, a segunda revolução da saúde teria de se centrar em novas concepções e definir novos princípios. Dado as novas epidemias não terem origem em organismos patogênicos nem serem unicausais, a Teoria do Germe deixou de ser aplicável. 
O equivalente ao germe, nesta epidemia, é o comportamento individual, o comportamento social, os hábitos e a interação entre o comportamento e o meio ambiente. A vacina, agora, teria de ser a modificação dos comportamentos, tomando este um sentido lato.

A segunda revolução da saúde foi consequência das investigações que, de modo crescente, alertavam para as novas epidemias, e cujos estudos epidemiológicos só começaram a ser conclusivos e a ganhar notoriedade na década de 1970 (LALONDE, 1974; MICHAEL, 1982; RICHMOND, 1979). O livro branco sobre a saúde dos canadianos, publicado pelo então Ministro da Saúde e dos Assuntos Sociais Marc Lalonde, defendia o estabelecimento de uma política nacional de saúde baseada em quatro pilares: biologia humana, meio ambiente, estilo de vida e organização dos cuidados de saúde, que constituíam o que denominou de Health Field Concept. Com base neste modelo, o autor defendia que se devia fazer uma distribuição equilibrada das verbas disponíveis para a saúde pelos quatro pilares.

McKeown (1972) alertava, na mesma época, para o erro no modo de abordar a saúde e as doenças. Dizia que a sociedade estava a utilizar mal os investimentos na saúde e que as ciências médicas estavam a seguir uma direção errada, porque partiam de premissas erradas acerca das bases da saúde humana. Assumiam que o corpo humano podia ser visto como uma máquina cuja proteção das doenças e dos seus efeitos dependia, em primeiro lugar, das intervenções internas. Ignoravam as influências externas e o comportamento humano que seriam os determinantes primordiais da saúde.

A década de 1970 é rica nas críticas e propostas de orientação para o campo da saúde. Elas não foram seguidas nem parecem estar em vias de ser, embora todos estejam conscientes da sua importância. Estas críticas e propostas têm chamado 
a atenção dos profissionais da saúde e das doenças para a importância de alterar o estilo de vida da população. A modificação de alguns comportamentos, tais como deixar de fumar, cuidar da alimentação, controlar o stress, praticar exercício ou atividade física regularmente, dormir um número de horas adequado, verificar periodicamente a saúde, permitiria reduzir drasticamente a mortalidade. Pelletier (1988) afirma que cerca de dois terços de todas as doenças e mortes prematuras em idades inferiores a 65 anos são passíveis de ser prevenidas através de intervenções comportamentais. No entanto, apesar de este panorama ser reconhecido tanto no relatório de Lalonde como no de Richmond, os orçamentos para a saúde, nos Estados Unidos e Canadá, atribuíam menos de 5\% ao pilar do estilo de vida (ABELIN, 1991; PELLETIER, 1988).

As mudanças que ocorreram, nas últimas décadas, na política, na economia, nos movimentos sociais e nas ciências médicas, entre outros, impuseram nova revolução.

Terceira revolução da saúde

A emergência da Psicologia da Saúde é uma "oportunidade para ajudar a nação a reduzir a aceleração dos custos de saúde” (MATARAZZO, 1980, p. 808). Esta afirmação reflete uma preocupação que já acompanhara o desenvolvimento da segunda revolução da saúde e que se tornou, dez anos depois, num elemento central.

Além das mudanças na etiologia da morbilidade e mortalidade, outros fatores contribuíram para a emergência da terceira revolução da saúde. Ramos (1988) se refere aos seguintes:

1. Alterações demográficas tais como envelhecimento da população, diversificação da família, a que se podem acrescentar a mobilidade social dos indivíduos e as migrações; 
2. Revolução tecnológica que, aumentando as possibilidades de intervenção na doença, exige mais e melhores especialistas, aumentando os custos da assistência médica;

3. Aproximação dos serviços de saúde à comunidade.

Pode-se, ainda, acrescentar o aumento do poder do consumidor que, tornando-se mais exigente e com mais capacidade crítica, força os políticos a serem mais sensíveis à opinião pública.

O final do século XX traz grandes mudanças para as sociedades desenvolvidas, nomeadamente no modo de conceber o Campo da Saúde, e pela discrepância entre os custos, a satisfação dos utentes ou da sociedade, e os resultados das intervenções neste universo.

A terceira revolução da saúde decorre dos efeitos da segunda revolução da saúde e da incapacidade desta em dar resposta aos problemas que se vieram a deparar. Como explicava Ellwood (1988), o presidente dos Estados Unidos da América proclamava, já em 1969, que a nação enfrentava uma crise no sistema de cuidados de saúde: os custos disparavam, os doentes começavam a contestar a autoridade dos médicos e a dúvida instalava-se acerca da eficácia de certos procedimentos médicos dispendiosos.

Outra alteração decisiva tem a ver com o aumento da expectativa de vida da população. King (1990) utilizou a expressão "Armadilha Demográfica" para designar o resultado da passagem de um modelo de elevada natalidade e elevada mortalidade para outro de baixa natalidade e baixa mortalidade. Chama a atenção para o impacto destas mudanças, nomeadamente no ambiente e no colapso dos sistemas ecológicos. Este autor afirma que esta ideia não é nova e que constitui uma nova versão do que Malthus defendera no século XVIII. 
O modelo biomédico abordou com êxito as doenças agudas, as que causavam mais mortalidade nas idades mais novas, contribuindo para o envelhecimento da população e deslocando as preocupações dos problemas de saúde para as doenças crônicas.

Com efeito, se observarmos a evolução da expectativa de vida, por exemplo, em Portugal desde o início do século $\mathrm{XX}$, constata-se, segundo o Instituto Nacional de Estatística, que a esperança de vida de um recém-nascido que, em 1920, era de 35,8 anos para os homens e 40,0 para as mulheres, passou, no final do século XX, para perto dos 70 e 80 anos respectivamente. Ou seja, em 80 anos a expectativa de vida à nascença duplicou.

Enquanto nos primeiros anos de vida predominam as doenças agudas, nos últimos predominam as crônicas. Cerca de 86\% das pessoas com mais de 65 anos sofrem, pelo menos, de uma doença crônica (RODIN; SALOVEY, 1989). Estes fatos permitem conceitualizar, do ponto de vista do sistema de saúde, a existência de dois mundos: um mundo gerontológico versus um mundo pediátrico, em vez de um mundo desenvolvido versus não-desenvolvido ou em desenvolvimento. As doenças do foro gerontológico tendem a ser crônicas, enquanto as do foro pediátrico tendem a ser agudas. Esta constatação aponta para a necessidade de sistemas de cuidados de saúde diferenciados, provavelmente mesmo separados, dadas às diferenças de equipamentos, tecnologias e tipo de apoio em geral que estes dois grupos de doenças exigem.

\section{A psicologia da saúde e o futuro}

Nos últimos 60 anos, mais concretamente após a Segunda Guerra Mundial, verificaram-se alterações importantes no sistema de saúde. O aparecimento de novos medicamentos (como a penicilina), de novas vacinas, de novas técnicas 
de diagnóstico, e de tratamento tende a manter uma tensão no sistema de saúde impondo atualizações constantes. A Psicologia não é a única a ter de se adaptar.

A Psicologia da Saúde nasceu numa época em que havia uma orientação claramente positiva da sociedade. A década de 70, tendo sido uma época de crise, foi também uma época de esperança. Após a Segunda Guerra Mundial, verifica-se uma orientação positiva da Saúde, que é formalmente definida no documento constitutivo da Organização Mundial de Saúde, como um estado de bem-estar físico mental e social completo e não somente a ausência de doença ou incapacidade (WHO, 1948). Como explicam Chatterji, Ustun, Sadana, Mathers e Murria (2002), a definição de Saúde chama a atenção para os estados de saúde em vez das categorias de doenças ou mortalidade, que têm ocupado um lugar importante nas estatísticas de saúde, para não dizer a totalidade destas estatísticas. A definição coloca também a saúde num contexto alargado de bem-estar humano em geral.

No campo da Psicologia, há propostas anteriores à Psicologia da Saúde com uma orientação positiva como sejam as de Carl Rogers ou de Marie Jahoda (1958), esta vinda do campo da Psicologia Social intitulava o seu livro "Current concepts of positive mental health" e é dos primeiros autores na área da Psicologia a focar o lado positivo da saúde, neste caso a mental. Norman Bradburn, num texto clássico de 1969, explicava logo no primeiro parágrafo que a investigação que abordava nesse livro constituía uma tentativa de aplicar a perspectiva da Psicologia Social ao estudo da saúde mental em populações normais e não aos problemas psiquiátricos, que tanto interessavam os psicólogos na época. Já no final do século XX, surge um movimento intitulado Psicologia Positiva (SELIGMAN; CSIKSZENTMIHALYI, 2000), que vem expressar uma orientação da Psicologia para os aspectos positivos para substituir a anterior orientação para os aspectos negativos. 
Também a Organização Mundial de Saúde adotou, no virar do século, uma orientação mais positiva publicando, em 2001, a International Classification of Functioning, Disability and Health (ICF) (WHO, 2001), para substituir a versão de 1980, a International Classification of Impairements Disabilities and Handicaps (ICIDH) (WHO, 1980). Esta classificação ao contrário da anterior foca o que as pessoas são capazes de fazer ao invés do que são incapazes de fazer.

A Psicologia da Saúde, como todas as Psicologias que interagem com o Campo da Saúde, necessita de estar em constante ajustamento às mudanças políticas, econômicas e sociais. Esta tensão permanente é positiva porque enriquece o universo da Psicologia da Saúde enquanto conteúdo científico e de práticas, e área de conhecimento.

\section{Referências}

ABELIN, T. Health promotion. In: W.Holand; R. Detels; G.Knox (Eds.) Oxford textbook of public health (2nd ed.), Vol 3. Oxford: Oxford Univerity Press.Albee, 1982, ed 1991. P. 557-589.

ALCORN, J. D. Counseling Psychology and health applications. The Counseling Psychologist, 19 (3), 1991. P. 325-341.

AMERICAN PSYCHOLOGICAL ASSOCIATION. Archival description of clinical health psychology as a specialty in professional psychology. Minutes of the Council of Representatives Meeting, August 1997. Washington, DC: American Psychological Association. 1997.

APA TASK FORCE ON HEALTH RESEARCH . Contributions of psychology to healt research: patterns, problems and potentials, American Psychologist, 31, 1976. P. 263-274.

BELAR, C.D.; DEARDORFF, W.W.; KELLY, K.E. The practice of clinical health psychology. New York:Pergamon Press, 1987. 
BIBACE, R.; WALSH, M.E. Developmental stages in children's conceptions of illness. In: STONE, G.C.; COHEN, F.; ADLER, N. E. (Eds.). Health Psychology-a Handbook. San Francisco: JosseyBass, Inc., Publishers, 1979.

BRADBURN, N. The Structure of Psychological Well-Being. Oxford: Aldine, 1969.

BRANDT, E. Prevention policy and practice in the 1980s. American Psychologist, 37 (9), 1982. P. 1038-1042.

CHATTERJI, S.; USTUN, B.; SADANA, R.; MATHERS, C.; MURRIA, $C$. The conceptual basis for measuring and reporting on health. Gpe discussion paper No 45. Geneva: WHO, 2002.

DELEON, P.; PALLAK, M. Public health and psychology: an important, expanding interaction. American Psychologist, 37 (8), 1982. P. 934-935.

DUBOS, R. J. Pasteur's dilemma-the road not taken. American Society of Microbiology News, 40, 1974. P. 703-709.

ELLWOOD, P. Shattuck Lecture - Outcomes managemant. A Technology of patient experience. The new England Journal of Medicine, 318 (23), 1988. P. 1549-1556.

ENGEL, G. L. The need for a new medical model: a challenge for biomedicine. Science, 196, 1977. P. 129-136.

ENRIGHT, M.; RESNICK, R.; DELEON, P.; SCIARA, A.; TANNEY, F. The practice of psychology in hospital settings. American Psychologist, 45 (9), 1990. P. 1059-1065.

ENRIGHT, M.; WELCH, B.; NEWMAN, R.; PERRY, B. The hospital: Psychology's challenge in the 1990s. American Psychologist, 45 (9), 1990. P. 1057-1058.

FOX, R. The need for a reorientation of clinical psychology. American Psychologist, 37 (9), 1982. P. 1051-1057. 
FOX, R. Training professional psychologists for the twenty-first century. American Psychologist, 49 (3), 1994, P. 200-206.

FOX, R.; BARCLAY, A.; RODGERS, D. The foundations of professional psychology. American Psychologist, 37 (3), 1982. P. 306-312.

GARFIELD, S.L. Historical introduction. In: WOLMAN, Benjamin B. (Edt.) Handbook of clinical psychology . New York: McgrawHill Book Company, 1965. P. 125-140.

GATCHEL, R. J.; BAUM, A.; KRANTZ, D.S. An introduction to health psychology. New York: McGraw-Hill International Editions, 1989.

GOLDMAN, L. Quantitative aspects of clinical reasoning. In: WILSON, J.; BRAUNWALD, E.; ISSELBACHER, K.; PETERSDORF, R.; MARTIN, J.; FAUCI, A.; ROOT, R. (Edts.) Harrison's principls of internal medicine (12th Edition). New York: McGraw-Hill, Inc, 1991.

HATCH, O. Psychology, society, and politics. American Psychologist, 37 (9), 1982. P.1031-1037.

HETTLER, B. Wellness promotion and risk reduction on university Campus. In: FABER, M.M.; REINHARDT, A.M. (Eds.) Promoting health through risk reduction. New York; Collier MaCmillan Publishers, 1982.

ISCOE, I. Toward a viable community health psychology: caveats from the experiences of the community mental health movement. American Psychologist, 37 (8), 1982. P. 961-965.

ISSELBACHER, K.; ADAMS, R.; BRAUNWALD, E.; PETERSDORF, R.; WILSON, J. Harrison's principls of internal medicine (9th Edition). New York: McGraw-Hill, Inc, 1980. 
KAPLAN, R.; SACCUZZO, D. Psychological testing: principles, applications, and issues. (third edition). Pacific grove; Brooks/ Cole Publishing Company, 1993.

KING, M. Health is a sustainable state. The Lancet, 336, 1990. P.664-667.

LALONDE, M. A new perspective on the health of Canadians. Ottawa; Minister of National Health and Welfare, 1974.

MADDUX, J. E.; ROBERTS, M. C.; SLEDDEN, E. A.; WRIGHT, L. Developmental issues in child health psychology. American Psychologist, 41 (1), 1986. P. 25-34.

JAHODA, M. Current Concepts of Positive Mental Health. New York: Basic Books, 1958.

MARKS, D.F. (Ed.) The Health Psychology Reader. London: Sage, 2002.

MATARAZZO, J.D. Behavioral health and behavioral medicine. American Psychologist, 35 (9), 1980. P. 807-817.

MATARAZZO, J.D. Behavioral health's challenge to academic, scientific and professional psychology. American Psychologist, 37 (1), 1982. P. 1-14.

MATARAZZO, J.D. Behavioral health: a 1990 challenge for health services professions. In: MATARAZZO, J.D.; WEISS, S.M.; HERD, J.A.; MILLER,N.E.;WEISS, S.M. (Eds). Behavioral health. New York: John Wiley \& Sons, 1984. P. 3-40.

MATARAZZO, J.D. Thre is only one psychology, no specialities, but many applications. American Psychologist, 42 (10), 1987. P. 893-903.

MCDERMOTT, M. Redifining health psychology: Matarazzo revisited. Health Psychology Update, 10, 2001. P. 3-10 
MCKEOWN T. An interpretation of the modern rise in population in Europe. Populations Studies,26, 1972. P.345-382.

MICHAEL, J. The seconde revolution in health: health promotion and its environmental base. American Psychologist, 37 (8), 1982. P. 936-941.

MILLER, H.; FOWLER, R.; BRIDGERS, W. The public health psychologist: an ounce of prevention is not enough. American Psychologist, 37 (8), 1982. P. 945-948.

MILLON, T. On the nature of clinical health psychology. In: MILLON, T.; GREEN, C.; MEAGHER, R. (Edts.). Handbook of clinical health psychology. New York; Plenum Press, 1982. P. 1-27.

MIYAZAKI, M.C.; DOMINGOS, N.; VALERIO, N.; SANTOS, A.R.; ROSA, L.T. Psicologia da saúde: extensão de serviços à comunidade, ensino e pesquisa. Psicologia USP, 13 (1), 2002. P. 29-53.

MORROW, G.; CLAYMAN, D. A membership survey of the division of health psychology. American Psychological Association. Unpublished manuscript, 1982.

MUCCHIELLI, A. ; MUCCHIELLI, R. Lexique de la psychologie. Paris: Editions Sociales Françaises, 1969.

MULLEN, K.; GOLD, R.; BELCASTRO, P.; MCDERMOTT, R. Connections for health. Dubuque: Wm.C.Brown Publishers, 1986.

MYERS, S.; BENSON, H. Psychological factors in healing: a new perspective on an old debate. Behavioral Medicine, 18, 1992. P. $5-11$

NOACK, H. Concepts of health and health promotion. In: ABELIN, T.; BRZEZINSKI, Z.J.; CARSTAIRS, D.L. (Edrs.). Measurement in health promotion and protection (WHO Regional Publications, Europe Series No 22, p. 5-28), Copenhagen: World Health Orhanization Regional Office for Europe, 1987. 
OLBRISCH, M.E.; WEISS, S.M.; STONE, G.C.; SCHWARTZ, G.E. Report of the national working conference on education and training in health psychology. American Psychologist, 40 (9), 1985. P. 1038-1041.

OMS. As metas de saúde para todos: metas da estratégia regional Europeia da saúde para todos. Lisboa: Ministério da saúde, Departamento de Estudos e Planeamento, 1986.

PAIS RIBEIRO, J.L.; LEAL, I. Avaliação e psicodiagnóstico em psicologia da saúde. Psicologia:Teoria, Investigação e Prática, 2 (2), 1997. P. 357-370.

PAIS RIBEIRO, JLP. A intervenção psicológica na promoção da saúde. Jornal de Psicologia, 8(2), 1989. P. 19-22.

PELLETIER, K. Cost-effective data: searching for the unicorn continues. American Journal of Health Promotion, 3 (1), 1988. P. 57-59.

RAMOS, V. Prever a medicina das próximas décadas: Que implicações para o planeamento da educação médica? Acta Médica Portuguesa, 2, 1988. P. 171-79.

RICHMOND, J. Healthy people: the surgeon general's report on health promotion and disease prevention. Washington: U. S. Department of Health, Education, and Welfare, 1979.

RODIN, J.; SALOVEY, P. Health psychology. Annual Review of Psychology, 40, 1989. P. 533-579.

SCHWARTZ, G.; WEISS, S. Behavioral medicine revisited: An amended definition. Journal of Behavioral Medicine, 1, 1978. P. 249-251.

SELIGMAN, M.; CSIKSZENTMIHALYI, M. Positive psychology: An introduction. American Psychologist, 55 (1) 2000. P. 5-14. 
SHAKOW, D. Clinical psychology. In: FREEDMAN, A. ; KAPLAN, H.; SADOCK, B. (Edts.). Comprehensive textbook of psychiatry/ II (Vol.1, 2th Ed.). Baltimore: The Williams \& Wilkins Company, 1975. P.2376-2386.

SHERR, L. Challenges for tomorrow. Psychology, Health \& Medicine, 1 (1), 1996. P. 5-6.

STABLER, B.; MESIBOV, G.B. Role functions of pediatric and health psychologists in health-care settings. Professional Psychology: Research and Practice,15 (2), 1984. P. 142-151.

SWEET, J.; ROZENSKY, R.; TOVIAN, S. Handbook of clinical psychology in medical settings. New York. Plenum Press, 1991.

TANABE, G. The potencial for public health psychology.

American Psychologist, 37 (8), 1982. P. 942-944.

WHO. Officials Records of the World Health Organization, no.2. United Nations, World Health Organization. Geneve, Interim Comission, 1948. P. 100.

WHO.International Classification of Impairements Disability and Handicaps. Geneva. WHO, 1980.

WHO. Contribution of psychology to programme development in the WHO Regional Office for Europe. Copehnagen: WHO Regional Office for Europe, 1985.

WHO. International Classification of functioning, Disability and Health. Geneva. WHO, 2001. 


\section{2}

\section{Abrangência e níveis de aplicação da Psicologia da Saúde}

Railda Fernandes Alves

Maria do Carmo Eulálio

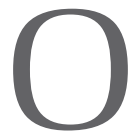

presente capítulo enuncia, enfaticamente, dois objetivos: o primeiro é demonstrar a importância das ações dos psicólogos no nível da promoção de saúde. O segundo, e principal, é apresentar, explicar e justificar a pertinência da intervenção do psicólogo na prevenção de enfermidades no âmbito da saúde pública/coletiva. A partir do desenvolvimento desses dois argumentos, propõe-se, sem ânimo de exaustividade, uma lista de atividades voltadas à prevenção de doenças para orientar minimamente as atuações do psicólogo nos três níveis de assistência de saúde.

Para dar um caráter mais didático ao texto, cada intervenção será vinculada a seu nível de atenção de saúde, de modo a destacar as diversas possibilidades desde, onde e quando fazer a prevenção.

Cabe sublinhar que a prevenção de doenças é, entre todas as novidades das intervenções psicológicas na saúde pública/coletiva, a menos desenvolvida e conhecida. Motivo pelo qual lhe será dada maior ênfase. 
A ênfase sobre a prevenção indica, por um lado, uma pluralidade de ações e, por outro, uma dificuldade em adequar cada ação a seu nível de pertinência. Essa conjuntura deverá ter na Psicologia da Saúde seu suporte epistemológico e prático.

\section{Promoção de saúde geral}

Apesar de todas as discussões e avanços observados na formação acadêmica dos profissionais de saúde, hoje em dia, ainda se registram dubiedades quanto à compreensão dos conceitos de promoção de saúde e prevenção de doenças. Fenômeno que se explica pelo fato de que, algumas vezes, uma mesma intervenção sirva aos dois casos. Godoy (1999), preocupado em diferenciar a promoção de saúde da prevenção de doenças, define a promoção de saúde como

[...] o conjunto de atuações dirigidas à proteção, manutenção e aumento da saúde e, em nível operativo, ao conjunto de atuações (centradas no indivíduo el ou na comunidade) relacionadas com o desenho, elaboração, aplicação e avaliação de programas e atividades direcionadas à educação, proteção, manutenção e acréscimo da saúde (dos indivíduos, grupos ou comunidades)" (p. 61-62). 
Guibert Reyes, Grau Abalo e Prendes Labrada (1999) explicam a promoção da saúde associando-a a educação para a saúde, como se pode ver a seguir:

Promover saúde significa educar, ou seja, instaurar na população comportamentos que sejam realmente eficazes para a construção de uma saúde ótima. Isto requer a formação de novas condutas, a modificação de atitudes, e o fomento de crenças favoráveis através de diferentes tipos de relações funcionais: formulações verbais, campanhas, trabalho em grupo, intermediação em centros laborais, intersetorialidade, etc., que propiciem a condição de saúde, definindo também como esses comportamentos hão de se instaurar (p. 182).

Definir estas duas etapas da intervenção é difícil em razão da existência de uma relação dialética entre elas e ainda a falta de consenso nos meios acadêmicos, em relação à existência de uma hierarquia entre si. Na perspectiva aqui estabelecida, há de ficar claro uma relação hierarquizada entre as ações de promoção de saúde e as de prevenção de enfermidades, fato que implica em ser a promoção da saúde uma intervenção anterior à prevenção de doenças. Assim, a promoção deve ser pensada sobre a base do perfil epidemiológico da comunidade ou grupo específico no qual se deseja intervir; voltada à proposição das assistências antes mesmo do aparecimento das enfermidades; e, finalmente, que tenham um caráter amplo e respondam ao compromisso ético de melhorar o potencial de saúde socioecológico das comunidades. (Alves, 2008). 


\section{A prevenção de enfermidades}

Tal como foi explicado anteriormente, a prevenção de doenças é posterior à promoção da saúde. Assim, depois de involucrar-se com a promoção de saúde, as intervenções do psicólogo se voltam para a prevenção de doenças nos diversos níveis de atenção de saúde.

Costa e López (1986), falando sobre prevenção, argumentam que esta pretende contribuir com a diminuição da incidência de enfermidades, a diminuição da prevalência, mediante o encurtamento do período de duração da doença ou a diminuição das sequelas e complicações da doença.

De acordo com a compreensão desenvolvida no âmbito deste capítulo, sobre os níveis de intervenção de saúde dos psicólogos, as ações que visam à diminuição da incidência das enfermidades são consideradas prevenção primária; as que visam à diminuição da prevalência são prevenção secundária; e a diminuição de sequelas e complicações das enfermidades são prevenção terciária (Alves, 2008; Alves et al, 2009).

\section{Prevenção e intervenção primárias}

O primeiro nível de intervenção psicológica se faz nos serviços de APS $^{1}$ e deverá ser realizada em duas etapas: no nível da prevenção primária e no da intervenção primária.

\section{Prevenção primária}

A prevenção primária deve estar diretamente relacionada e condicionada à promoção da saúde. Suas ações não devem dirigir-se a um indivíduo, senão aos planos de educação para a saúde, os quais devem ter como suporte conteúdos de outras áreas de aplicação da Psicologia (Psicologia

1 Atenção Primária de Saúde 
do Trabalho, Psicologia Social, Psicologia Comunitária, Psicologia Educacional). Tem como característica central a atuação nos problemas epidemiológicos da população beneficiária e investe na construção de estilos de vida saudáveis e na evitação de comportamentos de riscos. Busca desenvolver práticas de prevenção que se prolonguem ou se utilizem durante toda a vida. Assim, a prevenção primária deverá ser realizada antes que se encontre um problema concreto. Para tal intervenção o conhecimento epidemiológico prévio do coletivo social a ser assistido deverá ser utilizado como guia das ações de saúde. Numa palavra: seria trabalhar com as possibilidades de que possa aparecer uma enfermidade.

O trabalho de Vázquez e Méndez (1999) sobre os procedimentos comportamentais para o controle da diabetes pode ser aqui utilizado como exemplo. Estes afirmam que os programas de educação diabetológica não devem ser dirigidos somente aos indivíduos afetados, como também aos seus familiares e cuidadores. Os objetivos deste programa se voltam ao treinamento de estratégias tanto para evitar a enfermidade, no caso de filhos e netos dos enfermos, como ao desenvolvimento de condutas favoráveis à adesão aos programas de tratamento dos familiares enfermos.

Ainda que se executem as ações de saúde mediante a observância dos planos elaborados a partir do conhecimento a priori do coletivo social beneficiário do serviço, o plano deve ter como meta o desenvolvimento da autonomia do coletivo em relação aos temas trabalhados e a ser melhorados. Quer dizer que o grupo deverá ser estimulado a tomar decisões no que se refere às atividades programadas no plano. 


\section{Intervenção primária}

A intervenção primária pode ser explicada como uma intervenção direta sobre uma queixa detectada em um indivíduo ou em um coletivo social. Trata-se da primeira ação de saúde ante a presença de um problema que deverá ser identificado e orientado. Em seguida, se o caso necessitar de uma intervenção psicológica especializada será encaminhado a um dos outros níveis de atenção de saúde, já que neste nível a intervenção nunca deverá ser especializada.

A adequada abordagem dos problemas no nível primário poderia descongestionar os serviços de saúde nos níveis especializados. Nestes casos, dedicar-se-ia mais tempo para solucionar problemas mais complexos que necessitam maior atenção, já que muitos dos problemas trabalhados em APS seriam solucionados primariamente.

A intervenção primária do psicólogo na equipe de saúde, ainda que desempenhe um papel específico, deverá ser realizada numa perspectiva interdisciplinar e multiprofissional. Ou seja, todo o trabalho necessita ser compreendido, planejado e executado em equipes multiprofissionais. Mas não só isso. Além de trabalhar em equipe multiprofissional, o psicólogo deve amparar sua intervenção num modelo de saúde-enfermidade-cuidado-vida-morte compreendido como um processo construído coletivamente, ainda que se revele nas pessoas individualmente.

Por isso, o psicólogo, para trabalhar neste nível de atenção de saúde, necessita transcender os conhecimentos psicológicos e somar outros sobre conhecimentos de epidemiologia, de políticas sociais, de antropologia da saúde, de sociologia da saúde, de educação para saúde, entre outros conhecimentos.

As intervenções do psicólogo na APS deverão priorizar a saúde geral. Sabendo-se que a APS é a porta de entrada 
para todos os episódios relacionados à saúde-doença, o psicólogo terá de cumprir o seu papel acolhendo a todas as pessoas que ali cheguem. Entretanto, terá de ter clareza quanto ao que fazer na APS. Os casos pertinentes à saúde mental deverão ser encaminhados aos níveis especializados de atenção de saúde, quer seja o especializado ou o de alta complexidade.

Para atender a estas ações de saúde, o psicólogo deverá ter um perfil profissional que contemple os conhecimentos teóricos e técnicos de Psicologia (clínica, comunitária e social), bem como de outras disciplinas como epidemiologia, antropologia, saúde pública/coletiva, políticas sociais, políticas públicas de saúde, indicadores do desenvolvimento humano (IDH), além de uma ampla gama de conhecimentos.

\section{Guia não exaustivo de atividades compatíveis com a prevenção e intervenção primárias:}

- atuar na atenção básica de saúde/APS (compor as equipes e trabalhar nas Unidades Básicas de Saúde da Família e Centros de Saúde);

- assistir os pacientes em consultas primárias. Trindade (2007) afirma que tal assistência não pode ser confundida, em nenhum caso, com a prática da psicoterapia;

- atuar na saúde geral dos coletivos sociais a serem assistidos;

- elaborar e implementar programas de promoção e de educação para a saúde (MARTÍNEZ, 2003);

- $\quad$ propor programas de humanização e melhoria da qualidade dos serviços (TRINDADE E TEIXEIRA, 2007); 
- estudar o perfil epidemiológico dos coletivos sociais sob a responsabilidade profissional, visando a elaboração de um plano de intervenção primária;

- abordar temas/problemas de saúde coletiva, como: prevenção de transtornos alimentares; prevenção do abuso de drogas legais ou ilegais; desenvolvimento de estilos de vida saudáveis; evitação de comportamentos de risco; prevenção de enfermidades sexualmente transmissíveis; desenvolvimento das responsabilidades sobre a concepção ou evitação da gravidez indesejada; prevenção da violência (urbana, de gênero, do trânsito etc.); desenvolvimento de programas sobre sexualidade; programas particularmente voltados à saúde e melhoria da qualidade de vida de idosos, frente ao envelhecimento das populações, entre outros (SANTOS E TRINDADE, 1997; PÉREZ ÁLVAREZ, 1999) ;

- participar das reuniões das unidades básicas de saúde e das equipes de saúde;

- fazer uso das técnicas de dinâmica de grupos;

- propor e organizar grupos informativos (CARDOSO, 2002);

- fazer interconsulta com outros profissionais de saúde;

- apoiar os profissionais das escolas da comunidade sob sua responsabilidade através de orientações e da elaboração de programas de educação para a saúde;

- fazer encaminhamento a outros profissionais e/ou serviços tanto de saúde como sociais; 
- dar assistência por telefone ou por Internet (FORTÍN E CONSENTIDO, 2007; FORTÍN, 2004; FREIRE E GRANDINO, 1999);

- fazer visitas domiciliares e assistências familiares etc.

\section{Prevenção e intervenção secundárias}

\section{Prevenção secundária}

Faz-se nos ambulatórios e/ou centros de especialidades. Seu principal objetivo é dar acompanhamento ao paciente ajudando-o no seguimento de seu tratamento, seja físico ou psicológico, com o objetivo de prevenir o agravamento da doença. Para atuar bem neste nível, os psicólogos da saúde devem lançar mão do conhecimento produzido através das investigações das causas e fatores associados à falta de adesão ao tratamento. Conhecer bem as características associadas à falta de adesão a determinados tratamentos facilita a formulação de programas preventivos, voltados à proposição de diversas atividades dedicadas a evitar comportamentos que reforcem a dificuldade de seguimento do tratamento.

Acerca da adesão é importante destacar a falta de consenso quanto ao uso desse termo. Friedman e DiMatteo (1989) preferem falar de cooperação para enfatizar a natureza bilateral das interações entre os profissionais de saúde e os enfermos. Rodríguez Marin (1995) considera que o cumprimento das pautas do tratamento é uma parte da adesão terapêutica. Maciá y Méndez (1996) e Ferrer (1995) empregam indistintamente os conceitos de 'cumprimento ou adesão terapêutica'. Moore et al (2003) relacionam a falta de adesão aos erros médicos na condução do tratamento dos enfermos.

Ferrer (1995) acrescenta que, no idioma espanhol, nenhum dos termos utilizados parece representar exatamente 
o sentido que se pretende atribuir entre o ajustamento às prescrições do profissional de saúde e a implicação ativa do paciente, a estas. Sugere que seja feita uma reflexão maior deste tema com vistas a lograr uma denominação de consenso que posteriormente seja empregada de forma habitual, evitando confusões, desconhecimento e incompreensão.

Martín Alfonso (2004) considera que é adesão terapêutica o termo mais adequado dentro dos propostos até o momento pelo sentido psicológico que este incorpora e a define como uma conduta complexa, porque reúne aspectos propriamente comportamentais a outros relacionais e volitivos que conduzem à participação e à compreensão do tratamento e do plano para seu cumprimento, por parte do paciente. Tudo isso em conjunto com o profissional de saúde, e a conseguinte resposta modulada por uma busca ativa e consciente de recursos para lograr o resultado esperado.

Epstein e Cluss (1982) afirmaram que um dos problemas mais difíceis que têm que afrontar os profissionais de saúde é a falta de seguimento ou a não adesão às prescrições de saúde, por parte dos pacientes. Segundo Peck e King (1985), as prescrições de saúde de larga duração apresentam menor seguimento que as de curta duração. As recomendações de larga duração apresentam baixo nível de adesão desde o início do tratamento e vai incrementando-se com o tempo. Quanto mais complexas são as demandas, mais difícil é seu cumprimento.

Vázquez e Méndez (1999) apresentam uma proposta de procedimentos comportamentais para o controle da diabetes. Em seus estudos, mostram a importância de conhecer os fatores que explicam tanto a adesão ao tratamento como a falta de seguimento do mesmo e apontam um conjunto de meios pelos quais se pode valorizar o apoio familiar no tratamento da diabetes e as habilidades de afrontamento. Assim, eles propõem alguns protocolos pertinentes às intervenções 
comportamentais para o manejo da diabetes, ou seja, para promover e melhorar a adesão ao tratamento.

A condição crônica desse transtorno exige, de fato, o seguimento de algumas condutas durante toda a vida. Dentre os programas de Vázquez e Méndez (1999), é possível destacar os protocolos dedicados ao autocuidado para insulino-dependentes. O programa visa ao treinamento da autorregulação e o automanejo e consiste em reuniões semanais de uma hora de duração durante seis semanas. Nessas reuniões, utilizamse leituras e discussões de material informativo e exercícios de modelado e "role playing". Depois do treinamento, pedese aos adolescentes que elaborem seu próprio programa de autorregulação para seu regime diabético.

O referido programa, aqui compreendido como de prevenção secundária, é um exemplo do nível de integração existente entre os demais níveis de saúde considerados em seus estatus tanto de prevenção como de intervenção. Neste caso, para que se chegasse à elaboração, foi necessário antes uma investigação (intervenção de terceiro nível de saúde) da enfermidade e dos processos comportamentais que estariam em seu entorno. Também, ter-se-ão realizado as assistências primárias de saúde. De tal modo que a integração das assistências de saúde nos distintos níveis e seu caráter interdisciplinar é a condição básica para uma boa condução da saúde pública.

Com relação aos estudos sobre o papel do contexto social como fonte de estresse na diabetes, Hanson et al. (1989) estudaram os níveis de estresse e as estratégias de afrontamento relacionadas à adesão ao tratamento. Os resultados evidenciaram uma relação positiva entre as variáveis estudadas.

Surwit et al (1989) investigaram a efetividade do treinamento em relaxação frente à educação convencional para melhorar o controle metabólico. Seus resultados confirmaram que os sujeitos portadores da diabetes tipo II que 
receberam o treinamento em relaxação, após oito semanas, melhoraram sua tolerância à glucose.

Labbé (1999), em seu estudo sobre a preparação psicológica anteprocedimentos de Ressonância Magnética Nuclear (RMN), afirma que a avaliação dos fatores contribuintes ao aparecimento de problemas psicológicos durante ou depois da RMN, pode prevenir que estes ocorram. Os fatores listados pela autora são: ansiedade, claustrofobia diagnosticada anteriormente, dor e conhecimento íntimo do corpo.

Algumas técnicas preventivas apontadas por Labbé (1999) ajudam a preparação do paciente para a submissão à RMN. Tais técnicas objetivam facilitar a realização da exploração e também prevenir problemas futuros no paciente. A partir das recomendações, pode-se inferir que, quando atuamos na investigação de quem são os que apresentam dificuldades em submeter-se à exploração por RMN, ou quem são os que apresentam problemas psicológicos após a exploração, nós estaremos nos dedicando à intervenção de terceiro nível de saúde, quer dizer, à investigação. Nesta direção, quando manejamos as técnicas de prevenção dos possíveis problemas decorrentes da exploração com a RMN, estamos atuando na prevenção de segundo ou de terceiro nível.

A atividade psicológica em nível de prevenção é para os psicólogos um desafio, porque ainda que seja realizada em algumas situações em que a equipe de saúde tenha saturado suas possibilidades de convencimento do paciente para que lhe ajude em seu tratamento, a intervenção do psicólogo é ainda um último recurso. De fato, isso deve ser negativamente criticado porque indica que o psicólogo não participou na elaboração do programa proposto ao paciente, desde o início de seu tratamento. 


\section{Intervenção secundária}

Tem nas assistências especializadas a principal intervenção. Atende aos usuários derivados dos outros níveis de assistência proporcionando-lhes os tratamentos mais específicos. A atenção aos problemas de saúde mental tem aqui seus tratamentos mais específicos lugar apropriado.

A intervenção secundária é o campo tradicionalmente mais conhecido e desenvolvido tanto da Psicologia como das especialidades médicas em geral. Em termos da Psicologia, possui um fundamento teórico/prático bem sedimentado na Psicologia Clínica. Quer dizer, é o campo no qual se utilizam as técnicas mais tradicionalmente desenvolvidas a exemplo da psicoterapia.

Contraditoriamente, é o campo mais problemático quando se propõe sua aplicação em saúde pública/coletiva. Inúmeras investigações concluem que existe uma sobreutilização das intervenções especializadas no nível de APS, sem que os psicólogos percebam a inadequação entre suas práticas e seu nível de aplicação. Campos e Guarido (2007) e Dimenstein (2003), por exemplo, asseguram que a dedicação a $80 \%$ das atividades dos psicólogos de APS à psicoterapia individual lhes impede de desenvolver outras atividades importantes e mais apropriadas ao primeiro nível de atenção de saúde.

\section{Atividades compatíveis com a prevenção e a intervenção secundárias:}

- oferecer as assistências psicoterápicas em suas várias modalidades em todas as idades;

- realizar psicodiagnósticos diferenciais (mediante o uso de testes ou através de diagnósticos descritivos fenomenológicos;

- elaborar pareceres para responder às demandas de outros profissionais, inclusive para a justiça; 
- realizar orientação e propor atividades de suporte social;

- atuar em conjunto com os demais profissionais de saúde e equipes de saúde básica e especializada;

- fazer encaminhamento de pacientes a outros especialistas e serviços;

- elaborar em conjunto com a equipe multiprofissional programas de seguimento/adesão de tratamentos médicos (enfermidades crônicas, enfermidades mentais, cânceres etc.);

- reunir e empregar o conhecimento da neuropsicologia, já que este é decisivo nos cuidados das demências e nas sequelas dos traumatismos do crâneo (TRINDADE E TEIXEIRA, 2007).

\section{Prevenção e intervenção terciárias}

\section{Prevenção de terceiro nível}

Está involucrada com a assistência aos problemas de alta complexidade derivados dos outros níveis de atenção $\left(1^{\circ}\right.$ e $\left.2^{\circ}\right)$ e com as pesquisas em saúde. Em geral, faz-se nos hospitais. Entretanto, pode também ser feita nos centros de especialidades. A prevenção terciária inclui o seguimento de pacientes em tratamento clínico, cirúrgico, quimioterápico e radioterápico. 
De acordo com Antón e Méndez (1999):

as intervenções cirúrgicas são situações estressantes que implicam efeitos negativos ao funcionamento psicológico do enfermo, originando respostas de ansiedade, depressivas, transtornos do sono, da alimentação, etc. (p.227).

Assim, a preparação para as cirurgias é uma atividade muito corrente nas assistências aos adultos. "A informação proporcionada antes da operação que, além de modificar as respostas cognitivas, pode produzir mudanças nas respostas psicofisiológicas” (op. cit., p. 228). As técnicas de redução ou enfrentamento da ansiedade são também muito utilizadas nestas situações.

Com as crianças também se utilizam as informações preparatórias. Somam-se às informações, por exemplo, um passeio pelo hospital, a apresentação dos equipamentos hospitalares utilizados nas assistências. Técnicas que objetivam desmistificar a hospitalização e os procedimentos a que se lhes submeterá.

Yamamoto e Cunha (1998), em uma pesquisa sobre as ações dos psicólogos em hospitais, descrevem como atividades próprias do psicólogo hospitalar: a preparação dos pacientes para readaptação a nova situação pós-diagnóstico de câncer, SIDA ou outros. O objetivo destas ações é ajudar que estes pacientes desenvolvam uma nova expectativa de vida com outros valores capazes de dar-lhes o suporte necessário para enfrentar a nova realidade em consequência da doença.

As intervenções voltadas às famílias dos pacientes é uma importante intervenção preventiva. Promover a orientação e o preparo dos familiares ajuda a diminuir os impactos da notícia da doença e facilita a adaptação do grupo familiar à nova situação. O trabalho com as famílias é essencial, 
sobretudo, nos casos em que as enfermidades não são conhecidas pelas famílias. Considerando-se a importância do papel familiar na recuperação dos doentes, o trabalho desenvolvido junto a esta enquadra, de forma positiva, a condição geral do paciente.

\section{Intervenção de terceiro nível}

A intervenção de terceiro nível, no âmbito da Psicologia da Saúde, tem na pesquisa uma de suas mais importantes atividades. O psicólogo da saúde investiga os fatores biopsicossociais que intervêm na etiologia dos problemas de saúde, analisando como o entorno sociocultural afeta a saúde/ doença/cuidado/vida/morte em consequência dos estilos de vida.

No Brasil, de acordo com Yamamoto e Cunha (1998), as atividades de investigação do psicólogo da saúde estão muito relacionadas com as assistências desenvolvidas nos hospitais, e os temas onde se encontram o maior número de pesquisas se relacionam com a investigação dos diversos tipos de cânceres, das doenças infecto-contagiosas, das enfermidades provenientes de lesões medulares, das enfermidades pediátricas, dos problemas originários de setor de ginecologia e obstetrícia.

Andrasik et al (1999) recomendam que a epidemiologia deva ser situada nos primeiros degraus de qualquer projeto de pesquisa em Psicologia da Saúde. Estes projetos deverão dedicar-se à análise dos tipos de riscos aos quais, uma população está exposta, na busca de marcos precisos sobre o início e a manutenção da enfermidade.

De acordo com os citados autores, a aproximação epidemiológica é uma das formas mais significativas para a investigação e coleta de dados em Psicologia da Saúde, já que, por meio desta, é possível examinar os aspectos comportamentais, cognitivos, sociais, econômicos, evolutivos 
e fisiológicos que tenham alguma relação com a saúdedoença.

Através da epidemiologia é possível conhecer dados sobre a prevalência e incidência das enfermidades. A prevalência remete ao número total de casos de uma doença manifestada em uma população em um período específico de tempo. A incidência indica a frequência de novos casos em um espaço de tempo determinado. A prevalência e incidência das doenças são processos muito estreitos e o conhecimento destes é uma condição básica de pesquisa em Psicologia da Saúde já que "[...] permite ao pesquisador efetuar comparações entre diversos grupos de indivíduos. Ademais, a quantificação do risco constitui um elemento fundamental na formulação de políticas sanitárias [...]" (ANDRASIK et al 1999, p. 261).

Antón e Méndez (1999), ratificando o objeto de investigação da Psicologia da Saúde, confirmam a antiguidade da existência de uma relação significativa entre os hábitos e a conduta, por um lado, e a saúde-enfermidade por outro. Nesta mesma linha, dizem que é recente a preocupação dos estudiosos em submeter à investigação científica a natureza de tais relações. A base de tais investigações é saber que

[...] certos estados de enfermidade são causados por uma confluência de fatores biológicos, comportamentais, ambientais e sociais; e constatar-se que uns relativamente poucos fatores de risco, baseados no estilo de vida, são potencialmente responsáveis pela maior parte das principais causas de doença e morte precoce. (ANTÓN Y MÉNDEZ, 1999, p. 217).

Friedman e Rosenman (1959) assinalam seis áreas principais em que se desenvolvem algumas das linhas de 
pesquisa, a saber: 1 - Compreensão da gênese e manutenção dos problemas de saúde (enfermidades e repertórios de conduta, enfermidades e hábitos insalubres, padrão de conduta Tipo A que Friedman e Rosenman (1959) descrevem como: competitividade, necessidade de logro, agressividade, impaciência, inquietude, tensão da musculatura facial, sensação de estar constantemente pressionado pelo tempo, propensão a valorizar os acontecimentos como desafios pessoais e hostilidade); 2 - prevenção e promoção da saúde (Programas de atenção à criança, ao adolescente, ao adulto, à mulher, à saúde do homem², ao ancião e ao meio); 3 - facilitação e potenciação do diagnóstico e tratamento (Preparação para procedimentos médicos estressantes como: cirurgia, preparação para procedimentos médicos não cirúrgicos, preparação para a hospitalização); 4 - a adesão ao tratamento (definição e incidência, fatores que afetam, procedimentos de avaliação e intervenção); 5 - avaliação e tratamento dos problemas de saúde (dor, sistema neuromuscular, sistema circulatório, respiratório, gastrointestinal, dermatológico, endócrino, imunológico, visual); 6 - melhora do sistema de cuidados da saúde (variáveis físicas e organizativas do meio sanitário, formação e apoio dos profissionais da saúde, relação profissionais da saúde/pacientes).

\section{Atividades utilizadas na prevenção e intervenção terciária:}

- apoiar e orientar os pacientes hospitalizados;

- apoiar e orientar as famílias de pacientes hospitalizados;

- atuar nos cuidados paliativos (REVISTA CIÊNCIA E PROFISSÃO, 2006);

2 Schraiber, Gomes y Couto (2005) 
- assistir os profissionais de saúde - cuidar dos cuidadores (REVISTA CIÊNCIA E PROFISSÃO, 2006 );

- fazer consulta/interconsulta com outras equipes de saúde;

- desenvolver atividades com crianças (recreação, por exemplo);

- preparar os enfermos para as cirurgias;

- assistir os pacientes hospitalizados em UTI(OLIVEIRA, 2002);

- estimular as crianças ingressadas em UTI neonatal;

- orientar as mães das crianças hospitalizadas;

- atuar nas urgências psicológicas através de plantões em serviços substitutivos aos hospitais psiquiátricos (Centros de Assistência Psicossocial CAPS, Residências Terapêuticas, Centros de dia para idosos e outros);

- priorizar o desenvolvimento das atividades de pesquisa dos processos psicossociais da saúde-doença.

\section{Considerações finais}

Uma boa atuação dos psicólogos em saúde pública/coletiva deve ter em conta as possibilidades de intervenção nos diversos níveis de atenção de saúde, sopesando a adequação de cada ação em seu nível apropriado. É importante frisar que as intervenções de saúde primária objetivam a saúde geral através de ações voltadas à promoção da saúde e à prevenção de enfermidades; que as intervenções de saúde secundária devem voltar-se às assistências especializadas de seguimento, em que a saúde mental tem sua maior 
expressão. E as assistências terciárias, prioritariamente, guiadas pelas pesquisas dos processos psicossociais da saúde-doença. Ainda que englobem também os cuidados de saúde geral de pacientes hospitalizados para tratamentos de alta complexidade.

A prevenção de enfermidades deve ser encarada de forma ampla, ou seja, como uma atividade pertinente aos diversos níveis de assistência de saúde e não somente aos serviços de assistência primária, devendo ser executada por todos os profissionais/equipes de saúde. Cada qual contribuindo com o seu conhecimento especializado à equipe multidisciplinar objetivando a compreensão do perfil epidemiológico do coletivo social assistido e à elaboração dos planos de intervenção.

A intervenção de psicólogos se amplia na direção de novos campos de saúde, como no caso da prevenção de enfermidades. De igual maneira, exige-se um olhar e um preparo destes profissionais mais compatíveis com os procedimentos psicológicos exigidos para sua intervenção em saúde pública/ coletiva.

\section{Referências}

ALVES, R. F. Intervenciones de profesionales en el campo de la salud: estudio antropológico comparativo en Brasil, España y Portugal. 2008. 269 f. Tese de doutorado (Doctorado en Antropología) - Universidad de Granada, Granada, España. Editor: Editorial de la Universidad de Granada. D. L: GR. 19832008. ISBN: 978-84-691-5982-8.

ALVES, R. F. et al. La promoción de la salud y la prevención de enfermedades como actividades propias de la labor de los psicólogos. Arquivos Brasileiros de Psicologia, v. 61, n. 2, 2009. http:// www.psicologia.ufrj.br/abp/ 1 ACESSO EM 13 DE OUTUBRO , 2009. 
ANDRASIK, F. et al. Estrategias de investigación en psicología de la salud. In: SIMON, M. A. (Org.). Manual de psicología de la salud. Fundamentos, metodología y aplicaciones. Madrid: Editorial biblioteca Nueva, p. 259-306, 1999.

ANTÓN, D. M.; MÉNDEZ, F. X. Líneas actuales de investigación en psicología de la salud. In: SIMON, M. A. (Org.). Manual de psicología de la salud. Fundamentos, metodología y aplicaciones. Madrid: Editorial biblioteca Nueva, p. 217-256, 1999.

CAMPOS, F. C. B. y GUARIDO, E. L. O psicólogo no SUS: suas práticas e as necessidades de quem o procura. In SPINK. M. J. P. (Org.) A psicologia em diálogo com o SUS: prática profissional e produção acadêmica. São Paulo: Casa do Psicólogo, p. 81-103, 2007.

CARDOSO, C. L. A inserção do psicólogo no Programa Saúde da Família. Psicol. cienc. prof., Brasília, v. 22, n.1, p.2-9, 2002.

COSTA, M. Y LÓPEZ, E. Salud comunitaria. Barcelona: Martínez Roca, 1986.

DIMENSTEIN, M. Los (des)caminos de la formación profesional del psicólogo en Brasil para la actuación en la salud pública. Rev Panam Salud Pública/Pan Am J Public Health. v. 13, n. 5, p. 341345, 2003.

EPSTEIN, L. H. Y CLUSS, P. A. A behavioral medicine perspective on adherence to longterm medical regimens. Journal of Consulting and Clinical Psychology, 50, p. 960-971, 1982.

FERRER V. A. Adherencia o cumplimiento de las prescripciones terapéuticas. Conceptos y factores implicados. Rev Psicol Salud, v. 7, n. 1, p. 35-61, 1995.

FORTIM, I. Y CONSENTINO, L. M. Psicología Ciência e Profissão, Brasília, v. 27, n. 1, p.164-175, 2007. 
FORTIM, I. Terapia on line e Orientação Psicológica: Diferenças. In: FARAH, M. (Org.). Psicologia e Informática: o Ser Humano diante das Novas Tecnologias. São Paulo: Oficina do Livro, 2004.

FREIRE, A. B. Y GRANDINO, P. J. Atenção em rede: o psicólogo e a comunidade. Psi-Revista de psicologia social e Institucional, v. 1, n. 1, 1999.

FRIEDMAN, H. S. Y DIMATTEO, M. R. Adherence and practitioner patient relationship. In: Friedman, H. S. Y DiMatteo, M. R. (Orgs.). Health Psychology. New York: Prentice Hall, p. 68-100, 1989.

FRIEDMAN, M. Y ROSENMAN, R. H. Association of specific overt behavior pattern with blood and cardiovascular findings. Journal of the American Medical association, v.169, p. 1286-1296, 1959.

GODOY, J. F. Psicología de la salud: delimitación conceptual. In: SIMON, M. A. (Org.). Manual de psicología de la salud. Fundamentos, metodología y aplicaciones. Madrid: Editorial biblioteca Nueva, p. 61-62,1999.

GUIBERT REYES, W.; GRAU ABALO, J. y PRENDES LABRADA, M. C. ¿Cómo hacer más efectiva la educación en salud en la atención primaria? Rev Cubana Med Gen Integr, v.15, n. 2, p.176-183, 1999.

HANSON, C. L. et al. Coping styles in youths with insulindependent diabetes mellitus. Journal of Consulting and Clinical Psychology, v. 57, p. 644-651, 989.

YAMAMOTO, O. H. ; CUNHA, I. M. F. F. O. O psicólogo em hospitais de Natal: uma caracterização preliminar. Psicologia, Reflexão e Crítica, v. 11, n. 2, Porto Alegre, 1998.

LABBÉ, E. E. Preparación psicológica ante procedimientos de resonancia magnética nuclear. In: SIMON, M. A. (Org.). Manual de psicología de la salud. Fundamentos, metodología y 
aplicaciones. Madrid: Editorial biblioteca Nueva, p. 435-448, 1999.

MACIÀ, D.; MÉNDEZ. F. X. Evaluación de la adherencia al tratamiento. In: BUELA-CASAL,G.; CABALLO, V. E. Y SIERRA, J. C. (Orgs.). Manual de Evaluación en Psicología Clínica y de la Salud. Madrid: Siglo XXI, 1996.

MARTIN ALFONSO, L. Acerca del concepto de adherencia terapéutica. Rev Cubana Salud Pública, v. 30, n. 4, p. 0-0, 2004.

MARTÍNEZ, J. C. D. El discurso de los profesionales de atención primaria de la comunidad de Madrid acerca del trabajo con grupos: sobre técnicas y técnicos. Rev Esp Salud Pública, v. 77, p. 615-627, 2003.

MOORE, C. et al. Medical errors related to discontinuity of care from an inapatient setting. J Gen Inter Med, v. 18, p. 646-651, 2003.

OLIVEIRA, E. C. N. O psicólogo na UTI: reflexões sobre a saúde, vida e morte nossa de cada dia. Psicologia ciência e profissão, 22, v. 2, p. 30-41, 2002.

PECK, C. L. Y KING, N. J. Increasing patient compliance with prescriptions. Journal of The American Medical Association, v. 248, p. 2874-2877, 1985.

PÉREZ ÁLVAREZ, M. Promoción de la salud y iatrogénesis. In: SIMON, M. A. (Orgs.). Manual de psicología de la salud. Fundamentos, metodología y aplicaciones. Madrid: Editorial biblioteca Nueva, p. 155-176, 1999.

REVISTA CIÊNCIA E PROFISSÃO - DIÁLOGOS. O crescimento dos cuidados paliativos. Brasília, v. 3, n. 4, p. 18-19, 2006.

RODRÍGUEZ-MARIN, J. Efectos de la interacción entre el profesional sanitario y el paciente. Satisfacción del paciente. Cumplimiento de las prescripciones terapéuticas. In: Rodríguez 
Marín, J. (Org.). Psicología Social de la Salud. Madrid: Síntesis, p.151-60, 1995.

SANTOS, A. C. y TRINDADE, I. Intervenção psicológica em programas de saúde para idosos. In: J. L. PAIS RIBEIRO (Org.). Actas do $2^{\circ}$ Congresso Nacional de Psicologia da Saúde. ISPA. Lisboa: p. 385-398, 1997.

SCHRAIBER, L. B.; Gomes, R. y Couto. M. T. Homens e saúde na pauta da Saúde Coletiva. Ciência \& Saúde Coletiva, v.10, n. 1, p. 7-17, 2005.

SURWIT, R. S. et al. Does relaxation therapy add to conventional treatment of diabetes mellitus?, Diabetes, v. 38, n. 2, 9 A, 1989.

TRINDADE, I Intervenção psicológica em centros de saúde. In: TRINDADE, I. Y TEIXEIRA, J. A. C. (Orgs.). Psicologia nos cuidados de saúde primários. Lisboa: Climepsi Editores, p.41-54, 2007.

TRINDADE, I y TEIXEIRA, J. A. C. Aconselhamento psicológico nos cuidados primários. In: TRINDADE, I. Y TEIXEIRA, J. A. C. (Orgs.). Psicologia nos cuidados de saúde primários. Lisboa:

Climepsi Editores, p.105-118, 2007.

VÁZQUEZ, M. B. Y MÉNDEZ, F. J. Procedimientos conductuales para el control de la diabetes. In: SIMON, M. A. (Org.) Manual de psicología de la salud. Fundamentos, metodología y aplicaciones. Madrid: Editorial biblioteca Nueva, p. 469-503, 1999. 


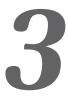

\section{La Psicología Clínica y de la Salud en España: evolución, perspectivas y modelos teóricos.}

Gualberto Buela-Casal

Raúl Quevedo-Blasco.

Universidad de Granada (España).

\section{Introducción}

Dara conocer aspectos relevantes sobre la evolución histórica de la psicología, hay que remontarse a trabajos de los años 70, 80 y 90 sobre como fue evolucionando la "Modificación de Conducta" en la cultura española (BARTOLOMÉ; CARROBLES; COSTA; DEL SER, 1977; BAYÉS, 1983; BUELA-CASAL, 1993; PECK; CÁCERES, 1981; PELECHANO, 1978, 1986; PÉREZ-ÁLVAREZ, 1991). La psicología en España nace el 1902, con la creación de la cátedra en Psicología Experimental (Facultad de Ciencias de la Universidad de Madrid) y el nombramiento como catedrático del médico Luís Simarro (BUELA-CASAL, 2005; SANTOLAYA, 2002a). La creación de la Psicología Clínica en España se demoró aproximadamente medio siglo, ya que su 
origen puede datarse en 1953 con la creación de la "Escuela de Psicología y Psicotecnia” en la Universidad Complutense de Madrid, creándose once años después en la Universidad de Barcelona (BUELA-CASAL; SIERRA, 1995). De forma paralela se fue instaurando la "Escuela de Psicología Clínica" en la Facultad de Medicina de la Universidad de Barcelona (BUELA-CASAL, 1994). Es en los años 60 y 70 cuando se va introduciendo en España el "Modelo Conductual", convirtiéndose en muy pocos años en el modelo de tratamiento de elección por la mayoría de los psicólogos que ejercitaban la Psicología Clínica (ÁVILA, 1989; BLANCO; LEÓN, 1994; BUELA-CASAL, SIERRA; CARROBLES, 1995; MOIX, 2000). Con respecto a la "Psicología de la Salud", actualmente existe bastante discrepancia en situar la aparición de la misma (GIL ROALES-NIETO, 2004; RODIN; STONE, 1987).

La delimitación conceptual de la Psicología de la Salud con respecto a la Psicología Clínica, no se aprecia con claridad, ya que muchos autores tratan a ambas disciplinas como única. En esta discrepancia, autores como Pelechano (1996), afirman que la Psicología Clínica, se ocupa preferentemente de problemas relacionados con la psiquiatría y por ello, se convirtió en una rama más de la salud. Como en cualquier área de conocimiento, hay autores que defiende la "Psicología Clínica" con base en la "Psicología de la Salud" (BELLOCH, 1996; BLANCO-PICABIA, 1996; BOTELLA, 1996) y autores que critican especialmente el campo de la salud (ECHEBURÚA, 1996). Existen también los que apoyan la independencia de ambas disciplinas (BUELA-CASAL, 2004; GIL ROALES-NIETO, 2004).

Actualmente, en el campo de la Psicología Clínica, se plantea la siguiente pregunta: ¿es una profesión sanitaria con distintas especialidades?. Diversos autores debaten y discuten este carácter sanitario de la Psicología apoyando dicho campo de actuación por parte del psicólogo (BUELACASAL, 2004; BUELA-CASAL, 2005; BUELA-CASAL ET 
AL., 2005a; BUELA-CASAL ET AL., 2005b; BUELA-CASAL ET AL., 2005c; SIERRA ET AL., 2005). La Ley 44/2003 de Ordenación de las Profesiones Sanitarias (LOPS), excluye a la Psicología de las profesiones sanitarias y sólo reconoce al psicólogo especialista en Psicología clínica (a través del PIR) como profesional sanitario. Dicha Ley, ha creado una situación de conflicto, ya que en el artículo sexto, manifiesta que actualmente las licenciaturas sanitarias son: Medicina, Farmacia, Odontología y los Médicos Especialistas en Estomatología Dentistas y Veterinaria. Por una parte el COP se manifestó la disconformidad a la no inclusión del Licenciado de Psicología en la relación de profesiones sanitarias y a la no mención explícita del Psicólogo Especialista en Psicología Clínica dentro de los profesionales sanitarios.

Desde hace unos años y hasta la actualidad, el área de la Psicología Clínica se ha convertido en la salida profesional con más demanda por parte de los estudiantes de Psicología. En este sentido, a nivel profesional, se ha de destacar que más del $70 \%$ de los profesionales se consideran clínicos. Todo ello tiene elevados efectos colaterales negativos importantes para la propia psicología, entre ellos, el propio "entaponamiento" profesional en este campo, ya que se licencian unos 5.000 Psicólogos al año en España y la mayoritaria opta por el ámbito de la Psicología Clínica y de la Salud como elección laboral preferente (concretamente en centros o gabinetes privados). Por eso, con perspectiva al futuro, esta elevada demanda de los estudios de psicología debería reducirse en los próximos años (SANTOLAYA; BERDULLAS-TEMES, 2003; SANTOLAYA, BERDULLAS-TEMES; FERNÁNDEZHERMIDA, 2002; VERA, 2004). 


\section{Psicología y Salud: antecentes y relaciones en la historia.}

Sin lugar a duda, el padre de la psicología lo situamos en Juan Huarte de San Juan (1529-1588). Muy escasas son las noticias sobre este autor. Se puede reseñar que fue licenciado en Medicina y natural de San Juan del Pie del Puerto (Navarra). Su obra "Examen de ingenios para las ciencias" (1575), sobre las diferencias que existen en los hombres, alcanzó una amplia difusión en Europa ocupando un lugar privilegiado entre las obras precursoras de la ciencia moderna y en concreto de la psicología experimental, ya que aportó una actitud científica y un correcto método para el examen descriptivo de los fenómenos psíquicos.

Tal y como específica Buela-Casal (2005), las figuras claves dentro de la Psicología Científica en España son Emilio Mira (gran impulsor de la psicología en Cataluña), Turró (en Madrid), e incluso Germain (el cual fue el responsable de la reconstrucción de la psicología en España después de la Guerra Civil). También contribuyeron a la creación y/o al desarrollo de la Psicología en España personas como Lafora, Marañón, Ramón y Cajal (todos ellos médicos de formación).

La mayoría de los grandes pioneros de la psicología a nivel internacional, también se formaron inicialmente en medicina. Algunos ejemplos notables son: Sechenov, Paulov, Luria, Weber, Lorenz, James (véase Tabla 1), e incluso Wundt (considerado por muchos autores y profesionales como el padre de la psicología científica) y Wolpe (uno de los pioneros de la terapia de conducta) (BUELA-CASAL, 2005) (Tabla 1). Ante toda esta evidencia, irealmente se puede diferenciar la psicología de la clínica y la salud, o por el contrario son disciplinas afines a la misma? 
Tabla 1. Breve recorrido histórico de la Psicología Clínica y de la Salud.

\begin{tabular}{|c|c|c|}
\hline Fechas relev & antes & Acontecimiento \\
\hline \multirow{7}{*}{ Siglo XIX } & 1879 & $\begin{array}{l}\text { Wundt funda el primer laboratorio formal de psicología en } \\
\text { la Universidad de Leipzig. }\end{array}$ \\
\hline & 1886 & Freud abre su consulta en Viena. \\
\hline & 1890 & $\begin{array}{l}\text { McKeen acuña el término "mental test" y James publica } \\
\text { "Principios de psicología". }\end{array}$ \\
\hline & 1892 & Fundación de la American Psychological Association (APA). \\
\hline & 1895 & $\begin{array}{l}\text { Breuer y S. Freud publican "Estudios sobre la histeria” y } \\
\text { Binet funda el primer laboratorio de psicodiagnóstico. }\end{array}$ \\
\hline & 1896 & $\begin{array}{l}\text { Witmer funda la primera Clínica de Psicología (Universidad } \\
\text { de Pennsylvania) y Freud utiliza por primera vez el nombre } \\
\text { de "Psicoanálisis". }\end{array}$ \\
\hline & 1897 & $\begin{array}{l}\text { Introducción del concepto y estudio del condicionamiento } \\
\text { clásico, por Pávlov. }\end{array}$ \\
\hline \multirow{6}{*}{$\begin{array}{l}\text { Siglo XX } \\
\text { Principios } \\
\text { de siglo }\end{array}$} & 1902 & $\begin{array}{l}\text { Primera Cátedra de Psicología (de Psicología Experimental) } \\
\text { en la Universidad de Madrid. }\end{array}$ \\
\hline & 1904 & $\begin{array}{l}\text { Pavlov recibe el Premio Nobel por su trabajo sobre la } \\
\text { fisiología de la digestión. }\end{array}$ \\
\hline & 1905 & $\begin{array}{l}\text { Se publica la "Escala de inteligencia Binet-Simon" y Freud } \\
\text { publica su obra titulada "Tres ensayos sobre teoría sexual". }\end{array}$ \\
\hline & 1907 & $\begin{array}{l}\text { Witmer funda la primera revista de Psicología Clínica } \\
\text { denominada Psychological Clinic. }\end{array}$ \\
\hline & 1908 & $\begin{array}{l}\text { Primer internado de psicología clínica ofrecido por la } \\
\text { Vineland Traimng School. }\end{array}$ \\
\hline & 1909 & $\begin{array}{l}\text { Conferencias de Freud en Estados Unidos de América (Clark } \\
\text { University). }\end{array}$ \\
\hline
\end{tabular}




\begin{tabular}{|c|c|c|}
\hline \multirow{7}{*}{$\begin{array}{l}\text { Siglo XX } \\
\text { Años } 10\end{array}$} & 1911 & $\begin{array}{l}\text { Introducción del concepto y estudio del condicionamiento } \\
\text { instrumental, por Thorndike. }\end{array}$ \\
\hline & 1913 & Watson publica Psychology as a behaviorist views it. \\
\hline & 1915 & Ortega y Gasset plantea sus investigaciones psicológicas. \\
\hline & 1916 & $\begin{array}{l}\text { Se publica el "test de inteligencia Stanford-Binet de } \\
\text { Terman". }\end{array}$ \\
\hline & 1917 & $\begin{array}{l}\text { Separación de la APA de la American Association of Clinical } \\
\text { Psychology (AACP). }\end{array}$ \\
\hline & 1918 & Se acuña el término "Medicina Psicosomática”. \\
\hline & 1919 & $\begin{array}{l}\text { La AACP se reintegra a la APA y se produce la publicación } \\
\text { de los trabajos de Watson y Rayner sobre el aprendizaje de } \\
\text { los miedos infantiles. }\end{array}$ \\
\hline \multirow{3}{*}{$\begin{array}{l}\text { Siglo XX } \\
\text { Años } 20\end{array}$} & 1920 & Fundación de la "Revista Archivos de Neurobiología”. \\
\hline & 1921 & Primeros trabajos de Klein sobre "Psicoanálisis infantil". \\
\hline & 1924 & $\begin{array}{l}\text { Mary Cover Jones emplea los principios del aprendizaje } \\
\text { para el tratamiento de miedos infantiles. }\end{array}$ \\
\hline \multirow{6}{*}{$\begin{array}{l}\text { Siglo XX } \\
\text { Década de } \\
\quad \text { los } 30\end{array}$} & 1931 & $\begin{array}{l}\text { La Sección Clínica de la APA nombra un Comité para la } \\
\text { fijación de los criterios de formación clínica. }\end{array}$ \\
\hline & 1935 & $\begin{array}{l}\text { Se publica el "Test de Apercepción Temática de Murray" } \\
\text { (TAT). }\end{array}$ \\
\hline & 1936 & $\begin{array}{l}\text { Louttit publica el primer texto de psicología clínica titulado } \\
\text { Clinical Psychology. }\end{array}$ \\
\hline & 1937 & $\begin{array}{l}\text { La Sección Clínica de la APA se independiza como American } \\
\text { Association for Applied Psychology (AAAP). }\end{array}$ \\
\hline & 1938 & $\begin{array}{l}\text { Publicación de la primera edición del Mental Measurement } \\
\text { Yearbook de Euros. }\end{array}$ \\
\hline & 1939 & $\begin{array}{l}\text { Se publica el "test de inteligencia Wechsler-Bellevue" y se } \\
\text { funda la Revista Psychosomatic Medicine. }\end{array}$ \\
\hline
\end{tabular}


1942 C. Rogers publica Counseling and Psychotherapy.

1943

Publicación del Minnesota Multiphasic Personality Inventory (MMPI).

1945 La AAAP se reintegra a la APA.

La Organización Mundial de la Salud define la salud como "un estado de completo bienestar físico, mental y social";

Siglo XX

Década de

$\operatorname{los} 40$
1946

la Veterans Administration y el National Institute of Mental Health (EE.UU) promueven el sistema de formación en Psicología Clínica y se produce la fundación de la Revista de Psicología General y Aplicada.

1948

Creación del Departamento de Psicología Experimental dentro del CSIC.

Conferencia de Boulder (Colorado) sobre las directrices de

1949 la formación en Psicología Clínica. Es donde se define el papel del psicólogo clínico.

1950 F. Alexander publica Psychosomatic Medicine.

Publicación de Eysenck sobre la eficacia de la psicoterapia,

1952 publicación del DSM-I por la American Psychiatric Association. Fundación de la Sociedad Española de Psicología.

Siglo XX

Década de $\operatorname{los} 50$

1953

Publicación de "Ciencia y conducta humana" de B.F. Skinner, se usa por primera vez en un informe técnico de la denominación 'terapia de conducta' (E.F. Skinner et al.), se realiza la publicación del código ético para psicólogos por parte de la APA y se crea la Escuela de Psicología y Psicotecnia en la Universidad Complutense de Madrid.

1958 Introducción de la terapia por desensibilización sistemática, por Wolpe y de la "terapia racional" de Ellis.

Beck introduce la terapia cognitiva para la depresión y

1963

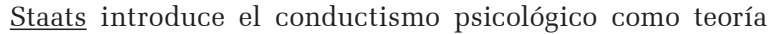
marco que unifica los esfuerzos de investigación cognitivas

Siglo XX y conductuales

Década de

1967 Beck publica un modelo psicológico de la depresión.

$\operatorname{los} 60$

1969 Inicio de los estudios de Psicología en la Universidad española (Sección de Psicología). 


\begin{tabular}{|c|c|c|}
\hline \multirow{5}{*}{$\begin{array}{l}\text { Siglo XX } \\
\text { Década de } \\
\quad \text { los } 70\end{array}$} & 1971 & $\begin{array}{l}\text { Introducción de la terapia de solución de problemas, de } \\
\text { D’Zurilla y Goldfried. }\end{array}$ \\
\hline & 1973 & $\begin{array}{l}\text { Aparece un texto con el título Biofeedback: Behavioral } \\
\text { Medicine y Meichenbaum introduce el entrenamiento por } \\
\text { inoculación del estrés. }\end{array}$ \\
\hline & 1974 & $\begin{array}{l}\text { Fundación de la Revista "Análisis y Modificación de } \\
\text { Conducta". }\end{array}$ \\
\hline & 1975 & José Luis Pinillos publica el texto Principios de Psicología. \\
\hline & 1978 & $\begin{array}{l}\text { Se crea la División } 38 \text { de la APA dedicada a la "Psicología } \\
\text { de la Salud" y la primera Facultad de Psicología en la } \\
\text { Universidad española. }\end{array}$ \\
\hline \multirow{7}{*}{$\begin{array}{l}\text { Siglo XX } \\
\text { Década de } \\
\quad \text { los } 80\end{array}$} & 1980 & $\begin{array}{l}\text { Fundación del Colegio Oficial de Psicólogos y publicación } \\
\text { del DSM-III. }\end{array}$ \\
\hline & 1981 & La APA revisa sus Principios éticos para los psicólogos. \\
\hline & 1982 & $\begin{array}{l}\text { Se funda la primera revista específica en el campo de la } \\
\text { salud Health Psychology. }\end{array}$ \\
\hline & 1984 & $\begin{array}{l}\text { Comienza el programa PIR (Psicólogo Interno Residente) } \\
\text { autonómico en Asturias y se celebra en España el I Congreso } \\
\text { del Colegio Oficial de Psicólogos (donde se establecieron } \\
\text { cinco áreas de trabajo, siendo una de ellas la "Psicología } \\
\text { Aplicada a la Salud"). }\end{array}$ \\
\hline & 1987 & $\begin{array}{l}\text { Primeras incorporaciones masivas de psicólogos al sistema } \\
\text { sanitario público en Andalucía. }\end{array}$ \\
\hline & 1988 & $\begin{array}{l}\text { Formación de la American Psychological Society y fundación } \\
\text { de la Revista "Psicothema” patrocinada por la Delegación } \\
\text { Norte del Colegio Oficial de Psicólogos. }\end{array}$ \\
\hline & 1989 & $\begin{array}{l}\text { Fundación de la Revista de Psicología de la Salud / Journal } \\
\text { of Health Psychology y de la Revista Clínica y Salud, } \\
\text { editada por la Delegación de Madrid del Colegio Oficial de } \\
\text { Psicólogos. }\end{array}$ \\
\hline \multirow{3}{*}{$\begin{array}{l}\text { Siglo XX } \\
\text { Década de } \\
\quad \text { los } 90\end{array}$} & 1993 & $\begin{array}{l}\text { Establecimiento en España del sistema de Psicólogo } \\
\text { Interno Residente como sistema de formación y fundación } \\
\text { de la Revista Psicología Conductual, patrocinada por la } \\
\text { Asociación Española de Psicología Conductual. }\end{array}$ \\
\hline & 1994 & Se produce la publicación del DSM-IV. \\
\hline & 1995 & $\begin{array}{l}\text { Se crea la Comisión Promotora de la Especialidad de } \\
\text { Psicología Clínica. }\end{array}$ \\
\hline
\end{tabular}

Nota. Tomado del Colegio Oficial de Psicólogos de España (1998). 


\section{La Psicología en el ámbito de las Ciencias de la Salud: Ámbito clínico y sanitario.}

Definir la salud actualmente conlleva cierta dificultad ya que presenta enormes dificultades y discrepancias. Una de las definiciones de salud más extendida en la sociedad es aquella que especifica a "la salud como ausencia de enfermedad". En 1946, la Organización Mundial de la Salud (O.M.S.) propone una definición de salud en la que se contemplan tres dimensiones: "la salud es el completo bienestar físico, mental y social y no simplemente la ausencia de dolencias o enfermedades”. El problema de dicha definición se encuentra principalmente en la explicación del bienestar que se hace de un individuo (BRESLOW, 1972; FERNÁNDEZBALLESTEROS; CARROBLES, 1988; OBLITAS, 2004; SANTACREU, 1991). Lo que si es común a todas las definiciones, es que la salud constituye uno de los aspectos más importantes de la vida de las personas (CASTRO-VÁZQUEZ; ESPINOSA-GUTIÉRREZ;

RODRÍGUEZ-CONTRERAS; SANTOS-IGLESIAS, 2007). Por lo tanto, es un área de especial importancia en cualquier disciplina asociada a ella y en concreto de la Psicología Clínica y de la Salud.

Cierto tipo de patologías (ej., las enfermedades crónicas), cuyo origen es multifactorial (donde influyen variables psicológicas, sociales, culturales y medioambientales), requieren un tratamiento diferente al de los estados agudos, ya que son producidos por agentes patógenos específicos. Ante esto, el modelo biomédico presenta numerosas deficiencias en cuanto a la conceptualización de los estados crónicos. Este modelo asume que la enfermedad puede ser explicada en términos de variables biológicas y ante esta perspectiva, la conducta social no tiene cabida en el mismo. En el caso de existir anormalidades conductuales, éstas se reducen a procesos somáticos, biomédicos o neurofisiológicos. Por ello, son muchos los teóricos que han apoyado la idea de que es 
necesario un nuevo modelo si se quiere progresar en la comprensión y control de la enfermedad (BRODY, 1973; ENGEL, 1977; JASNOSKI; SCHWARTZ, 1985) como es el caso del biopsicosocial planteado por Engel (LEÓN, 2004).

Actualmente, existen en España veintitrés Colegios Oficiales de Psicólogos (COP) distribuidos por toda la geografía (véase Tabla 2). Cada uno de ellos tienen dentro de sus áreas de trabajo "la Psicología Clínica y de la Salud" entre otras.

Tabla 2. Distribución de los Colegios Oficiales (COP) de Psicólogos en España.

Colegio Oficial de Psicólogos de Álava.

Colegio Oficial de Psicólogos de Andalucía Occidental.

Colegio Oficial de Psicólogos de Andalucía Oriental.

Colegio Profesional de Psicólogos de Aragón.

Colegio Oficial de Psicólogos de Bizkaia.

Colegio Oficial de Psicólogos de Cantabria.

Colegio Oficial de Psicólogos de Castilla-La Mancha.

Colegio Oficial de Psicólogos de Castilla y Léon.

Collegi Oficial de Psicòlegs de Catalunya.

Colegio Oficial de Psicólogos de Ceuta.

Collegi Oficial de Psicòlegs de la Comunitat Valenciana.

Colegio Oficial de Psicólogos de Extremadura.

Colexio Oficial de Psicoloxía de Galicia.

Colegio Oficial de Psicólogos de Gipuzkoa.

Collegi Oficial de Psicòlegs de les Illes Balears.

Colegio Oficial de Psicólogos de Madrid.

Colegio Oficial de Psicólogos de Melilla.

Colegio Oficial de Psicólogos de Navarra.

Colegio Oficial de Psicólogos de Las Palmas.

Colegio Oficial de Psicólogos del Principado de Asturias.

Colegio Oficial de Psicólogos de la Región de Murcia.

Colegio Oficial de Psicólogos de La Rioja.

Colegio Oficial de Psicólogos de Santa Cruz de Tenerife. 
En España, actualmente, hay cerca de 47.000 psicólogos colegiados y una minoría de ellos, algo más de 5.000, son los que tienen la especialidad. Este número está aumentando paulatinamente debido al proceso de homologación extraordinario que hay abierto. Se estima que pueden llegar a más de 7.000 especialistas (COLEGIO OFICIAL DE PSICÓLOGOS, 2007).

La relación entre la Psicología y las disciplinas de ciencias de la salud, está presente desde hace ya varias décadas. En la actualidad sigue existiendo dicha afinidad, a pesar de la opinión de muchos autores. Dicha unión bidireccional, se puede comprobar en diferentes niveles: a) formación universitaria, b) la necesidad de la Psicología dentro del ámbito hospitalario, c) la afinidad e interrelación de las especialidades en Psicología y Medicina, y d) revistas científicas (BUELA-CASAL, 2005). En referencia a la formación universitaria, no solo existen materias similares, sino que algunos planes de estudios entre Psicología y Medicina, también se encuentra dicha relación. Autores como Blanco-Picabia (1989), solicitan una estrecha vinculación de los planes de formación y las instituciones docentes de psicología con los servicios de salud. La incorporación de la actividad del psicólogo en el ámbito hospitalario, responde a la necesidad de ofrecer dicha intervención a nivel profesional. En un estudio llevado a cabo por Moix (2003), se puso de manifiesto que los profesionales que en mayor proporción llevan a cabo la formación del voluntariado en el ámbito hospitalario, son los psicólogos. De no haber existido demanda en este sentido, esta salida profesional no se hubiera producido. Si se presta atención a las especialidades sanitarias en psicología y sus análogas en medicina, se comprueba que la mayoría de ellas tienen su paralelismo en el campo de la psicología (véase BUELA-CASAL, 2005). Por último, existen una variedad de revistas de psicología incluidas dentro del campo disciplinar de la medicina. En esta vertiente, se han ido creando 
de forma creciente un número considerable de revistas científicas; por ej., en 1982 se funda la revista la primera revista específica en este campo, Health Psychology (véase Tabla 1), aunque antes, en 1978 había aparecido el Journal of Behavioral Medicine. En la actualidad, existe un nivel de calidad/cantidad bastante elevado en las revistas científicas en general, pero en concreto de la "Psicología Clínica y de la Salud". Entre las publicaciones periódicas se pueden resaltar tres revistas cuyo contenido se dedica exclusivamente a esta temática:

- Revista de Psicología de la Salud (editada por el Departamento de Psicología de la Salud de la Universidad de Alicante). Fundada en 1989, publicó dos números al año sobre trabajos de investigación, tanto teóricos como empíricos sobre diversos aspecto de la salud, dentro del modelo biopsicosocial. En el año 1996 pasó a ser editada por la Universidad Miguel Hernández de Elche. En la actualidad, se pueden consultar todos los números editados por la revista hasta el año 2005 (fecha en la que dejo de editarse).

- Clínica y Salud: Revista de psicología clínica y salud (editada por el Colegio Oficial de Psicólogos de Madrid). Fundada en 1990, publica tres números al año. Se trata de una revista especializada en la psicología clínica y de la salud. Admite artículos empíricos y teóricos sobre trastornos psicológicos, salud-enfermedad, prevención y atención a los diferentes niveles asistenciales.

- International Journal of Clinical and Health Psychology (IJCHP) (editada por la Asociación Española de Psicología Conductual, la Asociación Colombiana para el Avance de las Ciencias del Comportamiento y la Associaçao Portuguesa de Terapia do Comportamento / Sociedade Portuguesa 
de Psicoterapias Comportamentais e Cognitivas). Es la revista española más moderna en Psicología Clínica y de la Salud, que ha alcanzado una mayor difusión e impacto internacional. Fundada en 2001, edita tres números al año trabajos de carácter aplicado (tanto teóricos como experimentales) que supongan un avance en cualquier ámbito de la Psicología Clínica y de la Salud, en español e inglés. Esta publicación está incluida en las principales bases de datos, como es el Institute for Scientific Information (ISI) actual Thomson: Social Sciences Citation Index (SSCI) y Journal Citation Report (JCR) con un Factor de Impacto de 1,649 en 2008, lo que la sitúa en las primeras posiciones en el área de Psicología Clínica, siendo la revista española más reconocida en esta disciplina.

La muestra de este avance en España y del potencial actual de la psicología en productividad científica, se puede verificar en Journal Citatión Report (JCR), donde actualmente se encuentran indexadas 16 revistas con origen español (en la Social Sciences Edition del año 2008). De todas estas revistas, cinco de ellas son de Psicología $(31,25 \%)$ y una es especifica de "Psicología Clínica y de la Salud". Concretamente es ésta revista (International Journal of Clinical and Health Psychology) la que ocupa el primer puesto, atendiendo al Factor de Impacto (véase Tabla 3). 
Tabla 3. Revistas españolas indexadas en JCR en 2008 (Social Sciences Edition), según el Factor de Impacto.

\begin{tabular}{lc}
\hline \multicolumn{1}{c}{ Revistas } & Factor de Imparto \\
\hline International Journal of Clinical and Health & 1,649 \\
Psichology. & 1,213 \\
Psicothema. & 0,806 \\
Revista Española de Salud Publica. & 0,558 \\
Spanish Journal Psychology. & 0,481 \\
European Journal Psychiatry. & 0,400 \\
Profesional de la Información. & 0,397 \\
Infancia y Aprendizaje. & 0,370 \\
Pedagogía. & 0,333 \\
Psicológica. & \\
Acta Hispanica ad Medicinae Scientiarum que & 0,320 \\
Historiam Illustrandam. & \\
DYNAMIS. & 0,250 \\
Spanish Economic Review. & 0,171 \\
Investigaciones Económicas. & 0,118 \\
SCRIPTA NOVA. Revista Electrónica de & 0,100 \\
Geografía y Ciencias Sociales. & 0,097 \\
Hacienda Pública Española. & 0,000 \\
Boletín de la Asociación de Geógrafos Españoles. & \\
Revista de Economía Aplicada. & \\
\hline
\end{tabular}

Si se analiza más específicamente en el JCR la categoría de "Psicología Clínica", se comprueba como las principales revistas a nivel mundial hacen referencia a el área de la “Psicología Clínica y de la Salud” (Tabla 4). 
Tabla 4. Primeras 10 revistas en la categoría de "Psicología Clínica" en Journal Citation Reporte (JCR, 2008), atendiendo al Factor de Impacto.

\begin{tabular}{clc}
\hline Posición & \multicolumn{1}{c}{ Revista } & Factor de Impacto \\
\hline 1. & Clinical Psychology Review. & 6,763 \\
2. & Journal of Clinical Psychiatry. & 5,053 \\
3. & Journal of Consulting and Clinical. & 4,991 \\
4. & Psychology. & Psychological Medicine. \\
5. & Journal of Abnormal Psychology. & 4,718 \\
6. & Health Psychology. & 4,446 \\
7. & Neuropsychology Review. & 3,652 \\
8. & Neuropsychology. & 3,349 \\
9. & Journal of Clinical Child and Adolescent & 3,201 \\
10. & Psychology. & 2,928 \\
& & 2,895 \\
\hline
\end{tabular}

En referencia a la formación de posgrado, existe en España doce programas de doctorado con Mención de Calidad sobre Psicología Clínica y de la Salud ofertados en el curso 20082009 (MINISTERIO DE EDUCACIÓN, 2008a) (Tabla 5) y un total de 20 master oficiales relacionados con dicha temática (MINISTERIO DE EDUCACIÓN, 2008b) (Tabla 6). 
Tabla 5. Programas de Doctorado sobre Psicología Clínica y de la Salud ofertados en España durante el curso académico 2008-2009.

\section{Programas de doctorado}

- Análisis Funcional Aplicado a Contextos Clínicos y de la Salud.

- Clínica e Investigación Terapéutica.

- Diseños de Investigación y Aplicaciones en Psicología y Salud.

- Intervención e Investigación Psicológica en Justicia, Salud y Bienestar Social.

- Investigación en procesos básicos e intervención en Psicología de la Salud.

- Psicología Clínica y Práctica Terapéutica.

- Psicología Clínica y de la Salud.

- Psicología Clínica y Psicobiología.

- Psicología de la Salud, Evaluación y Tratamientos Psicológicos.

- Psicopatología, Salud y Neuropsicología.

- Salud Mental: Genética y Ambiente.

- Tendencias Actuales en Psicología: Intervención en Contextos Clínicos y de la Salud.

Tabla 6. Masteres Oficiales sobre Psicología Clínica y de la Salud ofertados en España durante el curso académico 2008-2009.

\section{Master Oficiales Universitarios}

- Actuaciones Psicológicas en Prevención de la Enfermedad y Promoción de la Salud.

- Análisis Funcional en Contextos Clínicos y de la Salud.

- Avances en Investigación y Tratamientos en Psicopatología y Salud.

- Diseños y Aplicaciones en Psicología y Salud.

- Investigación y Avances en Psicología de la Salud, Evaluación y Tratamientos Psicológicos.

- Investigación en Psicología de la Salud (Barcelona).

- Intervención e Investigación Psicológica en Justicia, Salud y Bienestar Social. 
- Investigación en Psicología de la Salud (Málaga).

- Psicología Clínica y de la Salud (Valencia).

- Psicología de la Salud.

- Psicología Clínica y de la Salud (Barcelona).

- Psicología Clínica y de la Salud (La Laguna).

- Psicología Clínica y práctica terapéutica.

- Psicología Clínica y de la Salud (Murcia).

- Psicología Clínica y de la Salud (Barcelona).

- Promoción de la Salud.

- Psicología, Salud y Neuropsicología.

- Salud Mental y Terapias Psicológicas.

- Salud y Calidad de Vida.

- Tratamientos Psicológicos y de la Salud.

Nota. Para los programas de Doctorado que coinciden en los títulos, se ha matizado donde se imparten.

Tal y como específica Buela-Casal (2006), la oferta en formación ha aumentado considerablemente, ya que en el 2006 existían veintisiete master para el área de Psicología en general y actualmente se ofertan más de setenta masteres oficiales en Psicología o en materias afines (MINISTERIO DE EDUCACIÓN, 2008b). Veinte de ellos ofrecen formación en "Psicología Clínica y de la Salud" (Tabla 6).

\section{La Psicología como Profesión Sanitaria.}

En la actualidad, tal y como se ha ido detallando, existen múltiples conexiones entre Psicología, Clínica y Salud. Según Reig (1985), existe una estrecha colaboración entre la Psicología y el Sistema Sanitario tanto en docencia, como en la investigación e incluso en el propio servicio asisten- 
cial (mediante la incorporación de la figura del psicólogo sanitario "generalista").

Atendiendo al objetivo principal de la Medicina y la Psicología, ambas persiguen conseguir el bienestar en las personas (REIG-FERRER, 2005). Según las aportaciones de la Psicología como profesión sanitaria "pocos profesionales han aportado tanto a la solución de problemas en ámbitos sociales, sanitarios y educativos como lo han hecho los psicólogos" (SANTOLAYA; BERDULLAS-TEMES, 2003).

Atendiendo a diferentes estudios realizados, autores como Harnett, Simonetta y Mahoney (1989), concluyen que los psicólogos no clínicos sólo buscarían ayuda profesional en un 25\% de los clínicos que conocen. Un 35\% se muestran indecisos o en desacuerdo en la efectividad de la terapia. En esta línea, Von Sidow y Reimer (1998), mediante la realización de un meta análisis, destaca que los psicólogos afirman que su profesión es percibida por la población general de forma más negativa de lo que ocurre en la realidad.

A nivel practico, en los últimos años se ha producido un incremento de las investigaciones en Psicología Clínica y de la Salud y en la evaluación de la eficacia de las intervenciones (SANZ, 2002). Por ello, se contrasta el progresivo avance de la Psicología en el ámbito sanitario en España.

Cabe pensar que cuanto mayor es el nivel de desarrollo del sistema sanitario mayor será la importancia en él del papel de los psicólogos clínicos (LAVIANA-CUETOS, 1998). En este sentido, se podría afirmar que existe una aptitud positiva de los médicos hacia los psicólogos. Es importante conocer la imagen de la Psicología de psicólogos y médicos, especialmente profesores universitarios encargados de la formación profesional. Para ello, Buela-Casal et al. (2005a) realizaron un estudio con el objetivo de conocer la opinión sobre la Psicología como Profesión Sanitaria en una muestra de 1.206 psicólogos colegiados. Los resultados demuestran 
como los porcentajes favorables en las diversas cuestiones es bastante significativo. El 99,2\% opinan que el psicólogo puede ayudar a problemas de salud y el 96,2\% dicen que están capacitados para diagnosticar problemas mentales. Dicho estudio se replicó con una muestra de 593 profesores universitarios (tanto de medicina, como de psicología) (BUELA-CASAL ET AL., 2005b). Un resultado muy relevante, reseña que el $64,4 \%$ de los médicos encuestados, afirmaron que la psicología se acercaba más a la medicina que otras áreas de conocimiento. Un porcentaje algo menor de psicólogos, respondieron favorablemente a dicha afirmación $(44,8 \%)$. Por último, Buela-Casal et al. (2005c) realizo en mismo estudio pero teniendo como muestra la población general. El 95,9\% piensan que el psicólogo es un profesional que debería estar en los hospitales y el 93,7\% opinan que debería formar parte del personal sanitario. Sierra et al. (2005) se centro en estudiantes de psicología y los resultados se declinan a favor de la Psicología como profesión Sanitaria de manera contundente. La mayoría de las cuestiones planteadas en todos estos estudios, apoya la afirmación de considerar la psicología como profesión sanitaria.

Los trabajos realizados en los últimos años acerca de las líneas prioritarias de investigación en la Psicología de la Salud (MACIÁ; MÉNDEZ, 1999; SANZ, 2002) ponen de manifiesto el crecimiento significativo que experimentó la disciplina en los años noventa del pasado siglo, sobre todo en cuanto a su proyección internacional. Se han publicado más artículos, en más revistas internacionales y con factor de impacto, principalmente en tres áreas de investigación.

\section{Modelos de Intervención en la Psicología Clínica.}

Atendiendo a Feixas y Miró (1993, 1995), los modelos de intervención que existen actualmente en el ámbito de la Psicología Clínica son: a) modelos Psicodinámicos, b) modelos 
Humanisticos-Existenciales, c) modelos Conductuales, d) Modelos Sistémicos, f) modelos Cognitivos y g) modelos cognitivos-conductuales (véase Tabla 7).

Tabla 7. Principales modelos actuales en psicología.

\begin{tabular}{cl}
\hline & Basados en el psicoanálisis, son modelos en los \\
MODELOS & que el conflicto intrapsiquico tiene un papel \\
central. El método terapéutico se basa en tres \\
procesos fundamentales: la "Asociación Libre", \\
el "Análisis de los fenómenos de Transferencia \\
y Contratransferencia" y el "Análisis de la \\
Resistencia".
\end{tabular}




\begin{tabular}{|c|c|}
\hline $\begin{array}{c}\text { MODELOS } \\
\text { COGNITIVOS }\end{array}$ & $\begin{array}{l}\text { Modelos centrados en los procesos cognitivos de las } \\
\text { personas. Por ello, la patología se produce desarrollo } \\
\text { disfuncional de dichos procesos: 1) Esquemas o } \\
\text { estructuras cognitivas, 2) Operaciones cognitivas, } \\
\text { y 3) Productos cognitivos. En este enfoque lo más } \\
\text { relevante es el significado que se le atribuye a los } \\
\text { eventos externos. }\end{array}$ \\
\hline $\begin{array}{c}\text { MODELO } \\
\text { COGNITIVO- } \\
\text { CONDUCTUAL } \\
\text { (Cognitive- } \\
\text { Behavioral } \\
\text { Therapies, CBT) }\end{array}$ & $\begin{array}{l}\text { Basado en el modelo ABCDE de Ellis (1962). Se } \\
\text { fundamenta en la idea de que la conducta incluye la } \\
\text { emoción y la cognición, y no sólo el comportamiento } \\
\text { motor públicamente observable. Por ello, la acción, } \\
\text { la emoción y la cognición trabajan conjuntamente } \\
\text { en cada persona y son mutuamente influyentes } \\
\text { junto con las condiciones ambientales y biológicas } \\
\text { tanto históricas como actuales, atendiendo además } \\
\text { a los efectos en retroalimentación que tiene la } \\
\text { conducta del individuo con su ambiente. }\end{array}$ \\
\hline
\end{tabular}

Actualmente en España, el modelo más utilizado es el Cognitivo-Conductual, basado en técnicas cognitivas (BECK, 1963, 1976; ELLIS, 1958; MEICHENBAUM, 1977), emocionales (BECK, RUSH, SHAW; EMERY, 1983; ELLIS, 1999; ELLIS; ABRAHAMS, 1980; GUIDANO, 1994) y conductuales (KAZDIN, 1978; SKINNER, 1973; WALTER; SHEA, 1987). Los resultados obtenidos de investigaciones clínicas controladas proporcionan un fuerte apoyo a estas terapias en general. Aunque el grado de eficacia es variable, dependiendo del tipo de problema, la integración de tecnología cognitiva y conductual parece propiciar unos mejores resultados.

Sin embargo, las terapias van avanzando y han surgido las denominadas “Terapias de Tercera Generación” (Tabla 8). Dichas terapias enfocan los casos desde una perspectiva contextualista e individual. El principal objetivo no es la reducción de los síntomas que presenta el paciente, sino una reorientación de la vida de la persona, sin importar si los síntomas se reducen o no. Por lo tanto, las técnicas que engloba están orientadas, no a la evitación/reducción de síntomas, sino a que la persona actúe con la responsabilidad de 
la elección personal y la aceptación de los eventos privados que conlleve ese proceder (LUCIANO; VALDIVIA, 2006). Los principales tipos desarrollados hasta el momento son:

Tabla 8. Principales “Terapias de Tercera Generación”.

- Terapia de Aceptación y Compromiso (ACT) de Hayes, Stroshal y Wilson (1999).

- Psicoterapia Analítica Funcional (PAF) de Kohlenberg y Tsai (1991).

- Terapia de Conducta Dialéctica de Linehan (1993).

- Terapia Conductual Integrada de Pareja de Jacobson, Christensen, Prince, Cordova y Eldridge (2000).

- Terapia Racional-Experiencial.

- Terapia de Activación Conductual (AC).

- Terapia Cognitiva con base en "Mindfulness".

- La Terapia de Aceptación y Compromiso (ACT) de Hayes, Stroshal y Wilson (1999). En España, la autora que más está trabajando con este tipo de terapias es Luciano (2001). Según Hayes (2004), es la más completa de las incluidas en la Tercera Generación de Terapias de Conducta. Esta terapia no trata de cambiar o reducir los pensamientos y/o recuerdos perjudiciales, sino que trata de alterar su función y de generar flexibilidad en la regulación del comportamiento (HAYES; STROSHAL, 2004; HAYES ET AL., 1999; WILSON; LUCIANO, 2002;). Para ello, busca un cambio de carácter contextual con el objetivo de alterar la función de los eventos privados sin cambiar sus contenidos. La clave es que el paciente acepte los eventos privados que tiene, porque esa aceptación está al servicio de la actuación impregnada de valores personales.

- La Psicoterapia Analítica Funcional (PAF) de Kohlenberg y Tsai (1991). En España, el autor que 
más ha trabajando en este tipo de terapias es PérezÁlvarez (1996). Luciano (1999) realizo a posteriori una comparación entre esta terapia y la ACT. Esta terapia se define como una terapia de conducta actualizada y conectada a la tradición conductista radical de Skinner, pero mediante el análisis funcional de la conducta. Por ello, lo realmente importante no serán las conductas específicas y moleculares, sino la "clase de conducta" (grupos más molares de tipo o patrones de conducta). En esta terapia, la relación terapéutica se realiza sobre todo mediante un intercambio verbal. La PAF se articula mediante una serie de componentes: 1) la noción de "Conducta clínica relevante", 2) la "identificación" de conductas clínicas relevantes, y 3) las "reglas para una actuación terapéutica relevante".

- $\quad$ La Terapia de Conducta Dialéctica de Linehan (1993). Sostiene que algunas personas, debido a ambientes familiares inadecuados y a diversos factores biológicos, reaccionan anormalmente al estímulo emocional (presentan una inestabilidad emocional extrema). Por ello, su nivel de excitabilidad se eleva mucho más rápidamente, llegando a un nivel más alto que una persona normal, y como consecuencia de ello, requieren de más tiempo para volver al punto de partida. El objetivo de esta terapia es proporcionar y enseñar habilidades útiles para esta controlar esta inestabilidad emocional.

- La Terapia Conductual Integrada de Pareja de Jacobson et al. (2000). En España uno de los autores que han trabajado sobre este tipo de terapia es Morón-Gaspar (2006). El objetivo en la terapia es el cambio en el contexto psicológico en el que ocurren los problemas de pareja. Incorpora un componente de "aceptación emocional” sin centrase en el cambio de conducta. El resultado de este cambio de contexto es la aceptación 
del comportamiento del compañero, consiguiendo de esta manera la reducción de los problemas y una recuperación más rápida cuando éstos se den. Con todo ello se consigue un aumento general en la satisfacción de la relación (MORÓN-GASPAR, 2006, 2007).

- La Terapia Racional-Experiencial. En esta terapia se distingue entre dos sistemas de procesamiento de la información cualitativamente diferentes en constante interacción: el racional y el experiencial. El sistema "racional" funciona siguiendo reglas establecidas, es lento, consciente, analítico y lógico. Es el que se utiliza, por ejemplo, para hacer un cálculo matemático. El sistema "experiencial" se basa en la experiencia vivida, es automático, preconsciente, rápido, fácil y está relacionado con las emociones y la personalidad. Según este modelo, la persona simultáneamente puede producir apreciaciones estos dos procesos (automáticos y controlados, cogniciones conscientes e inconscientes, cogniciones con carga emociona y sin emociones). Las estrategias de intervención deben ir dirigidas a adaptar la capacidad que la persona tiene de representar la realidad y de procesar la información de manera coherente y no cualitativamente distinta.

- La Terapia de Activación Conductual (AC). Es una nueva terapia dirigida principalmente a la depresión desarrollada sobre bases contextuales y funcionales. Según comenta Pérez-Álvarez (2007), la AC plantea que realmente es el contexto el que mejor puede explicar la depresión. Además, las conductas características de una persona deprimida juegan un papel significativo en esta enfermedad, siendo algo más que un mero síntomas. La conducta de las personas deprimidas funciona como evitación conductual provocando una alteración importante en la vida de la persona. El objetivo es por ello, fortalecer una "Activación 
Conductual”. Por lo tanto, el psicólogo debe indagar sobre qué condiciones ambientales propician estos tipos de conductas prototípicas de los sujetos deprimidos (contexto) y cuáles son las consecuencias de esta conducta para el paciente (función) para facilitar dicha activación. Para constatar su eficacia, Dimidjian et al. (2006) realizó un estudio donde examino la eficacia de la "Activación Conductual" en comparación con la terapia cognitiva y la farmacológica (medicación antidepresiva) en una muestra de pacientes adultos diagnosticados con Depresión Mayor. Los resultados mostraron como la AC obtuvo resultados compatibles a los antidepresivos en aquellos pacientes más deprimidos. Ambos tipos de tratamientos, además fueron considerablemente superiores a la terapia cognitiva.

- La Terapia Cognitiva con base en "Mindfulness". Se trata de un paradigma clinico-educativo que se encuentra en pleno desarrollo y evolución en Estados Unidos y Europa. Mindfulness no tiene una traducción exacta en español, algunos autores lo han traducido como: plena presencia o atención o consciencia plena (VALLEJO, 2006). Se puede describir como una "forma de percibir" y expandir el nivel de conciencia, una forma de meditación, una manera particular de "prestar atención", momento a momento de todo lo que pasa alrededor. De esta forma, la logra desarrollar un "nivel de intimidad" con sus propios sentidos, cuerpo y experiencia diaria. La experiencia se acepta tal y como es, tanto si es positiva como si es negativa, interpretándolas como naturales, ya que se produce una aceptación radical de la misma. Dicha aceptación implica renunciar al control. En el momento de aplicar esta terapia, la persona elige con qué experiencias quieren usar esta técnica (eligen en qué desean centrarse para vivir dicha situación). 


\section{Conclusiones}

El área de la Psicología ha mejorado notablemente en los últimos años. Muestra de ello, en un estudio realizado por Navarrete-Cortes, Quevedo-Blasco, Chaichio-Moreno, Ríos y Buela-Casal (2009) se puede verificar como España es el noveno país con mayor número de documentos científicos publicados en el campo de la psicología a nivel mundial. Este mismo aumento, se ha podido comprobar en la formación de posgrado en Psicología Clínica y de la Salud (Tabla 5 y 6), tal y como se detalla anteriormente (BUELA-CASAL, 2006) y en la cantidad/calidad de las revistas españolas en Journal Citation Report (JCR) (Tabla 4). Como en cualquier área de conocimiento, hay autores que defiende la Psicología Clínica fundamentada en la salud (BELLOCH, 1996; BLANCOPICABIA, 1996; BOTELLA, 1996) y autores que la critiquen (ECHEBURÚA, 1996), pero lo que es realmente evidente es el ejemplar avance en los últimos años, especialmente en la Psicología de la Salud (BUELA-CASAL, 2004; GIL ROALESNIETO, 2004) y el continuo desarrollo en los próximos años (SANTOLAYA, 2002b).

Tal es la relevancia que ha tomado la psicología en España, que diferentes autores han desarrollado trabajos específicos y de referencia sobre por ejemplo, el sistema de clasificación de las metodologías de investigación en Psicología (MONTERO; LEÓN, 2007), los criterios para el proceso de revisión de cara a la publicación de investigaciones experimentales y cuasi-experimentales en Psicología (RAMOS-ÁLVAREZ; MORENO-FERNÁNDEZ; VALDÉS-CONROY; CATENA, 2008), las normas para planificar, elaborar y redactar un artículo de revisión en Psicología (FERNÁNDEZ-RÍOS; BUELA-CASAL, 2009), las normas para el desarrollo y revisión de estudios instrumentales, con el objetivo de ofrecer diversas consideraciones sobre la selección de tests en la investigación psicológica (CARRETERO-DIOS; PÉREZ, 2007), etc. 
Lo que actualmente esta delimitado y correctamente especificado es el objeto de estudio, el método y los marcos teóricos con los que cuenta la Psicología Clínica. Por ello, se aprecia un futuro en constante avance y desarrollo, tanto por la gran utilidad del psicólogo en la práctica clínica, como en la investigación. Ante la necesidad del psicólogo como personal sanitario, actualmente se está creando una formación de posgrado mediante un master sanitario para aquellos graduados en psicología que deseen capacitarse para el ejercicio como profesionales sanitarios. Esta capacitación supondría la formación y el reconocimiento como psicólogo sanitario, lo que requeriría modificaciones en la LOPS para incorporar la figura del psicólogo sanitario "generalista".

Se puede defender de manera clara y justificada el carácter sanitario de la Psicología en las diferentes áreas de formación, intervención e investigación (BUELA-CASAL ET AL., 2005a, 2005b, 2005c). Una muestra de ello, es la participación notable de investigadores españoles en la aplicación y desarrollo de las denominadas “Terapias de Tercera Generación”, fruto del continuo avance y desarrollo de los modelos terapéuticos de la Psicología en el campo de la Clínica y la Salud.

En resumen, la consecución de la Especialidad en Psicología Clínica es uno de los logros más importantes de la Psicología española, junto con la futura incorporación de la figura del psicólogo sanitario "generalista". 


\section{Referencias}

ÁVILA, A. La psicología clínica en España: perspectiva de una década. Papeles del Psicólogo, n. 36/37, p. 84-89, 1989.

BARTOLOMÉ, P.; CARROBLES, J.A.; COSTA, M.; DEL SER, T. La práctica de la terapia de conducta. Madrid: Pablo del Río, 1977.

BAYÉS, R. Enseñanza y ejercicio profesional del análisis de la conducta en España. Revista de Psicología General y Aplicada, v. 38, p. 233-245, 1983.

BECK, A.T. Thinking and depression: Idiosyncratic content and cognitive distortions. Archives of General Psychiatry, v. 9, p. 324-333, 1963.

BECK, A.T. Cognitive therapy and the emotional disorders. Nueva York: International Universities Press, 1976.

BECK, A.T.; RUSH, J.; SHAW, B.; EMERY, G. Terapia cognitiva de la depresión. Bilbao: Desclee de Brouwer, 1983.

BELLOCH, A. Mentes y cuerpos: amores, desamores y renuncias. Análisis y Modificación de Conducta, v. 22, p. 235-268, 1996.

BLANCO, A.; LEÓN, J.M. Health Psychology in Spain. European Review of Applied Psychology, v. 44, p. 185-193, 1994.

BLANCO-PICABIA, A. Especialización en psicología clínica y de la salud. Papeles del Psicólogo, v. 38, p. 30-31, 1989.

BLANCO-PICABIA, A. Psicología Clínica, Psicología de la Salud... ¿En qué quedamos?. Análisis y Modificación de Conducta, v. 22, p. 219-234, 1996.

BOTELLA, C. En defensa de la Psicología Clínica. Análisis y Modificación de Conducta, v. 22, p. 181-218, 1996.

BRESLOW, L. A quantitative approach to the World Health Organization definition of health: Physical, mental and social 
well-being. International Journal of Epidemiology, v. 1, p. 347350, 1972.

BRODY, H. The systems view of man: Implications of medicine, science and ethics. Perspectives in Biology and Medicine, v. 17, p. 71-79, 1973.

BUELA-CASAL, G. Historia de la Evaluación Psicológica en España. En: Buela-Casal, G. (Ed.). Manual de evaluación Psicológica. Madrid: Siglo XXI, 1993.

BUELA-CASAL, G. Historia de la Evaluación Psicológica en España. En: Buela-Casal, G. (Comp.). Manual de evaluación Psicológica. Madrid: Siglo XXI, 1994.

BUELA-CASAL, G. La Psicología: ¿una profesión sanitaria con distintas especialidades?. Infocop, n. extraordinario, 103-111, 2004.

BUELA-CASAL, G. ¿La Psicología es una profesión sanitaria?. Papeles del Psicólogo, v. 26, p. 2-3, 2005.

BUELA-CASAL, G. Se publican los primeros másteres oficiales en Psicología. Infocop online, 2006. Disponible en: http://www. infocop.es/view_article.asp?id=941. Acceso en: 20 sept. 2008.

BUELA-CASAL, G.; BRETÓN-LÓPEZ, J.; AGUDELO, D.; BERMÚDEZ, M.P.; SIERRA, J.C.; TEVA, I.; GIL ROALES-NIETO, J. Imagen de la Psicología como profesión sanitaria en psicólogos españoles. Papeles del Psicólogo, v. 26, p. 16-25, 2005 a.

BUELA-CASAL, G.; GIL ROALES-NIETO, J.; SIERRA, J.C.; BERMÚDEZ, M.P.; AGUDELO, D.; BRETÓN-LÓPEZ, J.; TEVA, I. Imagen de la Psicología como profesión sanitaria en profesores de Medicina y Psicología. Papeles del Psicólogo, v. 26, p. 4-15, 2005b. 
BUELA-CASAL, G.; SIERRA, J.C. Psicología Clínica y Psicología de la Salud en España: su estado actual. Revista Latinoamericana de Psicología, v. 27, p. 25-40, 1995.

BUELA-CASAL, G.; SIERRA, J.C.; CARROBLES, J.A. (1995). Psicología clínica y de la salud en España: su estado actual. Revista Latinoamericana de Psicología, v. 27, p. 25-40, 1995.

BUELA-CASAL, G.; TEVA, I.; SIERRA, J.C.; BRETÓN-LÓPEZ, J.; AGUDELO, D.; BERMÚDEZ, M.P.; GIL ROALES-NIETO, J. Imagen de la Psicología como profesión sanitaria entre la población general. Papeles del Psicólogo, v. 26, p. 30-38, 2005c.

CARRETERO-DIOS, H.; PÉREZ, C. Standards for the development and review of instrumental studies: Considerations about test selection in psychological research. Internacional Journal of Clinical and Health Psychology, v. 7, p. 863-882, 2007.

CASTRO-VÁZQUEZ, A.; ESPINOSA-GUTIÉRREZ, I.; RODRÍGUEZ-CONTRERAS, P.; SANTOS-IGLESIAS, P. Relación entre el estado de salud percibido e indicadores de salud en la población española. Internacional Journal of Clinical and Health Psychology, v. 7, p. 883-898, 2007.

COLEGIO OFICIAL DE PSICÓLOGOS. Perfiles profesionales del psicólogo. Madrid: Colegio Oficial de Psicólogos, 1998.

COLEGIO OFICIAL DE PSICÓLOGOS. Situación actual del reconocimiento de la psicología como profesión sanitaria. INFOCOP online, 2007. Disponible en: http://www.infocop.es/view_article. asp?id=1600. Acceso en: 20 jul. 2009.

DIMIDJIAN, S.; HOLLON, S.D.; DOBSON, K.S.; SCHMALING, K.B.; KOHLENBERG, R.J.; ADDIS, M.E.; GALLOP, R.; MCGLINCHEY, J.B.; MARKLEY, D.K.; GOLLAN. J.K.; ATKINS, D.C.; DUNNER, D.L.; JACOBSON, N.S. Randomized Trial of Behaviorial Activation, Cognitive Therapy, and Antidepressant Medication in the Acute Treatment of Adult. Journal of Consulting and Clinical Psychology, v. 74, p. 658-670, 2006. 
ECHEBURÚA, E. La Psicología de la Salud en España: un camino errado. Análisis y Modificación de Conducta, v. 22, p. 235-268, 1996.

ELLIS, A. Rational psychotherapy. Journal of General Psychology, v. 59, p. 35-49, 1958.

ELLIS, A. Reason and emotion in psychotherapy. Nueva York: Lyle Stuart, 1962.

ELLIS, A. Una terapia breve más profunda y duradera. Barcelona: Editorial Paidós, 1999.

ELLIS, A.; ABRAHAMS, E. Terapia racional emotiva. México: Editorial Pax, 1980.

ENGEL, G.L. (1977). The need for a new medical model: a challenge for biomedicine. Science, v. 196, p. 129-136, 1977.

FEIXAS, G.; MIRO, M.T. Aproximaciones a la psicoterapia. Barcelona: Paidós, 1993.

FEIXAS, G.; MIRÓ M.T. Aproximaciones a la psicoterapia. Barcelona: Editorial Paidós, 1995.

FERNÁNDEZ-BALLESTEROS, R.; CARROBLES, J.A. Perspectivas de la Psicología de la Salud en Europa. Papeles del Psicólogo, v. 33, p. 3-12, 1988.

FERNÁNDEZ-RÍOS, L.; BUELA-CASAL, G. Standards for the preparation and writing of Psychology review articles. International Journal of Clinical and Health Psychology, v. 9, p. 329-344, 2009.

GIL ROALES-NIETO, J. Psicología de la Salud. Aproximación histórica y conceptual y aplicaciones. Madrid: Pirámide, 2004.

GUIDANO, V. El Sí Mismo En Proceso: Hacia una terapia Cognitiva Posracionalista. Barcelona: Editorial Paidós, 1994. 
HARNETT, J.; SIMONETTA, L.; MAHONEY, J. Perceptions of nonclinical psychologists toward Clinical Pscyhology and clinical psychologists. Professional Psychology: Research and Practice, v. 20, p. 187-189, 1989.

HAYES, S.C. Acceptance and commitment therapy, relational frame theory, and the third wave of behavioral and cognitive therapies. Behavior Therapy, v. 35, p. 639-665, 2004.

HAYES, S.C.; STROSAHL, K.D. A practical guide to acceptance and commitment therapy. Nueva York: Springer-Verlag, 2004.

HAYES, S.C.; STROSAHL, K.D.; WILSON, K.G. Acceptance and commitment therapy. Nueva York: The Guilford Press, 1999.

HUARTE DE SAN JUAN, J. Examen de Ingenios para las Ciencias (Princeps ed.). Baeza, España: Juan Baptista de Montoya imp, 1575.

JACOBSON, N.S.; CHRISTENSEN, A.; PRINCE, S.E.; CORDOVA, I.; ELDRIDGE, K. Integrative behavioural couple therapy: An acceptance-based, promising new treatment for couple discord. Journal of Consulting and Clinical Psychology, v. 68, p. 351-355, 2000 .

JASNOSKI, M.L.; SCHWARTZ, G.E. A Synchronous Systems Model for Health. American Behavioral Scientist, v. 28, p. 468485, 1985.

KANFER, F.H.; SASLOW,G. Behavior diagnosis. En: Franks, C.M. (Comp.). Behavior therapy: Appraisal and status. Nueva York: McGraw Hill, 1969.

KAZDIN, A. Modificación de la conducta y sus aplicaciones prácticas. México: El manual moderno, 1978.

KOHLENBERG, R.J.; TSAI, M. Functional analytic psychotherapy. Nueva York: Plenum Press, 1991. 
LAVIANA-CUETOS, M. Los psicólogos clínicos en el sistema sanitario público. Papeles del psicólogo, 1998. Disponible en: http://www.papelesdelpsicologo.es/vernumero.asp?id=773. Acceso en: 21 jun. 2009.

\section{LEÓN, J.M. Psicología de la Salud y de la Calidad de Vida.} Barcelona: Editorial UOC, 2004.

Ley 44/2003 de 21 de noviembre de Jefatura de Estado, de Ordenación de las Profesiones Sanitarias (BOE de 22 de noviembre 2003, n. 280). Disponible en: http://www.boe.es/aeboe/ consultas/bases_datos/doc.php?coleccion=iberlex\&id $=2003 / 2134$ 0. Acceso en: 14 jun. 2009.

LINEHAN, M.M. Cognitive-behavioral treatment of bordeline personality disorder. Nueva York: Guilford, 1993.

LUCIANO, M.C. La psicoterapia analítico funcional (FAP) y la terapia de aceptación y compromiso (ACT). Análisis y Modificación de Conducta, v. 25, p. 497-584, 1999.

LUCIANO, M.C. Sobre el trastorno de evitación experiencial (TEE) y la terapia de aceptación y compromiso (ACT). En: Luciano, C. (Ed.). Terapia de aceptación y compromiso (ACT).

Libro de casos. Valencia: Promolibro, 2001. p. 3-18.

LUCIANO, M.C.; VALDIVIA, M.S. La Terapia de Aceptación y Compromiso (ACT). Fundamentos, características y evidencia. Papeles del Psicólogo, v. 27, p. 79-91, 2006.

MACIÀ, D.; MÉNDEZ, F.X. Líneas actuales de investigación en Psicología de la Salud. En: Simón, M.A. (Ed.). Manual de Psicología de la Salud. Madrid: Biblioteca Nueva, 1999. p. 217 258.

MEICHENBAUM, D.H. Cognitive behavior modification. Nueva York: Plenum, 1977. 
MINISTERIO DE EDUCACIÓN. Estudios de doctorado a los que se concede y renueva la mención de para el curso 2008-2009, 2008a. Disponible en: http:/www.educacion.gob.es/educacion/ universidades/convocatorias/entidades/mencion-calidad-doctorado.html. Acceso en: 15 jul. 2009.

MINISTERIO DE EDUCACIÓN. Relación de universidades coordinadoras de másteres oficiales curso 2008/2009, 2008b. Disponible en: http://web.micinn.es/04_Universidades/ AA2ConBAP/02@Titulados/06@MovVis/01@ConAnt/00@ Con08/01-InfoGral/2008-master-oficiales.doc. Acceso en: 15 jul. 2009.

MOIX, J. El papel del psicólogo: formación y asesoramiento a profesionales y colectivos hospitalarios. En: Ortigosa, J.M; Méndez, F.X. (Eds.). Preparación psicológica a la hospitalización infantil. Madrid: Biblioteca nueva, 2000.

MOIX, J. El papel del psicólogo de la salud en el voluntariado hospitalario. Cuadernos de Medicina Psicosomatica y Psiquiatria de Enlace, v. 65, p. 73-77, 2003.

MONTERO, I.; LEÓN, O.G. A guide for naming research studies in Psychology. International Journal of Clinical and Health Psychology, v. 7, p. 847-862, 2007.

MORÓN-GASPAR, R. Terapia Integral de Pareja. EduPsykhé. Revista de Psicología y Educación, v. 5, p. 273-286, 2006.

MORÓN-GASPAR, R. Un acercamiento a la terapia integral conductual de pareja. INFOCOP online, 2007. Disponible en: http:// www.infocop.es/view_article.asp?id=1175. Acceso en: 12 jun. 2009.

NAVARRETE-CORTES, J.; QUEVEDO-BLASCO, R.; CHAICHIOMORENO, J.A.; RÍOS, C.; BUELA-CASAL, G. Análisis cuantitativo por países de la productividad en psicología de las revistas en la Web of Science. Revista Mexicana de Psicología, v. 26, p. 131143, 2009. 
OBLITAS, L. 20 enfoques psicoterapéuticos contemporáneos. Bogotá: PSICOM, 2004.

ORGANIZACIÓN MUNDIAL DE LA SALUD. Crónica de la OMS, v. 1, p. 31, 1946.

PECK, D.; CÁCERES, J. Avances en la terapia de Conducta. Bilbao: Ediciones Deusto, 1981.

PELECHANO, V. Formulación y panorama actual de la modificación de conducta. Análisis y Modificación de Conducta, v. 5, p. 63-88, 1978.

PELECHANO, V. Diez años de terapia de conducta en España. Análisis y Modificación de Conducta, n. 31/32, p. 5-12, 1986.

PELECHANO, V. Psicología Clínica, Psicología de la Salud y la búsqueda del santo grial. Análisis y Modificación de Conducta, v. 22, p. 323-364, 1996.

PÉREZ-ÁLVAREZ, M. Prehistoria de la modificación de conducta en la cultura española. En: Caballo, V.E. (Comp.). Manual de técnicas de terapia y modificación de conducta. Madrid: Siglo XXI, 1991. p. 51-65.

PÉREZ-ÁLVAREZ, M. La psicoterapia desde un punto de vista conductista. Madrid: Biblioteca Nueva, 1996.

PÉREZ-ÁLVAREZ, M. La Activación Conductual (AC): un nuevo acercamiento al tratamiento de la depresión. INFOCOP online, 2007. Disponible en: http://www.cop.es/infocop/vernumero. asp?id=1444. Acceso en: 14 jun. 2009.

RAMOS-ÁLVAREZ, M.; MORENO-FERNÁNDEZ, M.M.; VALDÉSCONROY, B.; CATENA, A. Criteria of the peer review process for publication of experimental and quasi-experimental research in Psychology: A guide for creating research papers. International Journal of Clinical and Health Psychology, v. 8, p. 751-764, 2008. 
REIG, A. La Psicología en el Sistema Sanitario. Papeles del Colegio, v. 20, p. 7-12, 1985.

REIG-FERRER, A. ¿Qué debe saber un médico de psicología?. Análisis y modificación de conducta, v. 31, p. 136-137, 2005.

RODIN, J.; STONE, G.C. (1987). Historical highlights in the emergente of the field. En: Stone, G.C.; Weiss, S.M.; Matarazzo, J.D.; Millar, N.E.; Rodin, J.; Belar, C.D.; Follick, M.J.; Singer, J.E. (Eds.). Health Psychology. A discipline and a profesión. Chicago: The University of Chicago Press, 1987. p. 15-26.

ROGERS, C.R. Psicoterapia centrada en el cliente. Buenos Aires: Paidós, 1951.

ROGERS, C.R. El proceso de convertirse en persona. Buenos Aires. Paidós, 1961.

SANTACREU, J. Psicología Clínica y Psicología de la Salud: Marcos teóricos y modelos. Revista de Psicología de la Salud, v. 3, p. 3-20, 1991.

SANTOLAYA, F. El Colegio Oficial de Psicólogos y la institucionalización de la Psicología. En: Campos, J.J.; Bandrés, J.; Carpintero, H. (Coords.). Luis Simarro y la psicología científica en España: cien años de la cátedra de psicología experimental en la Universidad de Madrid. Madrid: Universidad Complutense, Servicio de Publicaciones, 2002a. p. 43-44.

SANTOLAYA, F. La psicología como profesión. En: Ardila, R. (Dir.). La psicología en el futuro. Madrid: Pirámide, 2002b.

SANTOLAYA, F; BERDULLAS-TEMES, M. ¿Existen los psicólogos? INFOCOP, n. 19, p. 5-7, 2003.

SANTOLAYA OCHANDO, F.; BERDULLAS-TEMES, M.; FERNÁNDEZ-HERMIDA, J.R. La década 1989-1998 en la Psicología española: análisis del desarrollo de la Psicología profesional en España. Papeles del Psicólogo, v. 82, p. 65-82, 2002. 
SANZ, J. La década de 1989-1998 en la Psicología española: análisis de la investigación en personalidad, evaluación y tratamiento psicológico (psicología clínica y de la salud). Papeles del Psicólogo, v. 23, p. 54-87, 2002.

SIERRA, J.C.; BERMÚDEZ, M.P.; TEVA, I.; AGUDELO, D.; BRETÓN-LÓPEZ, J.; GUTIÉRREZ, O.; GONZÁLEZ CABRERA, J.; LEÓN JAIME, J.; GIL ROALES-NIETO, J.; BUELA-CASAL, G. Imagen de la Psicología como profesión sanitaria entre los estudiantes de psicología. Papeles del Psicólogo, v. 26, p. 24-29, 2005.

SKINNER, B. Tecnología de la enseñanza. Barcelona: Labor, 1973.

VALLEJO, M. Mindfulness. Papeles del psicólogo, v. 27, 2006. Disponible en: http://www.papelesdelpsicologo.es/vernumero. asp?id=1340. Acceso en: 28 jun. 2009.

VERA, M.M. La hora de la verdad de la Psicología. Situación de la Psicología como resultado de la aplicación de la LOPS. Gaceta de Psicología, v. 24, p. 7-10, 2004.

VON SYDOW, K.; REIMER, C. Attitudes toward Psychotherapists, Psychologists, Psychiatrists and Psychoanalysts. A meta-content analysis of 60 studies Publisher between 1948 and 1995. American Journal of Psychotherapy, v. 52, p. 463-488, 1998.

WALTER, J.; SHEA, T. Manejo conductual. México: Manual moderno, 1987.

WILSON, K.G.; LUCIANO, M.C. Terapia de aceptación y compromiso. Un tratamiento conductual orientado a los valores. Madrid: Pirámide, 2002. 
126 


\section{4}

\section{Saúde: apontamentos topográficos para a cartografia de um conceito}

Edmundo de Oliveira Gaudêncio

\section{Terreno:}

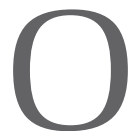

terreno no qual trabalho é o território de um conceito. Como todo território, um conceito contém extensão, fronteiras, relevos. Enquanto metáfora, todo conceito é construção histórico-social que resulta de forças sociais, econômicas, culturais, políticas que o tornaram possível. Um conceito só existe graças aos sentidos que lhe emprestamos, o qual colocamos em palavras.

Quando falo em território, falo automaticamente em desterritorialização, perder fronteiras. Acontece o mesmo com os conceitos, que interagem uns com os outros, estabelecem dobras, um se transmudando em outro, dois ou mais conceitos se somando e derivando um terceiro. Como exercício, procure o significado do conceito de árvore, por exemplo. Quantas dezenas, centenas de conceitos são necessários para conceituar-se o que é árvore? Da mesma forma, compreendo o conceito de saúde, do qual me interessa fazer a 
prospecção do território, investigando a rede interconceitual que é inventada, objetivando a construção daquele conceito. Com esse procedimento, tenho por objetivo elaborar apontamentos sumários para uma cartografia da saúde.

\section{Levantamento topográfico}

Como dito, um conceito é um território. Fazer o levantamento topográfico de um dado território implica em aerofotografar, fazer a prospecção dos relevos de um determinado terreno, demarcando os acidentes que deverão ser levados em conta quando da composição da cartografia desse território. Ou seja, fazer a cartografia de um conceito significa executar o levantamento dos diversos conceitos que dão sustentação a um específico conceito. Para fazer esse levantamento, ninguém melhor que Gilles Deleuze. Dele faço leitura particular, tomando-lhe emprestadas a metáfora do rizoma e a concepção de platô. Rizoma, para Deleuze e Guattari (1995), é bifurcação, rede, trama e dispersão. Um buraco de rato, uma rede de pescador, tudo que enlaça, produz nó e simultaneamente dispersa é rizoma. No mundo das palavras, ou seja, dos conceitos, um dicionário obedece ao princípio do rizoma, vez que para apreender-se o sentido de um dado vocábulo, são necessárias as centenas dessas outras palavras que lhe possibilitam aquele sentido.

Quanto à ideia de platô, mais fácil imaginá-lo através de uma figura: maré alta, maré baixa, a depender do nível das águas, ora nada se vê, além de ondas, ora ficam expostas aos nossos olhos dezenas de ilhas de alturas variadas. Cada ilha dessas pode ser considerada um platô. Na dependência do baixar ou subir das águas, ora o que era submerso vem à tona, ora o que está à tona submerge, engolido pelas águas. Olhando da praia um arquipélago, vemos as ilhas que vemos e não pensamos nas ilhas submersas. Da mesma forma, os conceitos: alguns são enunciados claramente no discurso, 
outros, submersos, somente são referidos nas entrelinhas dos conceitos que se destacam formando núcleos discursivos dentro da frase. Tomo cada ilha que se vê sob a denominação de platô e aplico tal metáfora às ilhas dos conceitos no oceano dos discursos: cada conceito é apenas ilha em um arquipélago de conceitos, alguns postos à vista, outros submersos, em um dado enunciado.

\section{Cartografia}

\section{Primeiro platô}

Saúde é discurso polissêmico que só pode ser apreendido pelo viés do rizoma, trama entre conceitos, relações interconceituais capazes de determinar relações teóricas entre saberes e relações concretas entre conceitos e práticas históricas, sociais, culturais, políticas, econômicas (MACHADO, 2006). Em todo caso, pensar o conceito de saúde, a partir dessa perspectiva, significa ser obrigado a pensar também os conceitos de doença, enfermidade, normalidade, anormalidade, corpo, medicina, infinitos conceitos que se bifurcam nos mais diversos discursos e práticas discursivas, toda a vez que proferimos a palavra saúde.

A linguagem, graças aos conceitos que formaliza, impedenos o acesso à natureza mesma das coisas. Com isso concorda Foucault (1996), com sua ideia de separação entre palavras e coisas. Após a invenção da linguagem, vivemos em um mundo de conceitos. Tudo é conceito, uma mesa, um lápis, um gato, uma pedra, uma pessoa, tudo é aquilo que como tal se conceitua. $\mathrm{O}$ que se não pode conceituar não existe. Por outro lado, contar a história de conceito significa examinar o modo como, a cada tempo, as sociedades usaram ou usam tal conceito. São conceitos, também, vida, morte, doença, saúde. Assim sendo, nada existe que seja "natural", uma vez que mesmo a natureza somente pode ser apreendida pelo 
ser humano, através da cultura - e tudo é cultura porque é conceito, fruto não da natureza, mas da História e de sociedades. O caso da dor, por exemplo: embora exista o substrato orgânico da dor, dor é sofrimento e sofrimento é o conceito que se atribui a uma dor, nomeando-se o biológico pela via da cultura. Ou seja, não se trata de negar o orgânico; tratase, sim, de realçar a socioculturalidade que torna possível a apreensão da organicidade.

\section{Segundo platô}

Evidentemente, quando falo em conceito e em conceituação, falo, simultaneamente, em leitura, pois sem uma leitura qualquer sobre quaisquer fatos, não existem conceitos: os conceitos são formados no processo da leitura que se faz do mundo. E acredito que só existem quatro formas de ler-se o mundo, tal como sugere Campos (2001): a forma religiosa, a forma filosófica, a forma artística e a forma científica. A forma religiosa em tudo enxerga a presença de Deus ou de um deus. O mundo é o livro da natureza, ditado pelo Onipotente, mas só para quem tenha olhos capazes de enxergar o infinito, o eterno, o invisível e ouvidos de escutar estrelas. Seu modo de uso social se dá através das religióes e sua palavra fundante é crer. A forma filosófica, por outro lado, em tudo vê uma questão posta à razão, sendo maneira especulativa de investigar o mundo. Seu modus operandi social se encarna nas Filosofias e sua palavra fundamental é pensar. A forma artística, de modo diferente, presentifica-se no uso da sensibilidade para ler o mundo. Não se chega à verdade pela via religiosa, ou pela via filosófica, somente se vai à verdade através da capacidade de reinventar o mundo e das manifestações artísticas. Sua expressão social se dá através das artes e sua palavra de cabeceira é sentir. A forma científica, por fim, parte de um pressuposto colocado às coisas: o que são, em sua natureza íntima, e para que servem? Como modo de ler o mundo através da medida, da pesagem, da análise, seu modo social de exprimir-se se dá por meio das Ciências e sua palavra central 
é fazer. Se existem apenas essas quatro formas para se ler os conceitos com que construímos nossos mundos, existem apenas três modos de leitura (CHARTIER,1994): primeiro, uma leitura vertical, que chamo, como Foucault (2000), de leitura arqueológica, a que interessa investigar a questão de como, onde, quando são formados os conceitos; segundo, uma leitura horizontal, ou leitura genealógica, a quem cabe questionar o que torna possível os conceitos e quais os interesses subjacentes a sua invenção, estabelecendo relações de força entre os saberes necessários à construção de um dado conceito e; terceiro, a leitura ao modo da trama, resultante da soma das duas anteriores, a quem compete estabelecer correlações entre saber e saberes, entre saber e poder, entre poder e poderes, leitura arquigenealógica somente possível mediante a aplicação do paradigma do rizoma.

\section{Terceiro platô}

Um conceito íntimo à caracterização do conceito de saúde é o conceito de corpo (RODRIGUES, 1999). Como quanto a qualquer conceito, posso fazer uma leitura religiosa do corpo: o corpo é a casa de Deus; posso fazer uma leitura filosófica: no corpo, onde se esconde a alma?; posso fazer, do corpo, uma leitura artística: o Pensador de Rodin, a Mona Lisa, de Da Vinci, Las Demoiselles d'Avignon, de Picasso, são, antes de mais nada, representações, leituras artísticas, do corpo humano. Posso fazer, do corpo, uma leitura científica, quando, por exemplo, uso da anatomia, da bioquímica, na leitura clínica do corpo, por exemplo. Evidentemente, posso ler o corpo de modo horizontal ou arqueológico, o que significa investigar as formas através das formas pelas quais o corpo foi visto e como o conceito de corpo foi compreendido, ao longo da história da civilidade. Dessa forma, pela via do saber hegemônico da época, a Política, o corpo foi pensado, entre os gregos, como soma, aquilo que, desde Platão, colocou-se como oposto à psiquê; na Idade Média, o corpo foi sobretudo pensado como carne, 
fonte de todo pecado, de acordo com o saber hegemônico constituído pela religião. No Classicismo, período que vai do final da Idade Média à Modernidade, pensou-se principalmente não o próprio corpo, mas o corpo próprio, pela via hegemônica da Filosofia, através da aplicação da racionalidade às corporalidades, objetivando a vida na Corte: o corpo é matéria a ser subjugada, de tal modo que não denuncie, em seu usufrutário, defeitos e falhas, os quais devem ser ocultados sob risco da própria vida. Na modernidade, sob a égide do laboratório, o corpo se transforma em organismo, isso com que, no corpo, trabalham as ciências, essas materializações do saber técnico hegemônico, pesando, medindo, contando, dissecando. Por outro lado, uma leitura genealógica (ou horizontal) pensará o corpo a partir das relações estabelecidas entre o conceito de corpo e outros conceitos, dedicando-se à investigação dos usos sociais do conceito de corpo: o conceito de pecado, de prazer, de sofrimento, disso tudo que, em termos de palavras, circunda o conceito corpo, dando-lhe sentido. Ler o corpo à maneira da trama consiste nisto que é tomar dos dois modos anteriores, somados, entrelaçados, procurando ler os conceitos a partir da história individual de cada conceito, mas também a partir da história de como diferentes conceitos se entrelaçam na construção social dos inúmeros sentidos adquiridos pela palavra corpo, vocábulo polissêmico com que ora se nomeia a individualidade corporal, ora a coletividade de determinados corpos, tais como, por exemplo, corpo docente e corpo político. Ou seja, fazer uma leitura do conceito de corpo nos moldes da trama é contar a história dos saberes sobre o corpo, levando-se em conta a ideia de que o saber sobre o corpo, qualquer saber, implica em poderes sobre corporalidades.

Aceitando isso, devo dizer que, primeiro, para além da materialidade do corpo, corpo é corporalidade, ou seja, corpo é o que se conceitua sobre o que seja corpo mais os 
usos que, em sociedade, são dados, historicamente, a esse conceito; e, segundo, que não existe o corpo, assim como não há o corpo. Existem corpos, ou melhor, como referido, existem corpos investidos de subjetividades e, por conseguinte, de historicidade. Entretanto, pensamos a partir de opostos e oposições. Por isso, ao investigar o conceito corpo, não posso esquecer que os sentidos formados a seu respeito passam também por seu oposto maior, qual seja, a alma. Daí, para compreender o que seja o corpo, necessário, também, contar as histórias que não contaremos aqui sobre o que seja a alma, sobre quais sejam os diversos sentidos atribuídos, a cada época, a tal conceito, bem como os sentidos sociais vinculados a essa palavra.

Pensado o corpo dessa forma, podemos pensar o conceito de saúde do mesmo modo, aceitando, de saída, que saúde é conceito e que os conceitos se expressam em discursos, nisso se considerando a importância que a visão tem para com a apreensão do mundo e, como decorrência, na produção dos conceitos com os quais trabalham os discursos. Com tal observação quero apontar para a ideia de que a concepção de saúde implica em tamanha abstração ou falta de visibilidade que, sem dúvida, sendo a doença mais visível, apreender o que seja saúde é tarefa que se dá mais facilmente mediante a caracterização do oposto que em grande medida o torna possível, qual seja, a doença.

\section{Quarto platô}

Mas, o que é doença? Convenhamos, não existe a doença; existem as doenças e existem doentes. A doença, no singular, é tão-somente o produto da aplicação do princípio da generalização, resultante da indução que torna possível a formação do corpus teórico de uma dada clínica. Ora, se existe uma história natural da doença, a qual interessa sobretudo à medicina, existe uma história individual da doença, relativa às vivências subjetivas do adoecer, do 
ficar, do estar e/ou do ser doente, ao lado de uma história social das doenças e de cada doença, a qual fala melhor dos usos sociais que uma dada sociedade imprime a uma determinada moléstia, do que dos sofrimentos de um dado sujeito que dela padeça - o que interessa sobretudo à análise da existência. À guisa de ilustração, pensemos, por exemplo, a loucura que, como toda doença, comporta uma história natural (ou clínica), escrita e descrita pela psiquiatria, ao falar de fatores predisponentes e desencadeantes, fatores causais ou etiológicos, incidências, prevalências, prognósticos, comportando, também, uma história social, tão bem contada por Michel Foucault (1978), ao lado de uma história individual da loucura de cada louco.

Não bastassem esses aspectos relativos à doença a serem considerados na investigação do conceito de saúde, há que ser lembrado que, tal como o conceito de corpo e tal como o conceito de saúde, doença também é termo polissêmico que fala de modo diverso a quem com o conceito trabalha, o médico, por excelência, e aquele que o suporta, o doente. Por isso não é à toa que a antropologia médica determina diferenças entre os vocábulos doença e enfermidade. Para Melman (2003), enfermidade, em linhas gerais, é a forma pela qual uma dada moléstia é percebida pela clínica, enquanto fato médico. Doença, por outro lado e enquanto fato sociocultural, é o conjunto de manifestações as mais diversas (psicológicas, sociais, culturais, trabalhistas, jurídicas e outras) que acompanham ou decorrem da instalação, em uma pessoa, de uma dada enfermidade.

\section{Quinto platô}

Evidentemente, pode-se pensar a doença, como em geral o fazemos, a partir de sua oposição em relação à saúde, da mesma forma que podemos pensar tal conceito de modo dialético, quando percebemos a complementaridade dos dois termos envolvidos na díade, podendo-se afirmar que 
a primeira condição da doença é a saúde, assim como da doença a saúde pode brotar - considerando-se que, das inúmeras doenças que acometem a maioria das pessoas ao longo da vida, quase todas são transitórias, porque curáveis, e somente uma é letal (quando a morte não é roubada à doença pelos acidentes fatais).

Evidentemente, é possível ler-se o conceito de saúde a partir da proposta que nos é oferecida pela medicina, interessando ali discutir uma tecnologia da saúde, a qual pode ser entendida de pelo menos duas formas: a- como o discurso técnico com que se constrói o discurso sobre saúde; b-como o conjunto de técnicas corporais imposto aos sujeitos, por uma dada sociedade, em nome da saúde. De qualquer modo, saúde se concretiza nos usos sociais do conceito de saúde: entre os gregos, se saúde era questão médica, era, simultaneamente, matéria estética e moral, conforme desejava o ideal helenístico. A saúde se conquistava através da ginástica, da dieta e dos cuidados de si (1997). Face ao apreço grego pela medida, saúde era o equilíbrio (ou crase) dos quatro humores, como queria Hipócrates (460-437 a.C.), correspondendo a doença a uma dyscrasia, desequilíbrio. Ocorre que, pensar um ideal, a saúde, é coisa por demais abstrata. Mais fácil pensá-la, na clínica, pela positividade dos sinais presentes na doença, o seu oposto. É Galeno (131-201 d.C.) quem opta declaradamente pela doença como positividade médica e como forma negativa de avaliar a saúde: tanto mais doença, menos saúde. Na Idade Média, sobre o conceito de saúde, as ideias de Galeno somarse-ão a crenças religiosas: doença é também punição pelo pecado (HELMAN, 2003). Deus expia o homem através das moléstias e dos infortúnios. No Classicismo, saúde é também medida de ordem prática e questão de Estado. Daí, a invenção da Polícia Médica, a quem compete, a partir do século XVII, o exercício do que será reinventado, no século XIX, sob a denominação de Saúde Pública. Estar sadio, quanto aos sujeitos, passa a ser a ordem do dia, devendo ser salubres os 
lugares, isentos de miasmas, sobretudo depois que William Harvey descobriu a grande circulação sanguínea e afirmou que a função do sangue era "aerar" o organismo. Da mesma forma, ventilem-se as cidades, abram-se largas avenidas, escancarem-se janelas, mas vasculhem-se também as intimidades, em busca de eventuais focos de doenças (RAGO, 1985). Justo por isso a invenção daquela Polícia Médica, a quem cabia, após descoberta a miséria como causa de moléstias, fazer não apenas a higienização de cada um, mas de todos os sujeitos de uma dada sociedade, mediante exclusão de quem manifestasse indícios de doença, sobretudo quando das grandes pestes, graças à ideia de contágio, depois transformado, no século XIX, em transmissão (CZNERESNIA, 1997). É, porém, somente na Contemporaneidade que se inscreve, no Preâmbulo da Constituição da Organização Mundial da Saúde, de 1946, com toda a visibilidade, o conceito de saúde, tão conhecido quanto polêmico: "Saúde é o completo bemestar biopsicossocial e não a mera ausência de doença ou enfermidade" (BERTOLOTE, 2000). É conceito polêmico, sim, vez que tanto pode ser criticado, quanto elogiado. Seu grande desacerto consiste na utopia que torna possível pensar-se uma situação de completude, graças ao idealismo que não prevê a incompletude, ou seja, a impossibilidade, por parte do ser humano, quanto a completar-se. Por outro lado, seus maiores acertos consistem, primeiro, na diferenciação entre enfermidade (forma como a Academia conceitua, teoricamente, uma moléstia) e doença, a forma como, do ponto de vista prático, dão-se os males corporais ou mentais, com todas as manifestações sociais, econômicas, culturais, políticas em que isso implica, como já sugerido (HELMAN, 2003). E, segundo, na mudança de paradigma clínico, mudando-se, da doença, para a saúde, e se mudando do modelo biomédico, para o modelo social ou cultural.

Como, porém, saúde é conceito que continua apelando para a abstração de um ideal, tal conceito vem gradativamente 
assumindo o sentido, ora de "qualidade de vida", ora de "Índice de Desenvolvimento Humano”, o que torna possível, senão objetivá-la e mensurá-la, pelo menos detectar, no plano da subjetividade ou das ações de Estado, a existência de um estado filiado à noção de saúde, qual seja, a felicidade, ou welfare state, quer do indivíduo, quer de comunidades.

Mas essa dificuldade em caracterizar o que seja saúde se deve à própria polissemia do conceito, como Adam e Herzlich (2001) dão a entender, quando sugerem que há uma saúde como forma de aptidão ou bem-estar (saúde como ter); há uma saúde como capacidade de funcionar ou desempenhar papéis sociais (saúde como fazer); e há uma saúde como ausência de sintomas ou enfermidades (saúde como estar), havendo-se que levar em consideração, portanto, que existe uma saúde objetiva, para a qual saudável é aquele de quem o laboratório assim o diz, quantificando-se tal estado a partir de critérios laboratoriais: número de células, taxas hormonais, capacidades volumétricas ou funcionais; e há uma saúde subjetiva: saudável está aquele que assim se sente, quando saúde assume a forma de capacidade para o trabalho ou a forma de capacidade para o prazer, como entre trabalhadores e burgueses, respectivamente, saúde como trabalho e saúde como gozo (RODRIGUES, 1986).

Sendo assim, saúde é mais que taxas laboratoriais, sendo também modo de estar, sentir-se e ser. Por tudo isso, é possível ser-se doente sem se ter doença, como nos "doentes imaginários” (HELMAN, 2003), sendo possível, também, estar-se saudável, porém doente, como nas situações em que, inexistindo sintomas, ainda assim existe a doença, mesmo que não evidenciada ou diagnosticada ainda. É dada essa relatividade do conceito de saúde que lhe foi inventado um conceito relativo, o qual "não se refere a um estado de saúde ideal e absoluto, mas ao melhor estado de saúde possível nas condições existentes” (cf. AHRENFELD, 1978, pg. 2). 


\section{Sexto platô}

Todas essas concepções sobre saúde me levam a pensar que, assim como no século XIX estilhaçaram-se os saberes, como deseja Foucault, fragmentaram-se, também, os conceitos com os quais tais saberes trabalham, como é o caso do conceito de saúde, a ser expresso em uma saúde orgânica, em uma saúde mental, em uma saúde social. Se o primeiro deles é coroado pela definição proposta pela Organização Mundial de Saúde, o segundo foi proposto, pela primeira vez, graças às lutas movidas, nos Estados Unidos, no início do século XX, por Clifford Beer, vítima da sociedade e da doença mental. De sua empreitada, resulta a concepção de que "saúde mental é uma condição, sujeita a flutuações devidas a fatores biológicos e sociais, que permite a um indivíduo atingir uma síntese satisfatória de seus próprios impulsos instintivos potencialmente conflituais, a estabelecer e manter relações harmoniosas com os demais, e a participar das modificações construtivas de seu ambiente social e físico", proposta pela Comissão de Peritos em Saúde mental da Organização Mundial da Saúde, em 1950 (BERTOLOTE, 2000). A terceira concepção, social, apelará para dados oriundos da própria vida em sociedade, sendo caracterizada a partir da existência ou inexistência do que pode facilitar ou dificultar a aquisição dos meios que levam à saúde, tais como emprego, educação, segurança social, os quais, sem serem propriamente saúde, facilitam ou a sua aquisição individual, ou possibilitam, senão o direito à saúde, o direito à posse dos meios que a tornam possível, tudo isso tornado possível graças à invenção dos direitos humanos (MAGALHÃES, 2000).

\section{Sétimo platô}

Por tudo isso, pode-se, também, falar sobre saúde dizendo de sua poética, ou seja, de sua lenta construção social. 
Enquanto vocábulo, saúde, do latim salus, salutis (HOUAISS, 2001, pg. 2526) é conceito geralmente tomado no sentido de estado: estar saudável. Não percebemos, porém, nesse dito estado, a transitoriedade de todo estado. Ser saudável é estar com saúde - mas estar com saúde é a primeira condição para se ficar doente. Não percebemos, em geral, a dialética saúde/doença, não enxergamos a saúde como um processo, encontrando-se, na dobra entre saúde e doença, o estar, ficar, ser doente ou, simultaneamente, ser, estar, ficar saudável.

Mas, o que é ser, estar, ficar saudável ou doente senão discurso? Lembremos: Discurso é conceito e conceito é o sentido que se atribui a uma dada ideia, expressa em uma determinada palavra. Dessa forma, em última instância, se é a clínica quem diz quem está saudável ou doente, quem diz o que são saúde e doença é a sociedade, através da cultura, lembrando que a sociedade precede a medicina. Assim, a cada sociedade seu conceito de saúde, ocorrendo, a cada tempo e lugar, específicos conceitos acerca do que seja doença, lembrando que, linhas atrás, referi-me à saúde como discurso social sobre saúde. De fato, pelo menos em certo sentido, cabe a paródia: Saúde, quantos males não são cometidos em teu nome...! Isso porque o discurso que se faz sobre saúde não provocaria tantos problemas e ocasionais sofrimentos não estivesse investido de uma prática social, uma vez que todo conceito serve a usos sociais. Dessa forma, na busca da saúde, quantos males não foram praticados em nome da saúde pública? Lembro dos excluídos e de assassinatos em nome da defesa da saúde de uma dada sociedade. 


\section{Oitavo platô}

Por tudo isso, o conceito de saúde há que ser pensado, ainda e por fim, a partir da Ética, uma vez que saúde é questão relativa à autonomia dos sujeitos, sendo, por isso, matéria relativa à felicidade, como insinuado anteriormente - o que remete a noção de saúde ao campo da Iatrosofia, ou seja, à filosofia da medicina (HEGENBERG, 1998).

Isso porque saúde implica autonomia pela via do direito de ir e vir, vez que a doença é quase sempre causa limitante de tal direito, tanto pela condição clínica individual (tudo é sempre mais distante para quem é ou está doente), quanto por motivos relativos ao campo da Saúde Pública, como no caso de quarentenas, em que o direito individual de ir e vir é supresso em nome dos direitos de uma dada coletividade. Mas saúde é felicidade, também, ou, pelo menos, uma de suas expressões, vez que a melhor manifestação da saúde é a alegria, oposta ao sofrimento implícito à doença.

Nisso tudo, impõe-se a questão: Existe um direito à saúde? Ou, de outra forma, deve ser garantido o direito de livre acesso aos meios de produção da saúde? Ora, como a saúde é também determinada por fatores genéticos e esses fatores não podem ser legislados, melhor que naturalizar a saúde é tomá-la pela via histórica, abordando-a como conceito e, com isso, implicando-a à medicina, sim, mas também com a política, a qual me diz que saúde é sobretudo direito de acesso aos meios socioeconômico-culturais que possam promovê-la, tomando-se isso como objetivo geral e particular da Saúde Pública.

\section{Nono platô}

Saúde é o discurso que se faz sobre saúde, discurso esse que é clínico, mas também social. Ocorre, entretanto, que discurso implica em saber, pela via do saber/poder dizer. Para o caso, um saber de verdade proferido pela clínica. 
Ou seja, como todo saber dito verdadeiro, o saber sobre a saúde é também poder, tal como de há muito sugeria Francis Bacon. Para o caso do conceito de saúde, tal poder se exercita mediante os usos sociais que são feitos desse conceito inicialmente médico e, em seguida, social, cultural, político, jurídico etc. Dentre esses usos, destacaria três, manifestos a partir de três correlações: a correlação sempre feita entre saúde e normalidade; entre saúde e vigilância e entre saúde e disciplina.

Ou seja, embora saúde e normalidade sejam conceitos diferentes, cada um contando com uma história e usos sociais particulares, inequivocamente o conceito de normalidade constitui interface com o conceito de saúde, vez que frequentemente apostamos na ideia de que "ser saudável é ser normal".

Como todo conceito se desdobra em outros, a noção de saúde remete, por extensão rizomática, à concepção de normalidade - a qual, evidentemente, tem sua própria história, contando a história de tudo que tornou possível a invenção de tal conceito. Assim, segundo Houaiss (2001, pg. 2027), norma é termo registrado na Língua Portuguesa a partir de 1670, normal (1836), normalidade (1873), normalizar (1958), normalização (século $X X$ ), não registrando, aquele autor, datas quanto aos termos normativo e normatividade, constituindo-se, o último vocábulo, como termo caro a Foucault. São palavras inventadas em épocas diversas, como se vê, que remetem todas ao vocábulo norma. Norma, por seu turno, é palavra que, na Grécia antiga, designava apenas um instrumento de mensuração utilizado em arquitetura, uma espécie de esquadro; metaforizado, o termo adquire o sentido daquilo que está em conformidade com a medida ou com o métron, prestando-se, a ideia de norma, como concepção a partir da qual se verifica se algo ou alguém está em conformidade com o esperado, o desejado ou o determinado, daí decorrendo o emprego político-social do conceito, o qual é investido, 
também, de sentido moral, expresso na noção derivada de esquadrinhar. E para esse esquadrinhamento bem se presta a concepção de saúde. Em nome da saúde - ou melhor, dos saudáveis -, necessário excluir os doentes, os não-saudáveis, os que não se enquadram nas normas de saúde ou, de forma diferente, mas assemelhada, aqueles que não preenchem os critérios adotados para avaliar a normalidade. Ora, o que é normalidade para uns, não o é para outros. O conceito do que seja normalidade varia. O que foi, o que é, o que será normalidade? A cada lugar e a cada tempo, sua noção de normalidade. Daí a necessidade de critérios para se caracterizar o que sejam normal e normalidades. Normal é aquele que é conforme as regras e normalidade é o nome que se dá àquilo que está conforme às regras. Na brincadeira em que se aposta, quando se joga o jogo da vida...

Se saúde é esquadrinhamento através do dispositivo da normaliddade, saúde é também vigilância, vigilância que é causa e resultado desse esquadrinhamento praticado por quem é saudável, sobre outros saudáveis e sobretudo quanto a quem seja suspeito de doença. Mas, da mesma forma que saúde é vigilância, saúde é também disciplina, tanto pessoal, no tocante ao enquadramento do próprio corpo à sociedade, mediante, por exemplo, exercícios e dietas, quanto coletiva, no que tange à adoção obrigatória de condutas que levem ao adestramento do corpo próprio à sociedade.

Um dos modos de uso social do conceito de saúde pode ser exemplificado através do que Foucault chamou de medicalização, metáfora que pode ser lida de duas formas, ora no sentido de intervenção social posta em prática através da medicina, quando, por exemplo, são propostas soluções medicamentosas para problemas sociais, ora quando da introdução de conceitos médicos na vida cotidiana, como, por exemplo, na proliferação taxonômica de transtornos clínicos, a qual termina por caracterizar como patológicas condutas antes referidas como saudáveis. Um exemplo: a anorexia de 
algumas santas católicas foi, durante muito tempo, expressão de santidade. Mas tudo isso são apenas meandros do conceito de saúde, saúde da qual talvez somente lhe apreendamos o sentido quando já perdida. Em todo caso em suma, podemos dizer que saúde é conceito e todo conceito é produção sócio-histórica colocada sob a capa de palavras. Assim, não confundir: Da mesma forma que Magritte referiu quanto à representação de um cachimbo sobre ela dizendo "Isto não é um cachimbo", do mesmo modo, a própria palavra saúde se constitui de forma completamente diferente do que seja a saúde própria - que aqui perseguimos enquanto conceito e outros a perseguem como questão de vida e morte.

\section{Referências:}

ADAM, P. e HERZLICH, C. Sociologia da doença e da medicina. Bauru, SP: EDUSC, 2001.

AHRENFELDT, R.H. "Las notion de santé mentale", In, LAFFONT, A. et DURIEUX, F (pres.). Encyclopédie médico-chirurgicale: psychiatrie. Paris: Editions Techiniques, 1978 (vol. 6, fasc. 37960 A10, pgs.1-8)

BERTOLOTE, J.M. "As origens do conceito de saúde mental", In Temas. v. 30, n. 58, pp.46-56, jan./jun. Hospital do Servidor Público Estadual: São Paulo, 2000.

BIRMAN, J. Enfermidade e loucura. Rio de Janeiro: Campus, 1980.

BURKE, P. Uma história social do conhecimento: de Gutemberg a Diderot. Rio de Janeiro: Jorge Zahar Ed., 2003.

CAMPOS, L.F.L. Métodos e técnicas de pesquisa em psicologia. Campinas, SP: Editora Alínea, 2001.

CANGUILHEM, G. O normal e o patológico. Rio de Janeiro: Ed. Forense-Universitária, 1982. 
CANGUILHEM, G. "As doenças", In Escritos sobre medicina. Rio de Janeiro: Forense Universitária, 2005. (pgs. 23-34)

CANGUILHEM, G. "A saúde: conceito vulgar e questão filosófica”, In Escritos sobre medicina. Rio de Janeiro: Forense Universitária, 2005. (pgs. 35-48)

CZERESNIA, D. Do contágio à transmissão: ciência e cultura na gênese do conhecimento epidemiológico. Rio de Janeiro: FIOPCRUZ, 1997.

CHARTIER, R. A ordem dos livros: leitores, autores e bibliotecas na Europa entre os séculos XIV e XVIII. Brasília: Ed. Universidade de Brasília, 1994.

DELEUZE, G. e GUATTARI, F. Mil platôs: capitalismo e esquizofrenia. Rio de Janeiro: Ed. 34, 1995. (vol. 1)

FIGUEIRA, S. Sociedade e doença mental [Coord.] Rio de Janeiro: Campus, 1978.

FOUCAULT, M. História da loucura. São Paulo: Editora Brasiliense, 1978.

FOUCAULT, M. Microfísica do poder [Org. e trad. Roberto Machado] Ed. Graal: Rio de janeiro, 1979.

FOUCAULT, M. O nascimento da clínica. Rio de Janeiro: Forense Universitária, 1994. ( $4^{\mathrm{a}}$. ed.)

FOUCAULT, M. As palavras e as coisas. Rio de Janeiro/Lisboa: Liv. Martins Fontes/ Portugália Editora., 1996.

FOUCAULT, M. "A hermenêutica do sujeito", IN Resumo dos Cursos do Collège de France: 1970-1982. Rio de Janeiro: Jorge Zahar Ed. 1997.

FOUCAULT, M. "Sobre a arqueologia das ciências. Resposta ao Círculo de Epistemologia”, IN FOUCAULT, M. Arqueologia das 
ciências e história dos sistemas de pensamento. Rio de janeiro: Forense Universitária, 2000. (Ditos \& Escritos II, págs. 82-118)

GAYON, J “Epistemologia da medicina”, In RUSSO, M. et CAPONI, S. (orgs.) Estudos de filosofia e história das ciências biomédicas. São Paulo: Discurso Editorial, 2006. (pgs. 39-63)

HELMAN, C. G. Cultura, saúde \& doença. Porto Alegre: Artmed, 2003. ( $4^{\mathrm{a}}$. ed.)

HEGENBERG, L. Doença: um estudo filosófico. Rio de Janeiro: FIOCRUZ, 1998.

MACHADO, R. Foucault: a ciência e o saber. Rio de Janeiro: Jorge Zahar, 2006.

MAGALHÃES, J.L.Q. Direitos humanos: sua história, sua garantia e a questão da indivisibilidade. São paulo: Editora Juarez de Oliveira, 2000.

MOURA, D. Saúde não se dá: conquista-se. Ed. Hucitexc: São Paulo, 1989.

NUNES, E. D. (Org) Medicina social: aspectos históricos e teóricos. São Paulo: Global Ed., 1983

NUNES, E. D. Sobre a sociologia da saúde. Ed. Hucitec: São Paulo, 1999.

OUTHWAITE, W. et BOTTOMORE, T. Dicionário do pensamento social do século XX. Rio de Janeiro: Jorge Zahar Editor, 1996 (pgs. 677-8)

PORTER, Roy Uma história social da loucura. Jorge Zahar: Rio de Janeiro, 1991.

RAGO, Margareth. Do cabaré ao lar: a utopia da cidade disciplinar: Brasil 1890-1930. Rio de Janeiro: Paz e Terra, 1985. 
RODRIGUES, J.C. Tabu do corpo. Rio de Janeiro: Dois Pontos Ed., 1986.

RODRIGUES, J. C. O corpo na história. Rio de Janeiro: Ed. FIOCRUZ, 1999.

ROSEN, G. Da polícia médica à medicina social: ensaios sobre a história da assistência médica. Rio de Janeiro: Ed. Graal, 1979.

RUSSO, M. e CAPONI, S. (Org.) Estudos de filosofia e história das ciências biomédicas. São Paulo: Discurso Editorial, 2006.

SADOCK, B. J. e SADOCK, V. A. (Orgs.) Compêndio de psiquiatria: ciências do comportamento e psiquiatria clínica. Porto Alegre: Artmed, 2007. (9a. ed.) 


\title{
5
}

\section{A saúde do homem na interface com a Psicologia da Saúde}

\author{
Railda Fernandes Alves \\ Ana Gabriella Barros de Lima \\ Fabiana Maria de Souza \\ Monalisa Vasconcelos Ernesto \\ Renata Pimentel da Silva
}

\section{Contexto}

saúde do homem tornou-se, no momento atual,
um assunto de interesse dos que fazem as políticas
públicas de saúde no Brasil. Finalmente, depois de tantos fatos e dados estatísticos/científicos que expõem as dificuldades dos homens brasileiros em utilizarem os serviços de saúde, o tema começa a tomar visibilidade midiática e a receber do sistema nacional de saúde um tratamento diferenciado.

A compreensão dos processos que explicam as dificuldades demonstradas pelos homens brasileiros a hora de zelar pela sua saúde é assunto para várias disciplinas. Aqui, no âmbito deste capítulo, o tema será abordado pelo viés da 
Psicologia da Saúde. Para isto, será indispensável apresentar o conceito de Psicologia da Saúde aqui utilizado.

A Psicologia da Saúde é entendida como um campo de aplicação da Ciência Psicologia dedicado aos cuidados de saúde geral. Sua prioridade assenta-se sobre as assistências de promoção de saúde e de prevenção de doenças. Nesse modelo de atuação psicológica, as práticas do psicólogo se alargam para além das práticas clínicas e da saúde mental já que o objetivo maior é a saúde global das pessoas inseridas em seus coletivos sociais (ALVES, 2008).

A Psicologia da Saúde avança na atualidade buscando novos espaços expandindo-se na direção de atender as novas demandas de produção de saber e de saúde que visam a contemplar comunidades antes não assistidas pelas prioridades das Políticas Públicas. Tudo isso exige do profissional de Psicologia desenvoltura e habilidades interdisciplinares e ensina que as profissões de saúde traçam caminhos paralelos a outras profissões, ou seja, necessitam cada vez mais, para a concretização da saúde pública, da interlocução multiprofissional.

No tocante às políticas públicas de saúde, faz-se mister destacar que, historicamente, elas estiveram voltadas para o atendimento do público feminino e somente, nas últimas décadas, a literatura sobre gênero e saúde voltou-se para o estudo do universo masculino (GIFFIN, 2002). Em consonância com essa perspectiva investigativa, emergem modificações institucionais e práticas protagonizadas por projetos cuja ênfase recai sobre a saúde dos homens.

Nesse caso, a problemática existente quanto a relação do sujeito frente ao processo de saúde-doença passa a ser influenciada por preocupações e indagações referentes aos altos índices de morbi-mortalidade dos homens quando comparados aos índices das mulheres (PINHEIRO et al, 2002). Esse dado configura-se como uma justificativa importante 
para confirmar a realização de investigações sobre a relação gênero masculino e saúde e denuncia também que as políticas públicas de saúde ainda são insuficientes e não contemplam, de modo satisfatório, as relações entre as construções culturais de masculinidade e a saúde preventiva.

Na intenção de somar algumas contribuições ao aprofundamento desta discussão, o presente capítulo pretende fazer um levantamento bibliográfico, não exaustivo, da literatura sobre a relação entre a saúde dos homens e as políticas públicas de saúde, numa interface com a Psicologia da Saúde. Concomitantemente, visa conhecer alguns desdobramentos dessa relação de gênero com a saúde.

\section{Psicologia da Saúde}

Nos últimos anos, a compreensão do processo saúdedoença sofreu muitas mudanças. Nesta trajetória, deixou de ser objeto de estudo apenas das disciplinas biomédicas para se tornar objeto do conhecimento interdisciplinar. De modo que, as ciências sociais passam a compor o conjunto de disciplinas dedicadas ao estudo e compreensão do referido processo. Segundo Alves e Rabelo (1998), as investigações, na área de saúde, contemplam essa relevante pluralidade teórico-metodológica em decorrência de sua natureza biopsicossocial, que exige contribuições de várias ciências a exemplo da Sociologia, da Antropologia, da Psicologia dentre outras. De acordo com Minayo (1991 apud ALVES e RABELO, 1998), isso se daria porque "a própria polissemia do termo saúde escapa do objeto de qualquer disciplina” (p. 14).

Entre as novas disciplinas a abordarem, de maneira singular, o processo saúde-doença, destaca-se a Psicologia da Saúde, cujo foco central é o interesse pela saúde geral das pessoas. Propõe-se a descrever os níveis de atenção de saúde (primário/básico, secundário/especializado e terciário/ de alta complexidade) em que se dão as ações do profissional 
de Psicologia, além de caracterizar-se, como já dito acima, como um campo de aplicação da Psicologia autônomo em relação à Psicologia Clínica. Ou seja, que abrange todas as intervenções de saúde inclusive as de saúde mental (ALVES, 2008).

Numa perspectiva histórico-conceitual, Matarazzo (1980 apud CALVETTI; MULLER; NUNES, 2007) corroborado por LOVELLE (2003) afirma que a Psicologia da Saúde pode ser entendida como uma área de contribuições profissionais, científicas e educacionais da Psicologia para a promoção e a manutenção da saúde; visando à prevenção e ao tratamento do processo saúde-doença e à identificação dos fatores relacionados ao desenvolvimento de enfermidades, além de buscar contribuir para a análise e a melhora do sistema dos serviços de saúde, bem como para elaboração de uma política sanitária.

Jesus e Rezende (2006) também corroboram tal definição e acrescentam que a Psicologia da Saúde "funda-se na perspectiva de ultrapassar as dicotomias tradicionais de indivíduo e sociedade, natureza e sociedade e saúde/doença” (p.123).

Fazendo uma diferenciação entre promoção de saúde e prevenção de doenças, Jesus e Rezende (2006) afirmam que promover saúde é aplicar à sociedade condições de vida que lhe garanta bem-estar no âmbito social, mental e físico. Ressalta, portanto, que:

(...) neste aspecto esta conceituação distancia-se na noção tradicional de que cuidar da saúde é tratar e prevenir doenças por profissionais de saúde para incluir a participação do indivíduo, da população e da sociedade em defesa da vida (JESUS; REZENDE, 2006, p.123). 
Rutsatz e Câmara (2006) apontam que “... a promoção de saúde tem sido o foco das atividades dos psicólogos, sendo promovida através de atividades de desenvolvimento comunitário, bem como disponibilidade e aprimoramento de atendimentos" (p.59).

Quanto à prevenção de doenças, esta consiste na prática de medidas preventivas que objetivam reduzir comportamentos e práticas de risco, que contribuem para o estabelecimento de uma enfermidade. Visa, portanto, "eliminar ou reduzir a probabilidade de doenças ou incapacidades" (JESUS; REZENDE, 2006, p.124). Para isso, são realizadas práticas educativas, campanhas de vacinação, exames médicos periódicos, entre outros.

\section{Gênero e saúde}

As contribuições mais atuais das ciências sociais se centraram no caráter relacional das questões de saúde abordando principalmente a característica social do processo de adoecimento e as perspectivas de gênero como maneiras de contemplar a relação saúde-sociedade (SCHRAIBER; GOMES; COUTO, 2005).

Impulsionados por esse novo ponto de vista, em que a saúde passou a ser entendida como um processo com variados aspectos psicossociais envolvidos e, contrário ao enfoque tradicionalmente biológico, as discussões da relação gênerosaúde também passaram por mudanças.

Até recentemente, essas discussões eram protagonizadas pelo movimento feminista as quais se centravam nas questões relativas à feminilidade e à desigualdade entre os gêneros. As mulheres eram percebidas como seres frágeis por serem vulneráveis a diversas influências fossem elas físicas, intelectuais ou morais. Tal percepção da mulher atribuía-se 
às suas supostas sensibilidades e aptidões à maternidade (AQUINO, 2006).

Os movimentos feministas, liderados pelas mulheres, travaram suas lutas colocando francamente a sua indignação frente a estes argumentos e representações. As principais reivindicações das mulheres foram romper as diferenças entre os gêneros e garantir a equidade entre os diversos meios, dentre eles a saúde. Estes movimentos da década de 80, como afirma Farah (2004), foram responsáveis pela implantação das primeiras políticas públicas com esse recorte de gênero.

Aquino (2006) revela em seus estudos referentes a gênero e saúde que estes são, em sua grande maioria, publicados por mulheres. Têm enfoques mais voltados para as questões do sexo feminino, feminilidade, feminismo e aborda temas como: sexualidade e saúde, violência doméstica, reprodução e contracepção, trabalho e saúde. Justificando este fato, Heilborn e Sorj (1999 apud AQUINO, 2006) dizem que:

Por um lado, isto reflete o peso que a hierarquia de prestígio entre os sexos tem em ordenar objetos científicos e cientistas; por outro, a percepção de que existe uma forte associação entre a área de estudos de gênero e movimentos de mulheres que dificulta a incorporação de pesquisadores homens (p.126).

A partir da década de 1970, novas perspectivas de análise incluíram também o universo masculino em suas investigações. Nessas, começam a aparecer as primeiras teses assegurando que os homens desempenham um importante papel na busca da igualdade de gênero (KORIN, 2001). Essa inclusão do masculino se justifica na própria dimensão de gênero, já que homens e mulheres precisam ser percebidos em suas idiossincrasias e pluralidades no limite constitutivo das relações sociais que formam (GOMES; NASCIMENTO; ARAÚJO, 2007; SCHRAIBER; GOMES; COUTO, 2005). Além disso, essa perspectiva está afinada com as recentes 
iniciativas em prol da promoção de saúde, que traz implícitas questões relativas à equidade de direitos (SCHRAIBER; GOMES; COUTO, 2005).

\section{Saúde da Mulher}

Como foi dito acima, os modos como homens e mulheres cuidam de sua saúde divergem em função de vários fatores psicossociais. No caso das mulheres, há que se registrar seu empenho em forma de protestos e denúncias pela falta de assistência equânime e global.

Cedendo às pressões dos movimentos feministas, o governo brasileiro instituiu, em 1983, o Programa de Atenção Integral a Saúde da Mulher - PAISM (FARAH, 2004, p.51). Tal Programa teve em sua filosofia original promover uma articulação entre os aspectos que interferem diretamente sobre a saúde da mulher. Este Programa representa um marco na história das políticas públicas dirigidas à mulher, permanecendo como uma referência na luta desta pela saúde. Neste caso, entendida como um direito de cidadania (LEÃO; MARINHO, s/d).

Durante muito tempo, a saúde da mulher foi considerada de forma reducionista, já que as práticas de saúde eram centralizadas em temas relacionados à maternidade, negligenciando-se, assim, a visão da mulher como possuidora de um corpo que merecesse atenção integral. Essa perspectiva da integralidade, na saúde, deveria referir-se também ao contexto social, psicológico e emocional das mulheres, as quais mereciam ser encaradas em sua completude (OSIS, 1998).

Dessa forma, o PAISM representava, conforme dito por Costa (1992, apud OSIS, 1998), um programa que reporta a "uma esperança de resposta ao dramático quadro epidemiológico da população feminina” (pag.30), enfatizando o controle das patologias, a exigência de uma nova postura 
no atendimento, devendo este privilegiar a integralidade da assistência. Segundo Osis (1998), o programa pregava que:

a atenção à mulher deveria ser integral, clínico-ginecológica e educativa, voltada ao aperfeiçoamento do controle prénatal, do parto e puerpério; à abordagem dos problemas presentes desde a adolescência até a terceira idade; ao contrário das doenças transmitidas sexualmente, do câncer cérvico-uterino e mamário e à assistência para a concepção e contracepção (OSIS, 1998, p. 27)

Mesmo trazendo inovações no enfrentamento aos problemas relacionados à saúde da mulher, o PAISM sofreu diversas e severas críticas, dirigidas principalmente à suposição de que o programa seria um artifício do governo para controlar a natalidade. A atribuição à mulher da responsabilidade total pela reprodução, a exclusão do homem do programa, e a pretensão de alcançar a integralidade e a universalidade das práticas de saúde centralizaram as principais queixas.

O uso do termo atenção integral foi considerado inadequado já que os objetivos do programa se voltavam quase exclusivamente para a atividade sexual e reprodutiva da mulher, retomando o reducionismo tão combatido, no qual a mulher se definia por sua capacidade de reprodução.

Giffin (2002) afirma que, apesar da existência de programas e iniciativas dedicados aos cuidados à saúde das mulheres; ainda que se constate uma feminilização tanto no nível dos programas quanto dos serviços de saúde, os cuidados voltados à saúde da mulher são ainda insuficientes. Tal conclusão se revela quando se verificam, por exemplo, os números sobre a incidência dos casos de AIDS em mulheres e as taxas de fecundidade em adolescentes brasileiras. Disto conclui-se que a situação da saúde do grupo em questão tem muito que melhorar. 
Segundo Osis (1998), o Programa para concretizar suas diretrizes deveria partir da elaboração de uma política de atenção à saúde do adulto. Esta última crítica é corroborada por Giffin (2002) que denuncia também um controle exacerbado exercido sobre o corpo feminino além da excessiva medicalização.

Como é possível constatar na citação a seguir, o PAISM, em sua constituição, pretendeu abarcar todas as exigências e recomendações preconizadas para garantir o desenvolvimento de uma política equânime em termos de gênero. Assim, almejava uma:

(...) mobilização e participação da sociedade civil organizada; sensibilização das autoridades e profissionais de saúde; mulheres em posições oficiais de comando; definição de um programa oficial federal com perspectivas de gênero, elaborado com a colaboração ativa da sociedade civil; e novas leis constitucionais. (GIFFIN, 2002, p. 109).

Esta foi a imagem do Programa oferecida internacionalmente. Ainda assim, o mesmo veio a fracassar em termos das metas previamente estabelecidas. Como é possível constatar o Projeto teve a intenção de resolver a maior parte dos problemas relacionados à saúde da mulher, contudo, as sequências de falhas impediram inclusive a sua implementação em rede nacional. A morosidade e o descompasso entre a discussão, a elaboração e a aplicação efetiva da política foram, de acordo com Osis (1998), os principais motivos do fracasso na cobertura nacional do programa. A autora alega que tudo isso resultou da falta de comprometimento com a própria política, bem como com todo o sistema de saúde.

Mesmo diante destas críticas, há que se registrar os avanços trazidos pelo PAISM. Avanços representados na 
preocupação de oferecer uma proposta inovadora e alternativa como resposta às precárias condições de vida da população feminina. Outro fator, apontado como positivo, foi a inclusão das informações e programas voltados à anticoncepção, que independente das intenções ocultas do governo, significou uma vitória para as mulheres, no sentido de ter permitido a estas a oportunidade de decidir sobre a quantidade de filhos que queria ter.

\section{Gênero e saúde do homem}

À medida que a literatura de gênero se volta para o estudo do masculino, surgem, também, na interface Gênero e Saúde, iniciativas voltadas para o estudo e elaboração de políticas específicas para os homens, impulsionadas por investigações de autores como, Laurenti, Mello-Jorge e Gotlieb (2005), que apontam, por um lado, uma maior mortalidade e sobremortalidade masculina comparando-se as causas de morte e, por outro lado, maior procura feminina pelos serviços de saúde, dando a ideia de que estão mais propensas a adoecer que os homens.

Pinheiro et al (2002), por sua vez, constataram a preferência masculina pelos serviços mais emergenciais como farmácias e pronto-socorros.

Vários autores, tais como Gomes, Nascimento e Araújo (2007), Villar (2007) e Korin (2001) revelaram estrita relação entre um modelo culturalmente construído de masculinidade e sua influência nos cuidados com a própria saúde. Korin (2001), ainda, acrescenta que "em vez de usar uma definição de gênero monolítica e estereotipada, é mais apropriado falar de masculinidades e feminilidades" (p.70). Essas devem ser entendidas como significados culturais atribuídos às diferenças sexuais, e que, à medida que são construídas e perpassadas culturalmente, são também referências para o modo de ser e se relacionar. 
Waldron (1976 apud AQUINO, 1991) aponta em seus estudos que $3 / 4$ da diferença da expectativa de vida entre homens e mulheres são atribuídos a aspectos ligados às questões de gênero. Harrison, Chin e Ficcarrotto (1989 apud KORIN, 2001), também, denunciam o gênero masculino tradicional - a masculinidade hegemônica para Korin (2001) - como algo ameaçador para a saúde do homem, embora isso ainda não tenha sido devidamente explorado.

Para além das questões de gênero, pesquisas apontam (GOMES et al, 2008) que podem coexistir outros fatores inerentes ao funcionamento dos serviços de saúde, capazes de obstaculizar o acesso masculino a esses serviços. Gomes, Nascimento e Araújo (2007) apontam alguns desses possíveis aspectos que estariam relacionados ao trabalho, acessibilidade aos serviços, especificidades das equipes profissionais e estrutura de funcionamento desses serviços, como outros elementos influenciadores de uma menor procura dos homens pelos serviços em saúde.

\section{Programa Saúde do Homem}

Dados do Ministério da Saúde dão conta de que, no ano de 2007, as mulheres realizaram aproximadamente 17 milhões de consultas preventivas, contra 2,7 milhões de consultas por parte dos homens (BRASIL, 2009). Reafirmando-se a prática da prevenção de doenças como prática mais constante no âmbito do universo feminino do que no do masculino. Percebeu-se, também, que essa população estava fora de todas as políticas de saúde, embora representem 41,3\% da população masculina, e $20 \%$ do total da população brasileira. Ela ainda corresponde à parcela preponderante da força produtiva e, além do mais, exerce um significativo papel sociocultural e político (BRASIL, 2008).

Corroborando com esses dados, Laurenti, Mello-Jorge e Gotlieb (2005) e BRASIL $(2006,2008)$ apresentam, em seus 
estudos, estatísticas preocupantes nas quais os homens lideram as causas de morte. Estes mesmos dados confirmam que a expectativa de vida destes é menor do que a das mulheres. Apesar disso, eles procuram menos os serviços de atenção primária de saúde (APS) que se caracterizam pela proposta de promoção de saúde e de prevenção de doenças (FIGUEIREDO, 2005; PINHEIRO et al, 2002). Tal atitude representa um privilégio dado à atenção secundária e terciária (ambulatorial e hospitalar de média e alta complexidade, respectivamente), em prejuízo da primária. Fato que contribui para uma demora na intervenção preventiva e diagnóstica, além de provocar o agravamento da morbidade e um aumento dos gastos com os tratamentos, pelo sistema de saúde (BRASIL, 2008).

Gomes, Nascimento e Araújo (2007) esclarecem que a "pouca procura" masculina pelos serviços de saúde não se refere necessariamente a um cálculo da relação ofertademanda, mas sim, aos hábitos preventivos que são práticas mais associadas ao mundo feminino. $\mathrm{O}$ artigo, em questão, aborda uma pesquisa que comprova a menor procura dos homens pelos serviços de APS, fato descrito por profissionais em diferentes contextos, mas que como aponta Figueiredo (2005), pode tratar-se de uma ausência ou ainda invisibilidade dos homens no interior desses serviços decorrentes de não serem os homens o foco de atuação das equipes.

Diante desse contexto, o Ministério da Saúde desde agosto de 2008 vem discutindo o Programa Nacional de Atenção Integral à Saúde do Homem - o PNAISH - política pública que incluirá a população masculina entre 25 e 59 anos nas prioridades da APS. Entre os principais objetivos do programa em questão está:

[...] promover ações de saúde que contribuam significativamente para a compreensão da realidade singular masculina nos seus diversos contextos socioculturais e político-econômicos 
e que, respeitando os diferentes níveis de desenvolvimento e organização dos sistemas locais de saúde e tipos de gestão, possibilitem o aumento da expectativa de vida e a redução dos índices de morbimortalidade por causas preveníveis e evitáveis nessa população (BRASIL, 2008, p.3).

O Ministério da Saúde (BRASIL, 2008) afirma através de seus documentos que o PNAISH está alinhado com a Política Nacional de Atenção Básica, com as estratégias de humanização e em consonância com os princípios do SUS, e tem por finalidade fortalecer as ações e serviços em redes e cuidados da saúde. Tem como princípios: 1. orientar as ações e serviços de saúde para a população masculina, com integralidade e equidade, primando pela humanização da atenção; 2 . mudar paradigmas no que concerne à percepção da população masculina em relação ao cuidado com a sua saúde e a de sua família; 3. capacitar tecnicamente os profissionais de saúde para o atendimento ao homem; 4. enfatizar os aspectos educacionais e organizar os serviços de modo a acolher e fazer com que o homem sinta-se parte integrante deles; 5. implementar a Política da saúde do homem de forma integrada às demais políticas existentes, priorizando a APS como porta de entrada de um sistema de saúde universal, integral e equânime.

Esse Programa é resultante de alguns Projetos de Lei $^{1}$ (FRAGOSO, 2005; ROLLEMBERG, 2009) destinados à saúde do homem que visam, de forma geral, à detecção e tratamento de doenças, buscando priorizar a promoção de saúde e a prevenção das doenças no coletivo masculino, tão pouco atendido em suas necessidades de saúde. Objetiva ainda trazer informações sobre as diversas vulnerabilidades às quais a população masculina está sujeita, como por exemplo: ao

1 O projeto de Fragoso encontra-se, na atualidade, em tramitação no Senado Federal. 
câncer prostático, ao hipo e hipertiroidismo, à diabetes, à hipertensão arterial, às doenças degenerativas, ao câncer de mama, dentre outras.

Atualmente, segundo dados do Instituto Nacional do Câncer - INCA (2008), o câncer prostático é um dos seis mais comuns do mundo. Tendo uma taxa de incidência maior em países desenvolvidos, o que provavelmente estaria associado a fatores como o estilo de vida e a alimentação. A mortalidade por câncer de próstata é relativamente baixa, o que reflete, em parte, seu bom prognóstico. A sobrevida média mundial estimada em cincos anos é de $58 \%$.

No Brasil, como em outros países do mundo, o perfil de morbimortalidade por câncer de próstata também tem se alterado nas últimas décadas. Ainda de acordo com o INCA (2008), o número de casos novos de câncer de próstata estimados para o Brasil, no ano de 2008, e válidos também para o ano de 2009, é de 49.530. Estes valores correspondem a um risco estimado de 52 casos novos a cada 100 mil homens. O risco estimado é de 69/100.000 na região Sul, 63/100.000 na região Sudeste, $47 / 100.000$ na região Centro-Oeste, 38/100.000 na região Nordeste e 22/100.000 na região Norte.

Ainda para o INCA (2008), alguns fatores de risco para o surgimento desta neoplasia estariam associados à idade, em que a incidência e a mortalidade crescem a partir dos 50 anos de idade; à hereditariedade, onde casos desta neoplasia na família alteram a incidência de 3 para até 10 vezes mais do que na população em geral; a hábitos alimentares, além do estilo de vida.

Segundo o deputado Heleno Fragoso, defensor do Projeto de Lei em saúde do homem

até 1990, o adenocarcinoma da próstata representava o terceiro tumor do sexo masculino, sendo menos frequente que o câncer de pulmão e o câncer de 
cólon. A partir daquele ano, tumores da próstata ultrapassaram em número essas duas neoplasias e passaram a representar o câncer mais freqüente do homem representando $40 \%$ dos tumores que acometem os indivíduos do sexo masculino (FRAGOSO, 2005).

Segundo o Sistema Nacional de Auditoria, órgão do Ministério da Saúde (BRASIL, 2006), no quadro da saúde pública brasileira, o câncer de próstata é um dos grandes problemas. Esse tipo de câncer é duas vezes mais frequente do que o câncer de mama de incidência masculina.

Apesar do aumento nas taxas de incidência, justificadas a partir da melhoria nos aspectos referentes a evolução dos métodos diagnósticos, por um melhor serviço de informatização e, pelo aumento da expectativa de vida da população brasileira, o número de homens possuidores de tal enfermidade poderá ser muito maior, devido a escassa procura masculina aos serviços de saúde, fato já confirmado em pesquisas (SCHRAIBER; NEMES; MENDES-GONÇALVES, 2000; GOMES et al, 2007; GOMES et al, 2008; BRASIL, 2008). A não procura justifica-se pela influência de duas principais categorias: dos fatores socioculturais e, dos fatores institucionais. A esse respeito encontramos, no PNAISH (BRASIL, 2008), a seguinte afirmação:

A compreensão das barreiras socioculturais e institucionais é importante para a proposição estratégica de medidas que venham a promover o acesso dos homens aos serviços de atenção primária, que deve ser a porta de entrada ao sistema de saúde, a fim de resguardar a prevenção e a promoção como eixos necessários e fundamentais de intervenção (p.6). 
No que se referem aos aspectos culturais, as perspectivas de análises procuraram, nos últimos anos, investigar a relação entre a percepção de gênero e os cuidados com a saúde. Percebeu-se que a masculinidade é geralmente associada com invulnerabilidade, fazendo crer que hábitos preventivos ficariam a cargo do sexo "frágil", o feminino (KORIN, 2001).

Para Braz (2005), a construção da subjetividade masculina é dificultada pela concepção social de que o homem deve possuir uma imagem identitária “... ligada a não ser homossexual, a não ser mulher, a ser forte, capaz, protetor, violento, decidido e corajoso". Ainda segundo este autor, “... ao homem caberia, então, ser forte - o que pode resultar em descuido com o próprio corpo" (BRAZ, 2005, p.101).

Segundo Korin (2001), em sociedades que equiparam poder, sucesso e força como características masculinas, os homens buscam, no processo de socialização (pela mídia, entre pares, na família), o distanciamento de características relacionadas ao feminino: sensibilidade, cuidado, dependência, fragilidade. Estas atribuições simbólicas diferenciadas entre homens e mulheres resultam, muitas vezes, para os homens, em comportamentos que os predispõem a doenças, lesões e mortes.

Além desses aspectos no campo do imaginário social também foram investigadas as jornadas de trabalho, neste caso entendidas como uma categoria relevante para a compreensão do fenômeno em tela. Os resultados dos estudos mostraram que as jornadas de trabalho não se encaixam com os horários dos serviços de saúde. Por isso, a falta de tempo; a impossibilidade de deixar as atividades para a realização do tratamento médico, o medo de que o problema de saúde seja revelado, foram utilizados pelos homens como justificativas para o não comparecimento aos serviços de saúde. $\mathrm{Na}$ realidade, os homens temem que a revelação de algum problema de saúde possa prejudicá-los, resultando na perda do posto de trabalho. 
A precarização dos serviços de saúde pública; a falta de recursos financeiros a falta de escolarização e informação dos usuários; a própria composição da equipe de saúde; entre outros aspectos também poderiam funcionar como empecilhos a um maior acesso masculino aos serviços de APS (NEMES; MENDES-GONÇALVES,; COUTO, 2005; GOMES; NASCIMENTO; 2000; KORIN, 2001; SCHRAIBER; GOMES ARAÚJO, 2007; BRASIL, 2008).

Uma vez que a maior parte dos estudos das políticas de saúde, no Brasil, centrou-se em aspectos relacionados com a categoria ‘jornada de trabalho', como aponta Giovanella e Fleury (1996), conhecer detalhadamente os aspectos que contribuem para o acesso insatisfatório dos homens aos serviços de APS, torna-se um ponto importante para o sucesso da política em questão.

Mudar a cultura do homem sobre a medicina preventiva, quebrando preconceitos e o mobilizando para questões referentes aos cuidados com sua própria saúde apresentam-se como o grande desafio do PNAISH. De posse dessas informações, poder-se-ão realizar ações capazes de levar os homens a modificarem seus hábitos de cuidados de si em prol de uma promoção da saúde e da prevenção de doenças, priorizando aspectos educacionais (BRASIL, 2008).

\section{Considerações finais}

Como palavra final é importante afirmar que é fato a constatação da existência de uma defasagem no conhecimento dos percalços que estão na base do comportamento dos homens frente aos cuidados com a sua saúde. Fenômeno que é decorrente, também, da maciça produção de estudos, realizados em sua maioria por mulheres, cuja ênfase recai sobre a saúde das próprias mulheres. Há que se registrar ainda a prioridade dada pelo governo brasileiro às políticas de saúde da mulher, nas quais os homens ficaram literalmente de fora. 
Estas conclusões permitem mostrar que estudar, pesquisar e difundir os saberes sobre os fatores que estão atrelados aos porquês de os homens não procurarem a assistência de saúde ainda no primeiro nível de atenção (APS), representa uma importante contribuição do mundo acadêmico ao sistema de saúde brasileiro, o qual rege as políticas de saúde no Brasil.

A investigação das relações intrínsecas ao processo saúde-doença ressalta a sua inter-relação com as concepções de gênero, considerando que os cuidados com a saúde estão, também, imbricados nas construções subjetivas e culturais das diferenças entre os sexos.

O conhecimento dos aspectos psicossociais que influenciam o comportamento dos homens no que se refere à procura pelos serviços de APS, pode estimular a apresentação de propostas de mudanças institucionais capazes de atrair esse público. Também, interferir nas construções culturais do binômio: cuidados com a saúde e percepções do masculino, de forma a aproximar essas percepções às práticas mais salutares e integrais.

Os estudos sobre gênero e saúde trazem uma importante contribuição à investigação desta problemática, já que se propõem a ampliar a visão das relações subjetivas e culturais que conduzem os comportamentos de homens e mulheres quando o tema é cuidar da saúde.

Nesta direção, a contribuição da Psicologia da Saúde na abordagem deste problema se foca sobre dois pontos principais: o primeiro dedicado à pesquisa, e o segundo voltado à intervenção.

A pesquisa dedicada à explicação do fenômeno permitirá abrir novas veredas para a criação e proposição de modelos e programas que estimulem o grupo, em foco, a desmistificar as práticas de prevenção de doenças e as de promoção de saúde. 
A intervenção, realizada no setor público de saúde, será guiada pelo conhecimento gerado na pesquisa. O qual auxiliará a implementação das práticas, originárias dos modelos e programas pensados a partir do conhecimento produzido na etapa anterior (na pesquisa). Evidentemente, da detecção e explicação da problemática até o desenvolvimento de novas percepções sobre o autocuidado com a saúde, poderá significar um longo caminho. Daí a necessidade e a urgência no trato desse tema. Que deve ser considerado não como um tema de moda, mas como uma política de saúde a ser acompanhada e cuidada com o intuito de evitar que fracasse antes mesmo de sua completa implantação.

\section{Referências}

ALVES, P. C.; RABELO, M. C. O status atual das ciências sociais em saúde no Brasil: tendências. In: . (orgs.). Antropologia da Saúde: traçando identidade e explorando fronteiras. Rio de Janeiro: Editora Fiocruz/ Editora Relume Dumará, 1998, p. 13-28.

\section{ALVES, R. F. Intervenciones de profesionales en el campo de} la salud: estudio antropológico comparativo en Brasil, España y Portugal. Espanhã, 2008. Tese (Doutorado em Psicologia da Saúde), Universidade de Granada, 2008.

AQUINO, E. M. L. de. Gênero e saúde: perfil e tendências da produção científica no Brasil. Revista de Saúde Pública, São Paulo, v. 40, 2006. Edição especial. Disponível em: <http://www.scielo. br/pdf/rsp/v40nspe/30631.pdf > . Acesso em: 27 de mar. 2009.

AQUINO, E. M. L. de et al. Mortalidade feminina no Brasil: sexo frágil ou sexo forte?. Cadernos de Saúde Pública, Rio de Janeiro, vol. 7, n. 2, abr/jun. 1991.

BRASIL. Ministério da Saúde. Painel de indicadores do SUS. Brasília, DF, 2006. 


\section{. Política Nacional de Atenção Integral à Saúde do}

Homem: princípios e diretrizes, Brasília, 2008. Disponível em: $<$ http://dtr2001.saude.gov.br/sas/PORTARIAS/Port2008/PT-09CONS.pdf $>$. Acesso em: 15 de maio 2009.

. Política nacional de atenção básica. 4. ed. Brasília, DF, 2007. Disponível em: <www.lachealthsys.org/index. php?option=com_docman $>$. Acesso em: 29 de mar. 2009.

BRAZ, M. A construção da subjetividade masculina e seu impacto sobre a saúde do homem: reflexão bioética sobre justiça distributiva. Ciência \& Saúde Coletiva, Rio de Janeiro, vol. 10, n. 1, jan/ mar. 2005. Disponível em: <http://www.scielosp.org/scielo.php?pi $\mathrm{d}=\mathrm{S} 141381232005000100016 \&$ script $=$ sci_arttext $>$. Acesso em: 4 de abr. 2009.

CALVETTI, P. U.; MULLER, M. C.; NUNES, M. L. T. Psicologia da saúde e psicologia positiva: perspectivas e desafios. Psicologia Ciência e Profissão, Brasília, v. 27, n. 4, dez. 2007.

FARAH, M. F. S. Gênero e políticas públicas. Revista Estudos Feministas, vol.12, $\mathrm{n}^{\mathrm{o}} .1, \mathrm{p} .47-71,2004$.

FIGUEIREDO, W. Assistência à saúde dos homens: um desafio para os serviços de atenção primária. Ciência \& Saúde Coletiva, Rio de Janeiro, v. 10, n. 1, mar. 2005. Disponível em: <http:// www.scielo.br/scielo.php?script $=$ sci_arttext\&pid $=$ S141381232005000100017\&lng $=$ pt\&nrm $=\overline{\text { iso }}>$. Acesso em: 4 de abr. 2009.

FRAGOSO, H. Projeto de Lei $\mathrm{n}^{\mathrm{o}}$, de 2005, Disponível em: < http:// www.camara.gov.br/sileg/integras/287523.pdf $>$. Acesso em: 4 abr. 2009.

GIFFIN, K. Pobreza, desigualdade e equidade em saúde: considerações a partir de uma perspectiva de gênero transversal. Cadernos de saúde pública, Rio de Janeiro, 18. p.103-112, 2002. Suplemento. 
GIOVANELLA, L.; FLEURY, S. Universalidade da atenção à saúde: acesso como categoria de análise In: EIBENSCHUTZ, C.(org). Política de Saúde: o público e o privado. Rio de Janeiro: FIOCRUZ, p. 177-198, 1996.

GOMES, R et al. As arranhaduras da masculinidade: uma discussão sobre o toque retal como medida de prevenção do câncer prostático. Ciência \& Saúde Coletiva, v.13, nº, nov/dez 2008.

GOMES, R.; NASCIMENTO, E. F do; ARAÚJO, F. C. de. Por que os homens buscam menos os serviços de saúde do que as mulheres [:] as explicações de homens com baixa escolaridade e homens com ensino superior. Caderno de Saúde Pública, Rio de Janeiro, v. 23, n. 3, mar. 2007.

INSTITUTO NACIONAL DE CÂNCER. Síntese de resultados e comentários, 2008. Disponível em: //www.inca.gov.br/estimativa/2008. Acessado em: 06 abr 2009.

JESUS, S. N. de; REZENDE, M. M. Atualidades em psicologia da saúde: colaborações Brasil e Portugal. Mudanças: psicologia da saúde, v.14, n.2, p.121-125, jul/dez. 2006.

KORIN, D. Novas perspectivas de gênero em saúde. Adolescência latino-americana. v.2, n.2, mar. 2001. Disponível em: <http:// raladolec.bvs.br/scielo >. Acesso em: 15 abr. 2009.

LAURENTI, R.; MELLO-JORGE, M. H. P.; GOTLIEB, S. L. D. Perfil epidemiológico da morbi-mortalidade masculina. Ciência \& Saúde Coletiva, Rio de Janeiro, v.10, n.1, mar. 2005. Disponível em: <http://www.scielo.br/scielo.php?script=sci_arttext\&p > . Acesso em: 18 abr. 2009.

LEÃO, E. M; MARINHO, L. F.B. Saúde das mulheres no Brasil: subsídios para as políticas públicas de saúde. Rev. Promoção da Saúde, p.31-36. S/d.

LOVELLE, R. P. La psicología de La salud en Cuba. Revista Electrónica Psicologia Cientifica, 2003. Disponível em: <http:// 
www.psicologiacientifica.com/bv/psicologia-112-1-la-psicologiade-la-salud-en-cuba.html>. Acesso em: 8 maio 2009.

OSIS, M.J.M.D. PAISM: um marco na abordagem da saúde reprodutiva no Brasil. Cad. Saúde Pública, Rio de Janeiro, 14 (supl.1): v25-32, 1998.

PINHEIRO, S. P. et al. Gênero, morbidade, acesso e utilização de serviços de saúde no Brasil. Ciência \& Saúde Coletiva, Rio de Janeiro, v.7, n. 4, 2002. Disponível em: <http://www.scielosp. org/scielo.php?script $=$ sci_arttext\&pid $=$ S1413-8123200200 0400007\&lng=pt\&nrm=iso $>$. Acesso em: 27 mar. 2009.

ROLLEMBERG, R. Projeto de Lei $\mathbf{N}^{\circ}$, 2009, Em tramitação. Disponível em: <http://www.camara.gov.br/sileg/integras/640411. pdf $>$. Acesso em: 4 abr. 2009.

RUTSATZ, S. N. B.; CÂMARA, S. G. O. O psicólogo na saúde pública: trajetórias e percepções na conquista desse espaço. Aletheia, Canoas, n. 23, 2006. Disponível em: <http://scielo. bvs-psi.org.br/scielo.php?script=sci_arttext\&pid $=$ S141303942006000200006> Acesso em: 8 maio 2009.

SCHRAIBER, L. B.; NEMES, M. I. B.; GONÇALVES, R. B. Saúde do adulto: programas e ações na unidade básica. São Paulo: Hucitec, 2000.

SCHRAIBER, L. B.; GOMES, R.; COUTO, M. T. Homens e saúde na pauta da Saúde Coletiva. Ciência \& Saúde Coletiva, Rio de Janeiro, v.10, n. 1, 2005. Disponível em: <http://www.scielo.br/ scielo.php?script $=$ sci_arttext\&pid $=$ S1413-81232005000100002 $>$. Acesso em: 18 abr. 2009.

VILLAR, G. B. Gênero, cuidado e saúde: estudo entre homens usuários da atenção primária em São Paulo. São Paulo, 2007. Dissertação (Mestrado em Medicina Preventiva), Universidade de São Paulo, 2007. Disponível em: <http://www.teses.usp.br/teses/ disponiveis/5/5137/tde-20062007-162247/>. Acesso em: 27 mar. 2009. 
SEgunda Parte

Investigação de temas da Psicologia da Saúde 



\title{
Os sentidos do termo Saúde em discursos de praticantes e não-praticantes de atividades físicas da cidade de Campina Grande/PB
}

\author{
Thelma Maria Grisi Velôso \\ Pedro de Oliveira Filho \\ Halline Iale Barros Henriques \\ Hamana Dáphne Barros Henriques \\ Karoliny Rafaela Sousa de Andrade \\ Marcela Costa Meira \\ Roseane Barros Pinto
}

\section{Introdução}

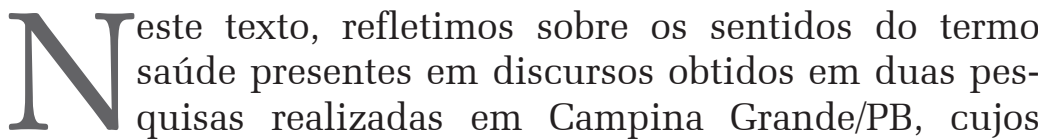
participantes eram idosos, adultos jovens e adultos de meia idade, praticantes e não-praticantes de atividades físicas. 
Fundamentando-nos na área da Psicologia Social, propusemo-nos a estudar a produção de sentidos através da análise das práticas discursivas. O estudo da produção de sentidos baseia-se, como afirma Spink (2003), no construcionismo, uma perspectiva teórica para a qual noções como as de sujeito, objeto e indivíduo, e outras que se apresentam com um caráter de necessidade, são construções sociais, historicamente contingentes. Nessa perspectiva, as práticas discursivas têm um papel fundamental na construção social daquilo que se define como sendo a realidade, na construção de identidades, formas de classificação, valores etc.

A construção de sentidos, tal como entendida aqui, é dialógica, elaborada nas relações intersubjetivas, no cotidiano, por meio de vivências, através das quais as pessoas tentam explicar e dar sentido ao mundo em que vivem. Como mencionam Spink e Medrado (1999, p. 60), "as pessoas descrevem, explicam e/ou compreendem o mundo em que vivem, incluindo elas próprias. [...] $\mathrm{O}$ foco do construcionismo é a interanimação dialógica, situando-se, portanto, no espaço da interpessoalidade, da relação com o outro, esteja ele fisicamente presente ou não”. Sendo assim, os sentidos, mobilizados nas práticas discursivas são fluidos, passíveis de (re)construção e estão sempre em movimento, impregnando o tecido social.

\section{Percurso Metodológico}

Para a geração de dados, utilizamos a metodologia qualitativa da História Oral, mais especificamente, as entrevistas de depoimento oral. Uma característica que nos interessa nesse tipo de depoimento é o "testemunho do entrevistado sobre sua vivência ou participação em determinadas situações ou instituições que se quer estudar" (LANG; CAMPOS; DEMARTINI, 2001, p. 12). 
Obtivemos 38 (trinta e oito) depoimentos orais: 24 (vinte e quatro) de adultos jovens e de meia-idade - 12 (doze) mulheres e 12 (doze) homens - e 14 (quatorze) orais de idosos - (05) cinco homens e 09 (nove mulheres).

A faixa etária dos adultos jovens e de meia-idade variou entre 22 e 55 anos - doze praticantes de atividades físicas e doze não-praticantes. Já a faixa etária dos idosos variou entre 62 e 88 anos - sete praticantes de atividades físicas e sete não-praticantes.

Os praticantes de atividades físicas foram abordados, de acordo com o critério de acessibilidade, em uma academia de ginástica da cidade de Campina Grande/PB. Com a intermediação desses sujeitos, conseguimos entrar em contato com os que não estavam praticando atividade física. Os depoimentos foram gravados em MP4, com a devida autorização dos entrevistados. Para garantir o anonimato dos participantes, empregamos pseudônimos.

O número de entrevistados foi delimitado de acordo com o critério do ponto de saturação. "A análise, na medida em que acompanha todo o processo de pesquisa, é condição necessária para que se possa determinar o momento em que o ponto de saturação (BERTAUX, 1980) é atingido, indicando que já se dispõe de informações suficientes sobre determinado aspecto" (LANG; CAMPOS; DEMARTINI, 2001, p. 13). Portanto, quando nos deparamos, na análise, com um conteúdo repetitivo, que já dava conta dos objetivos da pesquisa, encerramos o trabalho de campo.

Durante a realização das entrevistas, solicitávamos ao entrevistado um depoimento sobre o tema da saúde. Perguntas eram formuladas à medida que íam surgindo dúvidas ou necessidades de maiores esclarecimentos.

As observações feitas durante as entrevistas foram registradas em um diário de campo que, segundo Souza (2000, p. 1), tem por "função revelar a trajetória da pesquisa, os 
caminhos trilhados na tentativa de apreensão do objeto-tema investigado. Desde que se suponha a pesquisa como coisa viva e o diário como elemento dinâmico da pesquisa viva, é necessário pensar a investigação como uma trilha não traçada, como um caminho a se construir”. Tais observações serviram para subsidiar as análises.

Depois de gravadas, as entrevistas foram transcritas e submetidas à análise de discurso, seguindo a orientação teórico-metodológica da Psicologia Social Discursiva, perspectiva teórica que vem sendo elaborada, nas últimas duas décadas, por um conjunto de autores da Psicologia Social inglesa (BILLIG, 1985, 1987, 1991; POTTER; WETHERELL, 1987; POTTER et al., 1990; POTTER, 1996; WETHERELL; POTTER, 1992).

Nessa perspectiva, os discursos são vistos, fundamentalmente, como formas de ação social com as mais variadas consequências. O objetivo principal é descrever e analisar a construção discursiva de sujeitos, identidades e grupos sociais. Segundo Gill (2003), os analistas de discurso que se fundamentam na Psicologia Social Discursiva estão interessados no discurso em si mesmo. O discurso, nessa perspectiva, é abordado como o tópico de interesse, e não, como um meio de se chegar a alguma realidade subjacente. É concebido como uma prática social, como uma forma de ação, e o sentido é dependente do contexto de uso (WETHERELL; POTTER, 1992).

Nessa abordagem, o modo como o discurso é organizado para nos convencer da veracidade de determinadas versões da realidade é um dos tópicos de maior interesse. Em outras palavras, há uma atenção especial à organização retórica do discurso. Como consequência, procura-se focalizar o modo pelo qual determinadas argumentações procuram desacreditar uma ou mais argumentações alternativas, argumentações ou versões frequentemente não citadas diretamente, implícitas (WETHERELL; POTTER, 1992). 


\section{Os sentidos do termo saúde}

No material discursivo obtido nas duas pesquisas, o termo saúde apresenta-se como marcadamente polissêmico. Um dos sentidos recorrentemente produzidos é aquele no qual a saúde aparece como o elemento central na vida das pessoas, fator fundamental para a felicidade, para uma vida digna, como expressam estas falas:

(...) a saúde é tudo, você pode viver num palácio, cercado de todo o conforto material, mas se não tiver saúde, nada vai adiantar pra você (...) Então com saúde, você pode ser um agricultor, pode ser da classe menos favorecida, mas você tem saúde, você está feliz! Na felicidade existe a saúde, e no desânimo existe a doença. Então a felicidade vem muito da saúde. (...) É! A felicidade, né? é saúde! (...) E vida com saúde, onde a qualidade de vida tem que ser com saúde. Sem saúde não há qualidade de vida (Regina, 72 anos, praticante de atividade física).

Saúde é tudo! Tudo, o que a pessoa deve conservar durante a vida, né? Porque sem a saúde você não é nada! (...) a partir do momento em que você começa a uma etapa assim da vida, que é a partir dos vinte anos, por exemplo, que hoje eu já tenho quarenta, você tem que se cuidar em dobro, para poder você ter uma vida maior e melhor (...) Ser saudável é você se alimentar bem... é não fumar... não beber (...) E assim viver bem é realmente você se alimentar bem e procurar fazer as coisas certas, dormir melhor, comer melhor, para poder ter, uma resposta, assim... ter uma resposta de vida lá na 
frente, porque tudo é só acumulativo, né? A vida, o que você faz hoje reflete amanhã. Se você não se cuidar, não se alimentar, não fazer exercício, que é uma prioridade, é porque assim tem três coisas que você deve fazer: tomar muita água (...) fazer exercício físico, e assim não é obrigado você ter dinheiro pra fazer exercício físico, você pode fazer de qualquer jeito, uma caminhada, por exemplo, é um exercício. E... Se proteger do sol, pronto, pra mim isso aí é o básico (Lúcia, 40 anos, praticante de atividade física).

Nas duas falas, as expressões “a saúde é tudo!”, “sem a saúde você não é nada!", na fala de Lúcia, ou "então a felicidade vem muito da doença”, “a felicidade, né?, é saúde”, na fala de Regina, posicionam a saúde em um lugar central, na identidade do homem contemporâneo, e como algo a ser adorado, perseguido fervorosamente, como produtora e sinônimo de felicidade.

Segundo Nogueira (2001), na modernidade tardia, a concepção hegemônica do termo saúde, veiculado e legitimado pela mídia, tem como objetivo principal evitar associá-lo com outros que façam referência à morte, ao envelhecimento e à dor. Essa postura requer que se pense a saúde como sinônimo de juventude, a doença, como sinônimo de "velhice" e termina por produzir uma sobrevalorização da saúde, na medida em que a juventude é sobrevalorizada na modernidade tardia.

É interessante observar, também, no discurso de Lúcia, o uso do vocábulo "acumulativo" para falar das atividades e dos cuidados que garantirão uma vida longa e saudável. Da mesma forma que se planeja um futuro financeiramente estável, acumulando dinheiro, pode-se planejar um futuro sem 
doenças, desde que a saúde seja acumulada ao longo do ciclo vital. Esse discurso ascético, que recomenda que os prazeres perigosos sejam evitados, agora, para que sejam obtidos ganhos em termos de saúde no futuro, ilustra bem aquilo que Giddens (2002) chama de "colonização do futuro".

Tanto na fala de Lúcia, acima, quanto nas citadas abaixo (as que, como as duas primeiras, posicionam a saúde num lugar central na vida humana) são apresentadas diferentes práticas que devem ser realizadas cotidianamente no presente de modo a garantir um futuro pleno de saúde:

É saúde é... eu acho que é que a gente tem de melhor na vida da gente, por que, sem saúde, praticamente não somos nada, nós não podemos fazer nada na nossa vida, não é isso? (...) É, sem saúde, a saúde é... é fundamental pra todos, agora nem todos têm condições de ter uma saúde perfeita, entendeu? (...) É, porque a pessoa precisa de uma ginástica, precisa de uma caminhada, precisa de... Como é que se diz? ... é de uma boa alimentação, como é que você vai ter uma boa saúde? Não tem como, né? (Ana, 55 anos, praticante de atividade física).

Pra mim, eu acho que saúde é tudo, né? É essencial na vida da gente, a gente ter saúde, né? E atualmente eu não venho praticando assim muito esporte, fazendo qualquer atividade física, mas em decorrer ao meu tempo, que eu não tenho, mas futuramente eu pretendo praticar um esporte, porque é essencial pra sua saúde (...) Importante, muito importante, porque ela é tudo, né? Leva a gente a trabalhar (...) porque sem saúde não é nada. (...) Acho que saúde pra mim saúde 
é tudo, e a gente cuidar do corpo é saúde, e cuidar do corpo também vai cuidar da mente, vai cuidar de tudo, né? Então envolve tudo, acho que é importante a gente cuidar do corpo e da saúde, e você cuidando da saúde consequentemente o corpo vai aderir. (Mário, 23 anos, nãopraticante de atividade física).

Eu acredito que é um meio melhor de se viver, é um modo de você conseguir passar um tempo maior, né? Em vida, na terra, é praticando esportes, fazendo seus exames periodicamente, é você tá ajudando a fazer sua saúde melhor a cada dia (...) É... um bem-estar, um bem-estar da pessoa, é... e o interesse de melhorar aquele bem-estar a cada dia. (...) se você não tem uma boa saúde, não tem uma boa alimentação, alguma coisa que mantenha sua saúde em ordem, com certeza isso vai é prejudicar no seu trabalho, por motivos da saúde, por problemas, você vai é manter irritada, porque qualquer problema de saúde que nós temos é... reflete muito no lado emocional da gente também, né? E assim não vai contribuir, então só piorar a cada dia, né? (Paula, 29 anos, não-praticante de atividade física).

Para mim a saúde, como para, para todas as pessoas deve ser um conceito, é... (pausa) básico universal! A saúde é uma terminologia que define o equilíbrio das coisas, quer dizer, pode ser a saúde do corpo, a saúde da mente, pode ser a saúde financeira isso (pausa) mal aplicada, mas o correto mesmo definido da saúde generalizado é um termo convencional de saúde. (...) Agora, com relação à saúde 
mesmo, falando de saúde, o conceito da saúde está no alimento! E na qualidade de vida! (...) Então são muitas coisas para a pessoa comentar com relação à saúde, né? (...) Saúde é uma coisa muito importante, tanto quanto o financeiro, né? (pausa) Nós estamos sujeitos a nossa reação genética, né? (...) Mas, generalizando, de modo geral, a saúde é a principal fonte de alegria que nós temos, né? A pessoa estando com saúde, está bem, mesmo que esteja com problema, mas ele está, tem uma conta como ponto positivo que é a força que ele tem. Porque... Uma pessoa doente, quer dizer, é desequilibrada! Porque a doença não existe, existe desequilíbrio! (Antônio, 77 anos, não-praticante de atividade física).

A influência da atividade física para mim, a gente em televisão vê tanto os médicos recomendarem, recomendarem... e aí... (...) E eu me conscientizei que eu realmente deveria fazer mais, não só andar! (Kátia, 72 anos, praticante de atividade física).

Não, saúde basicamente é um tesouro que você tem, depende daquilo que você faz, que você procura fazer no seu dia-adia, pra continuar sobrevivendo, né? Não existe vida sem saúde, né? É uma coisa tão inerente quanto o ato de respirar, né? De se alimentar, então eu considero que são três fundamentos básicos à vida humana que é: poder respirar, poder se alimentar, é cuidar da saúde para ir fazendo outras coisas que vêm, né? Mais como consequência desses três pontos (...) se bem que pensando melhor a saúde 
de... ela é mais ampla (...) ela engloba né? A respiração e a alimentação, por que você se alimentando bem, você respira bem, você tem a possibilidade de ter uma estrutura cardiovascular boa, (...) decorrente de uma alimentação sadia, você tem um corpo mais disposto as atividades que porventura você venha a fazer, né? (...) Então a saúde ela é como se fosse a gasolina pra mover o carro, né? Então se há gasolina ela ativa o carro pra que o carro ande. A saúde é tudo aquilo que decorre do que é feito pra se ter saúde, é uma consequência que leva o ser humano a poder pensar, a poder escolher, a poder agir (Ricardo, 40 anos, praticante de atividade física).

Ana, para quem "sem saúde praticamente não somos nada”, enfatiza a impossibilidade de se ter uma "saúde perfeita“, sem atividade física e sem uma boa alimentação. Mário também posiciona a saúde em um lugar central para a vida humana. Para ele, a saúde é "tudo". Embora reconheça que não está praticando exercícios físicos no momento, afirma que a atividade física é "essencial” não só para a saúde física. Ele afirma que quem cuida do corpo “também vai cuidar da mente”. Paula cita os exercícios físicos, a qualidade da alimentação e os exames periódicos como condições indispensáveis para a saúde. Em seu discurso, ecoa a concepção de saúde da Organização Mundial da Saúde (OMS) - a saúde como "completo estado de bem-estar físico, mental e social”.

Na fala de Antônio, a saúde é apresentada como consequência de uma boa alimentação e da qualidade de vida e definida como equilíbrio. Para esse não-praticante de atividade física, a saúde adquire o caráter de equilíbrio, em oposição à doença, que é desequilíbrio. "A doença não existe, 
existe desequilíbrio!”, e o equilíbrio é favorecido por meio da alimentação e da qualidade de vida.

Kátia posiciona o discurso médico, nesse caso veiculado pela mídia, como legítimo e autorizado. O emprego do vocábulo "conscientização" apresenta a autora da fala como alguém que era resistente ou mesmo cega, até certo momento de sua vida, mas que, lentamente, vai cedendo às prescrições médicas e termina por aceitar a verdade trazida por esses profissionais: "em televisão vê tanto os médicos recomendarem, recomendarem... e aí... (...) E eu me conscientizei que eu realmente deveria fazer mais" O discurso de Kátia não pode ser compreendido sem que o coloquemos no quadro explicativo das análises foucaultianas, nas quais o saber médico é descrito como um saber que invade os espaços individuais e sociais, passando a regular os sujeitos e impulsionando-os a procurar modos saudáveis de viver (FOUCAULT, 1979).

Ricardo usa o termo "tesouro" como metáfora para a saúde. Em outra metáfora, a saúde é apresentada como a "gasolina" que move o "carro". Esse "tesouro" "depende daquilo que você faz, que você procura fazer no seu dia-a-dia". Aqui, a saúde é concebida como resultado de uma luta cotidiana, incansável. Nessa perspectiva, se a saúde é aquilo que move o carro, e se o movimento é um dos principais atributos da vida, então não pode haver "vida sem saúde" e sem atividade física. Porém, nesse discurso, não só o movimento decorre da saúde, mas também as qualidades mais características da vida humana. O pensamento, a capacidade de decisão e a ação aparecem como decorrências da saúde. Esse discurso defende, com uma retórica persuasiva, a necessidade de se ter uma preocupação obsessiva com a saúde.

Diferentemente dos discursos anteriores, o discurso de Graça, abaixo, apresenta o cuidado com a alimentação não como algo que dificultará o aparecimento de doenças no futuro, mas que evita agora, no presente, o agravamento de doenças já existentes: 
PESQUISADORA: Aí como é que a senhora vê isso na vida da senhora assim, essa saúde... de hoje, na vida da senhora?

Ah... tá muito melhor! (...) Muito melhor! (...) Só que eu não posso engordar, né? Que eu tenho problema de saúde e nas pernas né? ... aí...

PESQUISADORA: A senhora tem problema de quê?

Coração! Coração, rins...

PESQUISADORA: Aí tem que tá fazendo a... mantendo o peso...

É, o peso! Mas, eu tô relaxada! (...) Tem que controlar é tudo, é chocolate, comida, tudo! Por que do jeito que vai num dá não! (Graça, 68 anos, não praticante de atividade física).

Seu discurso denota uma tensão que se apresenta de maneira implícita nos discursos anteriores. A tensão entre a tendência para relaxar e o controle que deve ser exercido sobre o corpo para mantê-lo saudável agora e no futuro.

Em todas as falas analisadas aqui, encontram-se elementos do moderno discurso sobre a saúde, a preocupação obsessiva com as atividades físicas e com a alimentação, a legitimação e a reprodução dos preceitos do discurso médico, o cuidado com o corpo etc. Alguns entrevistados, por exemplo, apresentam claramente concepções de saúde muito próximas das modernas concepções de saúde, que vão muito além da mera preocupação com o bem-estar físico. Mas, nessas falas, também podem ser encontrados elementos de discursos mais tradicionais. 
Assim, em outros sujeitos, o conceito de saúde apareceu com o sentido de ausência de doença. Isso significa que, em alguns discursos, não encontramos conceitos positivos de saúde (ALMEIDA FILHO e JUCÁ, 2002), posto que esse termo aparece como ausência daquilo que a nega:

Mas, é... Quer dizer se você fala sobre saúde é necessário, porque quando vem o declínio da idade, vem também faltando a saúde. (...) Todas as idades há... falta de saúde, né? Há doença. Mas, logicamente a terceira idade é onde tem mais (Regina, 72 anos, praticante de atividade física).

Saúde é assim... a gente depende muito hoje em dia, depende muito da saúde e pra ter uma boa saúde tem que ter uma boa alimentação e pelo menos praticar... (...) antes de praticar um exercício físico pra melhorar sua saúde, você tem que procurar um especialista, um professor alguém que lhe indique o caminho certo pra você não tá fazendo alguma coisa exagerada, alguma coisa que seu corpo não vai aguentar (...) a minha saúde mesmo... pra eu morrer vai demorar muito se for de velhice ou de alguma doença, porque eu faço muito exercício físico (...) Sinceramente a saúde é um ponto básico hoje em dia pra se viver mais, que tem pessoas que vai no centro come uma besteirinha, uma coxinha, um pastel... E passa a ficar mais gorda, a se sentir mal (..) isso só faz ser prejudicial a saúde, porque se não tiver uma alimentação controlada ela vai ter problemas, tipo nos órgãos internos (pausa), assim a gente tem que ter atividade constante pra... (...) é só assistir alguns programas educativos 
(..) e assim vai ter uma vida saudável com esporte e alimentação (Lucas, 22 anos, praticante de atividade física).

É tudo para mim (pausa) sem a saúde, o caba não consegue fazer nada, tá doente, essas coisas, (...) para mim é... não pega doença fácil assim, fica arriado em cama (...) tipo a saúde assim: quem é doente mesmo, (...) bem dizer tá morto (...) tem que haver primeiro a saúde segundo vem o corpo. (Felipe, 25 anos, não praticante de atividade física).

Eu acho que a saúde, assim, pra mim assim, é uma pessoa saudável, certo? (...) que chega numa certa idade precisa tá tomando remédio é, não tá aquela, assim, não ter uma saúde, né? (...) a saúde não... lógico, a saúde é uma coisa e a doença é outra, né? (...) É isso (pausa). É porque a saúde pra mim é uma pessoa saudável, né isso? (...) Na saúde, porque assim, eu acho que principalmente praticar esporte é... se você ficar parado você vai adoecer, não vai? (...) tem também a alimentação também, né? Se você exagera também, né? (...) lógico que vai prejudicar seu corpo né? na saúde (...) Ter uma alimentação saudável, acho que futuramente é, vai ter assim, saúde, né? (Vanessa, 42 anos, não praticante de atividade física).

Saúde pra mim é... você estar de bem, assim, no caso, é você fazer uma prevenção antes pra que não chegue a adoecer, né? (...) É você deixar de ficar doente para procurar um esporte, procurar uma boa alimentação o melhor é prevenir, o melhor é a prevenção 
(enfático) (...) a maioria come tudo o que vê pela frente, então são pessoas que não se cuida, então se elas não tem uma qualidade de vida, essa pessoa vai ficar doente (...) por que eu sou uma pessoa que até hoje nunca senti nada... Por que? Eu corro todos os dias (...) procuro me alimentar direito, não comer muita carne vermelha, e ainda tem as revistas (...) o esporte é como um medicamento (...) aconselho que as pessoas que realmente pratiquem esporte. (...) por que não é farmácia que vai dar saúde.... esporte é um medicamento! (...) A melhor bula (ênfase), que não paga nada!! (...) E hoje você ver, você liga uma televisão e o que é que diz? Musculação, academia, não seja sedentário... (...) o que é prevenção? E fazer uma dieta equilibrada, e pra não ficar sedentário, por que a prática de esporte evita diabetes, depressão, evita câncer, evita tudo (ênfase) (...) tenho a assinatura da Boa Forma (ênfase), eu ainda faço a musculação, por isso (ênfase) que eu tenho essa idade e não sinto nada, cada dia eu me sinto mais disposta. (Andréia, 50 anos, praticante de atividade física).

Regina vai direto ao ponto: “todas as idades há... falta de saúde, né? Há doença”. Já na fala de Lucas, um conceito tácito de saúde como ausência de doença pode ser inferido de passagens como a seguinte: "a saúde é um ponto básico hoje em dia pra se viver mais” (ou seja, não ficar doente é essencial para a longevidade). Ele sublinha que, para adquirir uma boa saúde, as pessoas precisam se alimentar bem e praticar uma atividade física, que deve ser orientada por especialistas. 
O “especialista” é aquele que controla, apoia e dá suporte para uma prática de controle corporal e alimentar que contribui para a longevidade. Os recursos midiáticos ocupam também lugar de destaque, pois, como menciona Lucas, "é só assistir alguns programas educativos (...) e assim vai ter uma vida saudável com esporte e alimentação". Essa opinião também está presente em outros depoimentos.

O discurso de Felipe, por sua vez, é mais explícito. Ele refere que, “(...) sem a saúde, o caba não consegue fazer nada, tá doente (...)".

De acordo com as modernas concepções de saúde, não seria absurdo encontrarmos um discurso que afirmasse que alguém pode ter uma doença física e ainda assim, "vender saúde" pelo fato de viver em ótimas condições sociais, ter alta autoestima etc. Mas, segundo concepções mais tradicionais, isso seria absurdo. Ao afirmar que "a saúde é uma coisa, e a doença é outra", por exemplo, Vanessa torna as duas coisas mutuamente excludentes. Nessa fala, a boa alimentação e a prática de esportes afastam a doença e mantêm a saúde.

Andréia também concebe a saúde como ausência de doença: "Saúde, pra mim, é... você estar de bem, assim, no caso, é você fazer uma prevenção antes pra que não chegue a adoecer, né?”. Ao destacar o papel da prevenção na manutenção de um estado de saúde, ela faz uma analogia entre a prática de esportes e os medicamentos: "o esporte é um medicamento", um medicamento que "evita tudo". Para justificar as suas afirmações, para torná-las mais convincentes e legítimas para o interlocutor, a entrevistada mobiliza duas fontes de autoridade na sociedade moderna: os dados empíricos (suas próprias condições de saúde comprovariam o que ela está dizendo) e o discurso de especialistas veiculados pela mídia. 
No discurso que segue, no entanto, a saúde é relacionada ao bem-estar corporal e mental (psicológico) e não, simplesmente, concebida como ausência de doença:

Saúde a gente pensa assim, um corpo saudável, uma mente saudável, um hábito saudável, é tudo aquilo que, é assim, numa visão bem restrita, é aquilo que não provoca a doença (...) Mas pelo contrário, a saúde deve ser vista como aquilo que provoca bem-estar, não doença, bem-estar, seja ele corporal, seja ele mental, questão psicológica, é o que provoca o bem-estar, é a homeostase, tanto do corpo quanto da mente (...) Exatamente, mas voltado para o bem- estar, do que a questão de não provocar a doença, porque você pode muito bem não estar doente, mas mesmo assim, não estar num estado de bem-estar, né? Se você considerar saúde só porque você não estar doente, e pelo contrário o certo é você imaginar a saúde como um bem-estar, melhor (ênfase) do que aquela neutralidade, porque você simplesmente não adoecer. (Carla, 27 anos, não praticante de atividade física).

Nogueira (2001, p. 66-67), quando aponta as mudanças sofridas pelo conceito de saúde nos últimos três séculos, assinala que, no século XVIII, a saúde era concebida de forma negativa, como ausência de doença; já no século XIX, caracteriza-se como um estado de bem-estar, garantido por um conjunto de serviços de alcance coletivo. No século XX, esse conceito se amplia, e a saúde passa a ser entendida "como um completo estado de bem-estar físico, mental e social, que se pretende poder ser estendido a todas as pessoas como direito de cidadania”. O discurso de Carla, acima, reproduz essa concepção de saúde, veiculado pela OMS 
(Organização Mundial de Saúde), como bem-estar físico e mental. A entrevistada repudia, inclusive, a concepção de saúde como ausência de doença: "Exatamente, mais voltado para o bem-estar do que a questão de não provocar a doença, porque você pode muito bem não estar doente, mas, mesmo assim, não estar num estado de bem-estar, né?"

O discurso de Sara, a seguir, também reitera essa concepção de saúde como estado de bem-estar:

É, saúde, antes de mais nada, é o maior bem que nós temos, porque tá ligado diretamente a vida, né? Então cuidando da saúde estamos cuidando de nós mesmos, nos respeitando para que assim possamos viver com dignidade. (...) Isso, saúde, dignidade, é... são conceitos que acabam se relacionando pra o próprio bem-estar da pessoa. (...) É, primeiro por que a saúde ela é uma soma de fatores, ela não é apenas a ausência de doença, mas um completo bem-estar físico e mental, então é haver essa união, tanto corpo e mente pra que haja enfim qualidade de vida, essa qualidade de vida é como se fosse... é um direito de todas as pessoas que deve fazer por si só com que esse direito seja é... acontecido, que ele seja respeitado (..) (Sara, 32 anos, praticante de atividade física).

Saúde significa "completo estado de bem-estar físico e mental" e "dignidade". O discurso de Sara, além de reiterar a concepção de saúde veiculada pela OMS, enaltece uma preocupação com a promoção da saúde coletiva. Para ela, a saúde é "uma soma de fatores" e "um direito de todas as pessoas", ou seja, um bem coletivo. 
Caio endossa a ideia de saúde como bem-estar físico, psicológico e social, no entanto critica a forma como isso é alcançado:

Se for falar de uma forma abrangente, o que a gente quer entender sobre saúde é a questão de bem-estar, é como diz a UNESCO: é uma questão de saúde, bem-estar psicológico (ênfase), físico, social... E nesse ponto saúde pra mim é a interação de tudo isso, tá bem com você fisicamente, mentalmente pra que você possa agir de uma forma bem equilibrada (ênfase) (...) se você for levar ao pé da letra quando se fala de esporte competitivo, esporte profissional não é saúde! (ênfase). (...) Porque na verdade é... sempre você trabalha no limite, te cobra sempre o máximo, e esse máximo nem sempre é benéfico pro seu corpo. Então, o que pra mim envolver saúde é você ter prazer (ênfase) de fazer, você se sentir bem com você, se olhar no espelho e acordar bem, se sentir bem, usufruir desse resultados do exercício ao longo de toda uma vida, não é ter esse resultado imediato que muitas pessoas se cobram e pra mim saúde vai muito mais além do que isso que a gente vê, na... na mídia, nas revistas, e a cobrança em si geral, saúde é questão de bem-estar: cabeça e corpo. (Caio, 33 anos, praticante de atividade física).

Assim, Caio vincula, no seu discurso, a saúde ao prazer, diferenciando a busca pelo "prazer saudável” da busca pelo "prazer estético e competitivo". 
Como podemos observar, e cabe aqui sublinhar, a atividade física é ressaltada por grande parte dos entrevistados. Em alguns momentos, ela é descrita como uma atividade que participa não somente da construção do corpo, mas da construção do próprio "eu". A atividade física é entendida como uma prática que melhora a mente e que "preenche" a subjetividade, o "eu" dos sujeitos, com conteúdos adequados, e preenche espaços que poderiam ser ocupados pelo desejo de coisas supérfluas. Assim,

(...) quando você não malha, não pratica esporte, você vai para o shopping comprar roupa por achar que vai se sentir mais bonita, e você vê que praticar esporte preenche tanta coisa em você que você supera até o supérfluo... (...) Se você não entrar nessa vai adoecer e morrer antes do tempo! Ou você acorda (...). Pode falar com quem não faz esporte, é tomando remédio, encolhida, pode até fazer plástica, mas é vazia, é, o esporte melhora a mente (...) Você vem para academia e não encontra pessoas doente, encontra? Só malhando, e querendo ficar bem através do esporte e não através de um bisturi, de uma roupa bonita, aí... adquire uma qualidade de vida e só a melhorar (Andréia, 50 anos, praticante de atividade física).

No discurso de Andréia, a atividade física promove uma qualidade de vida melhor e ainda proporciona uma vida mais longa, pois, segundo o seu ponto de vista, "se você não entrar nessa... vai adoecer e morrer antes do tempo!”. Ressalta-se, mais uma vez, a preocupação com a longevidade.

A opção pela prática da atividade física é associada também ao bem-estar físico e mental, visto que o exercício serve para "curar" a doença: 
Eu já entrei aqui por que eu já tinha problemas de saúde, entendeu? E graças a Deus eu me recuperei. (...) tinha duas lesões no joelho, constatada pelo médico (...) e graças a Deus eu melhorei. Melhorei não, me sinto curada (ênfase) realmente, através dos exercícios. (Ana, 55 anos, praticante de atividade física).

Há quem afirme, inclusive, que optou pela prática de atividade física porque ela proporciona bem-estar e sensualidade:

Entrevistadora: Que influência você teve para a prática de atividade física?

O meu bem-estar, a minha sensualidade também, meu bem-estar também. (Bruno, 26 anos, praticante de atividade física).

A atividade física, então, assume um papel primordial nessa busca por uma vida saudável, como demonstram os seguintes depoimentos:

(...) Porque pra evitar doenças, evitar Osteoporose, evitar é... (pausa) Artrite, né? Essas coisas todas, porque essa é que é a minha finalidade! E principalmente a Osteoporose! (...) E por questão também por causa da minha idade, eu não posso parar. (Kátia, 72 anos, praticante de atividade física).

(...) É! É muito importante... a gente fazer atividade física né? pra a saúde da gente, e também pra a gente ter cuidado com a nossa é... quem tá no... idoso, né? (...) É! Nem deve beber, nem deve fumar, que eu também não faço isso, mas as pessoas que fazem se prejudicam muito, né? [...] a 
partir de vinte e quatro anos que eu fiquei hipertensa, mas controlo, tomo remédio todo dia, caminho, faço caminhada que é muito importante também pra saúde da gente, né? Num é nem por conta da idade, mas é por que, de qualquer maneira, a caminhada é muito importante, né? Evito também de comer sal, e tem a alimentação assim, num como carne, por que eu não gosto também, num é por conta da saúde, mas influi muito na saúde, né? (...) É uma opção minha! Mas é bom por que também influencia na nossa saúde, né? (...) Bom, aí foi por que eu fiquei hipertensa muito nova e já fui me habituando, né? comida salgada de jeito nenhum! Me habituando e a gente vê também a fama que... através da, de... médicos, né? que a gente vai constantemente pra os médicos, faz aqueles exames periódicos e também da mídia que a gente lê também muito, né? (...) a gente que trabalha na comunidade assim, a gente tem que dar exemplos, é... um... um...assim, pra a gente passar o da gente que é muito importante e para as pessoas também que trabalham conosco, né? que também já tem que dar o exemplo assim, saber... é... passar pra as pessoas que a gente comendo muito sal num é, de maneira nenhuma, é bom pra ninguém, né? o sal prejudica muito! (Sônia, 63 anos, praticante de atividade física).

Nos discursos acima, destaca-se a importância da atividade física para se viver de forma saudável, como afirma Kátia: "não posso parar”. Sônia, por sua vez, refere-se a outros mecanismos que promovem a aquisição da saúde: não beber, não fumar, não comer muito sal. 
A prática de atividade física garante, como afirma Pedro, "andar mais pra frente":

Aí eu procurei esse sistema de vida pra vê se eu ando mais pra frente, sabe? (...) Então, você... você fazendo uma previsão da sua saúde, você... Eu acho que prolonga mais sua vida. (Pedro, 73 anos, praticante de atividade física)

Em alguns depoimentos, a atividade física aparece também como fator que contribui para elevar a autoestima dos sujeitos:

PESQUISADORA: E como é que a senhora se sente fazendo atividade física?

Me sinto bem demais! Me sinto lá em cima! (Mércia, 69 anos, praticante de atividade física)

Assim, os benefícios da atividade física para a saúde são ressaltados até mesmo por aqueles que não a praticam, como já tivemos oportunidade de ressaltar, o que é também sublinhado nos discursos a seguir:

Bom, é atéinteressante, porque eu acredito que eu tenho até uma grande consciência (...) dos cuidados que tem que ter com o corpo, eu sei o que é correto eu sei o que meu corpo é, sinaliza como correto, que seria a questão da boa alimentação, da prática de exercícios físicos, e mesmo assim eu não desenvolvo muito esses hábitos saudáveis, eu me considero uma pessoa sedentária, a alimentação pra mim é bem complicada porque eu não sou aberta a todo tipo de alimentação (...) e até pela questão de... do momento que eu tô vivenciando agora, sou estudante 
universitária, então eu não moro com meus pais, eu sou de outra cidade (...) o tempo pra mim é bem corrido (...) então assim a prática da atividade física é mais difícil (...) nem sempre é possível, pra desenvolver hábitos saudáveis, a gente tem a consciência, mais às vezes a atitude fica um pouco aquém da situação (Carla, 27 anos, não-praticante de atividade física).

(...) se eu não me preocupar com a saúde, automaticamente vai refletir no corpo, se eu não pratico esportes, a tendência é eu ter problemas futuramente (...) as pessoas deveriam praticar mais esportes que é a parte física, né? do corpo, pra manter ele saudável, manter ele bem, e sempre fazer exames (ênfase), pra saber como anda sua saúde.(...) Pra assim equilibrar tanto saúde e corpo bem, porque se os dois não andarem bem, com certeza um lado vai enfraquecer o outro. (Paula, 29 anos, nãopraticante de atividade física).

A relação corpo/saúde/atividade física é ressaltada nesses discursos. A ideia veiculada é aquela que sublinha Paula: “(...) se eu não me preocupar com a saúde, automaticamente vai refletir no corpo, se eu não pratico esportes, a tendência é eu ter problemas futuramente".

\section{Considerações finais}

A análise e a discussão das entrevistas realizadas evidenciam que os sentidos atribuídos à saúde, tanto por adultos jovens e de meia idade quanto por idosos praticantes e nãopraticantes de atividade físicas se aproximam em vários aspectos. 
O termo saúde é recorrentemente seguido de expressões como "fundamental", "é tudo", "primordial", o que denota sua sobrevalorização. Para ser saudável, é preciso se submeter a uma disciplina rígida, priorizando uma boa alimentação e a prática de exercícios físicos, pois é através desses cuidados que se consegue a longevidade.

Os entrevistados tendem também a conceber a saúde como sinônimo de ausência de doença, ainda que alguns a definam como bem-estar físico e mental, ampliando ainda essa concepção para um bem coletivo, concebendo-a, então, como saúde coletiva. A saúde também é relacionada à busca do prazer, um "prazer saudável", que deve ser diferenciado do "prazer estético e competitivo".

Portanto, esses são discursos que estão em consonância com a concepção contemporânea sobre saúde veiculada pela mídia e pelo discurso médico. O discurso médico, por sua vez, dá suporte aos sentidos produzidos sobre saúde por nossos sujeitos e os legitima.

\section{Referências}

ALMEIDA FILHO, N; JUCÁ, V. Saúde como ausência de doença: crítica à teoria funcionalista de Christopher Boorse. Ciência \& Saúde Coletiva, 7 v., n.4, p. 879-889, 2002.

ANDRADE, K. R. S. et al A concepção de saúde em discursos de adultos jovens e de meia idade. Relatório final. Campina Grande: PIBIC/CNPq/UEPB, 2008.

BILLIG, M. Prejudice, categorization, and particularization: from a perceptual to a rhetorical approach. European journal of Social Psychology,15, p. 79-103, 1985.

. Arguing and thinking: a rhetorical approach to social psychology. Cambridge: University Press, 1987. 
. Ideology and opinions. London: Sage Publications, 1991.

FOUCAULT, M. Microfísica do Poder. Org. e trad. de Roberto Rocha. 13. ed. Rio de Janeiro: Edições Graal, 1979.

GIDDENS, A. Modernidade e identidade. Rio de Janeiro: Jorge Zahar Editor, 2002.

GILL, R. Análise de discurso. In: BAUER, N; GASKELL, G. (Orgs.) Pesquisa qualitativa com texto, imagem e som: um manual prático. Trad. de Pedrinho A. Guareschi. 2. ed. Petrópolis: Vozes, 2003. p. 244-269.

HENRIQUES H.I.B. et al A saúde em discursos de idosos: um estudo sobre produção de sentidos. Relatório final. Campina Grande: PIBIC/CNPq/UEPB, 2007.

LANG, A. B. S. G.; CAMPOS, M. C. S. S.; DEMARTINI, Z.B.S. História oral e pesquisa sociológica: a experiência do CERU. 29. ed. São Paulo: Humanitas, 2001.

NOGUEIRA, R. P. Higiomania: A obsessão com a saúde na sociedade contemporânea. In: VASCONCELOS, E. (Org.). A saúde nas palavras e nos gestos. São Paulo: Hucitec, 2001. p. 63-72.

POTTER, J. Attitudes, social representations and discursive psychology. In: WETHERELL, M. Identities, groups and social issues. London: Sage Publications, 1996. p.119-173.

POTTER, J.; WETHERELL, M. Discourse and social psychology: beyond attitudes and behavior. London: Sage Publications, 1987.

POTTER, J. et al. Discourse: noun, verb or social practice?

Philosophical Psychology., 3 v., n. 2., 1990. p. 205-217.

SOUZA, S. S. Memória, cotidianidade e implicações: construindo o diário de itinerância na pesquisa, 2000. Disponível em <http//www.csa.ufrn.br/anais/IX_seminario/dados/gt_42/ com_42_01doc>. Acesso em 05 de julho de 2009. 
SPINK, M. J. P. ; MEDRADO, B. Produção de sentidos no cotidiano: uma abordagem teórico-metodológica para análise das práticas discursivas. In: SPINK, M. J. P. (Orgs.) Práticas discursivas e produção de sentidos no cotidiano: aproximações teóricas e metodológicas. São Paulo: Cortez, 1999. p. 41-61.

SPINK, M.J.P. Psicologia social e saúde: práticas, saberes e sentidos. Petrópolis: Vozes, 2003.

WETHERELL, M.; POTTER, J. Mapping the language of racism: discourse and the legitimation of exploitation. Hemel Hemstead, Harvester Wheatsheaf, 1992. 


\section{7}

\section{Velhice e atividade profissional: um estudo sobre qualidade de vida}

Isis Simões Leão

Maria do Carmo Eulálio

\section{Introdução}

Apresentamos, neste capítulo, resultados de uma pesquisa realizada com pessoas idosas a fim de estudar a qualidade de vida das mesmas, tomando-se como referência o fato de elas exercerem ou não algum tipo de atividade profissional. Este artigo é parte de uma pesquisa mais ampla (LEÃO e EULÁLIO, 2008, p. 11) que teve como objetivo "comparar a relação entre memória de trabalho e qualidade de vida de idosos profissionalmente ativos e inativos". Nela, observouse que a escolaridade é um forte indicativo de diferenciação entre a capacidade mnemônica e as condições sociais dos dois grupos.

O foco das reflexões e questionamentos aqui levantados giram em torno dos fatores físico, psicológico, relações sociais e meio ambiente adotados pelo Grupo WHOQOL (World Health Organization Quality of Life) para estudo da 
qualidade de vida, definida como "a percepção do indivíduo de sua posição na vida, no contexto de sua cultura e no sistema de valores em que vive e em relação às suas expectativas, seus padrões e suas preocupações" (FLECK et al, 2008, p. 1405).

Para a Psicologia - área da ciência em permanente dinâmica em busca da compreensão dos fenômenos sociais a fim de contribuir com a promoção de estratégias de melhoramento da qualidade de vida - a atenção aos idosos se faz imprescindível, uma vez que a população mundial tem uma expectativa de vida cada vez mais longa.

De acordo com dados do Instituto Brasileiro de Geografia e Estatística (IBGE) (BRASIL, 2008), o número de idosos, no Brasil, cresce rapidamente e estima-se que, em 2050, um quinto da população terá mais de 60 anos, idade a partir da qual, segundo o Art. $2^{\circ}$ da Lei 8842 , o sujeito é considerado idoso.

O aumento na expectativa de vida deve-se principalmente à ampliação da cobertura previdenciária, à redução da pobreza, ao maior acesso aos serviços de saúde e ao desenvolvimento de tecnologias médicas. A diminuição nos índices de analfabetismo e a promoção de políticas públicas que favorecem a qualidade de vida da população também contribuem para a longevidade (MINAYO, 2007).

O crescente número de idosos e a atual modificação no perfil das pessoas, nessa faixa etária, concedem-lhes maior destaque na sociedade. Dados do IBGE (BRASIL, 2008) apontam o crescimento do número de aposentados responsáveis pelos seus lares (62,4\% dos idosos); isso implica na ampliação dos serviços voltados para esse grupo, percebendo-se, ademais, uma reconfiguração no cenário sociodemográfico brasileiro com consequências econômicas e sociais.

A consideração da condição do idoso, no mundo atual, deve, portanto, observar o modo como ele está inserido na 
sociedade bem como suas dificuldades para essa inserção, conforme relata a literatura corrente. E o que faremos a seguir, embora que resumidamente em razão da amplitude e complexidade dessa temática.

\section{Características e qualidade de vida dos idosos no mundo contemporâneo}

Bauman (2007) denomina "vida líquida" o estilo desprendido de viver das sociedades contemporâneas; vida caracterizada pela fluidez, pela capacidade de moldar-se, transformar saberes e costumes com rapidez, a ponto de não haver tempo para estabilização.

Numa sociedade líquido-moderna, as realizações individuais não podem solidificar-se em poses permanentes porque, em um piscar de olhos, os ativos se transformam em passivos, e as capacidades, em incapacidades (BAUMAN, 2007. p.7).

Pensemos então o lugar do idoso nessa sociedade. Teria ele a capacidade de moldar-se com tal rapidez a fim de acompanhar o ritmo frenético das inovações e transformações do mundo ou tornar-se-ia um passivo, classificado como incapaz frente ao turbilhão tecnológico?

Apesar de haver, nos dias de hoje, uma maior mobilização social no sentido de atender aos idosos, processo que se intensifica especialmente após os anos $90 \mathrm{com}$ os programas de aposentadoria (BARROS, 2004), não é fácil envelhecer numa sociedade em que a tecnologia avança e a todo momento novidades surgem tornando obsoletos aqueles que não acompanham e não contribuem para a manutenção do ritmo frenético do mundo globalizado. 
Minayo (2007, p.51) aponta a produção como um fator determinante do espaço social do idoso. Aqueles que adotam uma postura inativa são automaticamente marginalizados e se tornam "inúteis ou peso morto", pois não trabalham, ganham pouco ou nada e, muitas vezes, dependem totalmente de terceiros. Nesse sentido, envelhecer significa perder espaço social e estar condenado ao isolamento.

Zimerman (2000) acredita que a capacidade de flexibilidade e adaptação é um dos principais fatores do envelhecimento saudável. A autora afirma ainda que idosos que possuem ocupações e objetivos se mantêm mais atualizados e, consequentemente, melhor inseridos na sociedade. Para Stuart-Hamilton (2002, p.57) "A prática não só preserva habilidades existentes, como também renova habilidades supostamente perdidas ou em declínio".

Nesse sentido, o envelhecimento apresenta, também, progressos e, principalmente, a possibilidade de utilizar o que foi aperfeiçoado a fim de compensar as perdas e poder viabilizar uma boa qualidade de vida para os idosos.

A marginalização do idoso é apontada por Souza e Chaves (2005) como decorrente da forma patológica por meio da qual o envelhecimento é concebido não apenas pela sociedade em geral, mas pelos próprios idosos. A aposentadoria pode significar, para muitos, um abandono do meio social e certa passividade frente à vida, ocasionando prejuízo à saúde mental e física. Constitui-se ainda como um fator de risco para o declínio cognitivo e demência.

Com o passar dos anos, segundo Parente (2006), as mudanças devem dirigir-se para a melhoria da qualidade de vida. Nessa perspectiva, a concepção de idoso, na sociedade contemporânea, sofre mudanças. O estereótipo depreciativo e excludente, que enfatiza as limitações e dependências dos idosos, cede espaço para outro modo de pensar, considerando os benefícios advindos da idade. 
Trentini, Xavier e Fleck (2006) classificam a velhice em: "usual, bem sucedida e com patologia". Na "usual", ou "normal", há alterações parciais nas atividades cotidianas. A velhice "bem sucedida", ou "ótima", é caracterizada pela preservação da saúde e funcionalidade orgânica na qual a qualidade de vida e resiliência se mantêm. Por fim, a velhice com patologia é definida como o estado em que o indivíduo se torna severamente limitado.

O que leva um idoso a ter uma velhice bem sucedida é, de acordo com Pessini (2007), a capacidade de viver a vida como kairós e não como na dimensão do cronos. Isso significa que o envelhecimento pode ser agradável desde que o idoso ame a vida e esteja mais preocupado com suas experiências e qualidade de vida do que com os anos que passam e que o aproximam mais da morte.

Nesse caso, deparamo-nos com uma questão não de ordem apenas pessoal, mas social. Segundo Minayo (2007), são poucos os idosos de idade elevada que conseguem viver e morrer dignamente. Porém, "pelo menos parcialmente os indivíduos podem controlar como envelhecerão, dentro das limitações impostas pelo contexto socioeconômico onde estão inseridos" (RIBEIRO e YASSUDA, 2007).

Levanta-se agora uma discussão política de atenção ao idoso. Durante muito tempo, o Brasil foi classificado como um país jovem, sempre valorizou crianças e jovens, delegando os problemas dos idosos as suas famílias. Hoje, porém, a diminuição da natalidade e o aumento da expectativa de vida tornam a população do país cada vez mais "madura", emergindo daí novas necessidades (BARROS, 2004). Em consequência, enfatiza-se a importância de ações do poder público que atendam às novas demandas.

Neri (2001) destaca a fase de "sensibilidade social para a velhice” na qual, o Brasil se encontra. Os estudos desenvolvidos na área da gerontologia e a maior atenção aos idosos 
devem-se, além do envelhecimento populacional, às novas formas de viver a velhice e ao sonho de manter a juventude apesar do passar dos anos.

Viver mais não significa, necessariamente, viver bem. Cientificamente, a velhice é caracterizada pelo declínio das funções biológicas e da plasticidade, o que, segundo Neri e Yassuda (2004), tornam os idosos mais dependentes da cultura e da sociedade.

Por outro lado, a velhice pode ser também uma fase de ganhos, principalmente nos campos intelectual e afetivo, desde que haja um equilíbrio para que as inevitáveis perdas sejam compensadas pelos ganhos (NERI e YASSUDA, 2004).

Como equilibrar declínio cognitivo, enfraquecimento físico e dependência com sabedoria, experiência e maturidade? O que fazer para proporcionar uma boa qualidade de vida ao idoso?

A qualidade de vida, por ser um conceito amplo, é discutida pelas ciências da saúde e sociais tais como a Filosofia, Psicologia e História. Os enlaces de saberes tentam dar conta da complexidade desse fenômeno.

O primeiro registro do termo qualidade de vida foi encontrado na literatura dos anos 30 (COSTA NETO, ARAÚJO e CURATO, 2000). Desde então, estudos científicos buscam seu aprimoramento conceitual e metodológico. Para Santos (et al, 2002), a dificuldade em conceituar a qualidade vida, em função da subjetividade que a reveste, faz com que seja difícil também sua mensuração.

Além disso, a heterogeneidade das condições atuais de saúde, a inserção social e a história de vida de cada idoso exigem do estudo da qualidade de vida um olhar para o passado e o presente a fim de inferir perspectivas futuras. 


\section{Metodologia}

Esta pesquisa se caracteriza como um estudo transversal de tipo comparativo e analítico. Participaram da pesquisa 60 idosos, de ambos os sexos - sendo 30 profissionalmente ativos e 30 profissionalmente inativos - moradores do município de Campina Grande-PB, sem qualquer indício de déficit cognitivo ou de processo demencial degenerativo comprovados através do Mini Exame do Estado Mental (MEEM).

A escolha da amostra se deu de forma não-probabilística, por conveniência e acessibilidade. Para a coleta de dados, utilizamos os seguintes instrumentos: questionário sociodemográfico, MEEM e WHOQOL - abreviado ${ }^{1}$.

O questionário sociodemográfico - abrangendo questões pessoais e profissionais - foi realizado com a finalidade de obter dados para a caracterização da amostra. As questões pessoais incluíram sexo, idade, estado civil, escolaridade, renda mensal familiar e religião. Já as questões profissionais buscaram informações sobre aposentadoria ou pensão e atual condição profissional. O MEEM foi adotado como teste de rastreamento para assegurar a capacidade dos participantes em responder aos demais instrumentos. $\mathrm{O}$ WHOQOL - abreviado ofereceu informações acerca da qualidade de vida geral dos idosos, bem como dos 4 fatores que compõem o instrumento: físico, psicológico, relações sociais e meio ambiente.

1 Apesar de haver um instrumento específico para idosos, o WHOQOLold, por prezarmos pelo curto tempo de aplicação, não o adotamos, pois ele deve ser utilizado em conjunto com o WHOQOL-abreviado. 


\section{Resultados e Discussão}

O grupo de idosos ativos insere-se na média de idade de 66,6 anos (d.p.=5,4), sendo a idade mínima 60 e a máxima 76 anos. Os inativos têm em média 70,9 anos (d.p.=6,7), sendo a idade mínima 60 e máxima 80 anos.

Os idosos profissionalmente ativos $(\mathrm{n}=30)$ exercem as atividades: técnico hidráulico (1), secretária (2), empregada doméstica (2), padre (1), auxiliar de escritório (1), vigilante (1), agente administrativa (1), assistente social (3), gerente de marcenaria (1), professor (4), motorista (1), engenheiro (3), arquiteto (3), auxiliar técnico de laboratório (1), agente de estatística (1), médico (2), barbeiro (1) e diretora de instituição educacional (1).

O perfil sociodemográfico dos participantes é apresentado a seguir na Tabela 1, onde se pode ler dados acerca do sexo, estado civil, religião, renda mensal familiar, aposentadoria e escolaridades dos idosos ativos e inativos.

Tabela 1. Distribuição de frequências relativas ao sexo, estado civil, religião, renda mensal familiar, aposentadoria e escolaridade dos idosos profissionalmente ativos e inativos.

\begin{tabular}{ccccc}
\hline & \multicolumn{2}{c}{ ATIVOS } & \multicolumn{2}{c}{ INATIVOS } \\
& $\boldsymbol{F}$ & $\mathbf{\%}$ & $\boldsymbol{F}$ & $\%$ \\
SEXO & & & & \\
\hline FEMININO & 13 & 43,4 & 23 & 76,6 \\
MASCULINO & 17 & 56,6 & 7 & 23,4 \\
\hline TOTAL & 30 & 100 & 30 & 100 \\
\hline ESTADO CIVIL & & & & \\
SOLTEIRO (A) & 8 & 26,6 & 4 & 13,4 \\
CASADO (A) & 16 & 53,4 & 11 & 36,6 \\
VIÚNO (A) & 4 & 13,4 & 14 & 46,6 \\
DIVORCIADO (A) & 2 & 6,6 & 1 & 3,4 \\
\hline TOTAL & 30 & 100 & 30 & 100 \\
\hline
\end{tabular}




\begin{tabular}{|c|c|c|c|c|}
\hline RELIGIÃO & & & & \\
\hline CATÓLICA & 20 & 66,6 & 28 & 93,4 \\
\hline EVANGÉLICA & 7 & 23,4 & 2 & 6,6 \\
\hline ESPÍRITA & 2 & 6,6 & 0 & 0 \\
\hline SEM RELIGIÃO & 1 & 3,4 & 0 & 0 \\
\hline TOTAL & 30 & 100 & 30 & 100 \\
\hline RENDA MENSAL FAMILIAR & & & & \\
\hline < 1 SALÁRIO MÍNIMO & 2 & 6,6 & 4 & 13,4 \\
\hline 1 - 3,9 SALÁRIOS MÍNIMOS & 6 & 20 & 13 & 43,4 \\
\hline 4 - 6,9 SALÁRIOS MÍNIMOS & 11 & 36,6 & 11 & 36,6 \\
\hline 7 - 10 SALÁRIOS MÍNIMOS & 4 & 13,4 & 1 & 3,3 \\
\hline > 10 SALÁRIOS MÍNIMOS & 7 & 23,4 & 1 & 3,3 \\
\hline TOTAL & 30 & 100 & 30 & 100 \\
\hline APOSENTADO (A) OU PENSIONISTA & & & & \\
\hline SIM & 21 & 70 & 28 & 93,4 \\
\hline NÃO & 9 & 3 & 2 & 6,6 \\
\hline TOTAL & 30 & 100 & 30 & 100 \\
\hline ESCOLARIDADE & & & & \\
\hline ANALFABETO & 0 & 0 & 2 & 6,7 \\
\hline ALFABETO FUNCIONAL & 2 & 6,7 & 5 & 16,6 \\
\hline ALFABETIZADO (<5 ANOS DE ESCOLA) & 8 & 26,6 & 18 & 60 \\
\hline ALFABETIZADO ( >5 ANOS DE ESCOLA) & 5 & 16,6 & 3 & 10 \\
\hline ENSINO SUPERIOR & 12 & 40 & 2 & 6,7 \\
\hline MESTRE & 2 & 6,7 & 0 & 0 \\
\hline DOUTOR & 1 & 3,4 & 0 & 0 \\
\hline TOTAL & 30 & 100 & 30 & 100 \\
\hline
\end{tabular}

Fonte: dados da pesquisa

A predominância de mulheres no total de participantes (60\%) segue a tendência mundial de feminização da velhice (NERI, 2001), ou seja, o aumento da população feminina entre pessoas idosas. 
O fenômeno de feminização da velhice também justifica o número maior de viúvos entre idosos inativos. Isto porque, além da maior sobrevida feminina, é mais comum o recasamento de homens que de mulheres após a morte de seus cônjuges (BRASIL, 2008). Assim, a maioria dos idosos inativos constitui-se, na verdade, de mulheres viúvas.

Os idosos profissionalmente ativos apresentam renda mensal familiar e níveis de escolaridade mais altos que os idosos profissionalmente inativos. Conforme verificaram Giatti e Barreto (2003) em estudo que destaca, além da superioridade desses níveis entre os ativos, o fato de que eles são mais jovens, o que indica correlação entre os três fatores.

Os dados são analisados sob duas comparações: intra e intergrupos. As análises intergrupos comparam os fatores da qualidade de vida de idosos ativos e inativos ${ }^{2}$. As análises intragrupos são relativas às correlações estabelecidas entre os fatores da qualidade de vida e os da idade, renda e escolaridade de cada grupo, a fim de verificar a influência destes aspectos no envelhecimento.

\section{Correlações entre a qualidade de vida entre idosos profissionalmente ativos e inativos}

Primeiramente, a confiabilidade do instrumento foi avaliada pela consistência interna, verificada por meio do coeficiente alfa de Cronbach. Para que o instrumento seja confiável, o resultado precisa ser igual ou superior a 0,60 (WAGNER, MOTTA e DORNELLES, 2004). O alfa de Cronbach foi de 0,885 na aplicação com idosos inativos e 0,728 com idosos ativos, o que comprova a confiabilidade do teste para nossa amostra.

2 Conscientes da amplitude do conceito de atividade, restringimos aqui o uso das denominações "ativos" e "inativos" para referenciar, exclusivamente, ao exercício profissional ou não dos idosos. 
A seguir são fornecidas as estatísticas descritivas relativas aos resultados do WHOQOL-abreviado para idosos ativos e inativos, através da descrição das médias e desvio-padrão da qualidade de vida geral (QVGeral) e seus fatores: físico, psicológico, relações sociais e meio ambiente.

Tabela 2. Descrição dos fatores do WHOQOL-abreviado para idosos profissionalmente ativos e inativos.

\begin{tabular}{cc|c|c|c|c|c|c|c|c|c|}
\hline & \multicolumn{2}{c}{ QVGeral } & \multicolumn{2}{c}{ FÍSICO } & \multicolumn{2}{c}{ PSICOLÓGICO } & $\begin{array}{c}\text { RELAÇÕES } \\
\text { SOCIAIS }\end{array}$ & \multicolumn{2}{c}{$\begin{array}{c}\text { MEIO } \\
\text { AMBIENTE }\end{array}$} \\
\hline & ATIV. & INAT. & ATIV. & INAT. & ATIV. & INAT. & ATIV. & INAT. & ATIV. & INAT. \\
\hline Média & 92,9 & 84,5 & 27,8 & 24,6 & 23,3 & 21,03 & 11,2 & 11,3 & 30,5 & 27,5 \\
\hline Desv-pad. & 6,6 & 10,7 & 2,56 & 4,13 & 2,29 & 3,15 & 1,19 & 2,13 & 3,72 & 4,17 \\
\hline Mín. & 26 & 26 & 7 & 7 & 6 & 6 & 3 & 3 & 8 & 8 \\
\hline Máx. & 130 & 130 & 35 & 35 & 30 & 30 & 15 & 15 & 40 & 40 \\
\hline
\end{tabular}

Fonte: dados da pesquisa

A qualidade de vida geral dos idosos profissionalmente ativos $(92,93)$ é superior a dos idosos profissionalmente inativos $(84,53)$. Em relação à pontuação mínima e máxima $(26$; 130), os dois grupos apresentam uma média satisfatória. Os idosos profissionalmente ativos também obtiveram maiores médias nos fatores físico (27,87 ativos e 24,67 inativos); meio ambiente (30,53 ativos e 27,50 inativos) e psicológico (23,30 ativos e 21,03 inativos). Os dois grupos apresentaram média semelhante quanto ao fator relações sociais $(11,23$ ativos e 11,33 inativos), tendo o segundo grupo uma média maior, com diferença de apenas 0,1 ponto.

$\mathrm{O}$ fator físico, que apresenta maior diferença entre as médias de idosos ativos e inativos (3,2 pontos), avalia a existência e a intensidade de dor e desconforto, energia e fadiga, sono e repouso, mobilidade, atividades da vida 
cotidiana, dependência de medicação e capacidade de trabalho (CHACHAMOVICH e FLECK, 2008).

Pode-se inferir que as melhores condições físicas dos idosos ativos tenham relação direta com a atividade profissional, pois estar apto para o trabalho indica que eles têm condições físicas para o desempenho de tal atividade.

$\mathrm{O}$ segundo fator que mais difere quanto à média entre os grupos é o meio ambiente (3,03 pontos). Os resultados indicam que os idosos profissionalmente ativos possuem, dentre outras vantagens, melhores condições financeiras, de moradia, transporte, ambiente físico, maior acesso aos serviços de saúde e à informação.

Há um consenso entre estudiosos sobre o envelhecimento quanto à influência das condições sociais na forma como as pessoas envelhecem (MINAYO, 2007; RIBEIRO e YASSUDA, 2007). Assim, a maior renda e nível de instrução dos idosos ativos justificariam as melhores condições de meio ambiente deste grupo.

A análise comparativa entre as condições psicológicas dos idosos profissionalmente ativos e inativos indica, apesar da pequena diferença entre as médias (2,2 pontos), que o primeiro grupo apresenta melhores condições psicológicas que o segundo.

O fator psicológico avalia sentimentos positivos e negativos, o pensar, o aprender, a autoestima, a imagem corporal e a espiritualidade (CHACHAMOVICH e FLECK, 2008).

Inferimos que o fato de estar trabalhando, mais que aumentar a renda, faz com que o idoso se sinta socialmente inserido, útil, capaz e, assim, contribui para a existência de uma boa condição psicológica entre os idosos profissionalmente ativos.

Quanto às relações sociais, não são observadas diferenças relevantes entre os dois grupos, apresentando os idosos 
inativos uma média 0,1 maior que a dos ativos. Este fator avalia as relações estabelecidas com as pessoas do convívio do idoso e não sinaliza a influência da atividade profissional nesse aspecto da vida dos idosos.

O item seguinte explora as correlações entre os fatores da qualidade de vida e os aspectos socioeconômicos de cada grupo.

\section{Correlações entre a qualidade de vida e aspectos sociodemográficos de idosos profissionalmente ativos e inativos}

As influências entre as variáveis de qualidade de vida e dados sociodemográficos de idosos ativos e inativos são calculadas através do coeficiente de Pearson (r) através do SPSS 15. A tabela 3 expõe as correlações.

Tabela 3. Coeficiente de correlação de Pearson (r): nível de significância em relação ao WHOQOL-abreviado (qualidade de vida geral e seus fatores) e os dados sociodemográficos de idosos profissionalmente ativos e inativos.

\begin{tabular}{|c|c|c|c|c|c|c|}
\hline \multicolumn{4}{|c|}{ ATIVOS } & \multicolumn{3}{|c|}{ INATIVOS } \\
\hline & Idade & Escolaridade & Renda & Idade & Escolaridade & Renda \\
\hline QVGeral & $-0,405^{*}$ & --- & $0,453^{*}$ & --- & $0,454^{*}$ & \\
\hline Físico & --- & --- & --- & --- & $0,454^{*}$ & --- \\
\hline Psicológico & --- & --- & --- & --- & --- & --- \\
\hline Relações sociais & --- & --- & --- & --- & --- & --- \\
\hline Meio ambiente & $-0,444^{*}$ & $0,510^{*}$ & $\mathbf{0 , 5 0 3} * *$ & --- & --- & --- \\
\hline
\end{tabular}

Fonte: dados da pesquisa

* diferença estatisticamente significativa $(\mathrm{p}<0,05)$

** diferença estatisticamente significativa $(\mathrm{p}<0,01)$ 
Quanto à qualidade de vida geral dos idosos ativos, há uma correlação negativa com a idade $(\mathrm{r}=-0,405)$ e positiva com a renda $(r=0,453)$, o que significa que idosos de idade mais elevada possuem pior qualidade de vida; e idosos com maior renda familiar apresentam uma melhor qualidade de vida. Entre os inativos, a correlação com a qualidade de vida geral é significante em relação à escolaridade $(r=0,454)$.

O fator físico possui correlação significante apenas com a escolaridade dos idosos inativos $(r=0,454)$. Ou seja, os idosos com índices maiores de escolaridade se mantêm fisicamente saudáveis por mais tempo.

Entre os idosos ativos, o fator meio ambiente é influenciado negativamente pela idade $(\mathrm{r}=-0,444)$ e positivamente pela escolaridade $(\mathrm{r}=0,510)$ e renda $(\mathrm{r}=0,503)$. Ou seja, quanto maior a idade, piores as condições financeiras, de moradia, transporte, ambiente físico, acesso aos serviços de saúde, à informação, a atividades de lazer dentre outros aspectos que compõem o fator meio ambiente. Não há correlação significativa entre o meio ambiente e a idade, escolaridade ou renda dos idosos inativos.

Não foram encontradas correlações significativas entre os fatores sociodemográficos e as condições físicas, psicológicas e relações sociais dos idosos ativos, e o fator psicológico, as relações pessoais e o meio ambiente de idosos inativos, o que pode decorrer do pequeno número de participantes.

Mesmo assim, é visível que a idade, a renda e a escolaridade dos idosos influenciam na qualidade de vida dos mesmos. As maiores correlações, em ambos os grupos, relativas à escolaridade reforçam sua influência na forma como os idosos envelhecem. 


\section{Conclusões}

Observamos que os idosos ativos possuem melhores condições físicas, psicológicas e de meio ambiente que os idosos inativos. Inferimos, a partir da análise das correlações entre os fatores de qualidade de vida e os dados sociodemográficos, que a escolaridade é um dos aspectos de maior repercussão na forma como os idosos envelhecem.

Entre os idosos ativos, há correlação entre a escolaridade e o meio ambiente. Entre os inativos, há correlação entre escolaridade e a qualidade de vida geral e o fator físico. Idade e renda também influenciam na qualidade de vida geral e no meio ambiente de idosos ativos. Percebe-se, portanto, que os fatores sociais influenciam amplamente no envelhecimento.

A necessidade de melhores serviços de assistência a idosos é um consenso entre estudiosos do envelhecimento, especialmente em função do aumento mundial dessa população. Porém é preciso atentar para o fato de que as condições dos idosos não resultam apenas da atenção que lhes é oferecida na velhice, mas principalmente da forma como eles viveram durante toda a vida.

Nesse sentido, o cuidado aos idosos não pode se resumir apenas ao oferecimento de aposentadoria e serviços de saúde. Pois os idosos que precisam de cuidados hoje, possuem essa carência em função de uma formação escolar insuficiente, de más condições de moradia, da falta de atividades culturais e de lazer, entre outros aspectos do fator meio ambiente.

Para que as futuras gerações envelheçam de forma saudável, é necessário que sejam oferecidas, hoje, condições satisfatórias para o desenvolvimento de crianças, jovens e adultos. Assim, apesar de o Brasil não ser mais um país essencialmente jovem, as políticas públicas não devem simplesmente mudar o foco de atenção da população jovem para a de idosos. 
Sem esquecer os velhos, o Brasil continua precisando cuidar de suas crianças, mas agora não por serem elas as salvadoras do futuro do país, mas porque, com o aumento da expectativa de vida, elas precisam ser preparadas para viverem fisicamente bem e com melhor qualidade de vida os anos a mais que as aguardam.

\section{Referências}

BAUMAN, Z. Vida Líquida. Rio de Janeiro: Zahar, 2007.

BARROS, M. M. Envelhecimento, cultura e transformações sociais. In L. Py, J. L. Pacheco, J. L. M. Sá \& S. Goldman. (Orgs.). Tempo de envelhecer: percursos e dimensões psicossociais. Rio de Janeiro, RJ: Nau, 2004, p. 39-56.

BRASIL, IBGE. Perfil dos idosos responsáveis pelos domicílios. Disponível em: <http://www.ibge.gov.br/home/presidencia/ noticias/25072002pidoso.shtm>. Acesso em: 20 de jan. 2008.

CHACHAMOVICH, E.; FLECK, M. P. A. Desenvolvimento do WHOQOL-BREF. In: FLECK, M. P. A. A Avaliação de qualidade de vida: guia para profissionais da saúde. Porto Alegre: Artmed, 2008.

COSTA NETO, S. B; ARAUJO, T. C. C. F; CURADO, M. P., Avaliação da qualidade de vida de pessoas portadoras de câncer de cabeça e pescoço. 20(3):96-104, jul.-set. 2000. Disponível em: $<$ http://bases.bireme.br/cgi-bin/wxislind.exe $>$. Acesso em: 12 de jun. 2008.

FLECK, M. P. A. A Avaliação de qualidade de vida: guia para profissionais da saúde. Porto Alegre: Artmed, 2008.

GIATTI, L.; BARRETO, S. M. Saúde, trabalho e envelhecimento no Brasil. Cad. Saúde Pública, June 2003, vol.19, no.3, p.759-771. ISSN 0102-311X. 
LEÃO. I. S.; EULÁLIO, M. C. A memória e a qualidade de vida em pessoas idosas. Campina Grande, 2008, 65p. Monografia (Graduação em Psicologia) - Departamento de Psicologia, Universidade Estadual da Paraíba.

MINAYO, M. C. S. Visão antropológica do envelhecimento. In: Vários colaboradores. (Org.). Velhices: reflexões contemporâneas. São Paulo: SESC/PUC São Paulo, 2007, v. 1, p. 47-60.

NERI, A. L. Qualidade de vida na velhice e subjetividade. In: NERI, A. L. (Org.) Qualidade de vida na velhice: enfoque multidisciplinar. Campinas, SP: Editora Alínea, 2007 (p.14-59). Coleção velhice e sociedade.

. A. L. \& YASSUDA, M. S. (Orgs.). Velhice bem-sucedida: aspectos afetivos e cognitivos. Campinas: Papirus, 2004.

. A. L. Desenvolvimento e Envelhecimento. Perspectivas, Biológicas. Psicológicas e Sociológicas. Campinas: Papirus, 2001.

PARENTE, M. A. de M. P. et al. Cognição e envellhecimento. Porto Alegre: Artmed, 2006 (p. 67-84).

PESSINI, L. Finitude: Viver no pesadelo do cronos ou escolher a bênção do cairós? In: Vários colaboradores. (Org.). Velhices: reflexões contemporâneas. São Paulo: SESC/PUC São Paulo, 2007, v. 1, p. 61-71.

RIBEIRO. P. C. C.; YASSUDA, M. S. Cognição, estilo de vida e qualidade de vida na velhice. In: NERI, A. L. (Org.) Qualidade de vida na velhice: enfoque multidisciplinar. Campinas, SP: Editora Alínea, 2007 (p.189-204). Coleção velhice e sociedade.

WAGNER, M. R.; MOTTA, V. T.; DORNELLES, C. SPSS Passo a passo: satiatical package for the social sciences. Caxias do Sul: Educs, 2004.

SANTOS, S.R. et al. Qualidade de vida do idoso na comunidade: aplicação da escala de Flanagan. Rev Latino-am Enfermagem 2002 
novembro-dezembro; 10(6):757-64. Disponível em: <http://www. eerp.usp.br/rlaenf > . Acesso em: 15 de mai. 2008.

SOUZA, J. N. de; CHAVES, E. C. O efeito do exercício de estimulação da memória em idosos saudáveis. Rev Esc Enferm USP, 2005; 39(1);13-9. Relato de Pesquisa.

STUART-HAMILTON, I. A Psicologia do envelhecimento: Uma introdução. Porto Alegre: Artmed, 2002.

TRENTINI, C. M.; XAVIER, F. M. de F; FLECK, M. P. de A. Qualidade de vida em idosos. In: PARENTE, M. A. de M. P. et al. Cognição e envellhecimento. Porto Alegre: Artmed, 2006 (p. 19-30).

ZIMERMAN, G. I. Velhice: aspectos biopsicossociais. Porto Alegre: Artmed, 2000. 


\section{Saúde Mental em enfermeiros plantonistas do Serviço de Atendimento Móvel de Urgência - SAMU}

Silvânia da Cruz Barbosa

Renata Pimentel da Silva

José Ulisses do Nascimento

Sandra Souza

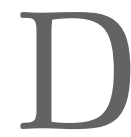

esde o final do século passado, alterações produtivas, tecnológicas e gerenciais vêm sendo introduzidas nas organizações, impulsionadas pelos efeitos combinados da globalização econômica e dos avanços científicos e tecnológicos. Para serem lucrativas e compensarem os altos investimentos realizados, muitas empresas passaram a operar ininterruptamente, o que conduziu o aparecimento de um novo tipo de sociedade, na qual já é possível se constatar um crescente número de organizações funcionando durante 24 horas.

Para oferecer produtos e/ou serviços a qualquer hora do dia e da noite, as empresas passaram a adotar várias estratégias, dentre elas a intensificação das jornadas de trabalho e a diversificação das agendas laborais dos empregados a partir de múltiplas combinações de horários (GARRIDO, 2006). 
Por outro lado, esta sociedade que funciona diuturnamente, precisa de serviços fundamentais, como os de segurança e de saúde, operando todo o tempo. E ainda que se ampliem outros serviços (restaurantes, postos de gasolina, supermercados, etc.) para atender às necessidades daqueles que trabalham em regimes noturno e alternado. Constata-se, então, uma tendência do uso de regimes de trabalho altamente diversificados e frequentemente rodiziados em turnos e turmas na atual sociedade 24 horas e, consequentemente, cresce o número de pessoas trabalhando em jornadas sensivelmente diferentes da escala regular ${ }^{1}$ comum à maioria da população (ROSA; COLLIGAN, 2002; FISCHER; MORENO, ROTENBERG, 2003).

O fenômeno vem despertando atenção da comunidade científica, existindo vários estudos nacionais e internacionais que fazem referência aos prejuízos na saúde e na vida das pessoas submetidas a formas incomuns de organização temporal do trabalho (BARBOSA, 2008; BARBOSA; BORGES, 2007; OLIVEIRA et al. 2006; FISCHER; MORENO, ROTENBERG, 2003; RÉGIS-FILHO; SELL, 2000). De um modo geral, esses estudos mostram que tais esquemas de horário interferem negativamente nos ritmos biológicos, sobretudo os circadianos, causam problemas nervosos, alimentares, gastrintestinais e cardiovasculares, disrupção na vida social e familiar, envelhecimento precoce e, muitas vezes, a chamada morte social derivada do constante isolamento que restringe a participação em atividades familiares, culturais, desportivas e de lazer.

Na Psicologia Organizacional e do Trabalho (POT), existe atualmente um campo específico que estuda a relação entre

1 Segundo Rutenfranz, Knauth e Fischer (1989), a escala regular ou normal, refere-se à divisão do tempo do trabalho no horário entre seis e dezoito horas, com base na semana de cinco dias e nas quarenta horas semanais. 
saúde mental e trabalho e, dentro dele, uma das preocupações tem sido avaliar os efeitos psicossociais que algumas modalidades de horário de trabalho podem causar ao trabalhador. No referido campo, onde a presente pesquisa se inclui, o regime de trabalho vem sendo estudado como uma dimensão das condições de trabalho que tem grande poder de estruturação do tempo na vida das pessoas (RÉGIS-FILHO; SELL, 2000; GARRIDO, 2006). Assim, perder controle sobre a organização do próprio tempo pode converter-se em poderosa fonte de estresse, por isso, quando as empresas privilegiam regimes de trabalho com mudanças consecutivas de turno, longas jornadas e rápidas rotações dos dias de descanso, podem estar contribuindo para potencializar efeitos nocivos à saúde do trabalhador e da própria organização. Apoiada na articulação entre as categorias saúde mental e condições de trabalho, a presente pesquisa teve como objetivo central analisar os efeitos do regime de plantão sobre a saúde mental em profissionais de enfermagem que trabalham no Serviço de Atendimento Móvel de Urgência (SAMU) em Campina Grande (PB).

\section{Saúde Mental e Condições de Trabalho}

A compreensão de que existe um nexo causal entre a saúde das pessoas e as condições em que elas trabalham não é um tema novo, contudo, muito atual e amplamente compartilhado por várias disciplinas científicas (Medicina, Sociologia, Psicologia, etc.). Entretanto, a forma de abordar essa relação tem mudado substancialmente, nos últimos anos, em decorrência da evolução conceitual de ambos os construtos,

Para acompanhar esse caminho evolutivo, convém encontrar um marco fundador dessa relação, tarefa bastante complexa, porque quase sempre leva o pesquisador a escolher arbitrariamente um ponto de partida e a filtrar apenas os 
detalhes que considera mais relevantes, o que resulta numa reconstrução parcial e enviesada da história. No entanto, o corte do tempo é fundamental porque irá situar, historicamente, o fenômeno que se deseja investigar. Resolveu-se, então, tomar como ponto de partida a ideia de saúde presente nas civilizações primitivas, mas, sobretudo, para destacar que a relação entre a vida laboral e os cuidados com a saúde têm raízes na cultura humana e no seio das religiões e dos mitos.

Entre os povos primitivos, durante muito tempo, predominou uma concepção mágico-religiosa de saúde que supunha a existência de entidades sobrenaturais (deuses e espíritos) agindo favoravelmente ou nocivamente sobre os indivíduos, e que estas ações poderiam ser manejadas por meio de ritos (por exemplo: cantos, danças) e por meio de poderes especiais de alguns homens (como feiticeiros, magos, bruxas) ou lugares (como rios e fontes sagradas). Acreditava-se que as doenças resultavam de forças espirituais demoníacas, podendo ser interpretadas ora como punição, ora como um sinal da ira divina. De um modo geral, as explicações às enfermidades ligavam-se a fenômenos extraterrenos; o alívio da dor dava-se por ações instintivas, observando-se como os animais agiam quando se feriam ou quando tinham dor ou febre; as orientações terapêuticas baseavam-se no empirismo e nas práticas mágico-religiosas voltadas, principalmente, para afugentar os espíritos do corpo e a posição social do médico ligava-se à figura do xamã ${ }^{2}$ (PIRES, 1998; SCLIAR, 2002).

À medida que o conhecimento humano avança, os fenômenos da natureza passam a ser explicados em termos de

2 Eram considerados xamãs aqueles que possuíam dotes especiais hereditários ou nasciam predestinados. Reconhecia-se a predestinação por meio de marcas de nascimento ou sinais desenvolvidos durante a infância. Nesses casos, os iniciantes passavam por um processo de formação para aprender como afastar os espíritos. 
forças abstratas (força química, força física, força vital, etc.). A saúde começa, então, a ser vista como resultante do equilíbrio entre as influências ambientais, o estilo de vida e os elementos da natureza (terra, fogo, água e ar), e o aparecimento das doenças como decorrente do desequilíbrio desses fatores. Na Grécia antiga, essa compreensão de que os fatores ambientais estão ligados à gênese das doenças aparece claramente nas obras de Hipócrates, o pai da medicina. Tais escritos traduzem uma visão mais racional do processo saúde-doença, porém sem se desvincular totalmente do misticismo, já que os gregos eram doutrinados por uma religião panteísta que supunha a existência de divindades identificadas com o universo. Assim, buscava-se a cura por meio de ritos religiosos e pelo uso de plantas medicamentosas (IBAÑES; MARSIGLIA, 2000; SCLIAR, 2002).

No mundo grego, a beleza corporal, representada pelo Deus Apolo, era um bem altamente cobiçado e intimamente relacionado à saúde. Para assegurar uma mente sã e um corpo são, era necessário encontrar um equilíbrio entre os fatores ambientais e o organismo. Hipócrates sustentava que a desarmonia desses fatores poderia interferir no equilíbrio dos quatro fluidos (humores) principais do corpo: sangue, fleuma (linfa), bile amarela e bile negra (ou atrabile), ocasionando o surgimento das doenças (ALBUQUERQUE; OLIVEIRA, 2002; QUEIROZ, 2003).

Na Idade Média, a influência do ambiente sobre a saúde passou a ser uma ideia bem aceita, existindo inclusive registros de doenças ocupacionais no decorrer desse período. Mesmo assim, os conhecimentos sobre a saúde praticamente não avançaram, prevalecendo explicações religiosas e práticas supersticiosas para a cura das doenças. Um indivíduo mentalmente enfermo não era considerado como tal, e sim, possuído por demônios. Essa visão perdurou pelo Renascimento, e a loucura continuou sendo ignorada como uma enfermidade (SCLIAR, 2002; VENÂNCIO, 2003). 
No século XVII, Descartes estabeleceu os métodos para se pensar o corpo humano como uma máquina, e com isso dicotomizou mente e corpo. Daí em diante, as explicações científicas passam a acompanhar essa ruptura para explicar o processo saúde/doença. Em meados do século XIX, a concepção predominante era de que os distúrbios comportamentais tinham origem exclusivamente orgânica, e a saúde era compreendida como ausência de doença. Foi dentro dessa visão dualista e biologizante que o modelo biomédico se fundamentou para diagnosticar e tratar as doenças, sem estabelecer relações com os problemas psicológicos e/ou sociais. Tal modelo se consolidou nos países ocidentais, servindo de referência para muitas áreas de conhecimento, inclusive na Psicologia. Em consequência, muitas pesquisas permaneceram e, até certo ponto, ainda permanecem voltadas para a avaliação de quadros clínicos e para a identificação de aspectos negativos da saúde (enfermidades) (BARBOSA; BORGES, 2007).

Esse olhar negativo sobre a saúde contribuiu para retardar o reconhecimento da relação entre saúde mental e trabalho, como também o da interação de aspectos não biológicos como agentes no processo de adoecimento. Contudo, em 1948, a Organização Mundial de Saúde - OMS se preocupou em traçar uma definição positiva de saúde, definindo-a como "um estado de completo bem-estar físico, mental e social, e não somente como ausência de enfermidades" (OMS, 1948, s/p.). Tal definição foi muito criticada por tornar a saúde uma meta inatingível, mas, ao mesmo tempo, veio atender a complexidade e abrangência do construto, sendo congruente com a ideia de que a enfermidade física é, apenas, uma das manifestações do desequilíbrio orgânico e que se devem levar em conta os aspectos psicológicos e sociais para compreender a saúde (GRILO, 2005).

A partir de 1960, as pesquisas passam a incluir fatores não-biológicos (meio ambiente, fatores sociodemográficos, condições e estilo de vida, etc.) para entender o processo 
saúde/doença e, desde então, a tendência tem sido identificar também os aspectos positivos de saúde. Um dos esforços mais recentes nesse sentido tem sido a atenção aos transtornos psíquicos leves que ganha destaque em 1970, defendendo que, mesmo aparentando estar saudável, os indivíduos podem sofrer pequenas alterações psíquicas (ansiedade, estresse e depressão), em diferentes graus (ALVARO, 1992). Outra contribuição importante veio de uma recente disciplina, a Psicologia da Saúde, que assinala a importância de se considerar os significados e as crenças que os indivíduos atribuem à saúde como aspectos relevantes na prevenção e promoção da saúde (OGDEN, 1999).

Apesar de ter percorrido um longo caminho evolutivo, vários autores da atualidade (CANGUILHEM, 1995; WARR, 1987; OGDEN, 1999) compartilham a ideia de que o conceito de saúde mental continua amplo e difícil de operacionalizar, visto que é carregado de valores sociais. Portanto, os processos psicológicos podem ser descritos e interpretados de diferentes formas, conforme a perspectiva teórica de cada autor. Dependendo, então, da perspectiva adotada, a saúde mental pode ser compreendida como um problema emocional, cognitivo, comportamental ou como uma realidade simbólica sócio-historicamente construída (ÁLVARO; TORREGROSA, GARRIDO, 1992).

No campo de estudos em saúde mental e trabalho, seja qual for a perspectiva, um ponto comum, nas pesquisas, tem sido destacar a influência do ambiente social na saúde mental dos indivíduos. Um estudo pioneiro nesse sentido foi realizado por Jahoda (1987) na década de 1930 para identificar os efeitos psicossociais do desemprego numa comunidade austríaca. Perspectivas teóricas mais recentes, como o modelo ecológico formulado por Warr (1987), apontam certas características presentes no ambiente de trabalho (recursos financeiros, segurança física, relações interpessoais, etc.) como fatores determinantes ao bem-estar psicológico. 
Outros estudos relacionando saúde mental com condições de trabalho mostram que estas variáveis estão significativamente associadas (ÁLVARO; TORREGROSA, GARRIDO, 1992; BARBOSA, 2008).

Dentro do referido campo, o conceito de saúde não foi o único que evoluiu. Também há, na atualidade, uma compreensão mais ampla do que significa condições de trabalho. Contudo, até meados de 1970, essa expressão era usada para se referir exclusivamente aos aspectos físicos do local de trabalho (ruídos, gases tóxicos e poluentes, luminosidade, temperatura, etc.) e os procedimentos de pesquisa buscavam informações objetivas sobre tais aspectos, sem levar em conta o valor que os trabalhadores atribuíam a eles.

Depois de 1970, com o advento da globalização econômica e dos avanços científicos e tecnológicos, são apontadas na literatura definições mais amplas, sendo praticamente ilimitada a quantidade de aspectos que podem ser considerados como condições de trabalho, incluindo dimensões psicossociais como: emprego, salário, relações interpessoais, sentimento de autonomia, fatores físicos de trabalho, tempo (regimes de trabalho), sistema de incentivos, dentre outros, como determinantes centrais do bem-estar psicológico. As pesquisas, além de buscarem informações objetivas, passam a incluir procedimentos que busquem informações subjetivas sobre a percepção e o valor que os trabalhadores atribuem às condições de trabalho (independente de como tais condições se apresentam), ou, ainda, o uso combinado de ambos os procedimentos: objetivo e subjetivo (ÁLVARO; GARRIDO, 2006).

Seguindo a tendência atual do campo de estudos em saúde mental e trabalho, a presente pesquisa abordará a saúde dentro de um conceito positivo (bem-estar psicológico). Portanto, estar mentalmente saudável significa manter um equilíbrio entre as experiências emocionais positivas e negativas, de modo que os sentimentos positivos prevaleçam sobre os negativos. Tomou-se por base a abordagem psicossociológica que 
tem como um dos pressupostos a ideia de que o bem-estar psicológico é um construto complexo e diretamente ligado ao ambiente social em que os indivíduos participam. Assim, para estabelecer relações mais apropriadas entre as variáveis estudadas (saúde mental e regime de plantão), foi imprescindível conhecer o ambiente laboral dos enfermeiros plantonistas, considerando o que eles pensam do seu horário de trabalho, das exigências e pressões que os envolve e como os influencia nas relações sociais, familiares e na autoeficácia do trabalho.

\section{Método}

A pesquisa é do tipo descritiva, visto que descreve os dados, estabelecendo relações entre as principais variáveis do estudo, mas sem manipulá-las (GIL, 1987). Também segue um desenho transversal, definido por Bordalo (2006) como um tipo de estudo no qual fator e efeito são observados num dado momento histórico.

\section{Participantes da pesquisa}

Na cidade de Campina Grande (PB), a equipe de enfermagem do SAMU é composta por 63 profissionais trabalhando em regime de plantão (15 enfermeiros e 48 técnicos-auxiliar de enfermagem). A amostra foi formada a partir de uma estratégia acidental, a qual Sarriá, Guardiã e Freixa (1999) classificam como um processo de amostragem casual, no qual, os participantes são incluídos de acordo com a acessibilidade e disponibilidade em colaborar com a pesquisa. Com base nesse procedimento, obteve-se a participação de 34 profissionais que estavam em pleno exercício da função, sendo 23 técnicos-auxiliares, 9 enfermeiros e 2 não especificaram a função. A amostra correspondeu a $54 \%$ da população, sendo a maioria do sexo feminino $(84,4 \%)$, casada $(76,7 \%)$, com idade variando entre 23 a 56 anos $(\mathrm{M}=36,7$; $\mathrm{DP}=8,9)$ e tendo em média 2 filhos. 
Quanto à escolaridade, 43,8\% dos técnicos-auxiliares de enfermagem completaram o ensino médio, sendo este o grupo com menor renda salarial (inferior a três salários mínimos), mesmo quando possui outro emprego ou atividade remunerada ${ }^{3}$. Dentre os enfermeiros, 21,9\% concluíram pós-graduação e ganham acima de três salários mínimos, podendo essa faixa salarial dobrar quando possui outro vínculo empregatício. A amostra trabalha há pelo menos 12 anos na profissão, sendo que os menos experientes têm oito anos de tempo de serviço e os mais experientes têm mais de dez, existindo casos com até 30 anos na profissão, sendo, portanto, uma equipe com larga experiência profissional.

\section{Instrumentos}

Avaliou-se o bem-estar psicológico da amostra por meio do Questionário de Saúde Geral (QSG-12), elaborado por Goldberg, em 1972, para identificar transtornos psíquicos menores de caráter não psicótico, em uma escala de quatro pontos (0 a 3). Existem várias versões desse instrumento, sendo que a de 12 itens corresponde a versão mais reduzida e vem sendo amplamente usada em estudos referentes a empregos e problemas ocupacionais. O QSG-12 conta com vários estudos de validação nacional (BORGES; ARGOLO, 2002; GOUVEIA et al., 2003), sendo que a análise fatorial desenvolvida por Borges e Argolo (2002) aponta a adequação em medir dois fatores do bem-estar psicológico: 1) Redução da Autoeficácia e, 2) Tensão Emocional e Depressão. O primeiro fator reúne itens que dizem respeito à competência percebida pelo sujeito para realizar suas atividades, e o segundo fator reúne itens referentes a sentimentos de tensão, esgotamento emocional e depressão.

3 Estimou-se que 59,2\% da amostra tem mais de um emprego ou exerce outra atividade remunerada. 
Para identificar o que pensam os enfermeiros sobre o regime de plantão, elaborou-se um questionário semiestruturado que possibilitou caracterizar o regime de plantão, levantar as principais vantagens e desvantagens desse regime e como os participantes organizam sua vida em torno dele. Utilizou-se também uma Ficha Sociodemográfica que recolheu dados gerais como: idade, estado civil, escolaridade, tempo de serviço, entre outros, para caracterizar a amostra, sendo tais características já resumidas na seção que descreve os participantes da pesquisa. A versão completa dos instrumentos foi organizada em forma de protocolo para fins de coleta dos dados.

\section{Procedimento de coleta dos dados}

A aplicação dos instrumentos ocorreu no próprio local de trabalho dos participantes, de acordo com a conveniência de tempo e horário dos mesmos e após autorização, por escrito, da direção geral do SAMU. Os protocolos eram entregues aos enfermeiros juntamente com o Termo de Consentimento Livre e Esclarecido (TCLE), e antes de preencher os questionários, todos eram informados sobre os objetivos e os aspectos éticos da pesquisa. Após aproximadamente 30 minutos, tempo levado para responder os questionários, os participantes voltavam ao trabalho. Participaram enfermeiros de ambos os sexos que estavam em pleno exercício da função e que aceitaram assinar o termo de concordância (TCLE).

\section{Procedimento de análise dos dados}

As respostas ao QSG-12 foram digitadas em forma de banco de dados do SPSS (Statistical Package for Social Science for Windows). No caso do questionário semiestruturado, as respostas foram categorizadas com base na técnica de análise de conteúdo proposta por Bardin (1995), sendo que o primeiro passo consistiu na preanálise das respostas, 
em seguida procedeu-se com a identificação e codificação das categorias empíricas existentes nas respostas e, finalmente, registraram-se as categorias no banco de dados do SPSS. Uma vez concluído o banco de dados, foram efetuadas as análises estatísticas descritivas (médias, percentagens e desvios-padrão) e elaboradas tabelas cruzadas.

\section{Análise e discussão dos resultados}

\section{O ambiente de trabalho dos enfermeiros em regime de plantão}

O SAMU é um tipo serviço criado pelo SUS (Sistema Único de Saúde) para prestar assistência de saúde em caráter de urgência à população, objetivando reduzir o número de óbitos, o tempo de internação e as sequelas decorrentes da falta de socorro (ARAÚJO, 2006).

Em Campina Grande, o SAMU foi inaugurado em junho de 2004, com atendimentos na Central de Regulação Médica de Urgências, local onde são recebidas ligações telefônicas, identificadas às informações e classificada a gravidade dos casos; em seguida, são decididos os procedimentos a serem tomados, podendo ser uma orientação médica ou envio de unidades para o local da chamada telefônica. Nesta central, trabalham 190 profissionais, incluindo médicos reguladores e intervencionistas, pessoal de enfermagem, condutores socorristas e telefonistas auxiliares de regulação médica. São os médicos reguladores que orientam os demais profissionais durante o atendimento à vítima, e caso a situação envolva risco de morte, um médico intervencionista será acionado para se deslocar até o paciente. Durante todo o processo de atendimento, conta-se com a ajuda dos enfermeiros e dos técnico-auxiliares de enfermagem, tendo-se em vista a estabilização do paciente, e se necessário, a transferência do mesmo para um hospital. 
Para manter um atendimento ágil e satisfatório, o serviço conta com dois tipos de veículos para prestação de socorro, no total de nove unidades, das quais sete são Unidades de Socorro Básico (USB) e duas são Unidades de Socorro Avançado (USA); dessa última, uma opera em parceria com a Polícia Rodoviária Federal. A USB conta com uma equipe formada por um condutor socorrista e um técnico-auxiliar de enfermagem, ambos responsáveis pelo atendimento de pacientes com risco de morte moderado e que não necessitam de intervenção médica direta no local e/ou durante o transporte até o serviço de destino, estando sob regulação médica durante todo o atendimento. A USA tem uma equipe composta por três profissionais, sendo um condutor socorrista, um médico e um enfermeiro. Esse tipo de veículo é destinado ao atendimento dos casos mais graves que necessitam de intenso cuidado médico (ARAÚJO, 2006).

Como o SAMU funciona durante 24 horas ininterruptas, os profissionais se revezam em regime de plantão de 12 horas, sendo que a troca de turmas ocorre regularmente em um determinado horário. No caso específico da equipe de enfermagem, a primeira turma inicia o expediente matutino às $7 \mathrm{~h}$ e encerra às $19 \mathrm{~h}$, quando começa o plantão noturno da turma seguinte. Na passagem dos plantões, as equipes se encontram e trocam informações sobre o que transcorreu durante o expediente. Após 12 horas consecutivas de trabalho, as equipes folgam dois dias.

Dentro desse esquema, os enfermeiros só poderiam cumprir, no máximo, 36 horas de trabalho semanal no SAMU (equivalente a três plantões). Contudo, quando se indagou no questionário semiestruturado sobre a carga horária de trabalho semanal, identificou-se que apenas $22,7 \%$ da amostra trabalham em torno de 36 horas, enquanto $77,3 \%$ trabalham muito acima dessa carga horária, inclusive $41 \%$ ultrapassam 64 horas de trabalho semanal. 
Essa sobrecarga horária seria impossível se o único vínculo empregatício fosse o SAMU. Mas, conforme dito, 59,2\% da amostra possui outro emprego ou atividade remunerada, o que vem ocasionando aumento na jornada laboral e, consequentemente, comprometendo o tempo de folga.

De fato, quando se perguntou como as folgas são distribuídas, constatou-se que somente $25 \%$ da amostra usufruem os dois dias de folga após o plantão no SAMU, enquanto $37,4 \%$ não dispõem desse intervalo ou sequer conseguem estipulá-lo por ter mais de um emprego (Tabela 1). Nota-se que, para a maioria, o tempo de folga praticamente inexiste e, mesmo entre aqueles que dispõem, os intervalos são muito curtos, sendo insuficientes à boa recuperação física e psíquica e à prática de atividades de lazer. Em decorrência da carga horária elevada e folgas reduzidas, constatou-se que entre os enfermeiros, os momentos de lazer são escassos, e quando existem, são frequentemente realizados em casa com amigos e familiares (52,9\% das respostas), sendo raras algumas atividades, como viajar (44,1\% das respostas). Esses resultados sobre o tempo dedicado ao trabalho e ao descanso impressionam por parecer que o modo de viver de boa parte dos enfermeiros se resume praticamente ao trabalho e, também, preocupam porque o bom desempenho de um trabalho depende, em parte, que a pessoa trabalhe descansada.

Tabela 1: Distribuição das folgas no trabalho dos profissionais de enfermagem

\begin{tabular}{lcc}
\hline \multicolumn{1}{c}{ Distribuição das folgas } & Frequência & $\begin{array}{c}\text { Proporçáo das } \\
\text { respostas }\end{array}$ \\
\hline Sem folga/não especificou por ter outros empregos & $\mathbf{1 2}$ & $\mathbf{3 7 , 4}$ \\
2 dias após o plantão & $\mathbf{8}$ & $\mathbf{2 5 , 0}$ \\
1 dia após o plantão & 6 & 18,7 \\
Finais de semana & 5 & 15,7 \\
Tardes e domingos & 1 & 3,1 \\
\hline Total de respostas & 32 & 100,0 \\
\hline
\end{tabular}


No questionário semiestruturado, também foi solicitado que os enfermeiros apontassem as vantagens e as desvantagens do regime de plantão. Conforme se vê na tabela 2, a maioria das respostas destaca como principal vantagem a possibilidade de conciliar trabalho e estudo $(41,7 \%)$, sendo, nesse caso, o regime de plantão visto como um horário flexível que oportuniza o crescimento profissional. A segunda maior vantagem é poder compatibilizar o tempo de descanso cuidando da família $(22,2 \%)$.

Tabela 2: Vantagens do regime de plantão

\begin{tabular}{lcc}
\hline \multicolumn{1}{c}{ Benefícios e/ou vantagens } & Frequência & $\begin{array}{c}\text { Proporção das } \\
\text { respostas }\end{array}$ \\
\hline Poder estudar e trabalhar / ter outro & $\mathbf{1 5}$ & $\mathbf{4 1 , 7}$ \\
emprego/ crescer profissionalmente & 8 & 22,2 \\
Poder descansar e cuidar da família & 7 & 19,4 \\
Servir à sociedade & 4 & 11,1 \\
Remuneração satisfatória & 1 & 2,8 \\
Horário traz pouca vantagem & $\mathbf{3 5}$ & $\mathbf{1 0 0 , 0}$ \\
\hline Total de respostas & &
\end{tabular}

Comparando-se as tabelas 1 e 2, fica evidente que os enfermeiros que apontam o beneficio da flexibilidade são provavelmente os mesmo que não conseguem ter folgas porque tentam conciliar o trabalho no SAMU com outros empregos ou estudo, enquanto os que preferem repousar e cuidar da família são provavelmente os mesmos que usufruem das folgas, livre de outros compromissos laborais.

Quanto às desvantagens (Tabela 3), 20,7\% das respostas se referem à ausência da família como o principal prejuízo do regime de plantão, pelo fato de trabalhar muitas horas seguidas. Existe ainda um número significativo de respostas $(17,6 \%)$ referentes ao desgaste físico e mental que podem estar relacionadas ao número de folgas insuficientes para a recomposição física e psíquica necessárias ao bom desempenho do trabalho. 
Tabela 3: Desvantagens do regime de plantão

\begin{tabular}{lcc}
\hline \multicolumn{1}{c}{ Prejuízos e/ou desvantagens } & Frequência & $\begin{array}{c}\text { Proporção } \\
\text { das respostas }\end{array}$ \\
\hline Ausência da família & 7 & $\mathbf{2 0 , 7}$ \\
$\begin{array}{l}\text { Desgaste físico e mental (estresse e } \\
\text { depressão) }\end{array}$ & 6 & $\mathbf{1 7 , 6}$ \\
Risco de acidentes & 5 & 14,7 \\
Noites sem dormir & 3 & 8,8 \\
Ausência de folgas em feriados e fins de & 2 & 5,9 \\
semana & 1 & 2,9 \\
Isolamento social & 1 & 2,9 \\
Má remuneração & 1 & 2,9 \\
Falta de qualidade de vida & \multicolumn{1}{c}{ Total de respostas } & $\mathbf{2 7}$ \\
\hline
\end{tabular}

Quando se perguntou mais diretamente se o regime de plantão traz alguma implicação para a vida familiar, 61,3\% das respostas revelam que a família não sofre nenhum tipo de prejuízo (Tabela 4). Contudo, algumas consequências negativas como: pouco tempo para estar com a família (12,9\%), não poder gozar dos feriados nem participar de confraternizações familiares $(9,7 \%)$ e problemas de relacionamento $(6,5 \%)$ evidenciam certo mal-estar no âmbito familiar provocado pelo regime de trabalho. 
Tabela 4: Prejuízos do horário de trabalho para a vida familiar

\begin{tabular}{lcc}
\hline \multicolumn{1}{c}{ Prejuízos e/ou desvantagens } & Frequência & $\begin{array}{c}\text { Proporção } \\
\text { das respostas }\end{array}$ \\
\hline Não traz implicações & 19 & $\mathbf{6 1 , 3}$ \\
Pouco tempo para assistir à família & 4 & $\mathbf{1 2 , 9}$ \\
Ausência em feriados e confraternizações & 3 & $\mathbf{9 , 7}$ \\
Problemas de relacionamento & 2 & $\mathbf{6 , 5}$ \\
Mais responsabilidades com a saúde da & 1 & 3,2 \\
família & 1 & 3,2 \\
Traz implicações, mas não sabe especificar & \multicolumn{1}{c}{ Total de respostas } & $\mathbf{3 1}$ \\
\hline
\end{tabular}

Um balanço geral desses resultados mostra que os profissionais de enfermagem do SAMU têm carga horária de trabalho extensa e folga reduzida, podendo estar submetidos a condições desfavoráveis ao bem-estar físico, psíquico e social, sobretudo, quando possuem outro vínculo empregatício. Como o regime de plantão demanda grande capacidade adaptativa, os enfermeiros vivem na contramão da sociedade, ou seja, veem-se constantemente forçados a ajustar seu horário aos do restante da sociedade e aos da família, por isso não é de estranhar que algumas repercussões negativas já se evidenciem na saúde e na vida desses trabalhadores, tais como: propensão a fadiga, participação restrita em atividades familiares e de lazer e conflitos de ordem familiar.

Apesar desses prejuízos, os enfermeiros percebem mais vantagens que desvantagens do regime de plantão, sendo que os maiores percentuais de benefícios percebidos estão diretamente vinculados às folgas, chamando a atenção para o fato de que a folga aparece como um aspecto altamente valorizado entre os enfermeiros. O problema é que o tempo de folga vem sendo preenchido, sobretudo, com outros empregos e não para fins de repouso ou prática de atividades de lazer, o que poderá agravar os prejuízos psicossociais já evidentes e levar à manifestação de outros que ainda não se evidenciaram na amostra. 


\section{Saúde mental (bem-estar psicológico) da amostra}

O bem-estar psicológico da amostra foi avaliado por meio dos dois fatores empíricos que compõem o QSG12: Depressão e Tensão Emocional e Deterioração da Autoeficácia.

O QSG-12 é uma escala tipo Likert que varia de 0 a 3, sendo o ponto médio igual a 1,5. Escores próximos ou acima do ponto médio da escala indicam efeitos nocivos à saúde; assim, quanto mais elevada a pontuação no fator Depressão e Tensão Emocional, mais o indivíduo se sente emocionalmente tenso e esgotado, e quanto mais elevada a pontuação no fator Deterioração da Autoeficácia, mais o indivíduo sente dificuldade em realizar as atividades profissionais que lhe competem.

A Tabela 5 aponta que a média encontrada no fator Depressão e Tensão Emocional foi de 1,35, estando este valor próximo ao ponto médio da escala, o que sinaliza haver certo nível de tensão emocional entre os participantes. Quando se examina a distribuição dos escores por intervalos, constatase que apenas 2 sujeitos (5,9\%) apresentam nível reduzido de tensão emocional, porém 32 sujeitos $(94,1 \%)$ se encontram emocionalmente esgotados, sendo que 1 deles $(2,9 \%)$ experimenta acentuado nível de tensão, podendo-se concluir que praticamente toda a amostra está com a saúde mental em risco.

Quanto ao fator Deterioração da Autoeficácia, a média foi de 1,09 (Tabela 5), indicando, a priori, discreta dificuldade entre os enfermeiros para executarem suas tarefas diárias. Porém, quando se calcula a distribuição dos escores por intervalo, os resultados revelam que apenas 3 sujeitos $(8,8 \%)$ sentem sua competência profissional pouco afetada, enquanto 31 sujeitos $(91,2 \%)$ já percebem a competência em declínio. 
Tabela 5: Escores do resultado do QSG-12 para os profissionais de enfermagem

\begin{tabular}{lcccccc}
\hline \multicolumn{1}{c}{ Fatores } & N & Média & \multicolumn{5}{c}{$\begin{array}{c}\text { Frequência de } \\
\text { participantes por intervalo }\end{array}$} & $\begin{array}{l}\text { Desvio- } \\
\text { padrão }\end{array}$ \\
\cline { 5 - 7 } & & & $\mathrm{X} \leq 1$ & $1 \leq \mathrm{X} \leq 2$ & $\mathrm{X} \geq 2$ & \\
\hline $\begin{array}{l}\text { Depressão e Tensão } \\
\text { Emocional }\end{array}$ & 34 & $\mathbf{1 , 3 5}$ & 2 & $\mathbf{3 1}$ & 1 & 0,65 \\
\hline $\begin{array}{l}\text { Deterioração da } \\
\text { Autoeficácia }\end{array}$ & 34 & $\mathbf{1 , 0 9}$ & 3 & $\mathbf{3 1}$ & - & 0,51 \\
\hline
\end{tabular}

Conforme se pode ver, os resultados apresentados, na tabela 5, sugerem que os sujeitos tensos e propensos à depressão são os mesmos que experimentam a competência no trabalho afetada. Para melhor caracterizar esses sujeitos, aplicou-se o cálculo de tabela cruzada tomando-se os fatores do QSG-12 e as variáveis sociodemográficas. Os resultados atestam que os sujeitos mais afetados psicologicamente são do sexo feminino, casados, com dois ou mais filhos e com renda mensal inferior a dois salários mínimos.

Conjuntamente, os resultados sugerem que a dificuldade dos profissionais de enfermagem em conciliar horário(s) de trabalho com a vida social e familiar está gerando tensão e esgotamento emocional e conduzindo os profissionais a perceberem baixa eficiência no serviço prestado à sociedade, sendo a situação das mulheres ainda mais grave, muito provavelmente porque sua jornada de trabalho se estende para as atividades domésticas, como cuidar da casa, marido e filhos.

De acordo com a literatura (ALMONDES, 2004; ROSA; COLLIGAN, 2002; RUTENFRANZ; KNAUTH, FISCHER, 1989), além de interferir na vida social, familiar e no lazer, as repercussões do trabalho em regime de plantão, também, podem se manifestar de outras formas, sendo as dificuldades de dormir e a falta de saúde alguns dos sintomas mais comuns. 
Mesmo considerando que a qualidade de sono varia entre as pessoas, alguns autores (OLIVEIRA et al., 2006; RUTENFRANZ; KNAUTH, FISCHER, 1989) compartilham a ideia de que um adulto deve dormir em média de sete a oito horas por dia. Quando se perguntou no questionário semiestruturado sobre a duração diária do sono, apenas $32,2 \%$ dos enfermeiros atestam dormir de sete a nove horas, estando dentro do tempo considerado pela literatura como suficiente para que desperte descansado. Contudo, a maioria (51,6\%) dorme menos de seis horas diárias e 16,2\% afirmam ter um sono irregular. Esses resultados apresentados na tabela 6 revelam valores inferiores aos necessários para o repouso e reabilitação física e mental da amostra que podem conduzir a uma fadiga crônica e, consequentemente, a erros e acidentes de trabalho.

Tabela 6: Duração diária do sono dos profissionais de enfermagem

\begin{tabular}{lcc}
\hline \multicolumn{1}{c}{ Duração do sono } & Frequência & Proporção das respostas \\
\hline Menos de 6 horas por dia & 16 & $\mathbf{5 1 , 6}$ \\
De 7 a 9 horas por dia & 10 & $\mathbf{3 2 , 2}$ \\
Sono irregular & 5 & $\mathbf{1 6 , 2}$ \\
\hline \multicolumn{1}{c}{ Total de respostas } & $\mathbf{3 1}$ & $\mathbf{1 0 0 , 0}$ \\
\hline
\end{tabular}

Quando se levantou os principais problemas de saúde que os enfermeiros declaram estar diretamente associados ao trabalho, as respostas (Tabela 7) indicam que a principal enfermidade contraída no trabalho é a hipertensão (10,6\%), seguida em uma frequência mais baixa dos problemas de coluna, cefaléia e estresse $(7,9 \%$, respectivamente). 
Tabela 7: Problemas de saúde associados ao trabalho que a equipe de enfermagem declara ter

\begin{tabular}{lcc}
\hline Problema de saúde & Frequência & Proporção das respostas \\
\hline Hipertensão & 4 & 10,6 \\
Problemas na coluna & 3 & 7,9 \\
Enxaqueca/cefaléia & 3 & 7,9 \\
Estresse/tensão & 3 & 7,9 \\
Dores corporais & 2 & 5,3 \\
Gastrite & 1 & 2,6 \\
Taquicardia & 1 & 2,6 \\
Depressão & 1 & 2,6 \\
Medo da morte & 1 & 2,6 \\
\hline \multicolumn{1}{c}{ Total de respostas } & 19 & 100,0 \\
\hline
\end{tabular}

Embora a manifestação desses sintomas seja mais visível no plano individual, é preciso considerar que repercussões negativas já podem estar ocorrendo no plano organizacional (diminuição da eficácia no trabalho) e societal (baixa qualidade dos serviços). Também é preciso considerar que esses sintomas, se prolongados, podem tornar o organismo susceptível ao surgimento de doenças, indicando o regime de plantão como um fator de risco à saúde.

\section{Considerações finais}

O regime de plantão, como insistentemente vem se expondo, supõe ameaça ao bem-estar psicológico dos enfermeiros, muito embora não se possa atribuir todos os efeitos negativos da saúde a tal regime isoladamente, mesmo porque foi possível verificar que a folga apresenta mais elementos positivos do que negativos para os participantes do estudo. A questão principal parece girar em torno do que se tem 
feito com as folgas e como isso tem afetado o bem-estar desses trabalhadores. Tomando-se por base a consistência das alterações psíquicas entre os enfermeiros sob tal regime de trabalho, e os conteúdos, segundo os quais eles o avaliam, não há como descartar o regime de plantão como uma dimensão das condições de trabalho que agrava a redução do bem-estar psíquico e que vem gerando dificuldades nos enfermeiros em compatibilizar a vida laboral com a familiar e de lazer.

Os resultados são preocupantes e, certamente, não são aqueles esperados ou almejados pelos trabalhadores ou pela instituição. Espera-se, no entanto, que tais resultados sejam úteis aos enfermeiros e aos dirigentes do SAMU para que, juntos, possam pensar alternativas contra as fontes dos problemas. Recomenda-se, então, a adoção de algumas medidas como: planejar e executar programas de qualidade de sono e introduzir massagens ou atividades de relaxamento antes, durante ou após o expediente, e outras providências mais amplas como: adoção de políticas de prevenção de saúde e contínuo aperfeiçoamento da organização do regime de plantão (horas de trabalho e de folga) a fim de minimizar os efeitos negativos desse tipo de jornada. Ainda que muitas empresas considerem estas medidas onerosas, elas podem se revelar extremamente úteis em combate ao desgaste físico e mental, sendo, portanto, perfeitamente viáveis para recuperação da saúde da amostra e, consequentemente, da própria organização, visto que trabalhadores saudáveis tendem a ser mais eficazes.

Em função do caráter exploratório do estudo, sugerem-se novas pesquisas que levem em consideração outras variáveis, como: apoio social e estratégias de enfrentamento, entre outras, para avaliar mais profundamente o bem-estar psicológico desses profissionais de saúde. 


\section{Referências}

ALBUQUERQUE, C.; OLIVEIRA, C. P. F. Saúde e doença: significações e perspectivas em mudanças. Revista do ISPV, n. 25, jan 2002. Disponível em: <http://www.ipv.pt/millenium>. Acesso em: 09 de jun. 2008.

ALMONDES, K. M. Qualidade do sono e qualidade de vida em trabalhadores: estudo de viabilidade da implantação de um programa de higiene do sono na Petrobrás. Relatório apresentado à Petrobrás (RN/CE). Universidade Federal do Rio Grande do Norte, Natal. 2004.

ÁLVARO, J. L. Desempleo y bienestar psicológico. Madrid: Siglo Veintiuno de España, 1992.

ÁlVARO, J. L.; TORREGROSA, J. R.; GARRIDO, A. Estructura social y salud mental. In: ÁLVARO, J. L.; TORREGROSA, J. R.; GARRIDO (Orgs.). Influências sociales y psicológicas sobre la salud mental. Madrid: Siglo XXI, 1992, p. 9-30.

ÁLVARO, J. L.; GARRIDO, A. Trabajo, ocupación y bienestar. In: GARRIDO, A. (Coord.). Sociopsicología del trabajo. Barcelona: UOC, 2006. p. 99-132.

ARAÚJO, A. A. A casuística do atendimento de urgência e emergência dos clientes atendidos pelo SAMU - Campina Grande - PB. Monografia - Universidade Estadual da Paraíba, Campina Grande, 2006.

BARBOSA, S. C.; BORGES, L. O. Saúde mental dos operadores de petróleo sob o turno fixo: os operadores de Alto do Rodrigues e de Mossoró. In: BORGES, L. O.; BARBOSA, S. C. Aspectos Psicossociais do trabalho dos Petroleiros: dois estudos empíricos no Rio Grande no Norte. Natal: EduFRN, 2007. p. 187-220.

BARBOSA, S. C. Saúde mental em operadores de petróleo do Rio Grande do Norte. 2008. Tese de doutorado - Universidade Federal do Rio Grande do Norte, Natal, 2008. 
BARDIN, L. Análise de conteúdo. Lisboa: Edições 70, 1995.

BORDALO, A. A. Estudo transversal e/ou longitudinal. Revista Paranaense de Psicologia, 2006. Disponível em: < http://scielo. iec.pa.gov.br>. Acesso em: 6 de fevereiro de 2009.

BORGES, L. O.; ARGOLO, J. C. T. Adaptação e validação de uma escala de bem-estar psicológico para uso em estudos ocupacionais. Avaliação psicológica, v. 1, 2002, p. 17-27.

CANGUILHEM, G. O normal e o patológico. Rio de Janeiro: Forense Universitária, 1995.

FISCHER, M. F.; MORENO, C. R. C.; ROTENBERG, L. Trabalhos em turnos e noturno na sociedade 24 horas. São Paulo: Atheneu, 2003.

GARRIDO, A. El trabajo: presente y futuro. In: GARRIDO, A. (Coord.). Sociopsicología del trabajo. Barcelona: UOC, 2006. p. 19-55.

GIL, A. C. Métodos e técnicas de pesquisa social. São Paulo: Atlas, 1987.

GOUVEIA, V. V. et al. A utilização do QSG-12 na população geral: estudo de sua validade de construto. Psicologia: Teoria e Pesquisa, 19, 2003, p. 241-248.

GRILO, A. M. Os modelos de saúde - suas implicações na humanização dos serviços de saúde. In: Congresso Hispano-Português da Psicologia, 2., 2004, Lisboa. Anais eletrônico...Lisboa: Revista de Psicólogia general y aplicada, 2005. Disponível em: <http:// www.fedap.es/IberPsicologia>. Acesso em: 11 jun 2008.

IBAÑES, N.; MARSIGLIA, R. Medicina e saúde: um enfoque histórico. In: CANESQUI, A. M. (Org.). Ciências sociais e saúde para o ensino médico. São Paulo: Hucitec, 2000. p. 49-98).

JAHODA, M. Empleo y desempleo: un análisis sócio-psicológico. Madrid: Morata, 1987. 
OGDEN, J. Psicologia da saúde. Lisboa: Climepsi, 1999.

OLIVEIRA, et al. O trabalho noturno e suas repercussões na saúde e na vida cotidiana de trabalhadores metalúrgicos do vale do Paraíba do estado de São Paulo. Revista Psicologia: organizações e trabalho, v. 6, n. 2, 2006, p. 65-84.

OMS. Organização Mundial de Saúde. 1948. Disponível em: <http://www.who.int/about/es>. Acesso em: 11 de jun. 2007.

PIRES, D. Reestruturação produtiva e trabalho em saúde no Brasil. São Paulo: Annablume, 1998.

QUEIROZ, M. S. Saúde e doença: um enfoque antropológico. Bauru, SP: EDUSC, 2003.

ROSA, R. R.; COLLIGAN, M. J. El trabajo por turno en lenguaje sencillo. 2002. Disponível em: <www.cdc.gov/spanish/niosh>. Acesso em: 08 de jan. 2007.

RÉGIS-FILHO, G. I.; SELL, I. Síndrome da má-adaptação ao trabalho em turnos: uma abordagem ergonômica. Itajaí: Univale, 2000 .

RUTENFRANZ, J.; KNAUTH, P.; FISCHER, F. M. Trabalho em turnos e noturno. São Paulo: Hucitec, 1989.

SARRIÁ, A.; GUARDIÃ, J.; FREIXA, M. Introducción a la estadística en Psicologia. Barcelona: Ediciones de la Universitat de Barcelona, 1999.

SCLIAR, M. Do mágico ao social: trajetória da saúde pública. São Paulo: SENAC, 2002.

VENÂNCIO, J. Textos de Apoio em Saúde Mental. Rio de Janeiro: Fio Cruz, 2003.

WARR, P. Work, unemployment, mental health. New York: Oxford University Press, 1987. 



\title{
9
}

\section{Grupo com pacientes institucionalizados portadores de esquizofrenia: contribuições da Psicologia da Saúde e da Psicologia Humanista}

\author{
Carla de Sant'Ana Brandão \\ Danielly Farias da Silva Araújo \\ Lorena Leal Máximo
}

\begin{abstract}
A pós a promulgação da Lei 10.216, a assistência em saúde mental passou a privilegiar o investimento nos $\angle$ serviços de base comunitária para o tratamento de pessoas portadoras de transtornos mentais. É a partir desta Lei e das Conferências Nacionais de Saúde Mental que a Reforma Psiquiátrica no Brasil passa a concretizar, com o apoio das políticas de saúde mental do Governo Federal, mudanças significativas no tratamento de portadores de transtornos mentais através de programas de desinstitucionalização. Ações fomentadas pelos governos federal, estadual e municipal possibilitaram a criação de programas substitutivos aos hospitais psiquiátricos, como o Programa de Volta para Casa (criado pela Lei 10.708, em 2003) e os Centros de Assistência Psicossocial (CAPS), a fim de reduzir progressivamente aquele modelo de assistência à saúde. Entretanto, apesar do fechamento gradual
\end{abstract}


dos hospitais psiquiátricos constituir parte importante do processo de reforma na saúde mental, é fundamentalmente importante o planejamento para a efetivação desta proposta. Até o fechamento de todos os hospitais psiquiátricos é necessária a avaliação e adequação do atendimento aos internos garantindo-lhes qualidade de vida e o restabelecimento de suas condições básicas de saúde e da capacidade de socialização possibilitando a estes a reintegração social.

Na perspectiva da Psicologia da Saúde, a análise das situações e dos problemas neste campo, bem como as intervenções decorrentes destas, direciona-se ao desenvolvimento da saúde humana, e não necessariamente a doença (REY, 1997). Com o foco na prevenção e na promoção da saúde, o trabalho do psicólogo torna-se essencial em espaços em que as condições não são favoráveis ao bem-estar físico, psíquico e social daqueles que neles se inserem. A necessidade de criação de novas formas de atendimento ao portador de transtorno mental nos serviços de saúde já anuncia a inadequação dos serviços e do tratamento tradicionalmente oferecido nas instituições psiquiátricas. Atualmente, sabemos que um dos principais desafios dos hospitais psiquiátricos é lidar com o abandono dos internos por parte dos familiares. Muitos dos que se encontram nesta condição, concomitante a perda de contato com a família, perdem também o contato social e a esperança de um possível retorno ao convívio social. Vivem em completo isolamento. Sabemos que a situação de isolamento por longo período é geradora, em grande parte das pessoas, de comprometimentos nas habilidades cotidianas dificultando, portanto, a reintegração social e circulação livre, autônoma e com segurança em ambientes externos ao hospital (DIMENSTEIN, 2006).

Um dos mais antigos hospitais psiquiátricos da rede pública situado na região nordeste do Brasil tem entre seus internos residentes várias pessoas nas condições de isolamento e abandono familiar. Muitos deles, oriundos de cidades do interior 
não têm contato com suas famílias há mais de dez anos. Assim, além das condições de saúde que motivaram a internação destes pacientes e que, de certo modo, excluíram-nos da sociedade, o abandono familiar representa uma segunda exclusão, já que a perda de contato com seus entes queridos rouba-lhes parte de suas histórias e, inclusive, a possibilidade de retorno. Sob tais condições, suas relações restringem-se ao contato com outros internos e com os profissionais de saúde e funcionários do próprio hospital, nem sempre com treinamento adequado para atuar de modo a promover saúde no contexto institucional da saúde. Promover saúde envolve, de acordo com o documento fundador deste movimento (A Carta de Ottawa), valores como igualdade, solidariedade, cidadania, desenvolvimento e participação, além de vida e saúde (BUSS, 2003). Nesse sentido, atuar na promoção a saúde requer um olhar que se sobreponha ao foco na doença. A base desta atuação é a transformação das condições de vida possíveis de gerar problemas de saúde. Trata-se da criação de estratégias geradoras do bem-estar e do desenvolvimento de condições favoráveis à saúde e à qualidade de vida (CZERESNIA, 2003). Entretanto, o que se verifica no modo de atuação nos hospitais psiquiátricos é o foco na doença, nos sintomas, no tratamento, na normatização da rotina e nas formas de disciplinamento dos internos (DIMENSTEIN, 2004). Desse modo, os pacientes psiquiátricos internos em condições de isolamento por longo período tendem a apresentar perda de habilidades para o cuidado pessoal, o aparecimento de dificuldades relacionadas a autonomia, às interações sociais e à afetividade. Nos casos em que estas dificuldades constituem características de determinados quadros clínicos, observamos a sua exacerbação ao longo dos anos. É o caso, por exemplo, de pacientes com diagnóstico de esquizofrenia que apresentam como sintomatologia principal, nas diferentes modalidades da patologia, as disfunções cognitivas e emocionais que acometem a percepção, o pensamento inferencial, a linguagem e a comunicação, o monitoramento comportamental, o embotamento afetivo, 
a fluência e a produtividade do pensamento e do discurso, a capacidade hedônica, a volição e a atenção, gerando ainda prejuízo no funcionamento ocupacional ou social (A.P.A./ DSM-IV 1995).

Para intervir adequadamente nas condições de vida de pessoas internas em tais condições é necessário compreender a interação da pessoa com o ambiente, identificar os fatores de risco à saúde física, emocional e social e os fatores de proteção, os quais estão relacionados à condições geradoras de mudanças positivas nas respostas pessoais ao meio. Tomando como base os objetivos estabelecidos pela American Psychological Association (APA) para a Psicologia da Saúde, tais como, compreender e avaliar a interação entre bem-estar físico e fatores biológicos, psicológicos e sociais e buscar nas teorias e métodos de pesquisa em Psicologia meios para a promoção da saúde e o tratamento de doenças (CALVETTI, MULLER, NUNES, 2007) foi proposta à mencionada instituição psiquiátrica da rede pública situada, no nordeste do país, a realização de um trabalho grupal facilitado por profissionais e estudantes de Psicologia direcionado a pacientes com diagnóstico de esquizofrenia crônica que apresentassem necessidade de uma intervenção diferenciada das oferecidas pela instituição, haja vista as condições de isolamento e de agravamento das suas condições de saúde. Esta intervenção teve como finalidade gerar condições de humanização àqueles que, devido ao quadro clínico, às condições de saúde, em geral, e ao abandono familiar, vivem a situação de exclusão institucionalizada. Tomamos o termo humanizar no sentido adotado por Dimenstein (2004), referindo-se ao compromisso ético com a criação de formas de vida contrárias àquelas pautadas no medo, na discriminação, na exclusão e na impotência. Portanto, trata-se da viabilização da transformação das pessoas envolvidas ou do seu meio. Neste caso, o foco é o resgate e potencialização das capacidades dos internos que foram atrofiadas pela condição de restrição, dependência e isolamento. 


\section{A esquizofrenia, as condiçóes do paciente institucionalizado e as terapêuticas utilizadas}

A esquizofrenia é um transtorno psicótico que tem como elementos etiológicos a associação entre fatores biológicos e psicossociais. Entre as décadas de 1950 e 1990, estudos apontaram explicações para o desenvolvimento da esquizofrenia a partir do estabelecimento de certos padrões relacionais familiares patológicos, os quais teriam como característica principal a comunicação interpessoal disfuncional. As conclusões do estudo realizado nos Estados Unidos, em 1952, pelo antropólogo Gregory Bateson, indicaram que situações norteadas por padrões de comportamentos em que os pais criam situações antagônicas, ambas insuportáveis, frente às quais a criança deveria realizar uma escolha, contribuiriam para a desconexão com a realidade. Os padrões disfuncionais da família não seriam, contudo, suficientes para explicar a etiologia da doença, mas são necessários para compreender funcionalmente os fatores desencadeantes. Estudos realizados entre a década de 1990 e os anos 2000 indicam, a partir do modelo do neurodesenvolvimento, que a esquizofrenia tem origem a partir de algum transtorno no desenvolvimento compreendido entre a concepção e o nascimento. Associado a este, os fatores genéticos e os riscos ambientais são fortes colaboradores para o desencadeamento da doença, considerando, portanto, o caráter dinâmico e interacional destes elementos, apesar da preponderância dos fatores genéticos no surgimento do quadro esquizofrênico (ANDRADE, 2002).

O desencadeamento da doença e o aparecimento dos primeiros sintomas surgem, comumente, entre a adolescência e o início da idade adulta, em geral, antes dos 30 anos de idade, tornando o portador da doença parcial ou completamente inválido, improdutivo e dependente de familiares. Apesar da variedade de características que podem evidenciar a emergência de um quadro de esquizofrenia, haja vista 
cada subtipo (paranóide, desorganizado, catatônico, residual e indiferenciado) apresentar uma sintomatologia específica, os sintomas mais comuns e presentes na maioria dos casos são as alucinações, delírios, processos de pensamento perturbados e inundações cognitivas (HOLMES, 1997), humor depressivo, desinteresse generalizado, isolamento e descuido com a aparência pessoal e, como característica marcante nos diferentes quadros, destaca-se a perda de julgamento da realidade (ANDRADE, 2002). A classificação dos sintomas da esquizofrenia subdivide-se em sintomas 'positivos' e sintomas 'negativos'. Dentre os primeiros, destacam-se as alucinações e delírios; já dentre os negativos, a pobreza do conteúdo do pensamento e da fala, o embotamento ou rigidez afetiva, prejuízo do pragmatismo, dificuldade de sentir e expressar emoções e prazer, isolamento social e diminuição de iniciativa e da vontade são aspectos marcantes (A.P.A./ DSM-IV 1995).

O tratamento farmacológico atenua ou elimina tanto os sintomas positivos quanto os negativos. A ação da atividade antipsicótica surge nas primeiras seis semanas de tratamento com continuidade das melhorias por até seis meses, contudo, pode haver variação nas respostas ao tratamento de acordo com o paciente e o antipsicótico prescrito. De acordo com Kaplan e Sadock (1995), cerca de 70\% dos pacientes com este diagnóstico apresentam melhora significativa com uso de antipsicóticos, embora a eficácia do tratamento seja maior contra os sintomas positivos (alucinações e agitação). Cabe destacar que o tipo de antipsicótico empregado no tratamento é um aspecto importante para a observação da diminuição dos sintomas, pois, na classificação dos psicóticos típicos (primeira geração) e atípicos (segunda geração) ${ }^{1} \mathrm{o}$

1 São antipsicóticos típicos (Primeira geração): Haloperidol, flufenazina, pimozida, trifluoperazina, clorpromazina e o levomepromazina. E os antipsicóticos atípicos (Segunda Geração): Tioridazina, sulpirida, clozapina, risperidona, olanzapina, quetiapina e aripiprazol. 
que os difere são os mecanismos de ação de cada um e, consequentemente, a eficácia no tratamento. Os antipsicóticos de primeira geração (APG), mais convencionais, atuam predominantemente no bloqueio dos receptores da dopamina; já os antipsicóticos de segunda geração (ASG) promovem um bloqueio nos receptores dopaminérgicos e serotonérgicos. A diferença principal entre estes dois tipos de medicação é que os de segunda geração possibilitam melhores resultados em relação a diminuição tanto dos sintomas positivos quanto dos sintomas negativos, além de apresentarem menos efeitos colaterais $^{2}$ (CORDIOLI, 2000). Sobre a escolha do antipsicótico, Oliveira diz que:

Os antipsicóticos atípicos podem contribuir para a melhor qualidade de vida. Entretanto, os antipsicóticos convencionais permanecem como primeira escolha quando se consideram estritamente questões relativas ao custo do tratamento. Esse último aspecto ainda prevalece em nosso meio. (OLIVEIRA, 2000; p. 40)

2 Dentre os efeitos colaterais mais comuns provocados pelos medicamentos, destacam-se os chamados efeitos extrapiramidais, que são: Acatisia (sensação subjetiva de agitação psicomotora, ansiedade, incapacidade para relaxar, dificuldade de permanecer imóvel e a necessidade de alternar entre estar sentado ou de pé), Distonias ou Discinesias Agudas (movimentos estereotipados de grupos musculares que iniciam minutos ou horas após o início do uso do antipsicótico), Distonias ou Discinesia Tardia (movimentos estereotipados de grupos musculares, periorais, da língua, cabeça, tronco ou membros, que iniciam geralmente após o uso crônico de alta dosagem da medicação. Esse efeito colateral pode manifestar-se em forma de crises oculógiras, torcicolo, abertura forçada da boca, protusão da língua); e o Parkinsonismo (diminuição dos movimentos dos braços, da expressão e mímica faciais, rigidez, tremor das extremidades, hipersalivação, bradicinesia (movimentos lentos), acinesia (diminuição da espontaneidade dos movimentos)) (CORDIOLI, 2000). 
Tratando-se dos serviços públicos de saúde mental, o custo do tratamento é um aspecto importante. Em grande parte dos hospitais psiquiátricos da rede pública, o tratamento farmacológico prescreve antipsicóticos típicos, ou de primeira geração. Este é um dado importante para a avaliação dos quadros dos pacientes internos, já que além dos sintomas da doença e decorrentes do isolamento, o surgimento dos efeitos colaterais da medicação são aspectos que agravam o estado de saúde. Além disso, a medicação de primeira geração não é suficientemente eficaz na redução dos sintomas negativos, ou seja, na redução do embotamento afetivo, da dificuldade na expressividade, do isolamento e da capacidade de estabelecer contatos e socializar-se. Estes são os principais motivos para que o tratamento em casos de esquizofrenia seja mais eficaz quando há combinação da terapia psicofarmacológica com procedimentos de intervenção psicossocial. Neste sentido, os trabalhos de grupo são bastante efetivos na redução do isolamento social, no aumento do senso de coesão e na melhora nos testes de realidade dos portadores da esquizofrenia (KAPLAN, SADOCK e GREBB, 1997). Uma vez que a esquizofrenia tem como elementos etiológicos os fatores genéticos, psicossociais e os riscos ambientais e os agentes farmacológicos são usados para presumíveis desequilíbrios químicos, estratégias não farmacológicas devem abordar questões não-biológicas. Portanto, dentre os profissionais de saúde é consenso que a combinação psicoterapia - farmacoterapia possibilita maiores chances de sucesso no tratamento do que qualquer tipo de terapêutica isolada (KAPLAN e SADOCK, 1995).

Andrade (2002), ao propor uma intervenção integrativa, sugere que a psicoterapia seja desenvolvida com cautela, sempre respeitando o ritmo, as necessidades e possibilidades do paciente. Nesse sentido, o estabelecimento da confiança na relação terapêutica e de um clima de segurança para com o paciente deve permear as etapas constituintes do processo psicoterápico. Haja vista a condição de isolamento em que 
comumente se encontram os pacientes com esquizofrenia residentes em hospitais psiquiátricos devido ao afastamento da realidade característico do quadro clínico da doença, as restrições institucionais e a discriminação social e familiar, o vínculo psicoterapeuta/paciente deverá, com base na confiança estabelecida, promover ao interno a consciência de si e da realidade de modo não ameaçador. Ressaltando a importância destes aspectos, Kaplan e Sadock (1995) afirmam que o profissional que conduz este tipo de terapia deve "ser especialmente empático e capaz de tolerar as manifestações bizarras da doença” (p. 297).

As características do portador de esquizofrenia evidenciam a importância da realização de um atendimento interdisciplinar que garanta a assistência médico-farmacológica, o apoio psicológico e a realização de atividades ocupacionais promotoras da autonomia. A partir desta tríade de tratamento, o portador de esquizofrenia terá como minimizar os sintomas positivos e negativos da doença, diminuir o sofrimento psíquico e o isolamento social e recuperar habilidades prejudicadas devido a sua condição. Promover a pacientes institucionalizados melhores condições de saúde por meio de relações terapêuticas favoráveis à integração, socialização e autonomia foi o ponto motriz para a realização da intervenção grupal com pacientes internos neste hospital psiquiátrico.

\section{Intervenção grupal com pacientes residentes: percurso e métodos}

A proposta foi direcionada primordialmente à pacientes crônicos e residentes no hospital, já que estas duas condições apontam para a gravidade de suas condições e maiores dificuldades no processo de reabilitação. Uma vez que o tratamento farmacológico de primeira geração atua basicamente na redução dos sintomas positivos (alucinações e delírios) o trabalho em grupo com estes pacientes tomou como principais 
objetivos minimizar as perdas decorrentes do quadro clínico e da condição de isolamento por longo período, através de condições favoráveis à interação e autoexpressão, a troca de experiências pessoais e desenvolvimento da autonomia. Assim, o médico psiquiatra responsável pela ala masculina do hospital encaminhou cinco pacientes residentes, todos com diagnóstico de esquizofrenia crônica, tendo como critério para o encaminhamento a presença de sintomas crônicos, a necessidade de outras modalidades de tratamento complementar e as condições de isolamento social destes pacientes. Os participantes do grupo têm idade entre 34 e 50 anos, são todos de origem rural e estão internos na instituição de doze a dezesseis anos e não têm nenhum contato com seus familiares. Todos estão submetidos a tratamento farmacológico, mas apenas dois participam da terapia ocupacional com profissionais do hospital. Os demais não têm indicação para usufruir desta modalidade de tratamento por serem considerados agressivos e, portanto, inaptos ao contato sociogrupal. Ainda assim, foram incluídos no grupo já que a proposta deste é a reabilitação para a interação social e a promoção do bem-estar e de melhorias na saúde.

\section{Características dos participantes}

Através dos prontuários de cada paciente, foram coletadas informações básicas referentes aos dados sociodemográficos, data da internação, terapêutica farmacológica aplicada e as condições psíquicas segundo a avaliação médica. No quadro 1, é possível conferir estas informações e as observações acerca do estado atual de cada participante de acordo com a avaliação das facilitadoras a partir das interações e comportamentos por eles apresentados durantes as atividades grupais. Todos eles recebem medicação de primeira geração e estão internos há mais de doze anos, fatores que evidenciam a necessidade de intervenções favoráveis a socialização e a promoção da saúde. 


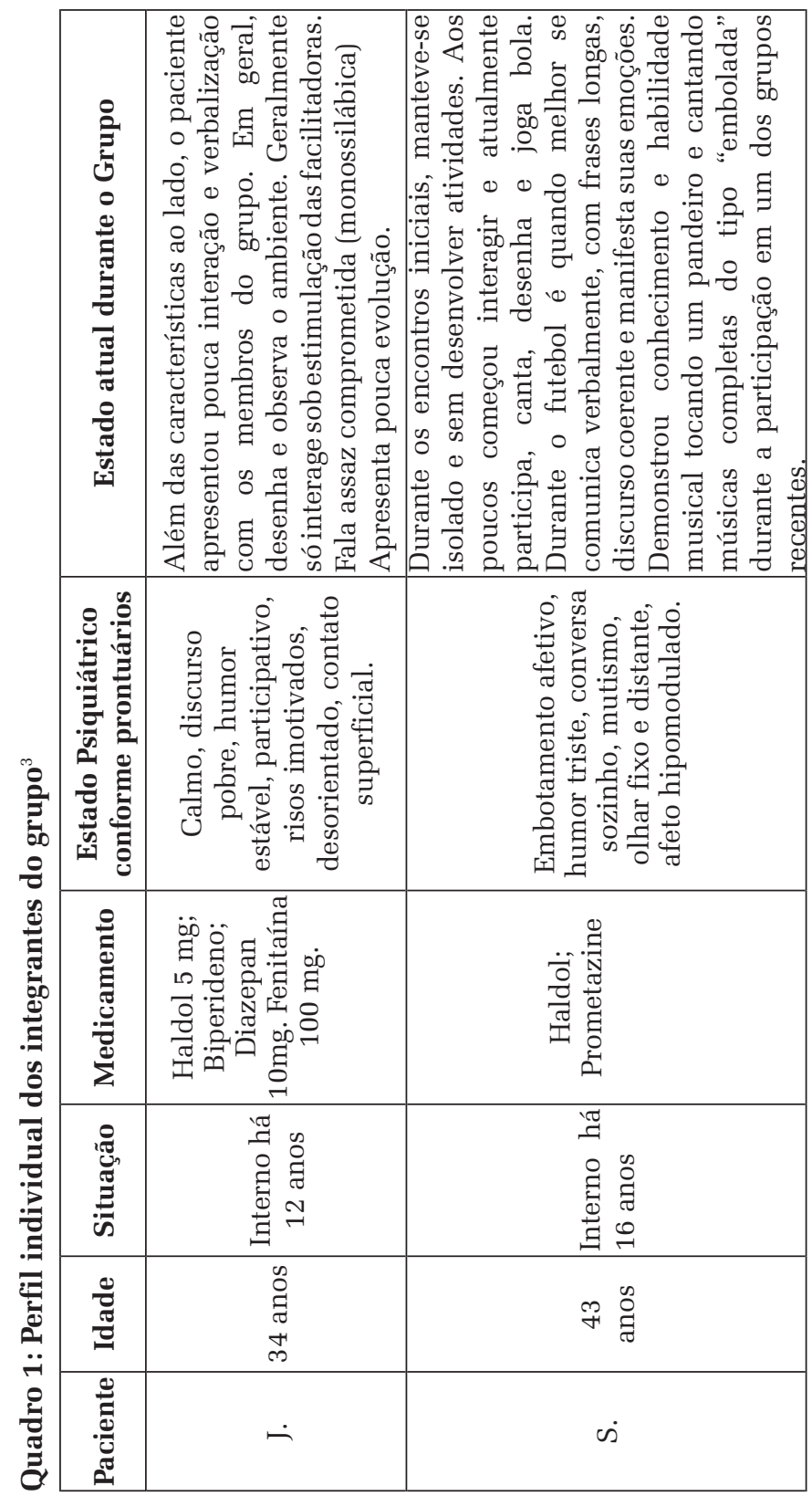

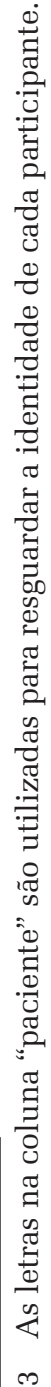




\begin{tabular}{|c|c|c|c|}
\hline$\Omega$ & $p$ & $x$ & 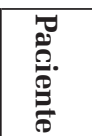 \\
\hline $\begin{array}{l}\text { o } \\
0 \\
\ddot{\Xi} \\
0 \\
0\end{array}$ & 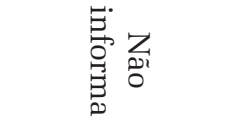 & $\begin{array}{l}\vec{b} \\
0 \\
0 \\
0 \\
0\end{array}$ & $\begin{array}{l}\frac{2}{0} \\
\frac{0}{2}\end{array}$ \\
\hline 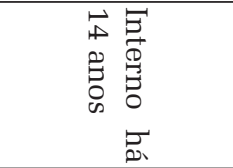 & 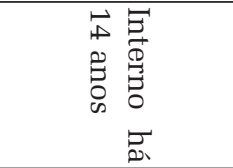 & 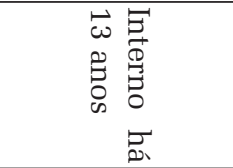 & 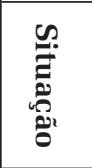 \\
\hline 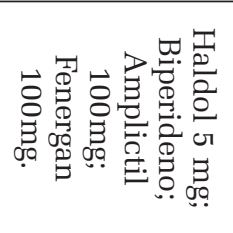 & 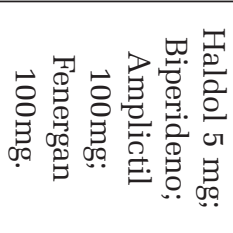 & 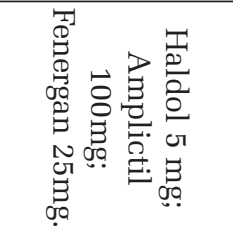 & 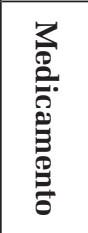 \\
\hline 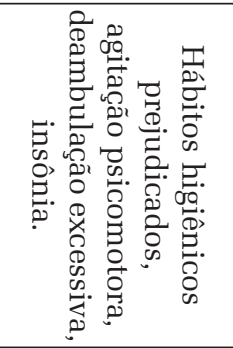 & 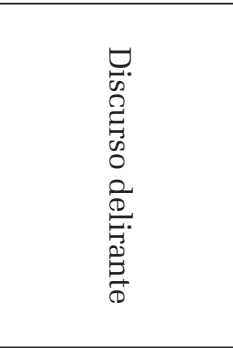 & 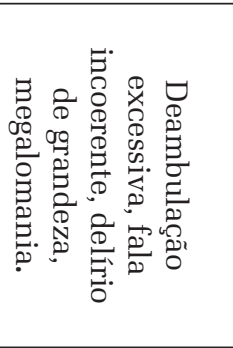 & 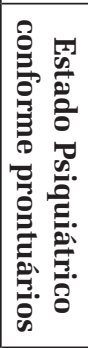 \\
\hline 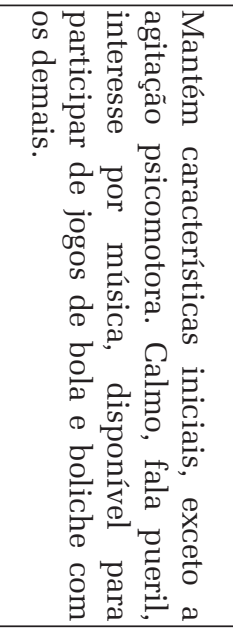 & 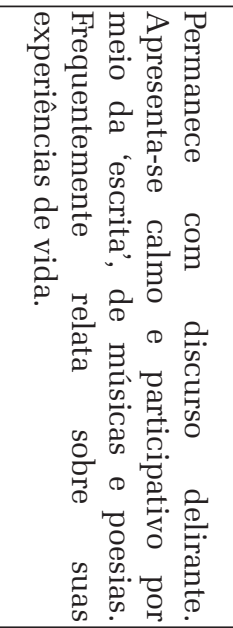 & 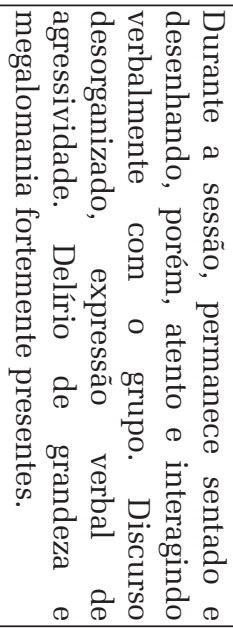 & 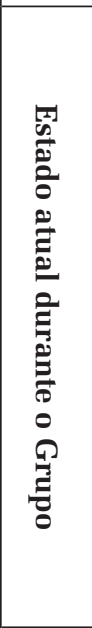 \\
\hline
\end{tabular}




\section{O setting, os recursos, a equipe de facilitação e a orientação teórico-metodológica}

A intervenção grupal realizada entre setembro de 2008 e dezembro de 2008, ocorria uma vez por semana com duração de uma hora e meia, sob a facilitação de duas psicólogas e uma estagiária. Após o encaminhamento dos pacientes pelo psiquiatra, foi dado início às atividades em uma sala no interior da instituição. O espaço amplo, com janela, pia e um banheiro é ambientado com uma estante e um armário onde ficam guardados materiais para realização de oficinas artesanais e a produção decorrente destas. No centro da sala, uma mesa retangular, bancos retangulares e algumas cadeiras; há ainda um grande espelho em uma das paredes. O primeiro encontro foi destinado para informação aos participantes sobre os procedimentos e as atividades terapêuticas que seriam oferecidas e realização do contrato propriamente dito (informações sobre dia, duração, sigilo, regras e limites). Nesta ocasião, também foi informado que eles só participariam dos grupos se e quando quisessem. $\mathrm{O}$ material disponibilizado para o uso dos participantes (bonecos de pano, revistas, jogos, lápis grafite e de cor, papel, tinta, cola colorida, cubo mágico, boliche, bola e micro-system) foi exposto na mesa e, desde o primeiro encontro, foi informado que eles poderiam utilizar os recursos que quisessem. $\mathrm{O}$ uso desses recursos foi de extrema importância devido a dificuldade inicial de interação.

Os aportes teóricos que nortearam o desenvolvimento desta intervenção têm como base os princípios da Psicologia Humanista, especialmente da abordagem centrada na pessoa e da Psicologia Positiva; os objetivos da Psicologia da Saúde; e o conceito de promoção da saúde.

A orientação não diretiva pautada nos princípios da abordagem centrada na pessoa norteou toda prática de intervenção grupal, a relação terapeuta-cliente e as intervenções 
verbais propriamente ditas realizadas durante os encontros. Dessa forma, em nenhum momento, foram estabelecidos temas para discussão ou atividades para realização. O foco no desenvolvimento da autonomia dos participantes e em possibilitar maior liberdade contrastou com a rotina destes no hospital, a qual ocorre em espaços delimitados, sem liberdade para escolhas de atividades e atendimento padronizado para atender aos cuidados necessários a todos os internos de modo similar e em horários previamente determinados. Assim, foi deixado aos participantes, inicialmente apáticos e sem saber como lidar com a nova situação, a responsabilidade de conduzir o movimento e o ritmo grupal. Haja vista a falta de motivação, o isolamento e a superficialidade que, em geral, caracterizam o comportamento dos esquizofrênicos, a relação terapêutica deve ser iniciada pelo profissional de saúde. Portanto, no momento inicial de cada grupo, as psicólogas apresentavam os recursos disponíveis e anunciavam a possibilidade de usar, ou não, quaisquer deles. Em vários momentos, as próprias psicólogas tomavam a iniciativa de desenhar, jogar ou desenvolver alguma atividade entre elas, evidenciando para os participantes a liberdade de escolha concomitante a estimulação por suas ações lúdicas. A expressividade do psicoterapeuta é um aspecto importante no acompanhamento de pacientes esquizofrênicos, pois, de certa forma, determina a qualidade da relação que pouco a pouco se estabelece, ainda que haja o predomínio do silêncio ou falas aparentemente irrelevantes por parte do paciente (GENDLIN, 1978).

Nesse sentido, as atitudes de empatia e de aceitação incondicional por parte do psicoterapeuta, fundamentais para propiciar o clima de segurança e de confiança, são também importantes para o desenvolvimento da expressão de sentimentos e, posteriormente, o reconhecimento destes por parte do paciente. Na medida em que os pacientes conseguem identificar a expressividade do outro - do terapeuta- 'aprendem' 
a se expressar, a identificar e a reconhecer seus sentimentos presentes. A aceitação incondicional do psicoterapeuta possibilita o estar livre para, ao aceitar o outro, 'mergulhar' na subjetividade deste outro à ponto de compreendê-lo com maior profundidade por meio da atitude empática (ROGERS, 1983). Desse modo, é possível proporcionar ao paciente, especialmente aquele com maior necessidade de segurança, um clima de confiança e com liberdade para expressar seus sentimentos, mesmo aqueles considerados absurdos. A compreensão por parte dos pacientes acerca dos significados de seus sintomas contribui para a ampliação de alternativas para estes lidarem com comportamentos antes incontroláveis e incompreensíveis através da ressignificação e elaboração de experiências traumáticas gerando, portanto, mudanças no comportamento. Laing (1982), na análise do caso "Joan”, anuncia que, quando o paciente esquizofrênico se sente compreendido, grande parte dos comportamentos bizarros considerados sintomas da doença desaparecem. Ele destaca tal importância através de falas da uma paciente que afirma:

As entrevistas eram o único lugar onde me sentia segura para ser eu própria, manifestar todos os meus sentimentos e verificar o que eles eram de fato, sem o temor que você ficasse perturbado e me abandonasse. (...) Com todos os demais eu procurava modificar-me para agradar-lhes. (p. 184). "O médico precisa demonstrar que percebe o ódio, mas que compreende e não fica magoado.” (p.185)

A presença de tais atitudes por parte da equipe de facilitação associada ao foco no momento atual do paciente e a intervenções verbais, que auxiliam na continuidade da fala e na identificação e compreensão de sentimentos evidentes ou subjacentes à comunicação (ROGERS, 1977) delinearam o clima estabelecido na relação terapêutica com 
os cinco participantes do grupo, favorecendo pouco a pouco ao estabelecimento de diálogos e de interações entre eles, à mudança em seus comportamentos e a gradativa evolução em suas condições de saúde.

Considerando que um dos desafios da Psicologia da Saúde é o desenvolvimento de uma compreensão de saúde que se sobreponha a considerações acerca de normalidade, equilíbrio e ausência de sintomas (REY, 1997), as mudanças observadas, durante o trabalho grupal, tomam como referência a capacidade de adaptação e de enfrentamento do indivíduo frente as mais diversas situações cotidianas. Sob um paradigma probabilístico, consideramos além dos aspectos biológicos e psicológicos, o contexto histórico, geográfico, político, cultural, as influências de uns sobre os outros e as influências decorrentes desta interação. A saúde não é, portanto, considerada um estado, mas um processo de construção indivíduo - mundo decorrente da atualização do organismo nas interações com o ambiente visando à manutenção do equilíbrio e a superação das dificuldades (ANDRADE, 2002). Nesta perspectiva, saúde e doença não são tomadas como polos opostos, pois são etapas de um mesmo processo que vai da desorganização à reorganização e vice-versa. Compreende-se que o ser patológico é aquele que se encontra impedido de mudar diante de situações adversas; enquanto que o ser saudável usufrui da sua liberdade existencial para modificar a si e as condições ambientais desfavoráveis (AUGRAS, 1986).

A gradativa mudança nas formas de interação e de expressão dos participantes foi constatada por meio da análise dos registros de gravação de cada encontro, os quais foram posteriormente transcritos, garantindo o sigilo das informações e a identidade dos pacientes, seguindo as orientações éticas da profissão e as recomendações da lei 196/96 do Conselho Nacional de Saúde. As informações obtidas por meio das gravações foram complementadas com o registro de observação, o que possibilitou garantir os detalhes das falas ocorridas 
durante os encontros e o registro de expressões não verbais. A análise do conteúdo (Bardin) destas informações tem como base os primeiros dez encontros grupais.

\section{Apresentação de resultados, análises e discussões}

Ao longo das dez (10) sessões analisadas, ocorridas no período de setembro à novembro de 2008, foi observado, entre os participantes do grupo, o estabelecimento de vínculos e a modificação nas suas formas de interação. Paulatinamente, passaram a se comunicar mais (verbal e ludicamente), a revelar conteúdos de suas experiências pessoais (concretas ou subjetivas) e expressar opiniões e sentimentos frente a situações expostas no grupo. Assim, com a finalidade de analisar a eficácia do grupo na diminuição das condições desfavoráveis à saúde, a intervenção grupal tomou como norte os objetivos de: a) promover a autonomia dos participantes; b) favorecer a interação social; c) estimular a comunicação e expressão de sentimentos por parte dos integrantes através do estabelecimento de relações saudáveis, igualitárias e democráticas em um clima de segurança e liberdade no grupo. Nesse sentido, as análises foram focadas na localização de informações que revelaram mudanças positivas, em maior ou menor grau, em cada um dos participantes e sistematizadas em duas (02) categorias de análise que possibilitaram identificar os elementos necessários para averiguar a consolidação das intenções que orientaram a intervenção. As categorias foram denominadas de: a) Interação entre pacientes e manifestação de opiniões e b) Relato de experiências pessoais e expressão de sentimentos. Cada uma destas categorias será descrita e ilustrada com conteúdos das falas registradas e as observações realizadas pelas facilitadoras durante as sessões. Nos trechos das falas, há a indicação de letras representando cada participante, mas estas não são indicativas da sigla dos respectivos nomes. Já nas intervenções realizadas pelas facilitadoras foram mantidos seus respectivos nomes. 


\section{Impressões iniciais:}

Durante a primeira sessão, apesar de haver perguntas dirigidas a cada um dos integrantes, como, por exemplo, você sabe o motivo de estar aqui? Ou, você poderia falar sobre o seu desenho? Nenhuma delas foi respondida. Ao longo da sessão $F$. e $A$ desenharam, isoladamente, em locais distantes um do outro. Não houve interação entre os integrantes nem resposta aos estímulos verbais das facilitadoras. De um modo geral, permaneceram sentados e em silêncio, sendo o desenho a única atividade desenvolvida por dois deles. No segundo encontro do grupo, foi observada a manifestação de opiniões e o estabelecimento de diálogo entre os participantes e as facilitadoras, porém, de modo muito sutil e apenas quando a fala era estimulada. Apenas a partir do terceiro encontro foi possível identificar maior segurança dos integrantes na relação com as facilitadoras e entre eles. Também foi verificado o aumento da autonomia entre os participantes. Inicialmente nenhum deles apresentou a iniciativa de pegar algum dos recursos disponibilizados. Aqueles que tinham interesse em usá-los pediam as facilitadoras e aguardavam a entrega. Mesmo sendo informados que poderiam utilizar quaisquer materiais, a condição de passividade por eles adotada durante os procedimentos de rotina do hospital prevalecia, impedindo-os de fazer escolhas e tomar decisões mínimas.

Tomando como referência a intenção da Psicologia da Saúde de estudar e intervir em prol da promoção, prevenção e tratamento da saúde do indivíduo para criar condições de melhoria da qualidade de vida (CALVETTI, MULLER, NUNES, 2007), estamos diante de uma situação em que as condições ambientais, as relações estabelecidas e as terapêuticas destinadas a estes internos não são suficientes para tratar da saúde, logo, também, não atingem a dimensão da promoção e prevenção em saúde. Tais práticas institucionais caminham na contramão dos debates sobre reforma psiquiátrica, saúde e direitos humanos e são prioritariamente norteadas pela 
vigilância, disciplina, normatização e controle. A padronização no atendimento aos internos desconsidera um princípio fundamental norteador da qualidade da assistência da saúde: a equidade. Equidade significa identificar e observar as diferenças para a realização de um atendimento especializado, que atenda às necessidades específicas de cada usuário de um serviço. Resguardar este princípio garante a igualdade de todos ao acesso ao serviço e o respeito à diferença no atendimento (DIMENSTEIN, 2004). O respeito às necessidades, ao ritmo e aos interesses específicos de cada participante no grupo foi um dos aspectos fomentadores da mudança observada ao longo desta intervenção. Durante os dez encontros, observamos que o contexto de interação com liberdade e estimulação à autonomia possibilitou avanços significativos nas condições de saúde dos integrantes do grupo, inicialmente identificados a partir da crescente interação entre os participantes.

\section{Interação entre pacientes e manifestação de opinióes}

A emergência de interações entre os participantes possibilitou identificar a manifestação de opiniões por parte dos internos, bem como a tomada de decisões durante as atividades. As primeiras manifestações são caracterizadas por opiniões breves quando estimulados, as quais paulatinamente passaram a direcionar escolhas e a possibilitar posicionamentos pessoais. O primeiro momento em que identificamos a expressão de opinião ocorreu no terceiro encontro:

A: "Ninguém quis ligar a televisão"

Lorena: Você gosta de televisão?

A: $E$.

Lorena: Alguém mais gosta de televisão? 
Carla: J, você gosta de televisão?

J: Não.

Carla: S, gosta de televisão?

S: [Olha firme enquanto bate os pés] "Quando é bom eu gosto!"

Apesar de breves e superficiais, as expressões verbais dos participantes representam um avanço importante para os encontros subsequentes. Aliás, vale ressaltar que, mesmo estimulados, não houve resposta de nenhum deles às perguntas realizadas no primeiro encontro. Durante a realização de atividades, em conjunto ou não, verificamos a diminuição do isolamento e o direcionamento de falas de um para o outro. Apesar dos contatos interpessoais aparentemente superficiais é necessário destacar o comprometimento psíquico e social dos participantes, em parte característico do quadro clínico, mas, principalmente, em decorrência dos efeitos colaterais da medicação e pelo isolamento social.

O contato social é um elemento básico para o desenvolvimento de condições humanamente saudáveis e o restabelecimento de condições favoráveis à qualidade de vida. No quinto encontro, a inclusão de um paciente visitante que pediu para participar do grupo estimulou a interação dos demais. $M$, o paciente visitante, por não ser residente e estar no hospital em uma condição provisória, tinha família, vínculos sociais e apresentava condições de saúde assaz diferenciada dos pacientes residentes. Os diálogos ocorridos durante este encontro ilustram o quanto o contato com pessoas mais saudáveis é importante para a diminuição dos sintomas negativos da esquizofrenia e estimula à verbalização e a ações participativas e criativas. A criatividade, a satisfação, o otimismo, o amor, o conhecimento e a sabedoria são aspectos relacionados ao desenvolvimento humano que tem ocupado lugar de destaque nos estudos sobre as 
contribuições da Psicologia Positiva à Psicologia da Saúde. $\mathrm{O}$ enfoque nos aspectos potencialmente sadios da pessoa permite resgatar e valorizar as possibilidades de mudanças direcionadas à melhoria das condições de saúde (CALVETTI, MULLER, NUNES, 2007).

M: "Dra ., me diga aí um tema pra eu me inspirar aqui"

Carla: "Que tipo de tema você gostaria que eu te dissesse?"

M: "Um tema. Qualquer coisa. Pode ser um trecho de uma música. Ah! Já sei... [cantarola um trecho de uma música do Rappa, fazendo gestos relacionados à música e canta] "Meu casaco de general”,

A: [repete a palavra] "General".

M: "Eu sei de outra melhor". [e cantarola música dos Engenheiros do Hawai]

S: [expressa de esforço para balbuciar algo e tenta acompanhar M.] Começa a cantar com muito esforço: "Era um garoto, e como eu (...) é Engenheiros.” [Sorri]

O pequeno trecho da música cantarolada por $S$. é bastante significativo por considerarmos a dificuldade dele para falar, ainda que palavras curtas, e as poucas ocasiões em que observamos a construção de frases completas e com coerência. Em grande parte das situações em que $S$ pronuncia algo é por meio de neologismos, uma característica bastante presente em alguns quadros de esquizofrenia. Zanini e Cabral (1999) afirmam haver grande chance de pacientes com predomínio dos sintomas negativos se beneficiarem com a psicoterapia de grupo, pois, ainda que não participem de maneira ativa, eles aproveitam a experiência de diversas formas. A importância da relação grupal é bastante evidente no caso de $S$ devido ao predomínio dos sintomas negativos. Dados do prontuário de $S$ e informações dos profissionais de 
Psicologia e de Enfermagem que dele cuidavam, anunciam o forte embotamento afetivo e seu isolamento social. Devido a esses sintomas, permanece grande parte do tempo no quarto e raramente sai pra fazer qualquer atividade. Apesar de $M$ ter participado de apenas 3 encontros, sua ação no grupo por meio de conversas coerentes e da estimulação para o desenvolvimento de atividades, como cantar e desenhar, estimulou e elevou o nível de interação entre os demais participantes. Além disso, a relação de igualdade estabelecida entre $\mathrm{M}$ e os demais membros do grupo estimulou o senso de capacidade dos demais que passaram a se esforçar para acompanhar o ritmo de $M$ e conseguiram superar alguns de seus limites. Aos poucos, com muito esforço, $S$ passou a participar no grupo através do jogo de futebol e a manter relações mais diretas com as facilitadoras ajudando-as, inclusive, ao término de um dos encontros, a guardar os objetos utilizados. Em grupos subsequentes, $S$ passou a se despedir das facilitadoras na saída com acenos e sorrisos rompendo, assim, seu isolamento e silêncio.

De acordo com Bechelli e Santos (2002), a psicoterapia de grupo é uma modalidade de intervenção que, independente da abordagem e das técnicas utilizadas, desde que ofereça condições para o desenvolvimento de mudanças, possibilita a emergência do potencial de recuperação dos participantes. A interação entre os participantes rompe com o modelo médico centrado no terapeuta e abre caminhos para o papel ativo do grupo em direção aos seus interesses e necessidades. De fato, observamos que a crescente interação entre os pacientes, aos pouco, cedeu lugar a integração através de jogos e desenhos. Além de se dirigirem um ao outro, também passaram a comentar sobre as ações dos outros e respeitar o ritmo dos outros na realização de atividades. A inte(g)ração por meio de diálogos e atividades foi observada no sétimo encontro entre vários participantes e em diferentes momentos: 
A: [Dirigindo-se a J]: "Eu quero esse lápis que esse aqui não é bom não. Eu quero prá escrever uma carta”

Carla: "A, você pode esperar ele terminar, aí ele te empresta." [J, permanece alheio ao pedido e continua desenhando e sorrindo]

A: "J, me dá essa caneta pra eu escrever uma carta prá meu bem querer". [J continua desenhando, sem responder]

Carla: "A, quando ele terminar você pode usar. Agora ele está usando". [A silencia, fica olhando para o papel de J. Parece estar aguardando o fim do desenho.]

J: [Conclui o desenho, vira-se para A e entrega a caneta. Entrega o desenho para guardar. A recebe a caneta e começa a 'escrever']

(...)

Carla: "S hoje está bastante quieto, não quis fazer quase nada".

F: “É, né isso, num faz nada!"

Enquanto isso:

J: [com agitação, vai diversas vezes ao banheiro tentar achar pedrinhas].

A e C: [Mexem no rádio]

A: [Dirigindo-se a C] "Coloca aí uma poesia matuta prá tocar".

A iniciativa de $A$ pedir a caneta a $F$ e pedir para $C$ colocar uma música específica aponta a autonomia emergente nos momentos de interação entre eles, nos quais também podemos observar escolhas, decisões e opiniões. Inicialmente, os participantes com melhores condições de verbalização, como $A, F$ e $C$, quando desejavam algo, pediam as facilitadoras, inclusive quando o material estava com outro membro do grupo. A situação acima ilustra a melhoria nas condições 
de comunicação entre eles e indica os benefícios proporcionados pelo grupo. No trabalho grupal, um importante fator gerador de mudanças é a possibilidade do aprendizado por intermédio do outro (BECHELLI E SANTOS, 2002). A relação dos participantes entre si e com as facilitadoras, haja vista as condições favoráveis no grupo impulsionaram a identificação e criação de alternativas para solução de problemas e o surgimento de novas formas de responder aos estímulos do meio. Entre o sétimo e o nono encontro, observamos que as relações entre os participantes permitem, inclusive, a construção de diálogos mais coerentes entre eles. A coerência considerada nestes diálogos não valoriza a existência ou a ocorrência concreta dos elementos e situações relatadas pelos integrantes, mas, a organização de uma construção lógica, compreensível e com argumentos pautados na realidade subjetiva de cada um deles.

A: (Relata uma situação) "[...] é, era uma cobra cascavel. Eu matei essa cobra. Ainda hoje eu tenho o couro dessa cobra."

Lorena: "Até hoje você tem o couro dessa cobra."

A: "Teeeeenho."

Lorena: "Faz tempo que tu matou essa cobra?"

A: "Faaazz."

F: "Essa noite tinha 2 cobras cascavel. Elas estavam cantando."

Carla: "E o que você fez?"

F: "Chamei o povo prá matar."

Carla: "J, tu pode passar esse apontador pra A?"

J: [entrega o apontador à $\mathrm{A}$ ] 
Carla: “Tu podes fazer a ponta A.?”
A: "Eu não posso não por que a minha mão é aleijada."
F: "A mão da gente tudinho é aleijada. A cabeça não, mas a mão é."

Nesse último diálogo, a fala de $A$ ao afirmar não poder fazer a ponta do lápis permite-nos observar a condição de dependência dos pacientes. A rotina orientada pelos funcionários da instituição estabelece uma condição de 'disciplina', dependência e incapacidade, conduzindo os pacientes a comportamentos cada vez mais passivos. O comentário de $F$ revela a percepção que ele tem de si próprio e sobre sua sanidade, haja vista contrapor o 'aleijo' da mão à condição de sua "cabeça". Parte da aflição de muitos pacientes psiquiátricos se deve principalmente a negação de suas experiências por parte dos que com eles convivem. $F$ parece querer evidenciar seu possível estado de doença, mas não de insanidade. É importante considerarmos que a concepção de saúde que norteia estas análises não é referendada pela ausência de sintomas, mas por um processo integral dos recursos do organismo para diminuir sua vulnerabilidade diante dos agentes causadores da doença (REY, 1997). Constatamos isso por meio das condições de saúde inicial dos participantes que, apesar de terem parte dos sintomas da esquizofrenia controlados pela terapêutica medicamentosa, se encontravam em condições mínimas para reagir, escolher, opinar e expressar seus sentimentos. Podemos dizer que parte de suas vidas estavam soterradas e, sob condições de interações favoráveis, ao menos em parte, a autonomia, a vontade e a expressividade destes foram resgatadas, permitindo uma maior participação deles em seus processos vitais.

A interação grupal que pouco a pouco revelou a conquista de autonomia destes pacientes também favoreceu a participação e colaboração de uns nas atividades desenvolvidas por outros. 
S: [cantarola uma música]

Carla: "É uma música que você está cantando....me ajuda a lembrar.."

S: (continua a cantar)

F. e S. [cantam a mesma música em conjunto].

O desenvolvimento de atividades em conjunto e bem integradas também foi observado no nono encontro, durante jogo com a bola. Iniciado por um integrante e uma facilitadora, o jogo seguiu até o final do encontro com a participação de quatro dos cinco pacientes e das três facilitadoras. Apenas $F$ não participou desta atividade e optou por ficar 'fazendo dinheiro'.

Carla: "Quer jogar também? (se referindo a S.)"

Carla: "Tu podes jogar pra J? Ele está no jogo também.”

S.: [Joga a bola pra J]

(jogam bola: Carla, J, S e Lorena)

S.: [rodopia a bola]

Carla: [Girando a bola] "Era isso que tu tava tentando fazer, não era $S$ ?"

(A, Carla, Lorena, S , J e C jogam bola)

A: "Eu sou o tocadooooor!"

Danielly: "Parece que A sabe jogar vôlei."

A: "Eu joooooogo"

[Jogam com expressão de alegria: sorrisos, saltos e vibração ao conseguir fazer gol].

A gradativa participação e integração entre os participantes e o estabelecimento de vínculos de confiança possibilitaram a manifestação e exploração de conteúdos mais profundos. O trabalho pautado na humanização, aqui entendida por ações comprometidas com o bem-estar e que fomentam mudanças nas condições desfavoráveis à saúde, mobiliza o envolvimento dos participantes e potencializa a superação das dificuldades. 
Os relatos que constituem a categoria a seguir ilustram algumas situações, nas quais, os participantes mencionam eventos de suas vidas, seus sentimentos e passam a se comportar como agentes de seus processos de desenvolvimento.

\section{Relato de experiências pessoais e expressão de sentimentos}

Foi a partir do quarto encontro que as manifestações por meio de relatos de situações experienciadas tornaram-se mais presentes. Os conteúdos de experiências pessoais (simbólicas ou concretas) foram observados nos relatos dos pacientes em diversos momentos. Durante as interações, as quais foram se ampliando ao longo das sessões, observamos que as falas breves foram, paulatinamente, apresentando-se de modo mais organizado, espontâneo e profundo. Assim, observamos nas conversas entre os participantes que os diálogos revelavam experiências particulares, como situações passadas em família, relatos sobre a rotina no hospital e outras situações experimentadas. Para Lemos e Cavalcante Jr. (2006), o clima de aceitação, autenticidade e empatia proposto pela abordagem centrada na pessoa favorece ao envolvimento do indivíduo que, aos poucos, passa a implicar-se no processo de 'tornar-se pessoa', de ser autêntico e tornar-se mais livre. Essa orientação encontra-se presente tanto nas intervenções individuais quanto grupais em conformidade com a crença na orientação positiva do homem baseada no conceito de tendência atualizante que anuncia que:

Preside o exercício de todas as funções, tanto físicas quanto experienciais e visa constantemente desenvolver as potencialidades do indivíduo para assegurar sua conservação e seu enriquecimento, levando-se em conta as possibilidades e os limites do meio (ROGERS, 1977; p. 41). 
No trecho abaixo, identificamos a espontaneidade de $A$ ao falar sobre sua fuga, sem receio de represálias, assim como o envolvimento com os sentimentos que emergem da lembrança da situação frustrada.

A: "Eu fugi de noite, pulei do [menciona nome do paviIhão], cai na boca da mata e fui para casa, de noite. Ele tinha uma cobra, criava uma cobra grande."

Carla: "Você chegou em casa?"

A: "Não, cheguei não, tava escuro. Eu caí na boca da mata e cortei o pé".

Carla: "Você cortou o pé aí não chegou em casa".

A: "Cheguei bem cedinho. No outro dia, eu tava no... [nome do pavilhão no hospital]".

Lorena: "Quem te trouxe de volta?"

A: (Silencia e abaixa a cabeça).

Ao relatar sobre sua fuga do hospital, $A$ expressa tristeza por não conseguir chegar em casa. Apesar de não termos conhecimento acerca da correspondência entre a situação relatada e a realidade, o mais significativo é o fato de esta situação ser, de algum modo, uma experiência marcante para $A$, que a revela com significado emocional, com coerência e associando ao seu contexto de origem. Sua origem rural foi por diversas vezes revivida em seus relatos sobre a vida no campo, o tipo de alimentação, no cantarolar de músicas denominadas por ele de "cantigas matutas", e sobre a dificuldade de acesso à escola. $A$ não é alfabetizado e a impossibilidade de ter estudado é algo marcante em sua vida. Em todos os encontros a sua principal atividade é um "texto" que ele apresenta como sendo sua tarefa escolar. Por meio dessa produção, $A$ declama poesias, lê cartas, sequência de números e cita trechos bíblicos. É através dessa atividade que tem resgatado e realizado sua história de vida, ressignificado experiências e 
compartilhado situações que, na rotina hospitalar, não são valorizadas. O espaço e as relações no grupo tem favorecido a $A$ e aos demais participantes, de diferentes formas e ritmos, a resgatarem aspectos fundamentais em suas vidas que, no decorrer dos anos de internação, foram suprimidos. Além da situação grupal, poucas são as situações em que estes são estimulados ou têm a oportunidade de participar ativamente de decisões no seu cotidiano, de ter diálogo mediado por atenção, respeito e credibilidade e a possibilidade de resgatar a memória de personagens importantes em suas vidas familiares, há anos, sem contatos ou notícias. Sob estas condições, constatamos a situação de vulnerabilidade em que estes pacientes se encontram em virtude da fragilidade do meio que não favorece a promoção, proteção ou garantia de seus direitos de cidadania (AYRES, FRANÇA JR., CALLAZANS e SALETTI FILHO, 2003) e de promoção de saúde. No atual contexto sócio- histórico, a principal alternativa para a viabilização de condições favoráveis à saúde mental tem sido a desinstitucionalização. Entretanto, a necessidade de manter estes pacientes internos devido a impossibilidade de encaminhá-los para seus familiares não deve ser justificativa para a manutenção de condições desfavoráveis à saúde, ao desenvolvimento e a reabilitação. É necessário enfrentar a falta de recursos sociais, institucionais e familiares como base de apoio para a recuperação dos pacientes internos. Portanto, o reconhecimento das consequências da condição de abandono e isolamento social é fundamental para a criação de estratégias institucionais que atendam às necessidades individuais de cada paciente e viabilizem a implantação de um atendimento mais humanizado e coerente com as atuais propostas dos serviços de saúde mental, neste caso, ainda que seja no contexto de institucionalização.

$\mathrm{O}$ abandono familiar, ainda que represente uma grande perda para aqueles que se encontram na condição de institucionalização, não inviabiliza a criação de novos vínculos afetivos relevantes para o estabelecimento de relações 
saudáveis e favoráveis a reorganização de novas formas de vida coerentes com um ambiente institucional que se propõe, ao menos em tese, a tratar, cuidar e restabelecer. $\mathrm{Na}$ análise em questão, o tempo de internação destas pessoas - mais de dez anos - poderia ser tomado como base para a criação de laços afetivos restauradores de uma nova família, um novo lar. Entretanto, o que verificamos é que a perda da família e das relações sociais permanece uma das lacunas marcantes na vida destas pessoas, ao lado de outras ausências e carências.

Além de $A, C$; J e $F$ também vivenciam as mesmas perdas e carências. Em todos os casos compreendemos que o contato com familiares, com sua cultura e o desenvolvimento das atividades que tinham como rotinas antes de se tornarem residentes da instituição seriam de elevado benefício para a recuperação da saúde dos mesmos. J, um paciente com bastante pobreza no discurso, após realizar um "desenho" representativo de uma casa, reporta-se a familiares e ao seu lugar de origem, com os quais, há mais de 10 anos, não mantém contato. A fala de $J$ se repetiu em outros encontros revelando um sentimento saudosista em relação ao lugar e as pessoas com quem viveu.

Carla: "J, o que você fez aqui [desenho]?”

J: "Casa".

Lorena: "Onde fica?"

J: "Salgueiro”.[nome fictício da cidade mencionada]

Lorena: "Quem mora nessa casa?"

J: "É Rita" [ nome original foi substituído por esse peudônimo]

Lorena: "São seus pais?”

J: “É". 
A expressão de sentimentos em relação a família, a moradia e experiências que supostamente antecedem a ida para o hospital são bastante presentes nos relatos dos pacientes. Muitas vezes, tais relatos são imbuídos de elementos sintomáticos, como alucinações e a mania de grandeza característica do discurso de $F$. Em diversos momentos, $F$ relatou que vendeu ou comprou algo. Desde os primeiros grupos, $F$ realiza o mesmo desenho, uma cédula de dinheiro. Apesar de o seu discurso ser relativamente desorganizado, dois focos são claramente identificados: a sua história de vida com posses abundantes, em um momento; e as perdas financeiras e pobreza em que também viveu. Em seu discurso as oscilações entre situações de poder e de perdas são mediadas por elementos de grandeza nos quais ele afirma ser o governo, a polícia, médico, professor, dono de grandes propriedades e de bens, por vezes ocupando todas as funções simultaneamente, além de ser 'fazedor' de dinheiro. Concomitantemente, $F$ também relata a necessidade de ter que trabalhar para manter a família e receber pouco por seu trabalho. Ambas as situações, apesar de superdimensionadas, revelam dois momentos marcantes na vida $F$, sendo o primeiro fundamental para a manutenção de uma realidade, agora, idealizada, porém necessária a ele.

F: "Eu tenho muito gado."

Lorena: "Você tem gado?"

F: "Tenho mil cabeças de gado."

Carla: "Fica onde esse gado?"

F: “ali, ali” (aponta para a janela)

F: "Eu comprei 30 casas em...(...)"

Carla: "Você mora em uma dessas casas?" 
F: "Não, eu moro em (...). Eu comprei porque eu gosto mesmo. Eu tava com dinheiro, aí comprei. Eu gosto de comprar. Você tem alguma coisa pra vender?”

Carla: "Não, não tenho nada pra vender."

F: "É, eu comprei uma fazenda, uma (...)"

No encontro seguinte, $F$ afirma:

F: [Enquanto 'produz' o dinheiro] "A pessoa quando tem filho não dorme, não!"

Carla: "Você não conseguiu dormir à noite por causa do seu filho?"

F: "A pessoa tem que trabalhar, num põe a cabeça tranquila na cama, não. Trabalho dia e noite. Plantei mandioca, arrumei o telhado da casa, limpei o terreno e o homem me pagou só 10,00 cruzeiros. Eu preferi dizer que me trocasse por dois lápis. O lápis é melhor".

Carla: "O lápis valia mais que esse dinheiro?"

F: "Num dá pra nada, não. Tem que trabalhar sem dormir mesmo."

As situações de perdas, de pobreza e das condições de institucionalização foram compartilhadas entre eles em alguns momentos. O diálogo, agora nem sempre necessitando da mediação das facilitadoras, evidencia opiniões, crenças e sentimentos relacionados às situações vividas. Esta dinâmica corrobora as afirmações de Bechelli e Santos (2002) acerca do 'paciente' em grupo ser o agente de sua própria mudança. Sob condições favoráveis, o movimento e o ritmo de cada participante atua coerentemente com as necessidades emergentes, favorecendo a mudanças e ao aumento de capacidades, tal como Rogers (1977) anuncia sobre a ação da tendência atualizante no organismo humano. 
A: [Conta uma história em que 'deu fim' a um gato...] "Deixei o bichinho apodrecendo no quintal".

F: "Quando mata um gato a vida da pessoa acaba”.

\section{(...)}

A: "Terminei Doutora. Tô dormindo com fome. Eu não posso vir prá essa escola não por que eu tô enfadado."

F: enquanto desenha a sua nota de dinheiro diz: "É ele dorme com fome todo dia. Eu também durmo com fome."

Carla: "O que você come de noite, A?"

F [responde a pergunta que foi feita para A]: "Pamonha, hambúguer. Eu durmo com fome e com sede. Olha, a pessoa dormir com fome e com sede, não aguenta não."

Danielly: "A pessoa com fome e com sede não aguenta?”

F: “Agüenta não. A pessoa com fome e sede não aguenta não."

A: "Tem mais de 100 noites que eu durmo com fome, não sei como eu não morri ainda."

Danielly: "Faz tanto tempo que você dorme com fome e com sede que parece que faz 100 noites que você não come não é A? Não sabe nem como não morreu ainda."

A: "Éééé."

F: "Não sei como consegue dormir com fome. A pessoa dormir com fome é triste."

Danielly: "É triste dormir com fome."

F: "É muito triste."

A postura física e a expressão facial de $A$, ao falar sobre a situação de fome, revelam tristeza. $F$, apesar de manterse concentrado no seu desenho durante a conversa, parecia referir-se não apenas a fome de $A$ e a sua naquele momento, 
mas a possíveis situações de privação em momentos anteriores a internação, os quais foram relatados por ele em outros grupos.

A análise dos dez encontros apresentados apontam a gradativa evolução dos pacientes caracterizada pela ampliação das suas relações, as quais tiveram início por meio de breves respostas às facilitadoras e, posteriormente, o estabelecimento de diálogos com posicionamentos e expressão de opiniões acerca das questões discutidas. Nas últimas sessões, vários diálogos entre eles e a observação de suas expressões são indicativos da melhoria de suas condições de saúde. Ainda que em níveis diferenciados, entendemos que a mudança proporcionada pelo grupo mantém estreita relação com a história pessoal, as necessidades e as dificuldades e limites individuais, inclusive em decorrência do quadro clínico e da medicação prescrita. O tipo de medicação e a dosagem aplicada representam variáveis sob as quais não temos controle. Contudo, não podemos deixar de observar o quanto a medicação, ainda que necessária, compromete a vitalidade, o desempenho e, numa compreensão ampla do termo, a saúde dos pacientes.

F: “Estou doente...não posso fazer não.” [com a mão direita tremendo excessivamente, e com excesso de salivação, cuspindo algumas vezes, refere-se a impossibilidade de 'fazer' dinheiro] (...)

F: [Demonstrando incômodo diz] "hoje não dá não..."

Danielly: "Você acha que hoje não dá pra desenhar porque a sua mão está tremendo?”

F: “É...dá não”(...)

Lorena: "É ruim querer desenhar e não conseguir, não é?"

F: [Olhando alternadamente para o chão e para a mão, com aspecto de tristeza, diz] "É." 
Lorena: "Tá difícil até de falar, não é?"

F: "É.".

Apesar de atuar prioritariamente no controle dos sintomas positivos (alucinações, delírios etc), alguns dos efeitos colaterais da medicação de primeira geração são impeditivos das atividades do paciente por gerarem mal-estar físico, sonolência, tremores, salivação e sede excessivas e, consequentemente, conduzirem-no a estados de incapacidade, dependência e isolamento, gerando sofrimento frente às limitações que impedem de executar atividades prazerosas. Os delírios de grandeza e megalomania de $F$ o levam a acreditar que faz dinheiro. Em todos os encontros, essa é a sua atividade principal e, demonstrando satisfação com sua produção, desenha e pinta as cédulas atribuindo-lhes valor monetário. Entretanto, na situação acima relatada, a expressão de tristeza de $F$ era evidente, quando este olhava para sua mão e observava o traço tremido e sem os detalhes no papel, diferente do detalhamento que caracteriza sua produção em cada um dos encontros. Duas semanas após este episódio, $F$ expressou sua satisfação (com sorrisos e comentários de autoelogio) diante dos seus desenhos de dinheiro. Nesta sessão, as facilitadoras levaram, juntamente com os demais recursos, algumas cédulas de brinquedo. Entretanto, na opinião de $F$, as cédulas que produz são as que têm valor.

Lorena: Mostra as cédulas de brinquedo e pergunta: "Quer?"

Carla: entrega algumas notas a ele.

F: Segurando uma nota de dez diz: "Esse num é bom, não. Num vale nada, não"

Carla: [Entrega a nota de $\mathrm{R} \$ 20,00$ a ele].

F: Segurando a nota diz: "Esse dinheiro num vale não. $O$ que eu faço vale mais, né? Esse que eu faço é bom. Esse 
aí não vale não". [Pega o papel e começa desenhar o seu dinheiro.]

$\mathrm{O}$ valor atribuído por $F$ às cédulas que produz não é apenas monetário, mas principalmente por representar o resultado de uma produção sua que é socialmente valorizada e tem a conotação de poder. Sorrisos e gestos ao desenhar indicam a satisfação com a possibilidade de produção sem os incômodos dos tremores decorrentes da medicação e pelo respeito a sua opinião ao afirmar que seu dinheiro vale mais que os outros.

Frente aos delírios e alucinações do esquizofrênico, muitos profissionais que trabalham com portadores de transtornos mentais adotam como medida para aproximá-los de uma 'realidade' aceitável a negação dos elementos decorrentes deste tipo de sintoma. Entretanto, o que verificamos é que quanto mais reconhecemos e aceitamos a 'realidade vivida' pelo portador de esquizofrenia, mais ele expõe e explora os conteúdos desta realidade que, embora classificada como sintoma, é parte vital da manutenção da existência destes. O reconhecimento e exploração destes elementos possibilitam o estabelecimento de relações com maior segurança e confiança para se expor e, ao invés de negar a sua realidade, direcionar-se para a sua compreensão. Nesse sentido, a melhor forma de compreender a realidade subjetiva do portador de transtorno mental é sendo empático. O estabelecimento de relações mais humanizadas é condição básica para a restauração de habilidades e a recuperação da dignidade e do respeito. Os estudos da Psicologia Positiva aplicada à Psicologia da Saúde têm indicado como fatores de proteção e de promoção da saúde variáveis como, o otimismo, a esperança, a criatividade, o respeito e a imagem corporal, entre outros, relacionados ao bem-estar e à qualidade de vida de pessoas doentes e não-doentes (CALVETTI, MULLER e NUNES, 2007). As manifestações de prazer e agradabilidade foram identificadas em momentos em que os participantes 
sentiram-se livres para fazer escolhas e dar opiniões. O uso dos recursos lúdicos e da música foram fundamentais para a estimulação inicial e para a busca e manifestação de interesses pessoais. A fala de $C$, no trecho abaixo, é reveladora das suas preferências.

Lorena: "Você gosta de música C?"

C: sintonizando em uma rádio diz: "Gosto"

Lorena: "Que tipo de música você gosta?”

C: "Sertaneja."

Lorena: "Você gosta de Sertaneja."

C: [Ao achar uma estação de rádio que tocava uma música sertaneja, aumenta o volume e sai caminhando]

A falta de um trabalho individualizado aos portadores de transtorno mental, no contexto de internação, despe-os de suas capacidades humanas e vitais básicas. O tratamento em massa, por meio do qual todos são submetidos às mesmas condições, horários e rotina, com diferenças resguardadas apenas para o tratamento farmacológico e em casos de necessidade de dieta alimentar específica, põe o indivíduo na condição de excluído do seu processo de 'cura' e priva-o de tomar decisões sobre ele e sua vida (FOUCAULT, 1994). Fazer escolhas não faz parte dessa rotina. Tudo é preparado para funcionar em conformidade com uma ordem preestabelecida que visa garantir a disciplina e o controle. A falta de espaços privados, de material de uso pessoal resguardado e de horários flexíveis em conformidade com as necessidades individuais dos internos favorece ao desenvolvimento de padrões de comportamentos que, orientados pela regra institucional, sufocam os interesses, saberes, opiniões e escolhas pessoais.

As condições que permearam as interações, durante os encontros grupais, favoreceram não apenas a interação e comunicação dos participantes - também embotadas, haja 
vista a falta de espaços estimuladores e permissivos - mas principalmente ao resgate da autonomia e a redescoberta de interesses, prazeres e possibilidade de escolher. Inicialmente manifestas apenas quando havia algum tipo de estimulação, as expressões de opinião, de gostos e de sentimentos dos participantes tornaram-se cada vez mais frequentes e espontâneas.

\section{Considerações finais}

Pensar sobre as possibilidades de intervenção no campo da Psicologia da Saúde requer, antes, um olhar crítico acerca do conceito de saúde e das condições atuais dos serviços de saúde. Não reduzir a compreensão de saúde à ausência de sintomas é fundamental para analisar as condições de vida e as formas de tratamento da saúde que, embora atenuadoras dos sintomas ou das dificuldades abordadas, não contemplam as necessidades básicas tomadas como condição sine qua non para o desenvolvimento da qualidade de vida e do bem-estar das pessoas e da sociedade. Assim, cabe ao psicólogo comprometido em contribuir para a saúde de indivíduos ou de grupos abandonar concepções de saúde que tomam como referência o tratamento da doença ou a minimização de sintomas e orientar-se pelo resultado da análise dos elementos contextuais desfavoráveis ao bem-estar. Intervir de modo a propiciar transformações no contexto e/ou mudanças nas pessoas que possibilitem novas formas de viver, gerando melhoria nas condições favoráveis à qualidade de vida é uma das alternativas para se pensar o fazer da Psicologia com a finalidade de contribuir para a promoção da saúde.

No campo da saúde mental, as mudanças decorrentes da reforma psiquiátrica ainda não são suficientes para oferecer a todos um serviço pautado na humanização e na equidade, apesar destes serem princípios norteadores das políticas de saúde do Sistema Único de Saúde (SUS) (BRASIL, 2004). A 
criação dos Centros de Atenção Psicossocial (CAPS) representa os esforços políticos e da sociedade para minimizar ou cessar os efeitos negativos e desumanos das formas de tratamento até então oferecidos nas instituições psiquiátricas aos portadores de transtornos mentais e aos seus familiares. Contudo, é preciso nos reportarmos àqueles que, por motivos sociais, econômicos e/ou políticos, ainda permanecem internos nos hospitais psiquiátricos sob formas tradicionais de 'tratamento'. Se, por um lado, temos os serviços especializados e de qualidade oferecidos nos CAPS e diversos estudos que auxiliam na avaliação e melhoria deste; por outro, temos as instituições psiquiátricas que agora parecem não mais existir, o que representa para os internos um duplo abandono: primeiro, da sociedade e dos seus familiares; segundo, dos profissionais e pesquisadores de saúde que não têm atentado para as condições de funcionamento destas instituições.

A realidade dos hospitais psiquiátricos ainda em funcionamento pouco ou nada tem relação com o que compreendemos por saúde. A concepção de saúde adotada pela Organização Mundial de Saúde (OMS) refere-se ao estado de completo bem-estar físico, psíquico e social. Recentemente, a Psicologia Positiva, pautada nos estudos clássicos de Carl Jung e de Carl Rogers e nos mais recentes estudos de Seligman e Yunes (LEMOS, 2006; CALVETTI, MULLER e NUNES, 2007), aponta como fundamental à saúde, além dos aspetos considerados pela OMS, a possibilidade de desenvolvimento das forças positivas inerentes à pessoa. Assim, sugere o investimento em intervenções que, a partir do enfoque nos aspectos sadios do desenvolvimento humano, contribuam para a prevenção e promoção da saúde norteada para o restabelecimento do bem-estar subjetivo, do otimismo, da felicidade, da autodeterminação, da criatividade, e das habilidades interpessoais. O contexto das instituições psiquiátricas em nada se aproxima das referidas considerações sobre saúde. Ao contrário, no estudo, em questão, observamos a falta de 
elementos favoráveis à melhoria das condições de saúde dos internos. O tratamento orientado para a minimização dos sintomas da esquizofrenia e para a manutenção da ordem na instituição não prioriza modalidades interventivas que estimulem a autonomia, a criatividade e a liberdade dos pacientes. A falta de recursos humanos e materiais adequados é um dos aspectos que dificulta mudanças nas formas de cuidar. Apesar da existência de trabalhos por meio de oficinas terapêuticas (música, artesanato, culinária etc) oferecidas a alguns dos internos, temos conhecimento de que apenas aqueles em melhores condições e que apresentam habilidades específicas são incluídos nestas atividades. Não deveria os 'menos adaptados' e com mais comprometimentos serem contemplados nestas oficinas para a estimulação e reabilitação de suas capacidades? Tanto do ponto de vista teórico quanto em termos da prática adotada, nos CAPS, esta tem sido a proposta para promover saúde e favorecer a inclusão.

$\mathrm{Na}$ intervenção grupal por nós realizada, verificamos que dos cinco internos participantes apenas dois tinham acesso a atividades de lazer e de integração. Os demais, considerados agressivos e pouco adaptados ao convívio social não participavam de oficinas. Suas 'atividades' restringem-se a responder a rotina estabelecida pelo hospital. Chama-nos a atenção o fato de ser um deles (S.) o que mais apresentou mudanças positivas, haja vista ser um dos que mais apresentava limitações na interação, na verbalização e no campo afetivo e emocional.

Em todos, observamos avanços significativos. As condições grupais, de fato, tiveram um importante papel nos comportamentos observados, haja vista não ter havido outras mudanças significativas (rotina, medicação, etc) que pudessem ter contribuído para transformações nas formas de relação entre estes. Em busca de compreender a subjetividade destes pacientes, acompanhada dos significados mais particulares e aceitarmos o 'mundo' e a dinâmica individual de 
cada um deles, acreditamos ter favorecido a eles no despir-se dos receios dos julgamentos comumente dirigidos a pessoas com transtornos mentais. A liberdade para não permanecer no grupo, comparecer e nada fazer, escolher o que fazer, falar, silenciar, delirar, cantar, entre tantos comportamentos que desabrocharam como possibilidades, foram fundamentais para o resgate da autonomia e da descoberta de várias formas de comunicação. Corroborando os resultados do trabalho grupal realizado por Lemos e Cavalcante Jr. (2006) em um serviço de saúde mental (CAPS), verificamos que a atuação no grupo mediada pelo respeito, liberdade para escolher, estimulação e por uma escuta profunda, facilitou a interação, a comunicação, a expressão de conteúdos emocionais e a aprendizagem de condutas que contribuíram para o resgate de condições psíquicas mais favoráveis ao desenvolvimento de novas habilidades entre os integrantes.

Apesar das condições inadequadas ao desenvolvimento saudável nas quais estes ainda se encontram, a intervenção realizada fomentou novas possibilidades na vida destas pessoas. A criação, a descoberta de interesses e habilidades e as manifestações de prazer e satisfação são os caminhos através dos quais identificamos estar minimizando a condição de vulnerabilidade e promovendo saúde a estes internos. As interações mais saudáveis favoreceram ao reconhecimento destes enquanto pessoas - e não mais como um sintoma ou diagnóstico - que durante todo o processo foram cuidadas com respeito e dignidade.

O desafio inicial na implantação deste trabalho, ainda com limites em virtude de aspectos político-institucionais, e os resultados reveladores das possibilidades de intervenção da Psicologia na Saúde indica a necessidade de outras ações inclusivas, bem como intervenções que atuem na estrutura das instituições psiquiátricas remanescentes, tanto no aspecto da capacitação dos profissionais para um trabalho que de fato esteja comprometido com a saúde; como nas 
bases políticas que sustentam a manutenção destas instituições que funcionam tal como antes da reforma psiquiátrica. Em síntese, destacamos a abrangência de possibilidades no campo da Psicologia da Saúde. Seja na prevenção, na promoção da saúde ou no tratamento de doenças, o importante é que o trabalho do psicólogo chegue onde houver a necessidade de favorecer o desenvolvimento de aspectos saudáveis.

\section{Referências}

ANDRADE, Leda de A. Araripe. Noções de Psicopatologia para Terapeutas: aspectos da intervenção integrativa. Fortaleza: CTS, 2002.

A.P.A. American Psychiatric Association. Manual diagnóstico e estatístico de transtornos mentais (DSM-IV). $4^{\mathrm{a}}$ ed. Porto Alegre: Artes médicas, 1995.

AUGRAS, Monique. O Ser da Compreensão: fenomenologia da situação de psicodiagnóstico. Petrópolis: Vozes, 1986.

AYRES, José R. C.M.; FRANÇA JR. Ivan; CALLAZANS, Gabriela J. \& SALETTI FILHO, Haroldo C. O Conceito de vulnerabilidade e as práticas em saúde: novas perspectivas e desafios. In: CZERESNIA, D. e FREITAS, C. (Org.) Promoção da Saúde: conceitos, reflexões e tendências. Rio de Janeiro: Fiocruz, 2003.

BECHELLI, Luiz Paulo de C.; SANTOS, Manoel Antônio dos. Psicoterapia de grupo e considerações sobre o paciente como agente da própria mudança. Revista Latino-Americana de Enfermagem. Ribeirão Preto, v. 10, n. 3, 2002. Disponível em: www. eerp.usp.br.rlaenf. Acesso em: 02/06/08.

BRASIL. Ministério da Saúde. Secretaria de Atenção à Saúde. Departamento de Ações Programáticas Estratégicas 2004. Saúde Mental no SUS: os Centros de Atenção Psicossocial. Brasília, 84pp. 
BUSS, Paulo M. Uma Introdução ao conceito de promoção da saúde. In: CZERESNIA, D. e FREITAS, C. (Org.) Promoção da Saúde: conceitos, reflexões e tendências. Rio de Janeiro: Fiocruz, 2003.

CALVETTI, Prisla Ü; MULLER, Marisa C; NUNES, Maria L.T. Psicologia da Saúde e Psicologia Positiva: perspectivas e desafios. Psicologia, Ciência e Profissão. V. 27; nº4; Brasília, dez. 2007.

CORDIOLI, Aristides Volpato. Psicofármacos. Porto Alegre: Artmed, 2000.

CZERESNIA, Dina. O Conceito de Saúde e a diferença entre prevenção e promoção. In: CZERESNIA, D. e FREITAS, C. (Org.) Promoção da Saúde: conceitos, reflexões e tendências. Rio de Janeiro: Fiocruz, 2003.

DIMENSTEIN, Magda. A reorientação da atenção em saúde mental: sobre a qualidade e humanização da assistência. Psicologia, Ciência e Profissão. V. 24; nº 4; Brasília, dez. 2004. Disponível em: http://scielo.bvs-psi.org.br/scielo.php?pid=S1414-

. O desafio da política de saúde mental: a (re) inserção social dos portadores de transtornos mentais. Mental. V.4; $\mathrm{n}^{\circ}$ 6. Barbacena, jun. 2006. Disponível em: http://scielo.bvs-psi.org.br/scielo.php?pid=S167944272006000100007\&script $=$ sci_arttext\&tlng $=$ pt

FOUCAULT M. O Nascimento da Clínica. Rio de Janeiro: Forense Universitária, 1994.

GENDLIN, Eugene. Comunicação subverbal e Expressividade do terapeuta: tendências da terapia centralizada no cliente com esquizofrênicos. In: ROGERS, C. e STEVENS, C. (Orgs.). De Pessoa para Pessoa: o problema do ser humano. São Paulo: Livraria Pioneira editora, 1978.

KAPLAN, Harold e SADOCK, Benjamin. Manual de Farmacologia Psiquiátrica. Porto Alegre: Artes Médicas, 1995. 
KAPLAN, Harold; SADOCK, Benjamin; GREBB, Jack. Compêndio de Psiquiatria: ciências do comportamento e psiquiatria clínica. 7 ed. Porto Alegre: Artmed, 1997.

LAING, David. O Eu Dividido: estudo existencial da sanidade e da loucura. Petrópolis: Vozes, 1982.

LEMOS, Patrícia M.; CAVALCANTE JR, Francisco S. Psicologia de Orientação Positiva: uma proposta de intervenção no trabalho com grupos em saúde mental. Revista Ciência e Saúde Coletiva, 2006. Disponível em http://www.cienciaesaudecoletiva.com.br. Acesso em: março de 2007.

OLIVEIRA, Irismar R. Antipsicóticos atípicos: farmacologia e uso clínico. Revista Brasileira de Psiquiatria, 2000, n. 22, p. 38-40.

REY, Fernando G. Psicologia e saúde: desafios atuais. Psicologia, Reflexão e Crítica. V. 10 n$^{0} 2$. Porto Alegre, 1997.

ROGERS, Carl \& KINGET, Marian. Psicoterapia e Relaçóes Humanas: teoria e prática da terapia não diretiva. Vol. I. Belo Horizonte, Interlivros, 1977.

. Um Jeito de Ser. São Paulo: EPU, 1983.

ZANINI, Márcia H \& CABRAL, Rita R. F. Psicoterapia de grupo na esquizofrenia. Psychiatry on Line. $\mathrm{n}^{\circ} 4$, jan. 1999. Disponível em: http://www.polbr.med.br/arquivo/psgresq.htm 


\title{
10
}

\section{La menopausia un ciclo de vida Análisis comparativo de la percepción que las mujeres urbanas y rurales de la provincia de Granada tienen de su propia menopausia}

\author{
Maria Jose Robles Delgado \\ Luciana Ramirez Imedio
}

\section{Introducción}

T a existencia humana está condicionada por el ecosistema en el que se desarrolla. La defensa de la salud de la población obliga a la propia población a modificar las circunstancias de su vida.

Tanto la salud como la enfermedad son una cuestión biológica, se produce en el interior de nuestro cuerpo, como una interacción entre los factores agresivos que vienen del exterior o del medio interno y nuestra biología que reacciona.

La prevención y promoción de la salud se encamina a eliminar o neutralizar los factores agresivos. 
A lo largo de la vida las personas van pasando por diferentes etapas (niñez, adolescencia, juventud, madurez y senectud) o ciclos de vida.

Ciclo de vida sugiere existencia humana individual, hablamos de ciclo de vida porque si bien la edad ha sido considerada como principio universal de organización social, queremos referirnos a periodos que marcan una serie de pautas de comportamiento, desarrollo y modo de vida.

La base universal de la existencia del ciclo de vida esta ligada a hechos biológicos antes que sociales, el nacimiento de un individuo ha de pasar por toda una serie de etapas vitales que le llevan hasta la muerte, lo interesante es ver como cada cultura impone sus normas y como estas pueden ir cambiando.

La existencia de unos rasgos comunes en cada grupo de edad no justifica la definición de un perfil general, cada persona es resultado de lo que ha vivido, como lo ha vivido y en qué entorno (BODOQUE, 2001).

La vida adulta supone en muchos casos tanto para mujeres como para hombres un periodo de reflexión, una etapa de cambios.

En la mujer esta etapa coincide con la menopausia que popularmente se entiende como un momento de cambio asociado a la vejez, a la perdida de la belleza y de la juventud, proyectando así una visión negativa del papel que representa la mujer madura.

La menopausia es un acontecimiento que marca el inicio de una etapa más en la vida de la mujer que va a estar influenciada por el entorno sociocultural en el que esta inmersa. Dentro de la cultura se debe contemplar hábitos como la alimentación y la actividad física entre otros, pero también los valores sociales que configuran el estereotipo de 
la mujer, es decir, como se establece el papel que desempeña ésta en cada sociedad (RIBERA, 2003).

Mensajes como la impureza de la menstruación, la importancia de la virginidad, o la infravalorización de la mujer estéril llenan la historia de culturas y formas sociales tan diferentes como la judía, cristiana, islámica, hindú, etc. Todas ellas con un factor común, el papel de la mujer en función de su capacidad reproductora y entorno al mundo de los hombres.

En las diferentes sociedades y culturas el significado de la menopausia esta relacionado con los conceptos de sexualidad, feminidad, fecundidad y maternidad. En la actualidad, en las sociedades occidentales existen estereotipos sociales, culturales y procedentes del modelo biomédico que proporcionan a la menopausia una visión negativa y patológica, puesto que se asocia a pérdida y a envejecimiento. ${ }^{3}$

Cuando se habla de los cambios que se producen desde el nacimiento a la madurez se utiliza el término desarrollo, que tiene una connotación positiva, mientras que en aquellos que se producen posteriores a esta etapa se habla de envejecimiento que posee una connotación negativa. Estos pensamientos negativos incluyen ideas de aislamiento, soledad, dependencia, necesidad de cuidados y pérdida generalizada (GREER, 1993).

Sin embargo, en otras culturas la mujer en esta etapa es reclasificada en positivo, puesto que se neutralizan tabúes relacionados con la menstruación, adquiriendo reconocimiento y prestigio social.

En la cultura celta a la mujer mayor se la compara con la semilla, esa parte que contiene en su interior el conocimiento y el potencial de todas las demás partes.

En algunas comunidades indígenas se pensaba que las mujeres menopausicas retenían su sangre sabia, se las 
consideraba más poderosas que las que menstruaban. Ellas no podían ser chamanas hasta que no hubieran llegado a la menopausia. En la India la mujer rahjput recibe la menopausia como una recompensa, después de vivir apartada en su cuarto de mujer impura, pueden salir libremente de sus casas, visitar a otras mujeres e incluso compartir actividades de los hombres. Las mujeres musulmanas pueden a partir de ese momento participar en los rituales religiosos.

Estos factores han ido cambiando a lo largo de la historia y por tanto también ha ido cambiando la percepción que la sociedad tiene de la mujer. Por lo que la menopausia se presenta entonces no como un concepto estático, sino como algo relativo que varia en función de cómo se dispongan los factores socioculturales que la condicionan.

Elementos como la edad en que se tiene el primer hijo supone que hace 50 años las mujeres menopausicas eran abuelas, hoy muchas están criando hijos adolescentes y dentro de unos años, sus hijos serán todavía pequeños.

El aumento en la esperanza de vida también esta influyendo en la percepción de la menopausia, esta significaba el inicio de la vejez, hoy con un tercio de vida por delante, podemos decir que esto le ocurre a las mujeres en un momento de madurez e incluso de plenitud.

Y la investigación científica cuyos últimos avances han facilitado la maternidad tras la menopausia, indican la importancia que tiene la situación individual y la influencia de factores psicológicos, sociales y culturales en la concepción de la menopausia.

\section{Menopausia y Climaterio}

Los términos menopausia y climaterio suelen utilizarse indistintamente por la población femenina y los medios de comunicación, sin embargo, desde el punto de 
vista ginecológico cada uno de ellos expresa eventos distintos. Según la Federación Internacional de Ginecología y Obstetricia (FIGO), el climaterio es el periodo de tiempo que se extiende desde la madurez hasta la senectud. Marca la transición entre la etapa reproductiva y la no reproductiva que viene determinada por el descenso de la actividad ovárica. La OMS, hace referencia al climaterio como una etapa de la vida de la mujer de límites imprecisos situada entre los 45 y los 64 años. Este periodo es una fase de transición compleja en la que intervienen factores biológicos, psicológicos, sociales y culturales. Mientras que el concepto ginecológico de menopausia señala un hecho puntual: el final de la menstruación. Es el fenómeno central del climaterio, aislado, natural, universal e inevitable para todas las mujeres, que sucede entre los 45 y 55, con una media de 51 años.

La menopausia es un proceso fisiológico que se produce en todas las mujeres, este es un suceso de importancia sociológica y cultural más que biológica. Solo representa un hecho en el contexto de un gran periodo de 20 a 30 años, denominado climaterio.

La edad de aparición de la menopausia no se ha modificado durante los últimos siglos situándose alrededor de los 50 años, lo que ha cambiado es la mayor esperanza de vida.

Considerando que en la Roma clásica la esperanza de vida al nacer era de 23 a 25 años, la mujer menopáusica como colectivo no es representativa hasta el siglo XX, momento en que la esperanza de vida, supera la edad de la menopausia.

Hasta hace solo algunas décadas las mujeres veían la menopausia como un hecho natural y biológico que reconocían y manejaban gracias a un sistema de auto cuidados construido culturalmente. En la actualidad los profesionales de la salud y los medios de comunicación han elaborado un discurso que se difunde permanentemente según el cual la 
menopausia es un proceso patológico, lleno de riesgos para las mujeres y por tanto susceptible de tratamiento, creando confusión y dudas.

El mensaje nos dice que la menopausia conlleva un incremento de riesgo para numerosas enfermedades y una disminución en la calidad de vida, cuando se analizan las palabras utilizadas en los textos de medicina para describir esta etapa fisiológica, encontramos términos como final, perdida, atrofia, déficit, ansiedad, nerviosismo etc. términos que suponen una desvalorización cultural de las mujeres mayores, así lo define Simone de Beauvoir, ”toda la tradición ha cargado esta palabra de sentido peyorativo, suena como un insulto, vieja" (BEAUVOIR, 1986).

Es muy difícil distinguir los efectos de la edad de los derivados de la menopausia solo tenemos la evidencia de que el descenso de estrógenos se asocia con tres fenómenos: síntomas vasomotores, disminución de espesor del epitelio vaginal y perdida de masa ósea, y además estos síntomas afectan de forma variable en frecuencia e intensidad a las mujeres en el climaterio.

La menopausia no es una enfermedad, ni tiene que representar un problema de salud, existen variaciones biológicas, psicológicas y culturales a las que es necesario adaptarse, pero que no deben identificarse como una enfermedad.

No obstante la enfermedad puede surgir, las alteraciones endocrinas son reales, los efectos del envejecimiento comienzan a evidenciarse, pero no deben atribuirse a todas las mujeres, sino de forma concreta a cómo cada una siente y comprende esta etapa.

La madurez se empieza a ver como un momento de la mitad de la vida, entre la experiencia del pasado y los proyectos de un futuro por hacer. 
El climaterio es un momento de hacer balance, de transformación espiritual además de física y seria una lástima no ser conscientes de ello.

\section{Ritos de paso}

En general la sangre ha supuesto un importante tabú para muchos grupos étnicos, además se considera un líquido con alto poder simbólico y de importancia social, es considerada la fuerza vital de los pueblos, un símbolo de vida que tenia atributos mágicos.

La pérdida de sangre en la mujer, fue lo que llamo la atención en casi todo el mundo y a lo largo de todas las épocas. La idea que relacionó menstruación con ciertos temores sociales y personales, hacen de ella una fuente de múltiples tabúes. Se creía que daba a la mujer una inteligencia extraordinaria.

La menopausia, el cese de la menstruación, es un cambio pero no un paso de la vida a la muerte, nos costaría menos percibirlo si las mujeres pudieran señalar también algunas ventajas o privilegios, status, respeto, intimidad, pero el climaterio no lleva adscrito ninguna señal de este tipo, más aún se espera que las mujeres finjan que no ocurre nada.

La mujer de 50 años tiene que tomar nota del cambio que se está operando en su interior, pero al mismo tiempo se ve obligada a mantener en secreto ese trastorno, la vergüenza que sintió cuando empezó a menstruar no es nada comparado con la que sentirá con la menopausia, ninguna mujer se presentara en público anunciando que espera ser tratada con especial consideración porque está pasando por el difícil momento de la menopausia.

Ningún rito de paso otorga solemnidad al momento que vive la mujer. Un rito de paso cumple la función de señalar como significativo un cambio crucial en la vida del individuo, ofrecerle apoyo de la sociedad durante ese cambio e 
intentar atraer la bendición de los dioses a través del ritual. No se le concede un descanso especial, no le queda más remedio que asumir el asunto y fingir que no ocurre nada. La invisibilidad de la menopausia no cumple ninguna finalidad. La menopausia ha sido y es un no acontecimiento en todas las sociedades.

\section{Diferencias de género}

Los hombres y mujeres tenemos niveles similares de inteligencia general, de responsabilidad y de sentido de la justicia. No hay razón para discriminar, ningunear o preferir a alguno de los dos sexos desde un punto de vista social, legal, político o de salud. De todos modos, establecida la igualdad legal y política y la libertad de hombres y mujeres, no se deduce que sean iguales en otros aspectos.

Las mujeres muestran de promedio una escala de valores distinta que los hombres, colocando la propia satisfacción personal en el trabajo y el cuidado de los hijos y de la familia por encima de las oportunidades de ascenso y promoción.

Los países punteros lo son porque han avanzado en toda una serie de aspectos, incluida la igualdad y libertad de hombres y mujeres, lo que incrementa la creatividad intelectual y la eficiencia económica del país, permitiendo así el óptimo aprovechamiento de los recursos humanos disponibles. No es así en todos los países donde imperan dogmas, mitos, y prejuicios opresivos como en China donde la deformación de los pies de las mujeres era una práctica habitual. En el Pakistán rural una mujer siempre pertenece al hombre. En los países islámicos la discriminación de las mujeres es constante incluso en países muy ricos como Arabia Saudi no se permite que las mujeres puedan conducir un automóvil, sin olvidarnos de las mutilaciones genitales del África islámica central y oriental o de las mujeres afganas que no pueden ni asistir al médico ni al hospital, ni tienen acceso a la escuela. 
El cuerpo del hombre es distinto al de la mujer, y esto condiciona también sus vivencias, actitud y aptitud frente al mundo, y no solo su cuerpo sino que su percepción, en otros temas de la vida diaria, es de manera distinta.; hasta hace poco tiempo la medicina ha sido y es ejercida por los hombres, así las mujeres nos hemos visto sometidas a la visión masculina en todos los aspectos de la salud y la enfermedad, desde el poder y el conocimiento no se debe manipular con enfermedades y con prevenciones.

La relación entre hombres y mujeres, a la vez deliciosa y conflictiva, aparte de ser básica para la supervivencia de la especie humana, impregna nuestra vida cotidiana y nuestra cultura, constituyendo el tema favorito de la literatura y del arte en general. Aunque muy anclada en la naturaleza humana y fundamentalmente impulsada por tendencias congénitas, la relación entre hombres y mujeres esta complicada y afectada por factores culturales (MOSTERÍN, 2005).

Las raíces de la belleza son biológicas y la selección natural marca unas preferencias estéticas por los cuerpos que emiten señales de salud y fecundidad, en nuestra sociedad esa tendencia congénita se saca de quicio, la forma bella, se convierte en fin en sí mismo, perseguido aun a costa de repetidas operaciones quirúrgicas que en ningún sentido mejoran la salud ni la fecundidad.

Aunque hombres y mujeres compartimos la misma naturaleza humana, hay diferencias manifiestas en nuestra anatomía, nuestra conducta y nuestros sentimientos.

El amor, sin duda algo maravilloso, es un problema semántico con el que definimos gran cantidad de fenómenos distintos, hombres y mujeres lo vivimos y manifestamos de distinta manera.

Estas diferencias de género, culturales en su mayoría, determinan socialmente el punto de partida de hombres y 
mujeres, las diferentes medidas que se nos aplican a unas y otros y su influencia en todas las etapas de la vida.

Muchas de las situaciones que se describen como propias de la mujer climatérica también le ocurren al hombre en ese momento de la vida, se puede deducir que gran parte de ellos no son atribuibles a la menopausia, sino a problemas vivenciales que coinciden en el tiempo.

\section{Sexualidad}

En nuestra sociedad se ha identificado la sexualidad de las mujeres con su capacidad reproductora y todavía en la actualidad se piensa erróneamente que la menopausia representa el fin de la sexualidad, de la capacidad de dar y obtener placer la intensidad de nuestra respuesta sexual puede variar a lo largo de los años y en cualquier momento de nuestra vida. Nuestra experiencia sexual es única, irrepetible y valida en la medida que responde a la necesidad de obtener placer con nuestros cuerpos, sin embargo tiende a ser unificada socialmente, olvidando que sus posibilidades son casi infinitas, por ejemplo, se nos presenta el coito como la única forma de placer sexual, siendo esta una de sus muchas formas de expresión. Casi en toda la literatura sobre la menopausia, que hemos consultado, se habla de dolor y molestias en las relaciones sexuales sin especificar que suceden exclusivamente en las relaciones cóitales, que a ninguna mujer le duele que la besen, que la abracen, y que la acaricien.

Todo nuestro cuerpo es capaz de proporcionarnos placer, reducir nuestra sexualidad a lo relacionado con la vagina, como órgano sexual asociado al coito y como única práctica sexual, masculina por excelencia, es reducir la capacidad de sentir de nuestro cuerpo, el de hombres y mujeres y reducir las infinitas posibilidades que tenemos. Durante el climaterio las mujeres tienen tanta capacidad como en otras etapas anteriores de disfrutar de su sexualidad y de conseguir a 
través de ella una fuente de placer, en contra de lo proclamado durante décadas, una mujer en ese periodo puede disfrutar y debe hacerlo del sexo, ya sea en pareja o a través de la masturbación, algo natural y beneficioso para el cuerpo y el espíritu.

Desde el punto de vista biológico el fin principal de la sexualidad es la reproducción de la especie, pero no es la única, ni siquiera la más importante. El placer sexual no va necesariamente unido a la reproducción, la mayor parte de las relaciones sexuales que tienen las personas son una búsqueda de placer y una manifestación de comunicación, ternura y afecto. La sexualidad es entendida como una dimensión humana. A pesar de que la tradición y los mitos sobre la sexualidad presentan a la mujer climatérica como una persona que ha perdido el interés en la relación sexual, muchas mujeres valoran su sexualidad como de mayor calidad durante esta etapa. Se trata de una etapa de liberación, se pierde el miedo al embarazo, se olvidan los métodos anticonceptivos, la menstruación etc., todo esto influye positivamente en que la mujer disfrute de la sexualidad durante el climaterio.

Las relaciones sexuales satisfactorias pueden continuar después de la menopausia ya que el cambio hormonal que se experimenta no tiene porqué modificar las posibilidades de sentir y vivir placer. También hay que recordar que la penetración no siempre es necesaria para gozar de las relaciones sexuales y que existen otras muchas formas de expresar la sexualidad que son igual de gratificantes.

La actividad sexual se mantiene hasta edades avanzadas en la mayoría de la población. La mayor parte de la población de mayores mantiene actividad sexual a pesar de los supuestos cambios fisiológicos, y sobre todo a pesar de los aspectos psicosociales que crean dificultades a quienes desearían tenerla. 
Elementos esenciales de la sexualidad, como el interés sexual, la identidad sexual, el rol de género, capacidad de enamoramiento, comunicación y afecto, el valor concedido a las caricias corporales..., no involucionan en relación con la edad

\section{Medicalizacion de la menopausia}

La medicalización es un proceso mediante el cual fenómenos humanos en principio normales son tomados bajo la competencia de la profesión médica, ellos son los expertos (BAILÓN; DELGADO, 1997).

Medicalización de la sociedad basándose en la idea de universalidad, que ha servido para sustentar el propio modelo medico hegemónico, medicalización que supone control social e ideológico sobre la población a través de la estigmatización y regulación de ciertos comportamientos y la negatividad asociada a determinados padecimientos.

Control social que se canaliza fundamentalmente a través de las intervenciones asistenciales directas, curativas o educativas y la influencia ideológica con los medios de comunicación y otros niveles de la sociedad. Todo ello va creando cada vez mayor dependencia, de las mujeres en esta etapa de su vida.

El fenómeno de la medicalización es el resultado de la interacción entre médicos-usuarias e industria farmacéutica.

La definición de enfermedad como desviación de una norma biológica, la uní causalidad o etiología especifica de las enfermedades, la noción de que las enfermedades son universales, la idea de neutralidad de la teoría y la practica biomédica, la dicotomía mente-cuerpo, la autonomía de la biología de la conciencia humana, el atomismo anatómico, son los denominados presunciones de cientificidad de la biomedicina. 
La medicalización de las mujeres es un ejemplo de cómo se ha ido desarrollando este proceso tanto dentro como fuera de Occidente, medicalización llevada a cabo específicamente a través del control de procesos corporales y reproductivos.

En relación directa con la menopausia está la construcción de una nueva edad media o madura, esta nueva etapa se suele relacionar con aspectos psicosociales muy amplios y diferentes, ligados más o menos directamente con la salud.

La edad media de las mujeres surge vinculada de manera muy estrecha con cambios sociodemográficos y de salud, como la elevada esperanza de vida en general y específica para las mujeres, pero no se define de la misma manera para hombres y mujeres, ni tienen las mismas connotaciones para ellos. En las mujeres se destaca sobre todo la dimensión de crisis y vulnerabilidad generalizable a todas y el riesgo de problemas físicos y psicológicos, así como una lectura reproductivista de sus vidas, puesto que se asocia siempre aunque sea de forma indirecta a la menopausia y al cese de la menstruación y por tanto a la capacidad reproductiva.

La provisión de hormonas a sustituir, las que se han perdido tras la menopausia, encarna la medicalización de la misma.

Tales conceptualizaciones están repletas de ideas de esencialismo biológico, relevancia de la edad y suposiciones heteroxesistas que alimentan el sexismo, la imagen de la menopausia como un síndrome de deficiencia de estrógenos. El empleo de la THS (Terapia Hormonal Sustitutiva) se ofrece en relación a tres promesas:

- Belleza más feminidad eterna (1966-1975)

- Menopausia segura y sin síntomas (1975-1981)

- Escapar de las enfermedades crónicas (1980 -hasta presente) (HUNT, 1994) 
Aunque todas las mujeres que han tenido la menstruación tienen una menopausia en el sentido biológico estricto, la experiencia más común, el climaterio, que es resultado de una compleja interrelación entre las sensaciones del cuerpo y las expectativas sociales, dista mucho de ser universal.

El cese de la menstruación y el descenso de la producción de estrógenos son fenómenos universales, todos los demás síntomas y sucesos asociados a la menopausia, no lo son.

La experiencia esta sujeta a un considerable condicionamiento social y cultural. El énfasis que la sociedad pone en el cliché de la atracción física y de la juventud es un factor de opresión mucho más poderoso para las mujeres que para los hombres.

Mientras el deseo sexual hacia un hombre y como ser social a menudo se describe en términos de personalidad, inteligencia, éxito y capacidad de ganar dinero, el de las mujeres esta mas ligado a su atractivo físico. No hay estereotipos culturales que nos rediman a las mujeres de las arrugas, patas de gallo, canas y michelines. Todas las mujeres sienten los efectos de una doble norma, las mayores con mas crueldad.

\section{Metodología}

En este trabajo se pretende analizar la percepción en las mujeres de su propia menopausia y ver si esta coincide con la visión médica y social que de la misma se tiene.

La muestra objeto de estudio incluye mujeres de distinta condición social y de situaciones diferentes, se centra en una población de mujeres de 46 a 93 años que residen en la ciudad y en la provincia de Granada, estudio que hemos dividido en mujeres urbanas y mujeres rurales. 
Para poder construir la conceptualización de la menopausia por las propias mujeres, se han realizado 12 entrevistas en profundidad, en las que se han abordado los siguientes temas: datos sociodemográficos entre los que cabe destacar la edad, el lugar de nacimiento, el lugar de residencia, el estado civil, la formación académica y la actividad laboral.

También se han contemplado diferentes aspectos de la menopausia como la edad de la retirada de la menstruación, las alteraciones o trastornos que aparecieron, los remedios y/o tratamientos realizados por las mujeres, los cambios en el estilo de vida, la percepción de esta etapa, los acontecimientos familiares o sociales que coincidieron con ese periodo, la sexualidad, la relación con la pareja y con los hijos.

La elaboración de un cuestionario que se ha pasado a 60 mujeres en el que además de los datos sociodemográficos hay una serie de preguntas que han sido agrupadas por bloques: salud física, salud psíquica, relaciones de pareja (con pareja y sin ella), sexualidad, relaciones sociales y familiares.

Para su elaboración nos hemos apoyado en la Escala Cervantes (MANUBENS; PARRILLA; ALBERICH; FERRER BARRIENDOS; PALACIOS; CASTELO-BRANCO I FLORES, 2003), Índice menopáusico de Kupperman (KUPPERMAN, 2003) y la escala de Mencav (BUENDÍA, 2001)

Tanto para la realización de los cuestionarios como de las entrevistas, hemos ofrecido a las mujeres que nos firmen un consentimiento voluntario, y a la vez hemos asegurado la confidencialidad de sus respuestas y opiniones.

Hemos realizado dos entrevistas a dos profesionales de la medicina, una Médica de Atención Primaria y un Ginecólogo, por ser éstas las dos vías de acceso que suelen utilizar las mujeres para interesarse por su menopausia.

Desde aquí agradecer profundamente el apoyo recibido por parte de todas las mujeres que han colaborado, por sus 
ganas de hablar, por sus confidencias, por su generosidad y por darnos la oportunidad de escuchar sus relatos tan entrañables.

\section{Análisis comparativo de los datos}

Aspectos demográficos: la edad media de las mujeres urbanas es de 55.93 años y de las mujeres rurales de 57.33; el $\mathrm{n}^{\mathrm{o}}$ de hijos es de 1.80 en MU (Mujeres Urbanas) y 2.77 en MR (Mujeres Rurales); están casadas el 76.67\% de MU y el 83\% de MR; el 50\% de MU son universitarias y el 90\% de MR tienen estudios primarios; son trabajadoras el 70\% de MU y el $56.67 \%$ de MR.

En cuanto al tratamiento casi la mitad de las mujeres no toman nada, siento las mujeres rurales las que toman más THS que las urbanas. (Cuadros 01,02).

\section{Tratamiento}
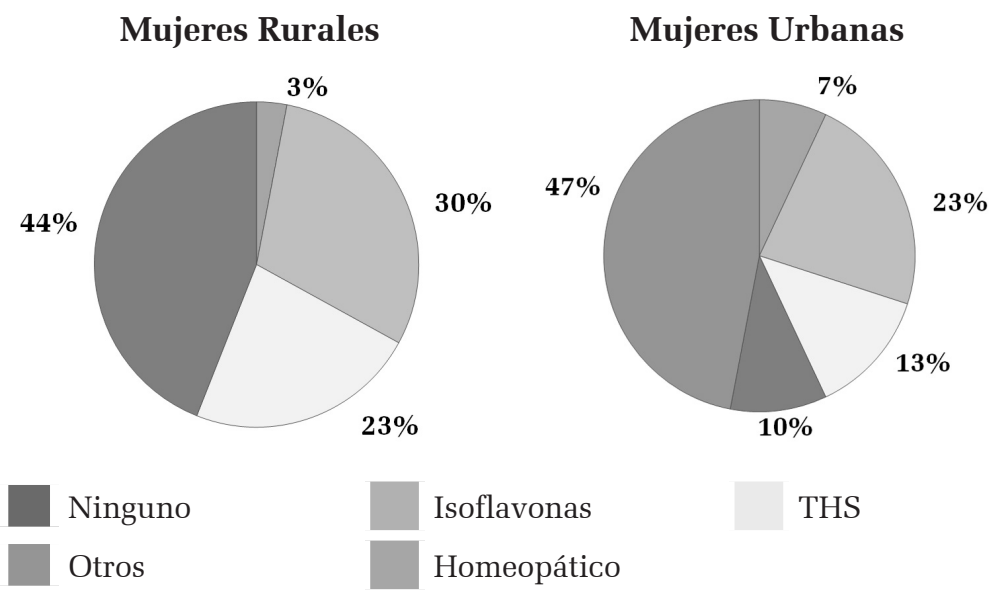

THS

Cuadro 01. 


\section{Formacion academica}

Mujeres Rurales

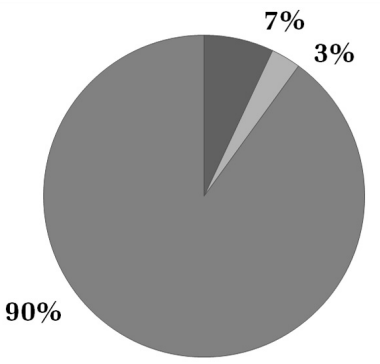

Mujeres Urbanas

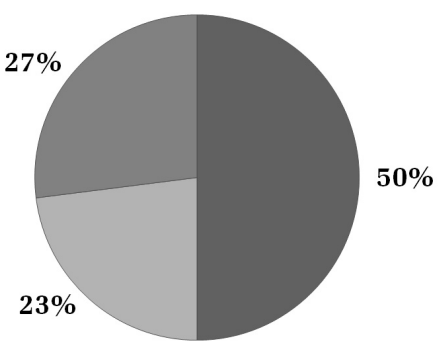

Secundaria

Universitaria

Cuadro 02.

El análisis comparativo manifiesta la presencia de sintomatología asociada a la menopausia en diferentes grados de intensidad, por ejemplo: presentan sofocos el 76.60\% de MU y el 60\% de MR;(cuadros 03 y 04) el 73.33\% de MU y el 50\% de MR tienen sequedad vaginal (cuadros, 05 y 06).

\section{Mujeres rurales}

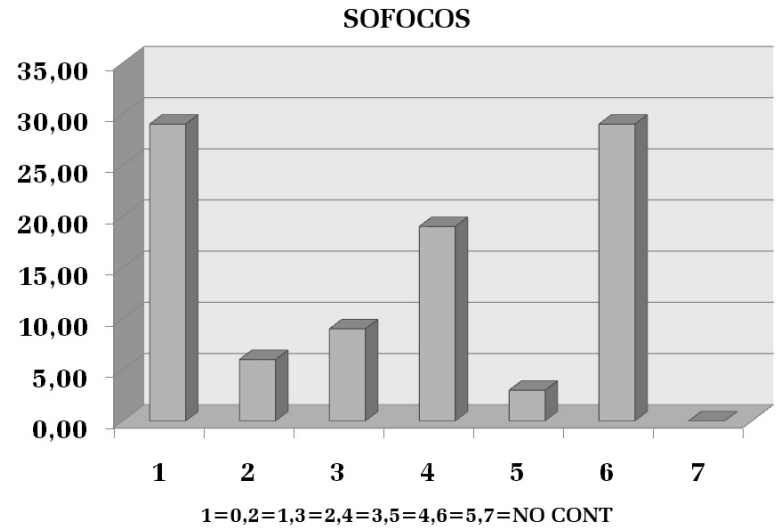

Cuadro 03 


\section{Mujeres urbanas}

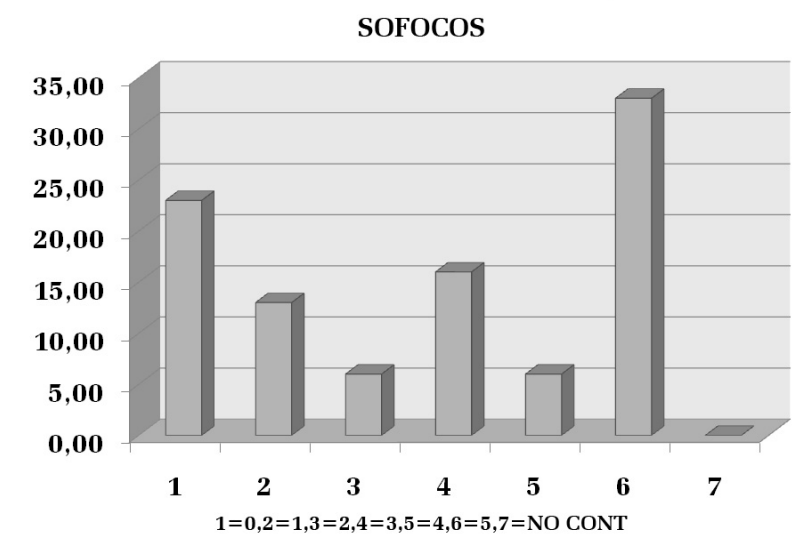

Cuadro 04

Con respecto a la sexualidad el 70\% de MU y el 66.67\% de MR manifiestan su deseo como algo presente "igual o más que antes" nos dicen; (Cuadros 07-08) la frecuencia en sus relaciones sexuales es alta para el $36.67 \%$ de MU y para el $26.67 \%$ de MR; son satisfactorias para el $53.63 \%$ de MU y para el 60\% de MR. La masturbación es una práctica sexual poco utilizada, en las MR el 26.67\%, lo interpretamos como una diferencia de género importante, si a los hombres desde niños se les inicia en esta práctica por sus hermanos o por otros niños, en las niñas y después en las mujeres es un tabú, algo prohibido, cuando hicimos esta pregunta, nos decían "no lo necesito", "lo entiendo en los hombres".

En cuanto a sus relaciones sociales y familiares se sienten útiles un 60\% de MU y un 60\% de MR; satisfechas con ellas mismas el 43.33\% de MU y el 46.67 de MR y les gusta cuidar su aspecto al $46.67 \%$ de MU y al $40 \%$ de MR.

El análisis comparativo nos muestra que apenas hay diferencias entre las mujeres urbanas y rurales sobre lo que sienten y como lo sienten en relación a su menopausia, 
manifiestan que la menopausia llega con la edad y que esta coincide con momentos vitales importantes.

Las entrevistas nos han demostrado que no podemos hablar de menopausia sin hablar antes de la vida de las mujeres, para algunas hay un antes y un después, no les gusta lo que significa esta etapa, para otras no ha supuesto cambio alguno en sus vidas, en su cotidianidad y otras creen que lo que les espera puede ser todavía mejor, todas coinciden en que la menopausia no es un problema de salud.

\section{Mujeres rurales}

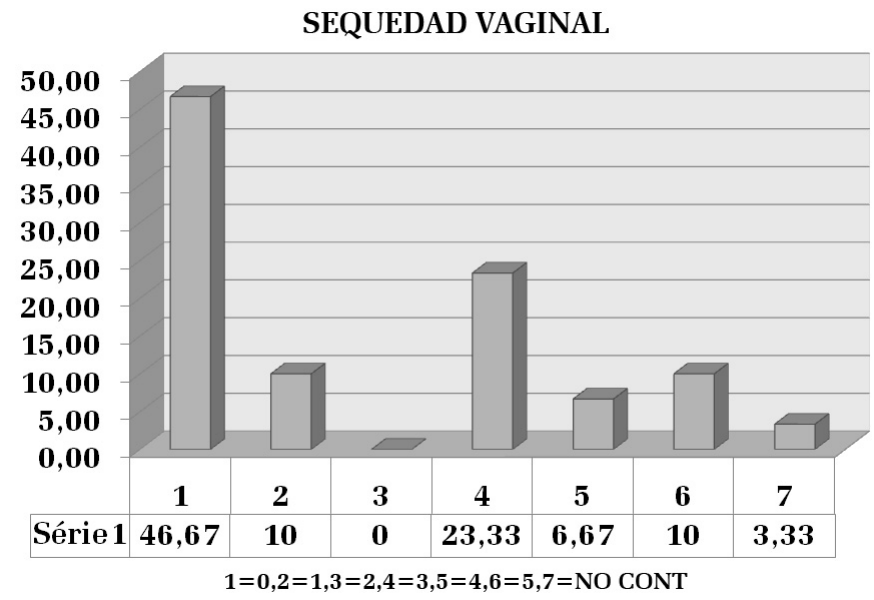

Cuadro 05 
Mujeres urbanas

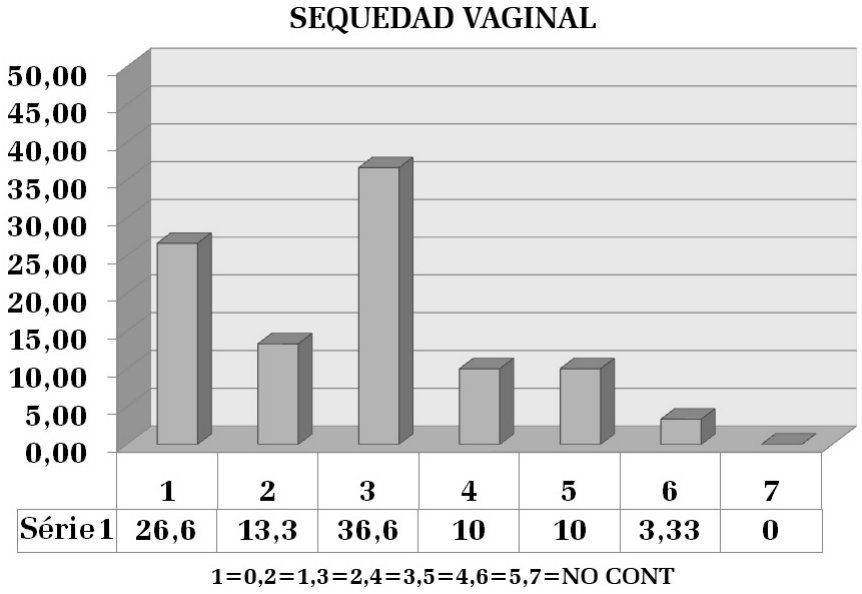

Cuadro 06

Mujeres rurales

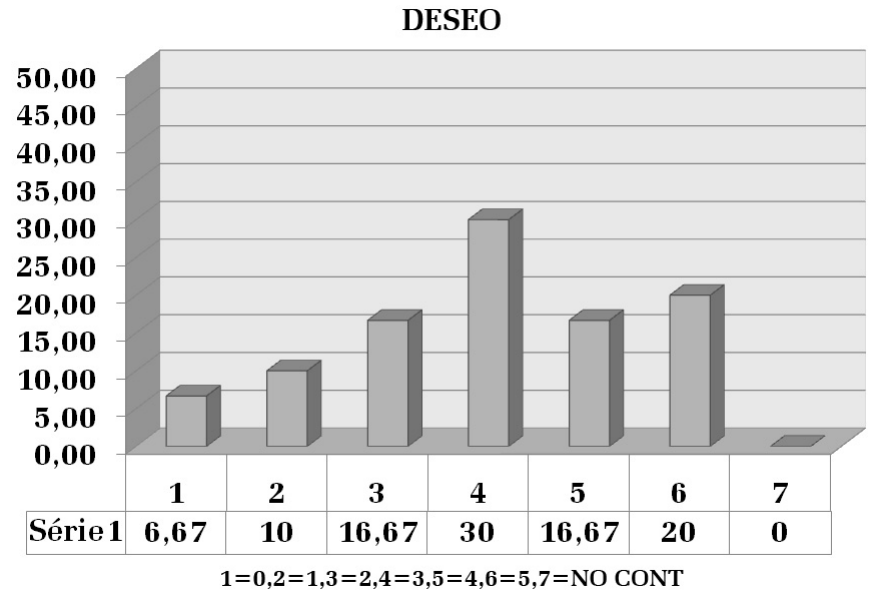

Cuadro 07 


\section{Mujeres urbanas}

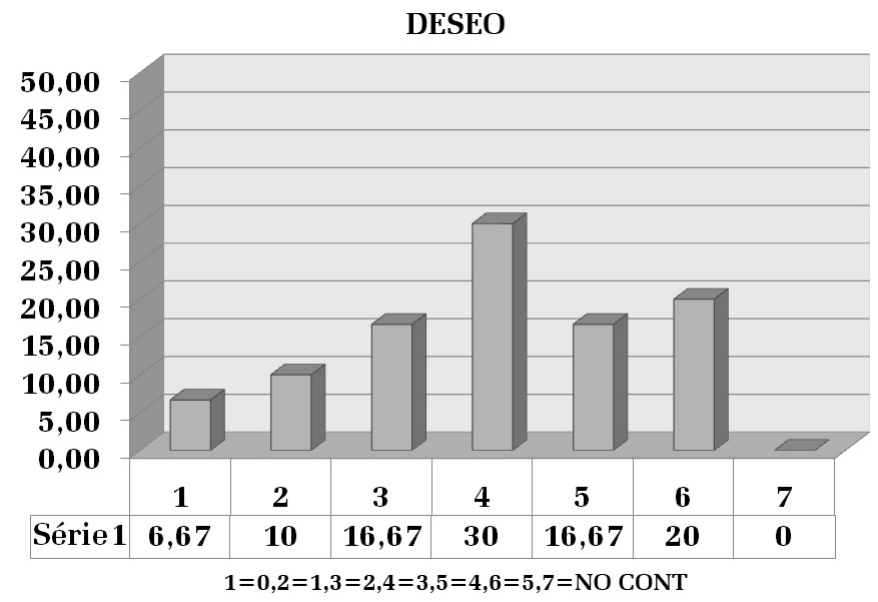

Cuadro 08

\section{Entrevistas}

“...y con una experiencia que me ha hecho madurar y valorar más las cosas de la vida. No hay máximos ni mínimos, todo es relativo".

Ana nació en un pueblo de Extremadura y vive en Granada, trabajó desde los diez años en la empresa familiar, a los veintitantos se fue a Madrid, tiene dos hijos y ahora vive una nueva relación, sin ataduras aunque son libres, no es partidaria de ataduras ni religiosas ni civiles "hoy podemos tener pareja a nuestra medida, las normas y leyes las ponemos nosotros, nuestros vínculos son afectivos, con casas y economías separadas, es una nueva forma de relacionarnos”.

Tiene 53 años, la regla se le retiro a los 52, es muy activa, alegre y confiada, no duda en hablar de su intimidad...se ríe mucho. 
"El primer síntoma de la menopausia me resulto gracioso, fue por la noche, me desperté con un calor especial en la cara y tórax, cedió enseguida pero me despertó, al principio me puse contenta de estar ante una nueva experiencia, se lo consulte al médico de cabecera y tome isoflavonas durante dos años, los análisis daban una menopausia a nivel de hormonas, pero continuaba con la regla de vez en cuando y un ovario seguía funcionante según la ecografía, no parecía que fuese a molestarme mucho, los calores parecían llevaderos, pero luego se fueron agudizando, me despertaba mucho por las noches y me costaba levantarme por las mañanas, estaba cansada, se lo comente al médico y me envió al psiquiatra...a éste no supe decirle porque iba, me hizo unas preguntas...en la menopausia es normal tener depresión me dijo, me mando un antidepresivo y un ansiolítico, después de dos meses lo deje; visite a mi ginecólogo y pase a tomar THS."

$\mathrm{Al}$ principio tuvo reacciones exageradas "a cosas que no tenían gran trascendencia, lo hable con mis hijos y luego se reían cuando saltaba de tono."

"Mi deseo sexual aumentó con la menopausia, mis relaciones son muy satisfactorias tanto si son cóitales como si no, me masturbo sola y en compañía, es placentero y no me duele la penetración aunque uso un gel porque a veces tengo poco flujo."

"Me siento y me he sentido atractiva y guapa, quizás porque mis amigas/os y hermanas me lo recuerdan siempre."

"No me siento mayor, me gusta mucho salir y divertirme, tengo una gran red de apoyo para pasear, cine, actividades culturales y sobre todo viajar."

A los 40 años, con toda la vida por delante le diagnosticaron a su marido un tumor, murió dos años después, "te queda el recuerdo...y cuando superas los primeros años, los peores, retomas la vida, el trabajo, la formación, la educación de mis hijos y con el tiempo el amor, el deseo y la satisfacción 
de seguir siendo útil, me siento muy feliz, querida, deseada y con muy buena comunicación con mis hijos que ya son mayores."

"Ahora me siento plena y con una experiencia que me ha hecho madurar y valorar más las cosas de la vida. No hay máximos ni mínimos, todo es relativo"

"La menopausia, ni más ni menos importante que otras etapas de la vida, no temo envejecer, solo me da miedo la enfermedad y el dolor."

"Lo de antes y después de la menopausia son dos orillas que tienen en medio el mismo río, las aguas bañan las dos orillas no sabría poner fronteras."

Lola tiene 53 años, a los 47 se le fue la regla, nació en Jaén y lleva en Granada más de 20 años. Su estado civil lo define como "casi monja" aunque es separada, vive con sus dos hijos de 25 y26 años, trabaja en salud mental infantojuvenil, actualmente no tiene pareja.

Estaba en tratamiento ginecológico por una conización, cuando comenzó con la menopausia "en una de mis revisiones al ginecólogo por mi conización, le consulte por los sofocos que eran muy intensos y agobiantes, me despertaba por las noches, me mando parches, mejore mucho aunque engorde un poco, anímicamente bien y físicamente también, el pelo bien, al año deje el tratamiento, continué con los sofocos aunque más leves.....también diría que son de la misma intensidad pero que tiene que ver con la situación vital en la que estés, ahora no me agobian, hay temporadas que no me acuerdo, cinco años da para incorporar muchas cosas".

"Estaba decaída y muy cansada, con insomnio, hoy no sabría decir si todo tenía que ver con la menopausia o con situaciones de mi vida, esa época coincidió con una ruptura amorosa, mi madre empezó con infartos cerebrales.....todo 
no era orgánico, tiene que ver con lo psíquico, yo tenía síntomas orgánicos reales, los sofocos por ejemplo, que no tienen que ver con sufrimientos amorosos o de abandono, he tenido otras rupturas y sofocos era la primera vez, no sabría decir donde empieza y acaba lo físico y lo psíquico, sentí mucho alivio con el tratamiento, yo me resistía por todo lo ideológico pero mejore físicamente, el pelo no se me caía, me brillaba , las uñas también me brillaban, estaba más activa, yo valoro mucho la actividad. De los huesos siempre he estado mal”.

Lola parece una mujer activa, es guapa y habla mucho, se nota que tiene muchas cosas que contar, la etapa de la menopausia le ha hecho reflexionar sobre la vida.

"Yo noto cada vez más el tema del envejecimiento a todo los niveles, sequedad de la piel, manchas, desmotivación, la memoria, yo noto la diferencia, tengo nostalgia de los años anteriores, no creo que no haya pasado nada en mi cuerpo y en mi cabeza, si pasan cosas, pero no sabría decir si tienen que ver con la edad o con la menopausia."

"Lo de antes y después de la menopausia son dos orillas que tienen en medio el mismo río, las aguas bañan las dos orillas no sabría poner fronteras.”

"Echo de menos las relaciones sexuales que ahora no tengo y otras cosas hermosas que no se dan y no porque yo haya renunciado a ellas."

La menopausia le coincide con una ruptura amorosa, las relaciones sexuales se cortaron, "el deseo está muy ligado a tu estado de ánimo, pase de tener una sexualidad muy activa a no querer saber nada ni de sexo ni de afectividad.

En los últimos tres años el deseo ha disminuido, no tengo mucho interés, abandono la seducción.”

"No tener pareja da menos prestigio social, yo intento neutralizarlo con mis recursos e ideología pero creo que sí, que a mi generación se nos mira de otra manera.” 
"Me gustaría tener pareja, con un perfil, claro y de mi ambiente, pero no lo tengo en mis tareas pendientes, yo creo que no voy a encontrar a nadie, aunque tenga el deseo y la nostalgia, en los últimos años tengo mis dudas sobre si soy deseable, creo que no estoy en el mercado.”

"No estoy más nerviosa, estoy más aplacada, a mi no me disgusta la palabra triste aunque tiene connotaciones negativas, estoy desmotivada, cada vez oigo menos cosas que me motiven. Socialmente no puedes decir que estas triste y sin embargo es una situación de la vida, es una tristeza sosegada no es depresión."

"No me siento satisfecha de mi misma, tiene que ver con la desmotivación, he perdido trenes, no me he montado en todos, los trenes no dejan de pasar otra cosa es que tu te montes en ellos."

"Este es un momento en el que la relación con la muerte adquiere protagonismo, estoy más sosegada, sublimo más cosas, tengo menos necesidades."

Acaba de llegar su hijo, lo dejamos, nos vamos a pasear, seguro que continuamos hablando...

"...he sido cada vez mas persona a medida que voy cumpliendo años.”

Amaral, nació hace 53 años en Jaén, vive en un barrio tranquilo y soleado de Granada desde hace 26 años, su estado civil es separada, su estado actual es "enamorada" de la vida, de la música, de la risa y de los viajes, tiene un hijo de 16 con el que vive, su profesión le llena y le deja tiempo para hacer aquello que más le gusta, seguir estudiando, viviendo y creciendo en un momento tan vital.

Hace unos dos años comenzó con sudores, bochornos, y a despertarse por las noches, lo comento con su ginecólogo y decidieron comenzar con isoflavonas durante unos meses, cuando llego el verano se agudizaron los síntomas 
"los sofocos, que hasta entonces habían sido llevaderos, comenzaron en plan salvaje, quince o veinte cada día, por las noches me despertaba continuamente, estaba muy cansada y pase a tomar THS."

Del resto de los síntomas de los que tanto se habla no ha tenido ninguno.

Esta etapa de la vida coincide con la educación de un adolescente, la presencia insistente de la enfermedad y la muerte, su separación de dos personas muy cercanas y queridas, esto hace que todo se haga más difícil "estoy cansada y a veces triste, pero ese es mi estado vital ahora, no tiene nada que ver con la menopausia."

No quiere pareja estable pero tiene varios amores muy especiales, que la hacen sentirse viva en este momento, "considero que la menopausia no es una etapa ajena al deseo sexual, el deseo no tiene edad, me he visto envuelta en una relación amorosa que me ha roto el corazón y en otra que me lo ha devuelto entero, como ves la menopausia también es época de enamoramiento, de sentimientos intensos y de mas reflexión, diría en este sentido que es una época de luces y sombras, como todas las de la vida."

La conversación discurre distendida y agradable en una tarde soleada de primavera, de esta ciudad tan mágica que se presta a todo.

"Me siento una mujer feliz, con muchos amigos y amigas con las que comparto mi vida y las aficiones de viajar, cine, vino, tertulias.....le doy un gran valor a la amistad y me siento querida y respeta, no tengo nostalgia de los años pasados, he sido cada vez mas persona a medida que voy cumpliendo años."

"No me siento mayor, me encuentro atractiva y deseada, me siguen mirando y no soy mujer que pase inadvertida a los 
ojos de los demás, no tengo miedo a la vejez pero si al dolor y a la enfermedad."

"Ahora tengo más ganas de iniciar proyectos que antes, me siento preparada para cambiar de vida, tengo más experiencia y mas madurez y no me cambiaria por nadie, quiero vivir este momento en toda su plenitud"

\section{"A mi el deseo no se me fue nunca"}

CARMEN, tiene 93 años, vive en un pueblo de la Vega de Granada, allí me recibe en una tarde fría y lluviosa de invierno, me cuenta que nació en un pueblo de Sevilla, trabajó desde muy niña en la panadería con su madre, en la casa, en el campo, en todo, "en aquellos años tan difíciles trabajábamos desde muy jóvenes, a la escuela fui poco".

Según su propio relato estuvo casada durante 77 años con el mismo hombre, tuvo 8 hijos, la ultima a los 42 años, la regla se le retiró a los 70 .

Nunca tuvo sofocos, ni dolor de cabeza, ni sequedad vaginal, no tuvo ninguna alteración física ni psicológica, ni siquiera cambio su deseo sexual... "con mi marido una, dos, tres veces al día, las que queríamos, lo pasábamos bien, teníamos las relaciones que queríamos, aprendimos mucho juntos".

"Desde que murió hace 7 años no he vuelto a estar con ningún hombre, ya no me apetece", sólo me ha cambiado una cosa, me ha desaparecido la pipa (Clítoris), pero no cuando la regla sino ahora más tarde".

Se sintió querida y muy deseada, no visito nunca al ginecólogo, ni a ningún médico por esta causa.

"Recuerdo de una vecina que cuando se le fue la regla se quedo con hipo, otras se ponían muy nerviosas, un poco locas... había un tratamiento, bueno una inyección que el 
médico de mi pueblo les mandaba una vez al mes para quitar los sofocos, pero no recuerdo como se llamaba".

"Soy una mujer con mucha suerte, durante 77 años estuve casada con mi hombre, me sentí bien iYa quisieran algunas de esta época!”.

"La verdad fui muy deseada por mi marido y a mí también me gustaba él, a mi no se me fue el deseo, bueno ahora sí, solo me acosté con él, nos enseñamos mucho, también disfrutamos mucho juntos".

"No me siento sola porque tengo a mis hijos, vivo aquí con mi hija, tengo a mis nietos y biznietos, pero ya no tengo ganas de estar con otro hombre”.

"En mi época no se le daba importancia a la retirada de la regla, aunque se sabía que alguna mujer le afectaba y se ponía un poco ida”.

Habla con toda naturalidad, de sus relaciones sexuales, es alegre, divertida y con buen humor. Me confirma su hija que lo que nos cuenta es verdad, se acuerda de las fechas mejor que ellos, "si ella lo dice,... no lo dudes"

"la THS, se vendió como la píldora de la felicidad... soy de la generación salvada"

JULIA, tiene 61 años, es farmacéutica, vive en un pueblo frente a Sierra Nevada, su estado civil es separada y tiene cuatro hijos, dos siguen viviendo con ella, su entorno emana ternura y tranquilidad, le acompaña un perro gran defensor de su intimidad, es un espacio especial, dirían los diseñadores minimalista.

Su aportación desde el punto de vista profesional y sus reflexiones acerca de la THS y de la propia vida, invita a buscar información científica que dé respuesta a tantas incógnitas, a meditar sobre la situación social en la que nos movemos. "Menopausia, solo tuve una...y tuve tiempo para 
prepararme ya que estuve dos años con problemas por un útero miomatoso, que me provocaron anemias, sangrados y una serie de alteraciones muy negativas. A los 48 años me hicieron una histerectomía y a continuación me mandaron estradiol y lo tome durante 10 años”.

"Soy de la generación en que las mujeres mínimamente formadas estábamos salvadas de la menopausia, éste era el mensaje que a mí me tocó, en cualquier comparación o conversación decíamos mira a las turistas, que bien están, como llevan tantos años tomando THS.

"Los parches tuvieron un gran impacto, al menos en mi entorno, yo lo tomé porque me lo dijo mi ginecólogo y porque yo también me lo quería tomar, con esta medicación no tuve ningún síntoma, ni sofocos, ni sequedad vaginal, ni disminución de la libido, fue un proceso muy reflexivo pero es que en la premenopausia lo pase muy mal, luego fue todo normal, me hice alguna revisión pero pocas, después no he notado ningún cambio ni físico ni psicológico, fui espaciando el dejar el tratamiento, llevo como tres años sin tomar nada y sigo bien, mi madre hasta hace poco tiempo ha tenido sofocos".

"Me siento útil y satisfecha de mi misma y ahora, últimamente me siento mayor y lo relaciono con la edad, me canso mas, estoy más lenta y además lo reivindico”.

"No siento miedo a la vejez, no es un escalón, es una etapa, un proceso diario de poco a poco, a lo que le temo hoy es al cerebro, me gustaría tener una vejez con la cabeza sana, me interesa el cerebro, para yo tener conciencia de mis propias limitaciones y así buscar otras alternativas, que yo estoy segura que las hay”.

"Me siento atractiva y no me siento mal, y me da rabia estar rodeada de gente que no lo aprecia, ellos se lo pierden, en mi entorno hay cierta discriminación por la edad, por lo culto y por lo joven, no en tu ambiente íntimo sino en la 
calle, en el ambiente laboral se percibe ese culto, a veces no te ven y los hombres valoran más lo joven y lo bello sobre todo la edad, es un elemento que los hombres tienen muy en cuenta, las mujeres no tanto".

"Invisibilidad o rechazo a las mujeres con mayor edad, la mujer sirve para traer hijos al mundo y nos tenemos que relacionar entre todas y promover un cambio histórico, que tiene que consistir en, hasta aquí tu función ha sido traer hijos al mundo y a partir de ahora tienes otro, esto es, a partir de aquí ¿qué hacemos ahora? también la esperanza de vida es mayor, nos queda un tercio de vida por delante".

"Las reminiscencias que quedan del pasado, es irreal, itodo va a quedar con las consideraciones que nos dejan los hombres? o vamos a volver a luchar por nuestra reivindicación y que la sabiduría a partir de los 50 años sea un valor en alza."

"Nos afecta que los hombres nos rechacen por no ser jóvenes y bellas, si, y ellos se lo pierden por no ver que somos interesantes o es que perdemos el valor porque ya no vamos a tener hijos?

“También hay cada vez más mujeres que su opción es la de no tener hijos; pero que pasa con las relaciones humanas y esto como se asimila en que la ciencia y las reinvicaciones feministas o un golpe de ley o en el día a día esos procesos no son tan grandes pero son largos en el tiempo esos ramalazos arcaicos".

"A veces los hombres nos jubilan, relacionan maternidad con sexo, después de mi histerectomía, un conocido me dijo: "total para lo que te servía".

"No me siento sola, ni deseo tener pareja, ni creo tener menos prestigio social por no vivir con un hombre aunque esta sociedad si valora a una mujer con pareja, tiene más 
prestigio, habitualmente salgo poco, bueno menos que antes".

"Si, la menopausia genera alteraciones psicológicas y físicas, la gente parcialmente no las comprenden y a los hombres en general les suena a chino".

"La menopausia es un proceso, como cambio físico creo que científicamente no está bien estudiada, el perder hormonas que regulan nuestro organismo iporque hay épocas en las que los parches no tienen efectos secundarios y ahora sí?, a partir de que se comprueba la incidencia del aumento de cáncer de mama y de ovario; por un lado quiero seguir joven, súper atractiva y sentirme bien, por otro lado los movimientos feministas radicales piensan que se ha medicalizado excesivamente a las mujeres, para cada síntoma hay un medicamento".

"La THS se vendió como la píldora de la felicidad, no hay osteoporosis ni bochornos, ni dolor de cabeza, ni infartos ¿quién ha hecho estos estudios?, la misma empresa farmacéutica. ¿porqué no hablamos de esto mismo en los hombres, son intocables, con sus canas, sus mujeres jóvenes, su alto poder adquisitivo pueden seguir teniendo hijos, pero la realidad es que envejecen igual que nosotras".

"Yo sigo diciendo que hoy en día tendría que estar científicamente claro tanto a nivel de hombres como de mujeres, hoy hablar de industria farmacéutica es hablar de poder y es un instrumento de manipulación y me rebelo y sigo pidiendo a la ciencia que si esto es un proceso fisiológico largo que se estudie y se dé a conocer, la sociedad demanda respuestas claras y esta es una, y no sé si están jugando con mi biología, yo al menos lo he vivido bien".

"Por un lado es un problema científico con respuestas claras porque se estudian los procesos hormonales tan bruscos, como la menopausia y no se estudia el cese del crecimiento 
que también es un proceso traumático porque también hay cambios en el organismo".

"A nivel ideológico es muy fácil que nos engañen y tenemos que estar alerta y darme armas para defenderme y cuestionarlo todo; veo un ejemplo en lo de los parches ipor qué no me dejan tener datos?, soy sanitaria y no tengo la respuesta científica, iporque no me dejan conocerla?”.

"Una vez se le recriminaba a un poeta que siempre estaba hablando de la edad y que todo lo tenemos marcado en el tiempo que marca un calendario, los ritmos biológicos, de esto si que tenemos que aprender, pero no te dejan, continuamente te bombardean, además todo o casi todo está escrito por hombres y responde a quien lo escribe".

“...Hace años que prescindí del físico, engorde como mecanismo de defensa, lo razono ahora"

ELENA nació y vivió en Valladolid hasta los 23 años desde entonces vive en Granada, está casada tiene 3 hijos que ya no viven en casa "aunque conservan la llave" se le retiró la regla a los 49 años aunque nunca visito al médico por este tema no ha tenido ningún cambio físico y psicológico excepto los sofocos que los sigue teniendo aunque ahora son más suaves, tiene 58 años.

"La menopausia la he vivido con absoluta normalidad, no pensaba que se me iba a retirar la regla, empezó a ir a venir y lo único que pensé era que lo que me faltaba era quedarme embarazada, tome isoflavonas durante 8 o 10 meses pero como no me hacían nada lo dejé, aun hoy siguen dándome aunque más suaves, le he dejado de dar importancia o me he acostumbrado es la única molestia que he tenido, desde que tengo recuerdos he tenido un gran dolor de cabeza y al llegar la menopausia ha desaparecido, ha sido un alivio". 
"A mí me alteró la vida y el cuerpo, la enfermedad de mi hija, que con muy pocos años debutó con una anorexia y bulimia, la menopausia no me ha cambiado nada, no me ha alterado nada, no me ha cambiado la vida”.

."Cuando yo tenía 28 años y mi marido 29 tuvo una enfermedad infecciosa en la que estuvo en coma 70 días, cuando se despertó había perdido la memoria, esto significo perder la propia identidad y no la recuperó en un rato, durante 15 años estuve recordándole cuando éramos novios, cuando nació nuestro primer hijo, el no tenía sentimiento de tener hijo, los tenía como adoptivos, sólo recordaba que cuando se despertó dijo tú no te vayas conocía mi voz, durante los 70 días del coma no pare de hablarle, de recordarle, continuamente estuve a su lado y al despertar identificó mi voz como algo cercano”.

"No reconocía a sus hermanos ni a sus padres ni a nadie. Tuvo que empezar a hacer la carrera, estudiaba y se le olvidaba, le tuve que enseñar el camino para ir al trabajo, tuvieron que dejar de venir los amigos a casa, es una experiencia poco común, ha sido una época triste y coincidiendo con la renovación, con la democracia de este país, toda la transición política de este país la perdimos.

Como secuela tenía una epilepsia, todos sabíamos en casa como tratarlo, que medicación había que darle, es una historia muy tremenda”.

"Empecé a comer como una desesperada, engorde 30 kilos en el embarazo de mi tercer hijo, para que su padre supiese que era tener un hijo, ya no como tanto ahora me lo planteo como algo serio y tendré que ponerme a dieta”.

"Otras de las secuelas es que dejó de funcionar el bazo, trasfusiones, hepatitis $\mathrm{C}$, operaciones, angina de pecho, nuevos tratamiento, problemas renales... y está como una rosa, parece que tiene 20 años menos que yo, sin arrugas”. 
"Después de esto ¿qué me iba a pasar a mi con la menopausia?, estaba tan entrenada a mirar a mi alrededor que no podía mirarme a mí, ahora ha llegado una época de paz y tranquilidad, mis hijos se han establecido han empezado a trabajar se fueron de casa, a esta edad no me siento necesaria como madre, lo normal es que pasen de mí igual que nosotros hicimos en su momento, siempre me he sentido súper útil, he sido pija y progre".

"Me sentí mayor cuando mi marido enfermó, la vejez es igual a años de plenitud, si has estado coherente contigo misma son años gratificantes".

"Hace años que prescindí del físico, era una preocupación más y yo engordé como mecanismo de defensa, lo razono ahora, todo lo negativo lo he convertido en positivo, tienes tal bagaje de experiencia que identificas lo de tu alrededor".

"Reflexiono que el dolor es común a todos los seres humanos y pobre el que no lo tenga o no lo conozca porque pasará por la vida sin esa experiencia. He tenido que ir investigándolo todo, mi sexualidad, mis relaciones, la relación de mis hijos, después cuando lo he visto escrito, anda esto me pasaba a mí, he tenido suerte de ser de ese $15 \%$ de la juventud que estudiaba en esa época, en aquel momento lo normal era ser tradicional, es mucho mejor ser mujer, somos más sensibles".

"Necesito que él deje mi espacio, tengo amigos y lo sé valorar, compartimos los espacios con suma facilidad, los seres humanos somos muy parecidos, con las mismas contradicciones. Mi madre se callaba sus penas, sus agobios y yo siempre he pensado que tenía que expresarlo y si hoy estoy bien lo tengo que decir y si estoy mal también, ya se pasara como un nubarrón”.

"Que sepas que lo más importante de esta historia soy yo, que estoy fuera de la moda fuera de la norma, uno mira como mandan los cánones y yo lo hice todo al revés, no me he 
cuidado nunca, todo lo hice contracorriente. Mi madre me preparó para casarme bien pero yo me casé con quien quise, toda una vida de elecciones, de clandestinidad".

"He tenido una vida de cuidadora, "Siempre pensé que la menopausia era algo psicológico."

Alba es la tercera de diez hermanos, nació en la Calahorra, Granada, y vive en Cenes, de niña emigro a Barcelona, solo fue al colegio hasta los trece años, el graduado escolar se lo ha sacado ahora "lo disfrute mucho porque también formamos un grupo de teatro y recorrimos Andalucía".

De su infancia recuerda que su madre era muy severa y se paso mucho tiempo ingresada en un hospital psiquiátrico.

Se casó joven y tuvo una hija que ahora tiene treinta años $\mathrm{y}$ vive independiente en otra ciudad "con ella tengo muy buena relación, también con mis hermanos y aunque los veo poco me quieren y me apoyan, nos llamamos por teléfono."

Se separó pronto, hace unos años volvió a Granada con su nueva pareja y la hija de ambos que tiene veintitrés años.

"He tenido una vida de cuidadora, durante un tiempo me marchaba a Barcelona un mes para cuidar a mi padre, después a mi madre, también colaboraban mis hermanos, y últimamente he cuidado de mis tíos, sordomudos, durante quince años, con cáncer los dos, estos dos últimos años han sido largos pero lo hice porque quise, eran mi familia”.

Coincidiendo con esta situación le llego la menopausia "yo que en ese momento estaba estudiando me hubiera gustado seguir, pero opte por el teatro y por cuidar a mis tíos."

Es una mañana de primavera, soleada, vive en un barrio tranquilo y pacifico de la sierra, ella continua con su relato "tuve tres abortos voluntarios producto de relaciones esporá- 
dicas, quiero que lo pongas, para que se sepa que las mujeres tomamos decisiones con nuestros cuerpos".

"Siempre pensé que la menopausia era algo psicológico."

Solo ha tenido sofocos, tomo Isoflavonas que dejo al poco tiempo cuando se le fueron suavizando "comencé a andar y se me fueron pasando," le tuvieron que hacer una histerectomía hace diez años, después no ha visitado a ningún médico ni especialista.

Cuenta que no recuerda haber tenido cambios físicos ni psicológicos "yo siempre he tenido cambios de humor y los enfados me han durado mucho y sigo igual, no tengo miedo a la vejez pero si a una enfermedad que no pueda llevar sola"

Sexualmente dice que tiene el mismo interés y deseo que siempre y que las relaciones cóitales son satisfactorias "he descubierto la masturbación hace poco tiempo, los hombres son muy machistas, pero todos, aunque me siento deseada por mi pareja y me siento feliz y necesaria"

Así es esta mujer, divertida, alegre y feliz.

"antes con 40/45 años todavía me echaban ojitos, ahora no me salen galanes".

Pilar es licenciada en Sociología tiene 54 años y es natural de Oaxaca (México), está divorciada aunque a ella le gusta decir que está soltera, tiene dos hijos chico/a que ya no viven con ella, es morena, guapa, alegre y con unos ojos chispeantes que te invitan a reír.

Se le retiro la regla a los cincuenta años y comenta que con la menopausia ha aumentado de peso, se nota más flacidez, piel seca, sequedad vaginal y sobre todo "empecé a notarme las arrugas", se siente más sensible, duerme menos $\mathrm{y}$ ha tenido sofocos pero muy leves. 
Se ha dado cuenta de que antes iba mucho a bailar "ir a candelear", le gusta mucho bailar pero ahora no lo propicia tanto "hay etapas que yo ya las he ido avanzando", también antes la llamaban señorita, ahora no, se siente señora porque se lo dicen y porque cuando se mira al espejo sabe que no es lo mismo, aunque sus antiguos alumnos le digan que "esta igualita", "antes con 40/45 años todavía me echaban ojitos, ahora no me salen galanes".

El inicio de la menopausia coincide con una etapa laboral muy agitada "era la directora de la Universidad Pedagógica, tenía a mi cargo a tres mil personas, muchas presiones, demasiado ocupada”, esta situación la hizo no estar muy pendiente de los síntomas de la menopausia "yo siempre he sido muy activa, esta ocupación me ha salvado de esa situación, sentir que no era como hace unos años"

Sexualmente no manifiesta cambios ni en su deseo ni en ni en su actitud "nunca he tenido inapetencia sexual, me gusta mucho hacer el amor, solo he sentido nostalgia por no tener relaciones o no poder estar con quien yo quería".

Para ella es importante tener pareja, dice acerca de una amiga suya que también tiene la menopausia y que tiene pareja "ella es una mujer plena."

Trabaja también con las mujeres indígenas que están en la cárcel por motivos de narcotráfico, del que la mayoría de las veces son inocentes, de ellas nos comenta "las mujeres indígenas de la cárcel no conocen la palabra menopausia, no saben lo que es, para ellas la retirada de la regla la viven con alivio, significa que no habrá más embarazos", "en México no hay ritual de menopausia", "no se habla mucho de ella y cuando se hace es para bromear".

"no he incorporado la transformación, es una injusticia, nos tocan muchas cosas y hay que disminuir el sufrimiento" 
Lucia tiene 46 años, está casada y tiene dos hijos, chica/o de 23 y 24 años, es psicóloga especialista en formación.

Es morena, atractiva, delgada y parece un poco triste, ha pasado por un periodo de crisis en el que ha coincidido salir de su país, venir a vivir a España, dejar a su familia "ya no me siento culpable por abandonar mi país y a mi madre", la llegada de sus hijos, la menopausia, etc.

Tuvo menopausia precoz a los 44 años, toma tratamiento hormonal y medicación para los huesos "para no sentir los síntomas de la menopausia, calor y sofocos".

Según su relato se irrita con más frecuencia, no tiene paciencia, está más celosa, dice lo que piensa, es menos diplomática y también esta mas cansada porque duerme menos, cree que la gente la observa y se siente menos atractiva, a ella no le gusta decir que tiene la menopausia.

Ahora dice encontrarse mejor "estoy satisfecha, feliz y contenta”. Sus hijos ya viven aquí con ella y a su marido no le falta trabajo.

En el aspecto sexual comenta que tiene menos deseo y sensibilidad "es diferente, anatómicamente es mejor porque parece que la vagina se ha cerrado, pero la intensidad es menor", tiene un poco de sequedad vaginal y miedo a dejar la medicación. No le duele el coito pero las otras prácticas le resultan más intensas y placenteras. Se siente deseada, pero por la calle la miran menos.

Tiene las mismas ganas de salir que siempre, le gusta relacionarse, pero ha observado que "si alguien no me cae bien o hace algo que no me gusta, soy más tajante en mi conducta de rechazo".

Sigue cuidando su aspecto externo igual que antes pero cree que su autoestima es menor "no he incorporado la transformación, me da vergüenza decirlo pero es como si tuviera fecha de caducidad, estoy perdiendo juventud, feminidad, 
no es solo una cuestión sexual, además de mujer hay que ser muchas cosas más, yo lo siento todo muy bien pero cuando me miro al espejo no me siento bien”, "es una injusticia, nos tocan muchas cosas y hay que disminuir el sufrimiento"

No considera la menopausia un problema de salud, es un ciclo más de la vida

\section{"...ahora soy libre y mientras estuve casada no lo fui"}

PAQUITA, ama de casa, 65 años. Nació en el Valle de Lecrin, es viuda desde hace 11 años, tiene 4 hijos entre 43 y 35 años sólo uno vive en casa "no se va porque aunque tiene su piso no quiere que su madre esté sola y así el tampoco y además porque se siente a gusto conmigo”, otra de sus hijas vive en la provincia y las otras dos viven en Cataluña.

"En la escuela ni lo básico, no estuve en la escuela nunca, trabajé repartiendo agua en el pueblo en cántaros y en calderas, seguí echando horas limpiando o trabajando en el campo, además de sacar adelante a mis hijos a mi casa y a mis mayores, pero sólo tengo cotizada una hora en la seguridad social, he sido muy explotada, ni pagada ni considerada”.

"Yo no he pasado los trámites de la menopausia, la gente me respeta tanto que nadie me dice nada, tengo cierto disgusto porque no tengo novio (entre risas)”.

"A los 59 años tuve la ultima regla, no he consultado al médico porque no lo he necesitado y no he tomado ningún tratamiento, para mí la menopausia es una etapa de la vida al igual que la regla, cuando vino, vino y después se fue, se ha retirado igual que vino, no he tenido ninguna molestia no ha sido ningún trauma.

Tiene otras cosas, una diabetes leve, tensión alta y algo de colesterol pero dice que los médicos a ella no le hacen la vida imposible. 
"La juventud se va con los años no con la menopausia, yo estoy muy activa, voy perdiendo algo de memoria y esto sí me preocupa porque mi abuela materna y mi abuela por parte de mi padre y mis tías tuvieron Alzheimer y como lo traigo de herencia si lo noto, igual me pasa con la lengua que me cuesta decir una palabra, pero en esto los médicos no me hacen ni caso".

"Yo no he sentido ningún trauma porque se vaya, no he notado nada, con mi peso sigo igual sólo la piel esta algo más seca y estas cositas blancas que me han salido, yo me pongo mis cremitas hasta donde llego".

"Se me escapa la orina y no lo noto y lo veo cuando me cambio de compresa, no estoy ni más nerviosa ni mas irritada pero sí mas cansada, me cuesta llegar... no me resulta difícil hacer mis encajes ni mis cosas habituales".

"No me siento útil, me siento explotada, primero te explotan los padres, cuando te casas resulta que te sientes manipulada por tu marido, después por los hijos, aunque lo haga con mucho gusto, crié a mi nieta desde los 7 días a los 7 años después me fui a Barcelona de Marzo a Octubre para que mis hijas trabajaran y yo cuidé a mis nietas y ahora me gustaría que se acordaran de mí, una llamadita, que se acordaran algo, mi hijo pequeño sí me llama todas las noches, tengo esa espinilla porque yo les cuidé a ellos y cuidé a sus hijas y ellos no sé si es que no se acuerdan o es que no me llaman".

Paquita tiene 65 años y es una mujer de pueblo, afable, cariñosa, parlanchina, se pone un poco triste cuando habla de sus hijas.

"Estoy satisfecha con mi vida, dentro de los límites de lo que yo tenía he escogido la vida que yo quiero, no total pero sí hago lo que más me gusta, en la asociación de mujeres me siento útil, me siento una más, aunque en otras cosa me 
siento coja por no haber estado más preparada, me hubiera gustado estudiar.

"Creo que todo lo que hemos hecho desde la izquierda no está correspondido, estoy metida en todos los follones que se forman en mi pueblo, también en la asociación de mujeres que se formo en 1977, tengo mucha actividad y no me siento mayor aunque sí me preocupa la vejez y depender de alguien sobre todo porque soy muy independiente".

"Cuando me veo en un espejo digo, esa no soy yo, mi deseo sexual no se ha ido, a mí me gustan los tíos buenos y los viejos me dan un poco de asco, me siento igual que antes, ojala yo sintiera algo manual, pero no siento nada, ya me gustaría... aunque siempre esto lo he asimilado con un hombre".

"A ratos me siento sola, el día lo tengo muy ocupado, por la noche es cuando me siento más sola y me gustaría estar con alguien especial, yo no he sido persona hasta que no he estado sola, he estado casada y mi libertad no la embargo más, hasta que no se tiene no se siente, ahora por buenísimo que sea hay que compartir y la libertad es otra cosa y yo ahora soy libre y mientras estuve casada no lo fui".

“... Hacemos lo que podemos, me siento deseada por mi marido, soy feliz y le quiero mucho".

MONICA, nació en Maracena, hace 62 años, vivió de joven en Barcelona, Sevilla, Badajoz, después hacia los 20 años volvió a su pueblo, tiene 2 hijas de 30 y 26 años, están casadas "pero la que se ha separado ahora viene a comer a casa con su niña de dos años, también le ayudo a cuidarla”.

"A los 7 años dejé de ir a la escuela, porque ya era suficiente, desde ese momento empecé a trabajar en un puesto de frutas, en el campo más tarde, sobre todo en la huerta recogiendo y plantando verduras, hortalizas, frutas, a los 20 
años empecé a trabajar en una peluquería y más tarde puse yo la mía, la he mantenido unos 34 años”.

"A los 50 años empecé con la menopausia, fui al médico porque tenía muchos bochornos, me mando Agreal y lo he tomado durante 11 años, se me quitaron y me iba muy bien, hasta el año pasado lo estuve tomando, en una revisión de la mama me dijeron que lo dejara y lo dejé radical, ahora me da algún bochorno pero muy suaves, cambios físicos no he tenido aparte de los bochornos, yo creo que es la edad, no la menopausia, me mejore del dolor de cabeza.

"Me gusta mucho leer, cuando lo cojo tengo que volver varias hojas atrás porque no me acuerdo, eso a mi antes no me pasaba, es desde hace 5 años, me dieron un cuestionario en mi médico y claro si eso no lo supiera era como para ponerme delante del tren (risas)....dos y dos..."

"Yo pensaba que la menopausia era psicológica, pero no, es de verdad, los sofocos son de verdad, el no encontrarte bien, no es que yo dijera no valgo como mujer, que yo al no tener regla... me despertaba por la noche con los sofocos y decía como la naturaleza ha cambiado, también tenía palpitaciones pero yo no sé si esto es de la menopausia o no, también subí de peso y la piel se quedó más seca, tenia mas ansiedad mas apetito".

"También todo coincidió con la enfermedad de mi madre y de mi padre, la asociación de mujeres, el partido, la peluquería, mi casa, siempre he estado embarcada en más de lo que podía, a mi marido le dio un infarto, estaba en una situación de nervios, se presentó todo junto".

"Ahora me canso, me canso mucho pero me siento súper útil, ya no me agobia tanto todo y le digo a mi marido , no se trata de que me ayudes, sino de que lo sepas hacer tu "."Me siento mayor porque tengo estas cosas, antes esto para mí era una copla y ahora me agoto, antes ya te contaba me leía un libro y te hacia un resumen, ahora digo este libro me 
gustó mucho pero ¿por qué? espero la vejez pero no le tengo miedo, para la edad que tengo estoy muy bien”.

"Antes, al principio de la menopausia tenía más deseo pero con lo del infarto tuvimos que modificar nuestras costumbres en función de eso, he sido un mujer muy activa sexualmente, siempre dando consejos de los anticonceptivos, de usar la píldora, los preservativos, que el coito interrumpido no, que eso era lo último, pues yo el coito interrumpido era lo que hacía, mi marido del condón no se fiaba, teníamos uno de muchos años y ya ves al usarlo se rajó de arriba abajo, mi método me iba bien, yo lo hacía bien cuando tenía síntomas de que iba a bajar la regla, a mí me iba bien pero se lo conté a una amiga y se quedó embarazada, incluso cuando tuve a mi hija pequeña eché mis cuentas y lo hicimos cinco días después de la regla pero yo ya estaba embarazada hasta los ojos.

"Ahora hacemos lo que podemos, no me molesta la penetración me siento deseada por mi marido, me siento feliz y le quiero mucho, me siento tratada de igual a igual, soy incapaz de vivir con una persona que no quiera, yo eso no lo admitiría."

"Mi vida social me encanta aunque a veces no soy comprendida por los demás me consideran un poco radical y soy así, el tiempo ahora lo empleo en echar una mano a mi hija y a mi nieta".

"La menopausia es un época más que yo estaba esperando y tenía muchas ganas de que llegara porque a mí me molestan las compresas, los salvaslips, ya te digo que solo los sofocos si no me hubiera coincidido con tantas cosas hubiera sido feliz y lo hubiera llevado mejor le achacamos todo a la menopausia y no es así”.

“... al faltarme la regla me dio cosilla, me gustan los niños terminaba mi vida fértil, mi relación con la maternidad". 
Eugenia tiene 50 años, es delgada y jovial, nos recibe en su casa en un pueblo de la Vega de Granada, está casada, tiene tres hijos entre 16 y 24 años que estudian y viven en casa.

Trabajó durante 10 años como auxiliar de farmacia, después se dedicó a la crianza y educación de sus hijos, "ahora que no me necesitan intento incorporarme al mundo laboral y está difícil, incluso como autónoma, pienso que debía haber aprovechado cuando era más joven y haberme preparado, pero no lo hice y ahora es tarde."

Acudió al ginecólogo con los primeros síntomas de la menopausia, le recetaron THS, una crema para la sequedad vaginal e isoflavonas para los calores, "que siguen en la mesita porque yo no las he tenido que usar, lo único que tome fueron las isoflavonas durante los meses de verano, en realidad no tuve ninguna cosa importante, se retiró la regla y me empezaron los bochornos unas 2 veces al día y a los 2 meses o así desaparecieron. Después y coincidiendo con un problema de trabajo en el que había puesto mucho empeño y mucha ilusión me apareció insomnio y tome valeriana, también estuve deprimida, no salía de casa....hasta que mis hijos se enfadaron conmigo."

Continúa la entrevista contando como ha vivido este cambio, "en realidad a mi no me ha cambiado nada, si dijera que la memoria... quizás por poco hábito, siempre he memorizado fatal, yo no lo noto, ni mi familia me comenta que esté más nerviosa, yo a lo que si le tengo miedo es a la enfermedad y a que no me quieran, ahora me siento guapa si cabe más que antes, mi realidad no ha cambiado, todo lo llevo como siempre."

"Las relaciones sexuales con mi pareja son satisfactorias, me siento bien, me siento deseada y mi relación de pareja me hace sentirme feliz a ratos, a mi me gustaría salir más en vacaciones, en los fines de semana, pero sola con él y 
él prefiere quedarse en casa, con el ordenador, no me hace mucho caso."

Seguimos tomando café y un bizcocho que ha hecho esta mañana para nosotras, “... al faltarme la regla me dio cosilla, me gustan los niños y no tuve más por la economía, terminaba mi juventud mi vida fértil, la relación con la maternidad, ya no soy tan joven, empieza otra etapa, he conocido gente más joven y me relaciono bien con ella."

Ella mantiene buenas relaciones sociales, incluso, se va de marcha con sus hijos, "si bailo salsa con mi hijo pienso, que van a decir, no me rechazaran?, soy yo la que pienso que no pego en el grupo, mi juventud se ha ido muy rápido."

\section{Comentarios a las entrevistas de los profesionales médicos}

"Las mujeres que acuden a la consulta del centro de salud no suelen hacerlo por la menopausia en sí, lo hacen en el transcurso de otra consulta y a menudo llegan confundidas por la contaminación informativa" así comienza la Dra. Amparo Ortega a contarnos como llegan las mujeres a la consulta, la mayor preocupación de ellas tiene que ver con un sentimiento de pérdida y de miedo, ella cree que su misión es la de reconvertir esa información y esa sensación en algo natural y fisiológico.

Piensa que la actitud con la que hay que enfrentarse a la menopausia debe ser positiva, que hay que cambiar el estilo de vida y si hay síntomas, tratarlos.

Ella está de acuerdo en que la vida de las mujeres está más medicalizada porque su mapa de quejas es mayor que el de los hombres, porque "es cuidadora, trabaja dentro y fuera de la casa, la mujer está muy sobrecargada en cualquier momento de la vida". 
Su actitud con respecto a la THS, es que tiene su aplicación pero que hay que tener en cuenta los efectos secundarios, que son muchos, durante tiempo no se permitió la publicación de ciertos trabajos de investigación porque dejaban claros los efectos adversos de la terapia.

Confirma que hoy tenemos más información en general, pero de peor calidad, promovida a veces por las instituciones sanitarias y en ocasiones lo único que se pretende es vender.

El Dr. Cuadros creó la unidad de menopausia en el Hospital Clínico en 1988, en ella sólo trata a mujeres que toman THS y cuando la abandonan vuelven a su ambulatorio de zona, el realiza en una sola visita la citología, ecografías y demás pruebas, si no tienen ningún problema les pone el tratamiento y las revisa una vez al año.

Nos comenta sus grandes beneficios, de cómo mejoran la T.A (Tensión Arterial) baja los niveles de colesterol, influye sobre la masa ósea y mejora los síntomas vasomotores.

Es un gran defensor de la THS, incluso razona con sus estudios que no aumenta el cáncer de mama y tiene pocas contraindicaciones.

"En Granada solo el 2\% de las mujeres toma tratamiento hormonal cuando lo optimo seria estar alrededor del 30\%". Entiende la menopausia como "que la naturaleza hace cosas que no están bien y hay que defenderse y aunque no es una enfermedad es innegable que la mujer a partir de los 30-35 años pierde masa ósea y el paso de la edad tiene sus problemas". 


\section{Conclusiones}

No se puede hablar de MENOPAUSIA sin tener en cuenta la peculiaridad de la vida de cada mujer.

La menopausia es un acontecimiento natural y una etapa más en la vida de las mujeres.

El síntoma físico generalizado es el sofoco.

La menopausia no es una enfermedad.

La actividad sexual se puede mantener en todas las edades de la vida.

La masturbación es una práctica sexual poco utilizada.

Esta etapa de la vida coincide con situaciones familiares y sociales (Familiares mayores, muertes, perdida de trabajo, nido vacío, etc.) que condicionan la realidad.

La única manifestación universal de la menopausia es el cese de la menstruación.

\section{Referencias}

BAILÓN, E.; DELGADO, A. "Menopausia en medicina familiar". Granada: SEMFYC; 1997.

BEAUVOIR, S. “La vejez”. Barcelona: Ed. Edhasa; 1986.

BODOQUE, Y. Tiempo biológico y tiempo social. Revista Gaceta de Antropología, 2001, P. 17.. Disponible en: http://www.ugr. es/ pwlac/G17_12Yolanda_Bodoque_Puerta.html. Consultado el $04 / 09 / 2001$

BUENDÍA J. Diseño y validación de un cuestionario en castellano para medir la calidad de vida en mujeres posmenopáusicas: el cuestionario MENCAV. Revista de atención primaria, Espanha, n. 2, p. 58-66, 2001. 
RIBERA, L. F. Análisis sobre los modelos culturales de la menopausia. Barcelona: Ed. Universidad de Barcelona, 2003. Disponible en: http://www.ub.edu/antropo/doctorat/Tesines/2003/ Frances_Lidia.PDF. Consultado el 10-02-2006.

GREER, G. El Cambio: Mujer, Vejez y Menopausia. Barcelona: Ed. Anagrama; 1993.

HUNT, K. Una cura para todas las enfermedades? Interpretación de la menopausia y las complicaciones del tratamiento hormonal sustitutivo. In: Wilkinson, S.; Kitzinger, C.; Mujer y Salud, una perspectiva feminista. Barcelona: Ed. Paidos; 1994. Pp. 155-175.

KUPPERMAN. Indice menopáusico de Kupperman [Internet]. Mèdica de Tarragona: 2003. Disponible en: http://www.medicadetarragona.es/aula/esclas/indice_menopausia.htm. Consultado en 13-12-2005.

MANUBENS, M; PARRILLA, JJ; ALBERICH, X; FERRER BARRIENDOS, J; PALACIOS, S; CASTELO-BRANCO I FLORES, CA. Escala Cervantes [Internet]. Madrid: Planner Media, 2003. Disponible en: http://www.plannermedia.com. Consultado en 13-12-2005

MOSTERÍN, J. La naturaleza Humana. Madrid: Ed. Gran Austral; 2005. 


\section{Sobre os autores \\ (de acordo com a ordem dos capítulos)}

\section{José Luis Pais Ribeiro}

Licenciado e doutorado em Psicologia. Professor Associado com Agregação da Faculdade de Psicologia da Universidade do Porto onde ensina disciplinas de Psicologia da Saúde e orienta mestrados e doutoramentos nessa área. Fundador da Sociedade Portuguesa de Psicologia da Saúde (SPPS), atual presidente da direção e ex-presidente (por três vezes), ex-editor responsável da revista da SPPS - Psicologia, Saúde \& Doenças. Autor de vários livros sobre psicologia da saúde, avaliação na área da psicologia da saúde, e metodologia da investigação em psicologia e saúde. Coeditor de vários livros sobre o mesmo tema, autor de inúmeros capítulos de livros. Membro da comissão científica de inúmeros congressos na área de aplicação da psicologia relacionada com a saúde, e membro da comissão científica ou editorial de revistas científicas na área de estudo. Revisor de jornais científicos internacionais na interface da psicologia com a saúde.

E-mail: jlpr@fpce.up.pt 


\section{Railda Fernandes Alves}

Professora da Universidade Estadual da Paraíba. Doutora em Antropologia da Saúde pela Universidade de Granada UGR. Mestra em Antropologia da Saúde pela UGR. Mestra em Saúde Coletiva pela Universidade Estadual da Paraíba. Psicóloga Clínica. Membro da Rede Latino Americana de Psicologia Humanista Fenomenológica Existencial. Membro da Rede Ibero-Americana Centrada nas Pessoas. Líder do Grupo de Pesquisa Psicologia da Saúde UEPBCNPq. Coordena projetos de pesquisa em Psicologia da Saúde. Coordena a linha de pesquisa Processos psicossociais e saúde. Diretora-Adjunta do Centro de Ciências Biológicas e da Saúde - CCBS/UEPB. Trabalha com temas ligados à Psicologia da Saúde, Representações sociais, produção de sentidos e práticas discursivas.

railda@uepb.edu.br; fernandes_railda@hotmail.com

\section{Maria do Carmo Eulálio}

Psicóloga clínica, mestra em Psicologia pela UFPB, doutora em Psicopatologia Clínica pela Université Paul Valéry (Montpellier-França). Professora do Curso de Psicologia da Universidade Estadual da Paraíba (UEPB), integrante do Grupo de Pesquisa em Psicologia da Saúde e líder do Grupo de Estudos e Pesquisas em Envelhecimento e Saúde (GEPES). Orientou 13 dissertações de Mestrado em Saúde Coletiva da UEPB e vários discentes do Programa de Iniciação Científica. Coordena um Projeto de Pesquisa financiado pela FAPESQ (PP/SUS) e outro pela PróReitoria de Pós-Graduação da UEPB (PROPESQ), orienta pesquisas na área da Psicologia da Saúde, Saúde Coletiva, Saúde Mental, Corpo, envelhecimento e Representações Sociais. É avaliadora Institucional e de Curso do INEP, publicou vários artigos em periódicos científicos e capítulos de livro.

E-mail: carmitaeulalio@terra.com.br 


\section{Gualberto Buela-Casal}

Doctor Psicología y Catedrático de Universidad (Universidad de Granada). En la actualidad posee publicados 25 libros, 70 capítulos de libro, 214 artículos (de los cuales 127 son ISI), 410 participaciones congresos (de las cuales 287 son en congresos internacionales) y un total de 40 proyectos financiados. Ha dirigido 18 tesis doctorales, 36 trabajos de investigación (DEA y trabajos Fin de Master). Ha sido director de 16 Becarios (tanto FPU/FPI, como becas asociadas a proyectos de investigación. Tienen docencia en 7 Programas de Doctorado con Mención de Calidad e imparte docencia en la asignatura de "Evaluación Psicológica" en la Facultad de Psicología de la Universidad de Granada. Actualmente posee también el 100\% de los tramos de Investigación evaluados. E-mail: gbuela@ugr.es

\section{Raúl Quevedo-Blasco}

Personal Docente Investigador de la Universidad de Granada (Licenciado en Psicología. Máster Oficial en "Diseños de Investigación y Aplicaciones en Psicología y Salud" y Máster en Psicología Infanto-Juvenil: aspectos clínicos, evolutivos y educativos). En la actualidad posee publicados 2 libros, 24 artículos en revistas JCRISI, 12 proyectos de investigación y 50 participaciones en congresos (la mayoría en congresos internacionales). Colaboración con la Editorial TEA Ediciones, mediante la baremación de aproximadamente seis instrumentos. Asistente Editorial de la revista IJCHP y revisor en un total de 6 revistas incluida en JCR. . Coordinador y ponente de diversos cursos y congresos de psicología. Miembro de diversos Comités (Científico y Organizador) de Evaluación de la Calidad de la Educació n Superior e Investigación. E-mail: rquevedo@ugr.es 


\section{Edmundo Gaudêncio}

Formação: Médico (Psiquiatra) pela Faculdade de Medicina de Campina Grande, PB. Especialista em Teoria da Psicanálise - UFPB. Mestre e Doutor em Sociologia - UFPB. Atuação Profissional: Professor do curso de Psicologia da UEPB. Professor do curso de Medicina da UFCG. Professor do curso de Medicina da FCM.

E-mail: edmundogaudencio@hotmail.com

\section{Fabiana Maria de Souza}

Aluna do curso de Formação e Licenciatura em Psicologia pela Universidade Estadual da Paraíba. Aluna de Iniciação Científica da linha de pesquisa Processos Psicossociais e Saúde.

E-mail: fabiana.ms@hotmail.com

\section{Ana Gabriella Barros Lima}

Aluna de graduação do curso de Psicologia da Universidade Estadual da Paraíba. Aluna de Iniciação Científica da linha de pesquisa Processos Psicossociais e Saúde, vinculada ao grupo de pesquisa Psicologia da Saúde UEPB-CNPq. Extensionista do projeto Escuta Psicológica individual e intervenção grupal em usuários do Centro de Atenção Psicossocial.

E-mail: gabriellabarroslima@hotmail.com

\section{Monalisa Vasconcelos Ernesto}

Mestranda em Psicologia Social pela Universidade Federal da Paraíba. Possui graduação e licenciatura plena em Psicologia, pela Universidade Estadual da Paraíba. Foi aluna de Iniciação Científica da linha de pesquisa Processos Psicossociais e Saúde, vinculada ao grupo de pesquisa Psicologia da Saúde UEPB-CNPq. Atuou como extensionista na Vara da Infância e Juventude situada no Fórum Affonso Campos em Psicologia Jurídica e como estagiária no Tribunal de Justiça.

E-mail:monagton@hotmail.com 


\section{Renata Pimentel da Silva}

Aluna do curso de Formação e Licenciatura em Psicologia pela Universidade Estadual da Paraíba. Aluna de Iniciação Científica da linha de pesquisa Processos Psicossociais e Saúde.

E-mail: renata_pimentels@hotmail.com

\section{Thelma Maria Grisi Velôso}

Possui graduação em Psicologia pela Universidade Federal da Paraíba (1985), mestrado em Serviço Social pela Universidade Federal da Paraíba (1990) e doutorado em Sociologia pela Universidade Estadual Paulista Júlio de Mesquita Filho (2002). É professora do Departamento de Psicologia da Universidade Estadual da Paraíba. Tem experiência na área da Psicologia e da Sociologia Rural. Adota a perspectiva da Psicologia Social, trabalhando, principalmente, com os seguintes temas: memória, identidade, produção de sentidos, práticas discursivas e representações sociais.

E-mail: thelma_veloso@yahoo.com.mx

\section{Pedro de Oliveira Filho}

Possui graduação em Psicologia pela Universidade Estadual da Paraíba (1992), mestrado em Psicologia (Psicologia Social) pela Universidade Federal da Paraíba (1997) e doutorado em Psicologia (Psicologia Social) pela Pontifícia Universidade Católica de São Paulo (2003). Atualmente é professor da Universidade Federal de Pernambuco (Departamento de Psicologia e Orientação Educacionais, Centro de Educação). Tem experiência na área de Psicologia, com ênfase em Psicologia Social, atuando, principalmente, nos seguintes temas: discurso, retórica, relações intergrupais.

E-mail: pedroofilho@ig.com.br; deoliveirafilhopedro@gmail.com 


\section{Halline Iale Barros Henriques}

Possui graduação em Psicologia pela Universidade Estadual da Paraíba (2007). Atualmente é psicóloga do Centro de Atenção Psicossocial - "Loucos pela Vida" e psicóloga do Centro Municipal de Especialidades Nossa Senhora de Fátima, na cidade de Picuí - PB. Tem experiência na área de Psicologia, com ênfase em Intervenção Terapêutica, atuando, principalmente, nos seguintes temas: idosos, saúde, práticas discursivas, identidade e comunidade virtual do second life.

E-mail: hallineiale@hotmail.com

\section{Hamana Dáphne Barros Henriques}

PossuigraduaçãoemPsicologiapelaUniversidadeEstadual da Paraíba - UEPB (2007). Formação em Psicologia Clínica Hospitalar pelo Centro de Treinamento e Consultoria Empresarial em Psicologia Hospitalar no município de Campina Grande/PB (2007). Especialização em Saúde Mental pela Faculdade Integrada de Patos - FIP (2009). Atualmente é psicóloga do Hospital Regional "Felipe Tiago Gomes", no município de Picuí/PB e psicóloga do Centro de Referência de Assistência Social - CRAS, no município de Frei Martinho/PB. Tem experiência na área de Psicologia, com ênfase em Intervenção Terapêutica, atuando principalmente nos seguintes temas: idosos, saúde, práticas discursivas, identidade.

E-mail: hamanadaphne@yahoo.com.br 


\section{Marcela Costa Meira}

Possui graduação em Psicologia pela Universidade Estadual da Paraíba (2009). Possui formação em Psicologia Hospitalar, na área clínica, pelo hospital da FAP - Fundação Assistencial da Paraíba. Especialização em Saúde Mental (em andamento), Universidade Federal de Campina Grande - UFCG. Atualmente é Psicóloga do Centro de Atenção Psicossocial (CAPSi Viva Gente) localizado na cidade de Campina Grande - PB. Experiência na área de Psicologia Clínica Infantil, com ênfase em tratamento e prevenção em Saúde Mental.

E-mail: marcelacostameira@hotmail.com

\section{Karoliny Rafaela Sousa de Andrade}

Estudante do Curso de Graduação em Psicologia (UEPB), $5^{\mathrm{O}}$ ano. Estágio supervisionado na área clínica, de base psicanalítica lacaniana (em andamento). Atualmente participa do Núcleo de Psicanálise e Adolescência da Escola Brasileira de Psicanálise. Realizou estágio no CLIPSI.

E-mail: karoluepb@yahoo.com.br

\section{Roseane Barros Pinto}

Estudante do Curso de Graduação em Psicologia (UEPB), $5^{\mathrm{O}}$ ano. Estágio supervisionado na área Clínica com ênfase Psicanalítica (em andamento). Formação em Clínica Hospitalar.

E-mail: roseane.bpsi@yahoo.com.br 


\section{Isis Simões Leão}

Possui graduação e licenciatura plena pela Universidade Estadual da Paraíba, especialização em Neuropsicologia pelo Centro Universitário de João Pessoa. Possui experiência em pesquisas na área de Psicologia com ênfase em Saúde Coletiva, representações sociais, educação em saúde, qualidade de vida e processos cognitivos.

E-mail: isisleao@gmail.com

\section{Silvânia da Cruz Barbosa}

Doutora em Psicologia Social pela Universidade Federal do Rio Grande do Norte (com estágio na Universidad Complutense de Madrid). Mestra em Psicologia pela Universidade Federal do Rio Grande do Norte. Especialista em Administração de Estratégia Empresarial pela Universidade Estadual da Paraíba. Professora do Departamento de Psicologia na Universidade Estadual da Paraíba.

E-mail: silv.barbosa@gmail.com

\section{José Ulisses do Nascimento}

Aluno do curso de Formação em Psicologia pela Universidade Estadual da Paraíba. Aluno de Iniciação Científica da linha de pesquisa Saúde, Trabalho e Subjetividade.

E-mail: jose-ulisses@hotmail.com 


\section{Sandra Souza}

Doutora em Psicologia Social pela Universidade Federal do Rio Grande do Norte (com estágio na Universidad Complutense de Madrid). Mestra em Psicologia Social pela Universidade Federal da Paraíba. Psicóloga graduada na área Humanista - Existencial pela UFPB. Professora do Departamento de Psicologia da Universidade Federal da Paraíba.

E-mail: sandra.souza_psi@yahoo.com.br

\section{Danielly Farias da Silva Araújo}

Psicóloga Clínica, realiza atendimento psicoterápico infanto-juvenil e adulto, facilita grupos e coordena Grupo de Estudo do Núcleo de Saúde Mental do Centro Universitário de João Pessoa (UNIPE), onde também desenvolve trabalhos no Núcleo de Psicologia Jurídica. Atua em instituições de saúde mental desde 2006 e atualmente é Psicóloga Plantonista no Complexo Psiquiátrico Juliano Moreira.

E-mail:danielly_araujo@hotmail.com

\section{Carla de Sant'Ana Brandão}

Psicóloga Clínica, Mestra em Psicologia Social (UFPB) e Doutora em Sociologia (UFPE), é Professora-supervisora de estágio em Psicologia Clínica e em Processos Clínicos e de Prevenção e Promoção da Saúde, na Universidade Estadual da Paraíba (UEPB) e no Centro Universitário de João Pessoa (UNIPÊ), respectivamente, e professora do Curso de Pós- Graduação em Psicologia Humanista na Universidade do Oeste de Santa Catarina (UNOESC). Foi orientadora no Mestrado em Saúde Coletiva (UEPB 2006/2008). Atualmente desenvolve estudos sobre psicologia e saúde e adolescência e juventude.

E-mail: carlasbrandaocosta@yahoo.com.br 


\section{Lorena Leal Máximo}

Psicóloga Clínica, com pós-graduação em Neuropsicologia, atua em instituições de saúde mental desde 2003. Foi psicóloga do Hospital Juliano Moreira e do Sanatório Clifford nos setores de internação e de ambulatório, respectivamente, no período de 2007-2008. Atualmente desenvolve trabalhos de grupo infanto-juvenil e grupos com usuários de serviços de saúde mental.

\section{María José Robles Delgado}

1972 Titulo de Ayudante Técnico Sanitario en la Escuela Universitaria de Jaén. 1983 Titulo de Diplomado en Enfermería por la UNED. 1985 Curso de Gestión Sanitaria "Gestión de Enfermería" en EADA (Escuela de alta Dirección y Administración) en Barcelona. 2000 Master en Sexología Terapia Sexual y Género impartido por el Instituto de Sexología Al-Andalus. Granada. 2003 Master en Autoconocimiento, Sexualidad y Relaciones Humanas en Terapia de Reencuentro impartido por el Instituto de Terapia de Reencuentro Valencia. 2004 Licenciatura en Antropología Social y cultural por la Universidad de Granada. 2006 Cursos de doctorado en Evolución Humana. Bases de la Antropología Física por la Universidad de Granada. 2005 Periodo de Docencia. 2006 Investigación Tutelada.

E-mail: iroblesamiga@telefonica.net 


\section{Luciana Ramirez Imedio}

Desde el 1975 vengo desarrollando mi profesión de enfermera en hospitales y Centros de Salud públicos de Madrid, Ciudad Real y Granada. He sido responsable de enfermería en atención primaria en la provincia de Ciudad Real, Directora de Enfermería en el hospital Príncipe de Asturias de Madrid actualmente trabajo como Jefa de bloque de Obstetricia y Ginecología Hospital Materno Infantil del Hospital Universitario Virgen de la Nieves. Granada. ACTIVIDAD ACADÉMICA: A.T.S. 1975 Universidad Complutense de Madrid. Especialidad en Psiquiatría, 1982 U. Complutense, Madrid. D.U.E. U.N.E.D. 1983. Asistente Social, U. Complutense, Madrid, 1979. Grafo patología, Escuela de Medicina Legal U. Complutense, Madrid, 1980. Licenciada en Antropología Social y Cultural, 2004, Universidad de Granada. Cursos de doctorado en el departamento de Antropología Física en la Facultad de Medicina de Granada. "Evolución humana, bases de la antropología física", 2005. Trabajo de investigación avanzada sobre "Percepción de la Menopausia en mujeres rurales de la provincia de Granada" 2006. Actualmente preparo la tesis doctoral sobre " Análisis comparativo sobre la percepción de la menopausia en mujeres de distintas culturas". PUBLICACIONES CIENTÍFICAS Y PONENCIAS: Catorce publicaciones en distintos congresos nacionales e internacionales, sobre temas relacionados con la salud y con la antropología. ASISTENCIA A CURSOS. He realizado 40 cursos relacionados con la Gestión de Servicios de Enfermería, Educación para la Salud, Formación en Sexualidad y Cuidados Paliativos. ACTIVIDAD DOCENTE: 300 horas repartidas entre, talleres de atención primaria, educación para salud y prevención de drogodependencia en colaboración con el ministerio de educación y ciencia.

E-mail: lucymedio@hotmail.com 
Este livro foi impresso na Gráfica Universitária da UEPB. Formato: $15 \times 21 \mathrm{~cm}$.

Mancha Gráfica: 10,5 x 16,5 cm.

Tipologias utilizadas: ZapfEllipt BT 11/13

Papel: Apergaminhado 75g/m2 ( miolo)

e Cartão Supremo 250g/m2 (capa). 